\title{
LOSS-OF-FLOW TEST L5 ON FFTF-TYPE IRRADIATED FUEL
}

by

R. Simms, S. M. Gehl, R. K. Lo, and A. B. Rothman

BASE TECHNOLOGY

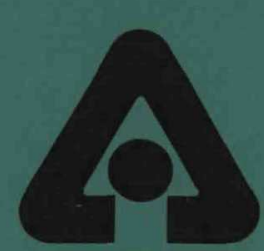

Uof C-AUA-USDOE

ARGONNE NATIONAL LABORATORY, ARGONNE, ILLINOIS

Prepared for the U. S. DEPARTMENT OF ENERGY under Contract W-31-109-Eng-38 


\section{DISCLAIMER}

Portions of this document may be illegible in electronic image products. Images are produced from the best available original document. 
The facilities of Argonne National Laboratory are owned by the United States Government. Under the terms of a contract (W-31-109-Eng-38) between the U. S. Department of Energy, Argonne Universities Association and The University of Chicago, the University employs the staff and operates the Laboratory in accordance with policies and programs formulated, approved and reviewed by the Association.

\section{MEMBERS OF ARGONNE UNIVERSITIES ASSOCIATION}

The University of Arizona

Carnegie-Mellon Univer sity

Case Western Reserve University

The University of Chicago

University of Cincinnati

Illinois Institute of Technology

University of Illinois

Indiana University

Iowa State University

The University of Iowa
Kansas State University

The University of Kansas

Loyola University

Marquette University

Michigan State University

The University of Michigan

University of Minnesota

University of Missouri

Northwestern University

University of Notre Dame
The Ohio State University

Ohio University

The Pennsylvania State University

Purdue University

Saint Louis University

Southern Illinois University

The University of Texas at Austin

Washington University

Wayne State University

The University of Wisconsin

\section{NOTICE}

This report was prepared as an account of work sponsored by the United States Government. Neither the United States nor the United States Department of Energy, nor any of their employees, nor any of their contractors, subcontractors, or their employees, makes any warranty, express or implied, or assumes any legal liability or responsibility for the accuracy, completeness or usefulness of any information, apparatus, product or process disclosed, or represents that its use would not infringe privately-owned rights. Mention of commercial products, their manufacturers, or their suppliers in this publication does notimply or connote approval or disapproval of the product by Argonne National Laboratory or the U. S. Department of Energy.

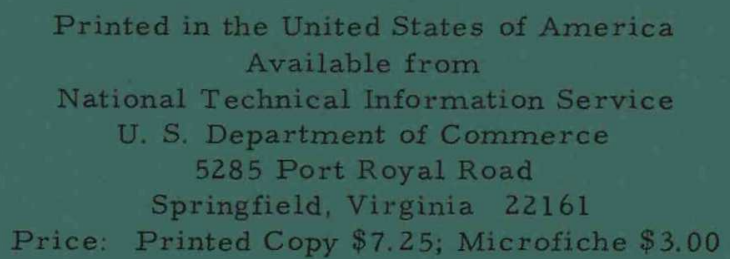


Distribution Category:

LMFBR Safety (UC-79p)

ANL-78-24

\section{ARGONNE NATIONAL LABORATORY \\ 9700 South Cass Avenue \\ Argonne, Illinois 60439}

\section{LOSS-OF-FLOW TEST L5 ON FFTF-TYPE IRRADIATED FUEL}

\section{by}

R. Simms, S. M. Gehl,*

R. K. Lo, and A. B. Rothman

Reactor Analysis and Safety Division

March 1978

$$
\begin{aligned}
& \text { This repor was prepared as an account of work } \\
& \text { sponsored by the United States Govemment Netther the } \\
& \text { United States nor the Unted States Department of } \\
& \text { Energy, nor any of their employees, nor any of therr } \\
& \text { contractors, subcontractors, or their employees, makes } \\
& \text { any warranty, express or impled, or assumes any legal } \\
& \text { liablity or responsibility for the accuracy, completeness } \\
& \text { or usefulness of any information, apparatus, product or } \\
& \text { process disclosed, or represents that its use would not } \\
& \text { infrnge privately owned nghts }
\end{aligned}
$$

\section{*Materials Science Division}


•

- 


\section{TABLE OF CONTENTS}

Page

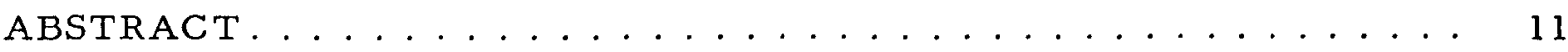

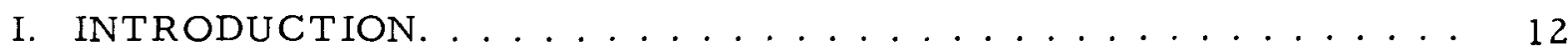

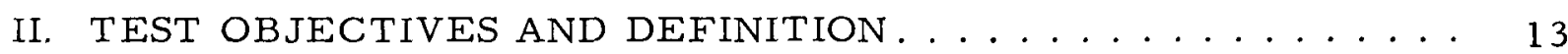

A. Requirements and Constraints ............... 13

B. Test Definition and Hardware Description . . . . . . . . . 14

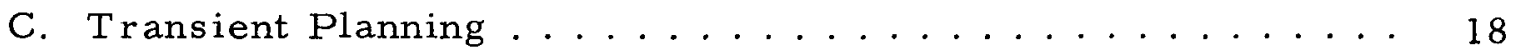

III. INSTRUMENT AND TEST-ELEMENT CALIBRATIONS . . . . . . 21

A. Calibrations of Test-vehicle Instrumentation ......... 21

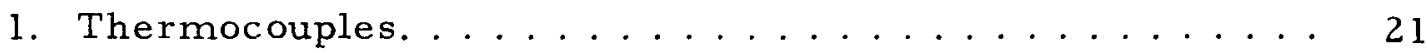

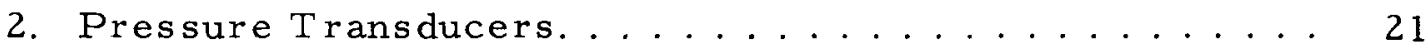

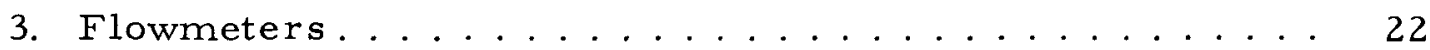

B. Power-calibration Experiments .............. 22

1. Calibration Test Objectives ............... 22

2. Results of Calibration Tests.............. 24

IV. RESULTS OF HEAT-BA LANCE TEST . . . . . . . . . . . 25

A. Comparison of Results with Thermal Analysis ........ 25

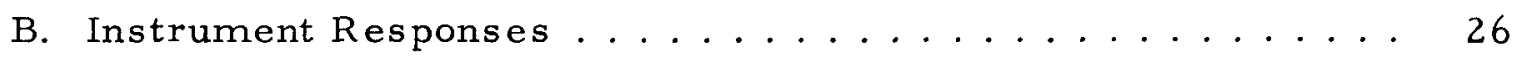

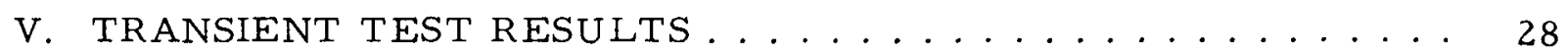

A. Test Transient Characteristics ............... 28

B. Results from Test Instrumentation. . . . . . . . . . . 29

1. Comments on Data Acquisition and Reduction. . . . . . . 29

2. Results from Test-vehicle Instrumentation . . . . . . . . 30

C. Summary of Fuel-motion Results . . . . . . . . . . 33

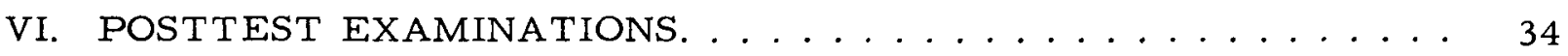

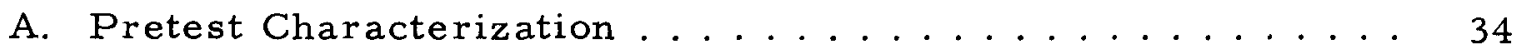

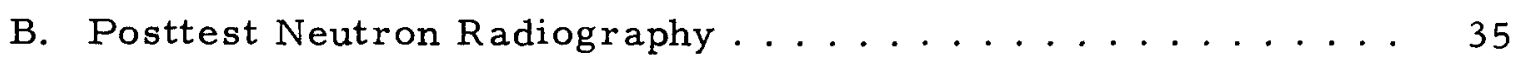


TABLE OF CONTENTS

Page

C. Disassembly. . . . . . . . . . . . . . . . 40

D. Examination Results .................... 43

1. Gamma Scanning. . . . . . . . . . . . . . . 43

2. Macroexaminations . . . . . . . . . . . . 43

3. Microexamination................. 52

E. Discussion of Results. . . . . . . . . . . . . . . . 72

1. Evolution of Microstructure . . . . . . . . . . . 72

2. Sequence of Transient Events: Early Stages . . . . . . . 74

3. Sequence of Transient Events: Later Stages . . . . . . . 75

4. Suggestions for Future Study. . . . . . . . . . . 76

F. Summary and Conclusions from the Postmortem Examina-

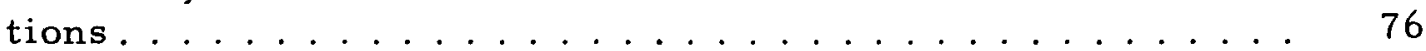

VII. THERMAL-HYDRAULIC ANALYSIS. . . . . . . . . . . 78

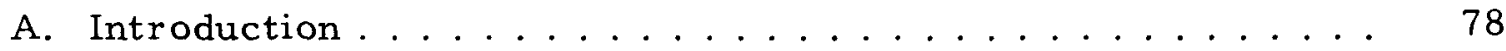

B. Description of SAS3A Computer Code and Accuracy of Its

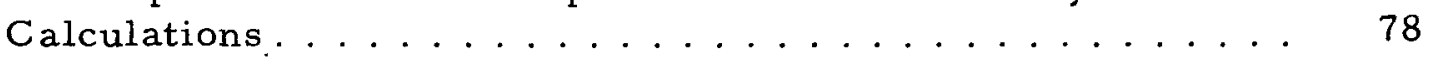

C. Calculated Thermal History . . . . . . . . . . . . 79

D. Concluding Remarks . . . . . . . . . . . . . 86

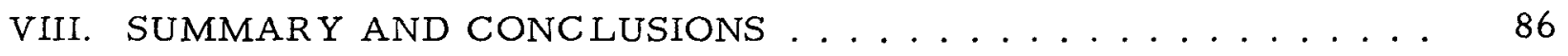
APPENDIXES

A. Information on Test Hardware. . . . . . . . . . . . 89

B. Results of Power-calibration Tests ............ 91

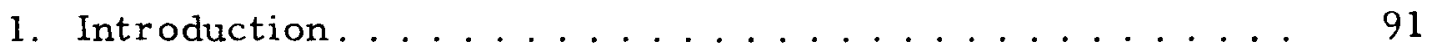

2. Theory ....................... 91

3. Transient-correction Factor. ............. 93

4. Results of Power Calibration for Unirradiated Fuel at Low-level TREAT Power. . . . . . . . . . . . . . . . 94

5. Conversion to Test Elements . . . . . . . . . . 95

6. Internal Radial Power Distributions . . . . . . . . . 96

C. Additional Data from L5 Heat-balance Test . . . . . . . . 100 


\section{TABLE OF CONTENTS}

$\underline{\text { Page }}$

D. Additional Data from Loss-of-flow Test L5 ......... 103

E. Input Data for SAS3A Calculations . . . . . . . . . 108

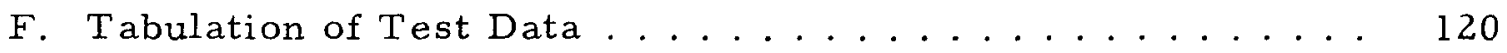

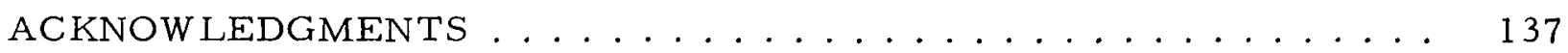

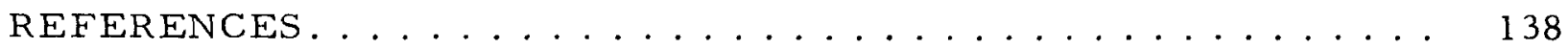




\section{LIST OF FIGURES}

No.

Title

Page

1. Schematic Diagram of HEDL-59 Fuel Element ......... 16

2. Schematic Diagram of L5 Cluster.............. 17

3. Mark-IIC Test Vehicle for TREAT Tests with Preirradiated

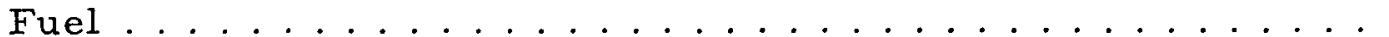

4. Conduct of Typical Fuel Dynamics Test Using Mark-II Integral Sodium Loop in TREAT. . . . . . . . . . . . . . . 23

5. TREAT Transient for L5 Heat-balance Test.......... 26

6. Responses of Flowmeters and Pressure Transducers in L5 Heat-balance Test . . . . . . . . . . . . . . 27

7. TREAT Transient 1606 for Loss-of-flow Test L5 ....... 28

8. TREAT Transient for Loss-of-flow Test L5 in Time Interval of

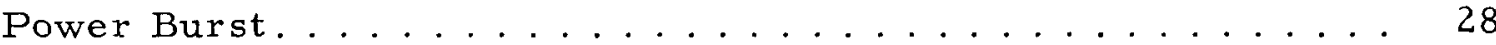

9. Test L5 Loss-of-flow Transient and Flow Coastdown. . . . . . 29

10. Signals from Inlet and Outlet Pressure Transducers in L5 Lossof-flow Transient. . . . . . . . . . . . . . . 30

11. Flowmeter Signals in L5 Loss-of-flow Transient.......... 31

12. Flow and Temperature Features of Loss-of-flow Test L5. . . . 32

13. Flow and Temperature Data in Time Interval of L5 Burst. . . . 32

14. L5 Pre- and Posttest ${ }^{106} \mathrm{Ru}$ Gamma Activity . . . . . . . . . . 34

15. Microstructure in Pin PNL-59-7 at Fractional Fuel-column Height of $0.48 \ldots \ldots \ldots 36$

16. Microstructure in Pin PNL-59-7 at Fractional Fuel-column Height of $0.36 \ldots \ldots \ldots \ldots \ldots$

17. Microstructure in Pin PNL-59-7 at Fractional Fuel-column Height of $0.87 \ldots \ldots \ldots 38$

18. Posttest Neutron Radiograph of L5 Test Section . . . . . . . 39

19. L5 Initial Cutting Scheme . . . . . . . . . . . . . . . 41

20. L5 Upper Flow Blockage. . . . . . . . . . . . . . . . 44

21. L5 Lower Flow Blockage. . . . . . . . . . . . . . . 44

22. Macrophotos of Transverse Sections through L5 Test Train ... . 46

23. Three Views of Fluted Tube Exterior in Region between +320 and $+380 \mathrm{~mm}$. 


\section{LIST OF FIGURES}

No.

$\underline{\text { Title }}$

Page

24. Longitudinal Section through Base of Region Shown in Fig. 23 . . 47

25. Fuel and Steel Spatter on Inner Surface of Fluted Tube. . . . . . 48

26. Transverse Section through Fuel Deposit Shown in Fig. 25 . . . . 49

27. Three Sides of Fluted Tube in Section 159A34.......... 50

28. Large Lumps of Fuel Recovered from $-220 \mathrm{~mm} \ldots \ldots 51$

29. Rundown of Steel on Outside of Fluted Tube at Base of Fuel

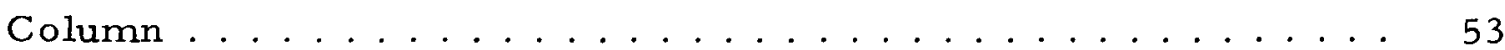

30. Transverse Section through Test Train at $+388 \mathrm{~mm} \ldots \ldots . \ldots 4$

31. Transverse Section at $+287 \mathrm{~mm} \ldots \ldots \ldots 5$

32. Transverse Section at $+250 \mathrm{~mm} \ldots \ldots \ldots \ldots$

33. Transverse Section at $+175 \mathrm{~mm} \ldots \ldots \ldots$

34. Transverse Section at $-302 \mathrm{~mm} \ldots \ldots \ldots 57$

35. Transverse Section at $-355 \mathrm{~mm} \ldots \ldots \ldots 57$

36. Axial Profile of Posttest Concentrations of Fuel, Steel, and Total Steel........................ 58

37. As-irradiated Microstructure at $+412 \mathrm{~mm} \ldots \ldots 61$

38. As-irradiated Fuel at $+412 \mathrm{~mm} \ldots \ldots \ldots 2$

39. Bubble-precipitated Structure at $+388 \mathrm{~mm} \ldots \ldots . \ldots 3$

40. Bubble-precipitated Structure at $-302 \mathrm{~mm} \ldots \ldots 63$

41. Examples of Bubble-precipitated Fuel . . . . . . . . . . . 64

42. Grain-boundary Fissures Marking Transition between the Bubbleprecipitated and Spongy Structures..............666

43. Spongy, Unmelted Fuel . . . . . . . . . . . . . . 67

44. Melted Fuel ........................ . . 68

45. Melting of Bubble-precipitated Fuel .............. 69

46. Melting of Spongy Fuel . . . . . . . . . . . . . . . 69

47. Axial Profile of Four Microstructural Types of Fuel . . . . . . 71

48. Coolant-temperature Difference between Fuel Top and Inlet and between Fuel Midplane and Inlet. . . . . . . . . . . . . . 79

49. Inlet and Outflow at Test Section. . . . . . . . . . . . . 80 


\section{LIST OF FIGURES}

No.

Title

Page

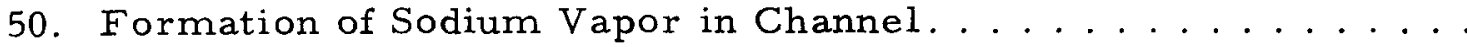

51. Coolant, Cladding, and Structure Temperatures, and Molten Fraction of Cladding . . . . . . . . . . . . . . 81

52. Temperature and Molten Fraction of Fuel. . . . . . . . . 82

53. Beginning of Cladding Motion ............... 82

54. Cladding Condition at Beginning of Dispersal of Fuel. . . . . 83

55. Upper and Lower Blockages . . . . . . . . . . . . . . 83

56. Fuel Dispersal at $12.98 \mathrm{~s} \ldots \ldots \ldots$. . . . . . . . . . 84

57. Fuel Dispersal at End of Transient ............ 85

A. 1. L5 Test-train Assembly. . . . . . . . . . . . . . . 90

B. 1. Average Axial Power Distribution for L5 Analysis . . . . . . . . 94

B.2. Location of Calibration Elements Relative to Test-element

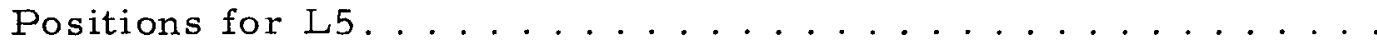

B. 3. Radial Power Distribution Obtained from Core-drilled

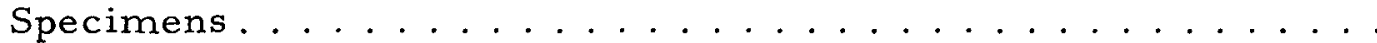

B.4. Radial Power Distribution Inter polated from Histogram. . . . . . 99

C. 1. Coolant Temperatures during L5 Heat-balance Test....... 100

C.2. Temperatures Measured by Structure Thermocouples in Lower

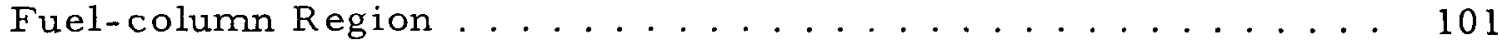

C.3. Temperatures Measured by Structure Thermocouples above Fuel-column Midplane................... 101

C.4. Temperatures Measured above Top of Fuel Column . . . . . . 102

C.5. Coolant Temperatures in Heat-balance Test for 2 -min Time Interval. . . . . . . . . . . . . . . . 102

D. 1. Coolant Temperatures in Loss-of-flow Test L5 . . . . . . . 103

D.2. Coolant Temperatures in Loss-of-flow Test L5 during 2-min Interval of Data Acquisition . . . . . . . . . . . . 104

D.3. Temperatures of Structure Thermocouples in Loss-of-flow Test L5. . . . . . . . . . . . . . . . . . . . . . 104

D.4. Temperatures of Structure Thermocouples above Fuelcolumn Midplane in Loss-of-flow Test L5 . . . . . . . . . 105

D. 5. Temperatures of Structure Thermocouples at and above Top of Active Fuel Column. 


\section{LIST OF FIGURES}

No.

D.6. Temperatures of Selected Structure Thermocouples during Time Interval of Burst. . . . . . . . . . . . . . 106

D.7. Flow Rate Measured by Inlet Electromagnetic Flowmeter in Loss-of-flow Test L5 . . . . . . . . . . . . . . . 106

D. 8. Outlet-flowmeter Data Recorded for Loss-of-flow Test L5 . . . 107 
LIST OF TABLES

No.

$\underline{\text { Title }}$

$\underline{\text { Page }}$

I. Design Parameters for Fresh HEDL-59 Fuel Elements . . . . 16

II. Thermocouple Locations for Test L5 . . . . . . . . . . . 19

III. Definition of Test Hardware . . . . . . . . . . . . . 19

IV. Experiment Operational Parameters for Loss-of-flow Test L5 20

V. Alternative Ways to Determine Calibration Factors. . . . . . . 23

VI. Restructuring Zone Radii in Pin PNL-59-7 . . . . . . . . 38

VII. Axial Displacements of Upper Components of L5 Test Elements . . . . . . . . . . . . . . . . . . 40

VIII. Summary of Quantitative Stereology Measurements . . . . . . . 59

IX. Sequence of Events in TREAT Loss-of-flow Test L5 . . . . . 8 87

B. 1. Summary of L5 Calibration Tests in TREAT . . . . . . . . 91

B.2. Transient-correction Factor for L5 Based on Monitor-wire Results from Test Section. . . . . . . . . . . . . . 93

B. 3. Transient-correction Factor for L5 Based on Monitor-wire Results from Secondary-containment-can Guide Tube . . . . . . 94

B.4. Experimental Radiochemical Values for Low-level Calibration Factors for L5 ...................... 95

B.5. Correspondence between Test and Calibration Elements. . . . . 96

B.6. Sample Power-calibration Factors for L5 Test Elements . . . . 96

B.7. Dimensions of Core-drilled Specimens from Mixed-oxide Fresh-fuel Pellets in Calibration Experiments . . . . . . . . 97

B.8. Azimuthally Averaged Radial Power Distribution Measured for Calibration Element L5C-3 . . . . . . . . . . . 97

B.9. Azimuthally Averaged Radial Power Distribution Measured for Calibration Element L5C-6 . . . . . . . . . . .

B. 10. Azimuthally Averaged Radial Power Distribution Measured for Calibration Element L5C-7 . . . . . . . . . . . . 98

D.1. Failure Times of L5 Thermocouples during Loss-of-flow Test. 103 


\title{
LOSS-OF-FLOW TEST L5 ON FFTF-TYPE \\ IRRADIATED FUEL
}

by

R. Simms, S. M. Gehl,

R. K. Lo, and A. B. Rothman

\begin{abstract}
Test L 5 simulated a hypothetical loss-of-flow accident in an LMFBR using three $(\mathrm{Pu}, \mathrm{U}) \mathrm{O}_{2}$ fuel elements of the FTR type. The test elements were irradiated before TREAT Test L5 in the General Electric Test Reactor to 8 at. \% burnup at about $40 \mathrm{~kW} / \mathrm{m}$. The test elements had an $864-\mathrm{mm}$ active fuel-column length, about $50 \mathrm{~mm}$ shorter than the design for the FTR. The preirradiation in GETR caused a fuel-restructuring range characteristic of moderate-power structure relative to the FTR. The test transient was devised so that a power burst would be initiated at incipient cladding melting after the los of flow. The test simulation corresponds to a scenario for FTR in which fuel in high-power-structure subassemblies slump, resulting in a power excursion. The remaining subassemblies are subjected to this power burst. Test L5 addressed the fuelmotion behavior of the subassemblies in this latter category.

Data from test-vehicle sensors, hodoscope, and postmortem examinations were used to construct the sequence of events within the test zone. From these observations, the fuel underwent a predominantly dispersive event just after reaching a peak power six times nominal at, or after, scram. The fuel motion was apparently driven by the release of entrained fission-product gases, since fuel vapor pressure was deliberately kept below significant levels for the transient. The test remains show a wide range of microstructural evolution, depending on the extent of heat deposition along the active fuel column. Extensive fuel swelling was also observed as a result of the lack of the cladding restraint.
\end{abstract}

The results of the thermal-hydraulic calculations with the SAS3A code agreed qualitatively with the postmortem results with respect to the extent of the melting and the dispersal of cladding and fuel. However, the calculated times of certain events did not agree with the observed times. 


\section{INTRODUCTION}

TREAT Test L5 examined, by simulation, the motion of irradiated fuel caused by a power burst in a hypothetical loss-of-flow accident without scram in the Fast Test Reactor (FTR). In the analysis of this hypothetical coredisruptive accident (HCDA), fuel slumping in some of the high-power-structure subassemblies causes a rapid increase in total reactor power. Test L5 was planned to examine the behavior of lower-power-structure fuel having steadystate peak linear heating rates of $26-36 \mathrm{~kW} / \mathrm{m}$ in subassemblies elsewhere in the core when subjected to such a power burst. These subassemblies would have experienced sodium voiding and some dryout, but not appreciable cladding movement at the time of a burst. The subsequent course of the accident depends, in part, on the characteristics of fuel motion produced in these voided subassemblies. Ir radiated $(\mathrm{Pu}, \mathrm{U}) \mathrm{O}_{2}$ fuel with a nearly prototypic length of the active fuel column and a realistic axial variation in fuel microstructure was desired.

Three HEDL-59 fuel elements, irradiated in the General Electric Test Reactor (GETR) to about 8 at. \% peak burnup, were subjected to a TREAT simulation of the accident in the Mark-IIC Integral Sodium Loop. The recourse to a three-element, channel-centered geometry was necessitated by the limited number of elements available. The HEDL-59 design met most of the desired criteria for the test, but the fission-gas pressure in the relatively undersized plenum region of the fuel element was reduced to atmospheric pressure to ensure against premature cladding failure. ${ }^{1}$

The desired axial power distribution was achieved by means of dysprosium neutron filters of varying thickness placed along the outside of the $50-\mathrm{mm}$-dia loop test section. The burst was timed to occur when the cladding reached incipient melting as based on predictions by the SAS2A code. ${ }^{2}$ A DataTrak controller regulated the pump power supply to the loop to achieve the desired linear coastdown in about $5 \mathrm{~s}$, beginning from an initially reduced flow rate. The TREAT reactor power level was set to heat the fuel initially at a peak linear power of about $36 \mathrm{~kW} / \mathrm{m}$. The power burst was then planned to raise the fuel temperature to temperatures below about $3500^{\circ} \mathrm{C}$ so that dispersive effects of fuel vapor pressure would be relatively insignificant. The peak power was planned to equal about $430 \mathrm{~kW} / \mathrm{m}$ or about 10 times nominal.

The planned powe $r$ burst in TREAT was the equivalent of adding about $1 \% \Delta \mathrm{k} / \mathrm{k}$ as a reactivity step. The actual reactor transient attained contained the desired energy in the power burst, but the peak reactor power level achieved was only about six times the nominal power. The flow coastdown was initiated about $4 \mathrm{~s}$ after the reactor reached the $42-\mathrm{MW}$ level needed to yield a peak linear heating rate of $36 \mathrm{~kW} / \mathrm{m}$. The first indication of boiling and flow reversal occurred about $4.3 \mathrm{~s}$ later. Flowmeter and thermocouple data indicated that the flow channel was voided when the power burst was initiated. No significant rapid pressure changes or spikes were recorded by either the 
inlet or outlet pressure transducers. After the test, but before the loop cooled, the pump current was restored to its pretest setting. No flow resulted, indicating that a blockage existed in the flow channel.

Posttest neutron radiographs and postmortem examinations of the test region confirmed that each of the three elements had failed over nearly the entire length of its original active fuel region. Much of the material relocated in the upper and lower thirds of the active region, with only some movement of cladding into the upper element reflector region.

Data from the fast-neutron hodoscope indicated that no significant fuel motion occurred during the powered portion of the transient. The fuel motion observed immediately after scram indicated that the final configuration had been attained as a mild dispersal as the power levels declined. Apparently, the energy input had been just enough to raise some fuel to the liquidus temperature, the axial fuel motion occurring almost at its threshold.

\section{TEST OBJECTIVES AND DEFINITION}

\section{A. Requirements and Constraints}

Test L5 simulated a loss-of-flow HCDA for moderate-power-structure fuel subjected to a power burst. Fuel of this type microstructure is present in a fast-reactor core, but fuel slumping elsewhere in the core causes a reactivity addition leading to the power burst. At the time of the burst, subas semblies with moderate-power-structure fuel will probably be voided of sodium coolant. In some cases, the cladding will be at its melting point. The transient and flow coastdown for L5 were therefore planned to bring the cladding to its melting point at the time the TREAT power burst was initiated. The primary intent was to observe fuel motion after failure for the test fuel. Additional slumping fuel in the moderate-power-structure subassemblies could affect the course and extent of the hypothetical accident. Note, however, that the reactivity feedback associated with any form of fuel motion does not occur in the test, since the TREAT reactor is largely unaffected by fuel movement in the test zone.

The test objectives included the desire to minimize the fuel vapor pressure so that the fuel motion would represent events expected at the liquidus temperature. Realistic axial variations in the fuel microstructure and the axial power profile were also considered important parameters. The microstructural variations could only be obtained with an element having an active fuel column of approximately the same length as the FTR. The axial power distribution was achieved by adjusting the existing distribution with neutron absorbers. The desired axial power profile as originally specified for Test L5 was peaked slightly below the midplane to represent a typical FTR axial power distribution. The peaking slightly below the midplane corresponds to the simulation of the operation of the control-rod banks in an actual reactor. 
The test planning was also influenced by practical considerations dealing with schedule and reactor limitations. The following constraints are among the most noteworthy:

1. Only three fuel elements irradiated in GETR met the fuel requirements for the test.

2. The current plutonium limit of $150 \mathrm{~g}$ could not be exceeded.

3. The instrumentation and design features of the test-vehicle hardware were to be based on proven designs.

4. The field of view of the hodoscope was limited to the existing collimator vertical dimension of $500 \mathrm{~mm}$.

5. The energy generated for the associated TREAT reactivity accident in the safety evaluation of the test itself was limited to existing values.

The principal limitations imposed on the test related to the execution of transients in TREAT were:

1. Not all the thermal characteristics of the reactor could be met.

2. "Preconditioning" of fuel was not feasible.

3. Because of experiment containment considerations, controlled bursts for LOF -type simulations tend to be limited to no less than about $500 \mathrm{~ms}$ (FWHM).

Future tests in TREAT may overcome some of these constraints. For example, the hodoscope view has been modified to observe fuel motion over the full length of the FTR active fuel region. Additional FTR-type fuel has been irradiated in GETR, some elements of which will be available for both transient testing and sibling destructive examination.

B. Test Definition and Hardware Description

At the time of test planning, no fast-neutron-irradiated fuel elements with the desired prototypic $914-\mathrm{mm}$ active length of the fuel column were available. However, three elements from a thermal-neutron irradiation in the General Electric Test Reactor (GETR) were made available to ANL for loss-of-flow Test L5. One possibility considered was to use one of these elements for a sibling examination, another for the test, and the third as a spare. The conclusion was that the test objectives would best be met within the constraints if all three elements were committed for the test with a channel-centered geometry. The three-element cluster would therefore possess at least one typical flow channel. In a sense, the outer channels of the cluster are similar to the channels in the outer rows of a reactor subas sembly. Planned future irradiations in GETR were relied upon to provide the element needed for the sibling-element characterization. Test L5 was committed without the availability of spares. 
Although the GETR elements possessed a near-prototypic fuel-column length, the elements were designed originally with a substantially reduced fission-gas plenum. Since the elements had already been irradiated to a burnup of 8 at. \%, the fission gas in the gas plenum was considered excessive for a loss-of-flow test. Rather than risk the consequences of a significantly premature failure of a fuel element, the gas in the plenum needed to be reduced. As a result, the gas in each element was removed in a hot cell and the elements backfilled with a combination of xenon and helium. The operation was accomplished by a laser drilling and rewelding technique at HEDL; however, technical limitations resulted in a back-fill gas pressure of only $0.1 \mathrm{MPa}(1 \mathrm{~atm})$. Admittedly, the reduced quantity and pressure of gas could influence cladding motion once the cladding reached its melting point. The compromise selected for L5 was nevertheless the more desirable route since the main test objective involved fuel motion, whereas other tests to examine cladding motion were being planned.

The elements available from GETR had been designated as HEDL-59 elements. The elements, in some cases, are also identified as "GETR-TREAT" capsules. Table I lists design characteristics and specifications ${ }^{3}$ for the unirradiated HEDL-59 elements. Because the elements were too long for a Mark-IIA sodium loop, the test used the newer Mark-IIC version. An extension piece was fastened to the bottom of the test elements in order to align the element centerline about $76 \mathrm{~mm}$ below the TREAT centerline and the corresponding axial center of the hodoscope view field. The $500-\mathrm{mm}$ hodoscope collimator was the refore viewing a greater proportion of the fuel column above the fuel-column midplane than below. The larger, $1.22-\mathrm{m}$ collimator now installed at TREAT will be available for future tests with the prototypic fuel column dimensions. Figure $l$ is a schematic diagram of the fuel element with its extension piece.

A cross-sectional view of the fuel-element arrangement within the test section of the Mark-IIC loop is shown in Fig. 2. The orientation of the elements, as shown in Fig. 2, allows the most desirable view of the three-element cluster by the hodoscope. By orienting the elements symmetrically in line with respect to the hodoscope view slot and pump leg, the element calibration (power) factors were hopefully to be equal, since element-to-element incoherences would be undesirable.

The general arrangement of the test assembly within the Mark-IIC loop is shown in Fig. 3. The Mark-IIC loop differs in several ways from its predecessor, the Mark-IIA loop, the most notable difference being that the Mark-IIC can accommodate $1.5-\mathrm{m}$-long fuel elements. In addition, the sodium dump reservoir of the Mark-IIA loop has been replaced in the Mark-IIC design by cylindrical safety tanks. Tests with fuel elements having long active fuel columns are particularly difficult to perform in the Mark-IIC loop with de sirable axial power profiles because of the axial variations in the loop cross sections. Axial power shaping by neutron absorbers was the refore required. These shaping filters, as well as other loop outfitting details, are not shown in Fig. 3 . 
TABLE I. Design Parameters for Fresh HEDL-59 Fuel Elements

\begin{tabular}{|c|c|}
\hline Element Parameter & Specified Value \\
\hline Fuel type & 75 wt $\% \mathrm{UO}_{2}, 25$ wt $\% \mathrm{PuO}_{2}$ \\
\hline Uranium enrichment & $30 \pm 1.0 \mathrm{wt} \%{ }^{235} \mathrm{U}$ in $\mathrm{U}$ \\
\hline Plutonium enrichment & $88 \pm 0.5$ wt $\%\left({ }^{239} \mathrm{Pu}+{ }^{241} \mathrm{Pu}\right)$ in $\mathrm{Pu}$ \\
\hline Fuel-pellet diameter & $4.928 \pm 0.038 \mathrm{~mm}$ \\
\hline Fuel-pellet geometry & Solid with dished ends \\
\hline Fuel-column length & $864 \pm 3 \mathrm{~mm}$ \\
\hline Fuel theoretical density & $10.975 \mathrm{~g} / \mathrm{cm}^{3}$ (Ref.) \\
\hline Fuel density & $9.98 \pm 0.22 \mathrm{~g} / \mathrm{cm}^{3}(90.9 \%$ TD Ref. $)$ \\
\hline Fuel smeared density (planar) & $9.39 \pm 0.25 \mathrm{~g} / \mathrm{cm}^{3}(85.5 \%$ TD Ref. $)$ \\
\hline Fuel-column weight & $165 \mathrm{~g}$ (Ref.) \\
\hline Natural $\mathrm{UO}_{2}$ pellet diameter & $4.928 \pm 0.038 \mathrm{~mm}$ \\
\hline $\begin{array}{l}\text { Total length of natural } \mathrm{UO}_{2} \\
\text { column (each end) }\end{array}$ & $12.7 \pm 0.4 \mathrm{~mm}$ \\
\hline Reflector material & Inconel 600 \\
\hline Reflector diameter & $4.928 \pm 0.025 \mathrm{~mm}$ \\
\hline Total reflector length & $76.2 \pm 0.1 \mathrm{~mm}$ \\
\hline Plenum-spring material & 302 stainless steel \\
\hline Cladding material & 316 stainless steel (Spec B 58992) \\
\hline Cladding dimensions & $\begin{array}{l}5.842 \pm 0.025 \mathrm{~mm} \text { OD } \\
x 0.381 \pm 0.025 \mathrm{~mm} \text { thick }\end{array}$ \\
\hline Cladding condition & $20 \%$ cold work (Ref.) \\
\hline Wire-wrap material & 316 stainless steel, $20 \%$ cold work \\
\hline Wire-wrap diameter & $1.02 \pm 0.01 \mathrm{~mm}$ \\
\hline End-cap material & 316 stainless steel \\
\hline Gas-plenum volume & $4.4 \mathrm{~cm}^{3}$ (Ref.) \\
\hline Fill gas & $\begin{array}{l}\text { Helium, } 0.1 \mathrm{MPa}(1 \mathrm{~atm}) \text { at room } \\
\text { temperature }\end{array}$ \\
\hline
\end{tabular}

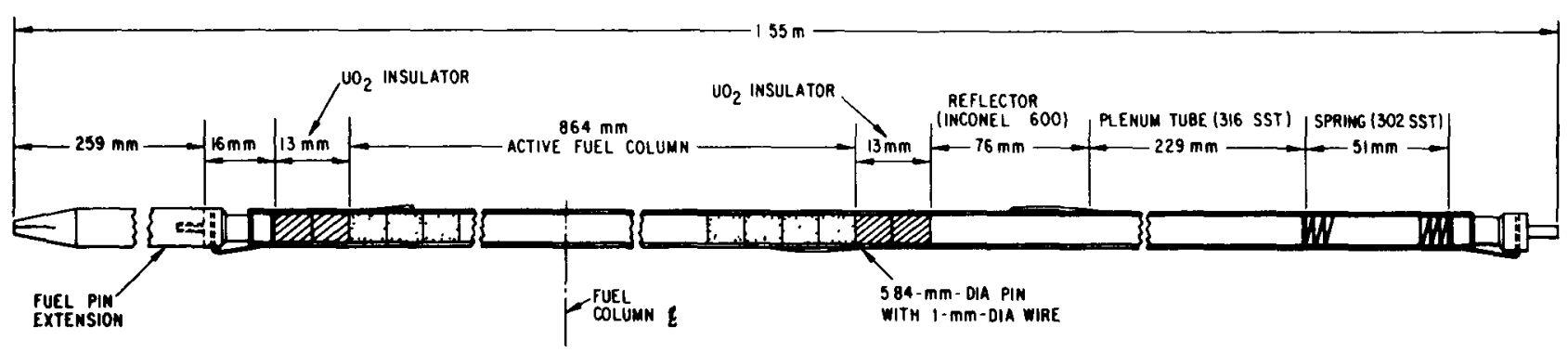

Fig. 1. Schematic Diagram of HEDL-59 Fuel Element. ANL Neg. No. 900-77-534. 


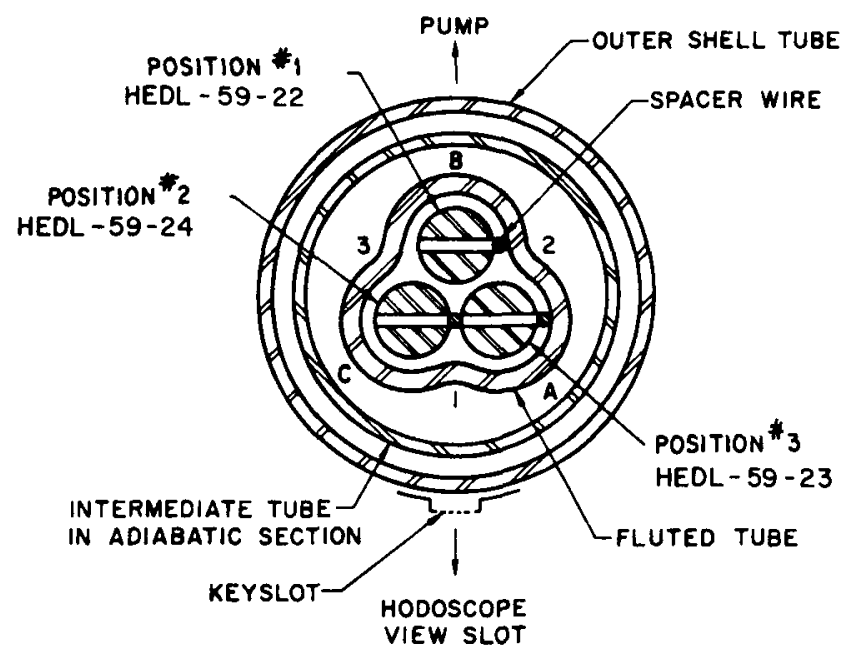

Fig. 2

Schematic Diagram of L5 Cluster

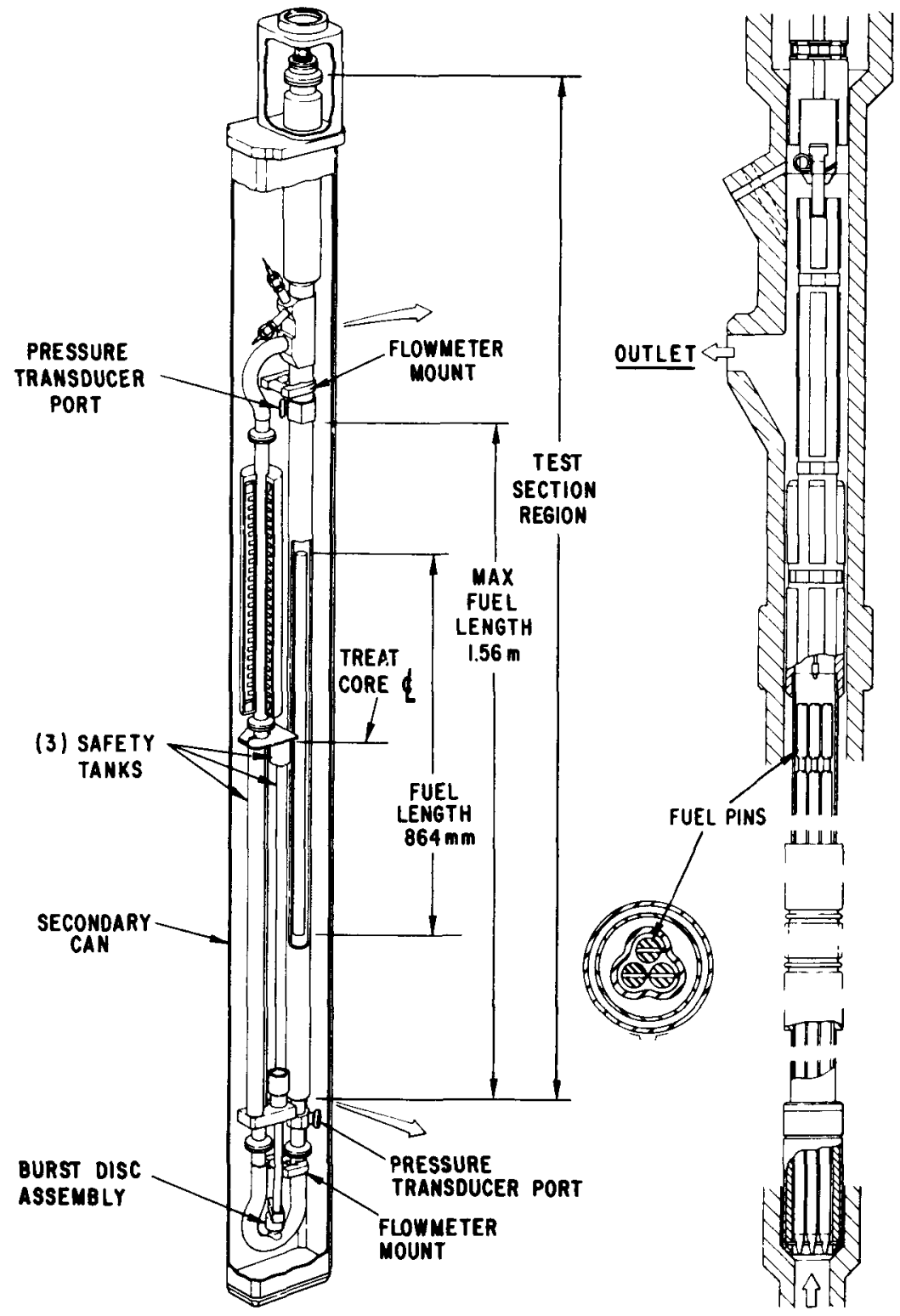

Fig. 3. Mark-IIC Test Vehicle for TREAT Tests with Preirradiated Fuel. ANL Neg. No. 900-77-531. 
The three test elements were loaded into an assembly, referred to as a test train, in the facilities in HFEF. The test train also contained the thermocouple instrumentation. To thermally isolate the flow tube from the loopbody weldment, the test train contained a gas-filled region surrounding the flow tube, identified as an "adiabatic section." The gas fill was a mixture of helium and argon at a pressure of $0.1 \mathrm{MPa}(1 \mathrm{~atm})$ at room temperature. The helium was used for leak detection. Other gases possessing a lower thermal conductivity, although desirable to reduce heat losses, were not as convenient for leak-checking.

Several of the thermocouples were routed down into the adiabatic section through a collar, which also supported the outer wall of the in-core section of the test train. The gas-filled region was isolated from the loop sodium by brazing the collar to the flow tube, thermocouple sheaths, and outer wall. Other thermocouples were located in the sodium at the inlet and outlet of the test section. Pressure transducers and flowmeters were mounted on the loopbody weldment at the inlet to, and outlet from, the test section containing the fuel elements. The final assembly was achieved in HFEF by lowering the test train with the test fuel into the loop already filled with the required quantity of sodium. A $34.5-\mathrm{MPa}(340-\mathrm{atm})$ pressure-containment capability for the assembly was achieved at the closure flange using a double-oval $\mathrm{O}$-ring with Inconel autoclave clamps. Instrumentation cables were routed through the closure region through a brazed gland before flexible leads were connected. A secondary-containment capability was maintained by using hermetically sealed electrical plugs.

Pressure transducers were located at the inlet and outlet to the test region. The loop instrumentation also included an outlet electromagnetic flowmeter, an inlet electromagnetic flowmeter, and an inlet permanent-magnet flowmeter. Twenty thermocouples were also placed within the primary pressure boundary, 18 as part of the test train. The location of the se thermocouples is given in Table II. The experiment parameters characterizing Test L 5 are summarized in Table III.

\section{Transient Planning}

Two transients were planned for Test L5: a heat-balance and a failure (final) transient. The heat-balance test (L5-I) was performed as a consistency verification relating the sample-to-reactor calibration factor to the calorimetric determination of the power generated by means of flow-rate and thermocouple data. The failure, or final, transient (L5-2) was a flow-coastdown simulation. The coastdown and reactor burst events were initiated by the on-line computer at TREAT using the reactor power integrator. Pretest analysis verified that the cladding melting point was more a function of the energy generated in the element, rather than an absolute function of the power-time history. Effects of minor variations in reactor (and, therefore, sample) power levels commonly associated with TREAT shaped transients were minimized by using the integrator for commands. The principal experiment and reactor operational parameters are listed in Table IV. 
TABLE $\amalg$. Thermocouple Locations for Test L5

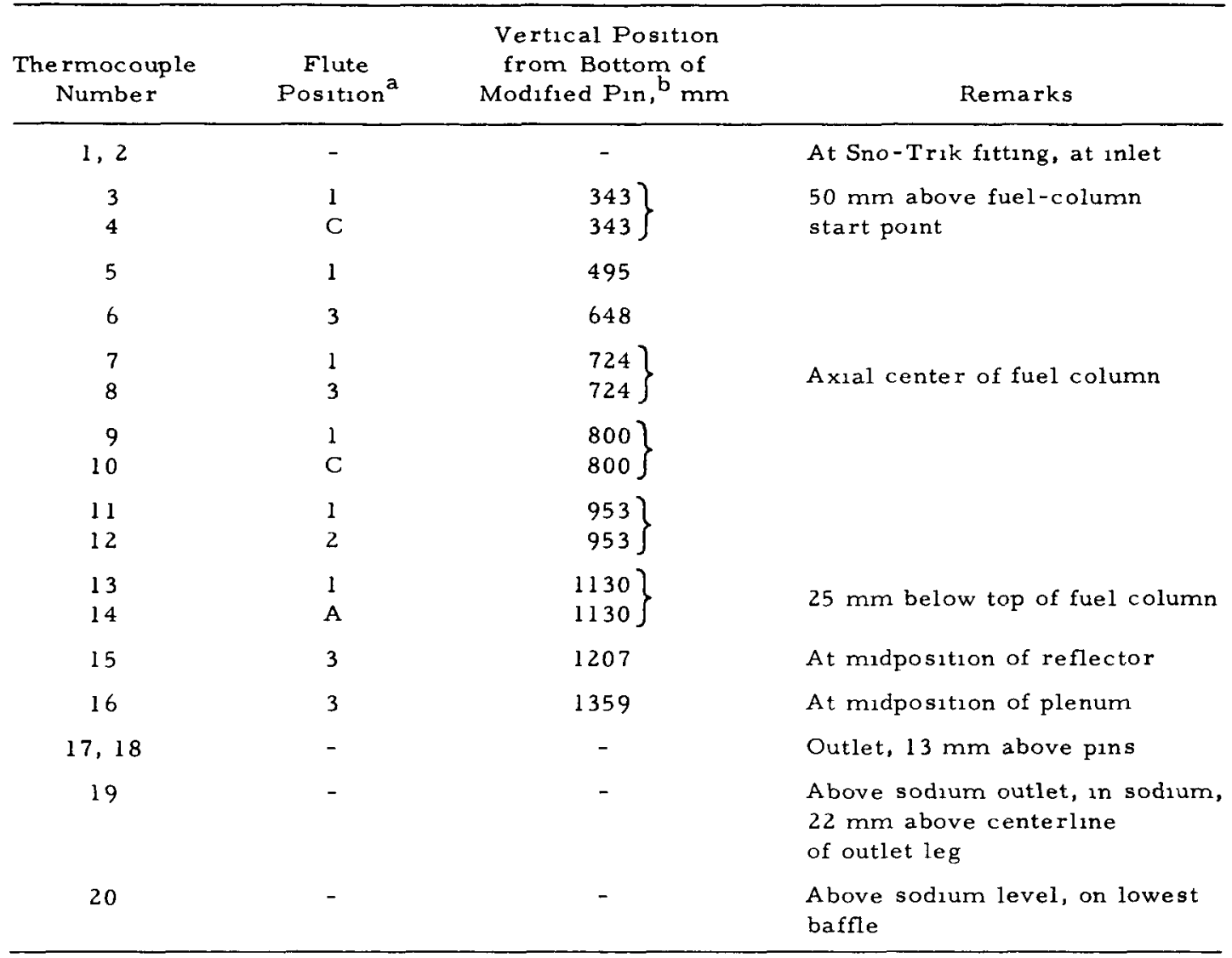

${ }^{a}$ See Fig. 2 for flute positions relative to fuel elements

$\mathrm{b}_{\text {All }}$ thermocouple tolerances $\pm 2 \mathrm{~mm}$, note that distance is measured from bottom of modified pin

TABLE III Definition of Test Hardware

\begin{tabular}{|c|c|}
\hline \multicolumn{2}{|c|}{ Fuel } \\
\hline Type (designation) & FTR-type (HEDL-59) \\
\hline Preir radiation (burnup) & In GETR ( 8 at $\%)$ \\
\hline Fissile content of fresh fuel & $25 \% \mathrm{PuO}_{2}, 75 \% \mathrm{UO}_{2}\left(30 \%{ }^{235} \mathrm{U}\right)$ \\
\hline Fuel-column length & $864 \mathrm{~mm}$ \\
\hline Gas pressure in element plenum & $0.1 \mathrm{MPa}(1 \mathrm{~atm})$ backfilled with xenon \\
\hline \multicolumn{2}{|c|}{ Test Section } \\
\hline Number of fuel elements & Three (channel-centered) \\
\hline Flow tube & 304 SS (trifluted) \\
\hline Radial heat loss restraint & Adrabatic section (gas-filled) \\
\hline Loop plenum gas & Argon- $10 \% \mathrm{He}(02 \mathrm{MPa}$ at operatıng temp) \\
\hline Neutron filters & None \\
\hline Axıal power-shaping collars & Dysprosium metal \\
\hline The rmocouples & 20 (Chromel-Alumel) \\
\hline Flowmeters & $\begin{array}{l}\text { Three (two electromagnetic-type, one } \\
\text { permanent-magnet type) }\end{array}$ \\
\hline Pressure transducers & Two $(0-17 \mathrm{MPa})$ \\
\hline Flow area & $0.63 \mathrm{~cm}^{2}$ \\
\hline
\end{tabular}


TABLE IV. Experiment Operational Parameters for Loss-of-flow Test L5

\begin{tabular}{ll}
\hline \multicolumn{1}{c}{ Parameter } & \multicolumn{1}{c}{ Value } \\
\hline Initial sodium temperature & $400^{\circ} \mathrm{C}$ \\
Initial flow rate of sodium & $170 \mathrm{~cm}^{3} / \mathrm{s}$ \\
Initial peak axial heating rate & $36 \mathrm{~kW} / \mathrm{m}$ \\
Coastdown initiation & $176 \mathrm{MJ}(4 \mathrm{~s})$ \\
Coastdown duration & $4 \frac{3}{4} \mathrm{~s}$ \\
Final flow rate of sodium & $23 \mathrm{~cm}^{3} / \mathrm{s}$ \\
Power burst triggered & $390 \mathrm{MJ}$ \\
Desired burst width & $550 \mathrm{~ms}(\mathrm{FWHM})$ \\
Corresponding peak power (target value) & $500 \mathrm{MW}$ \\
Reactor scram setting & $600 \mathrm{MJ}$ \\
\hline
\end{tabular}

The initial flow rate of about $3 \mathrm{~m} / \mathrm{s}$ in the test section was set below the full flow capability of the Mark-IIC loop and below the nominal flow velocity for FTR. The lower flow rate permits the fuel elements to heat more rapidly than at full flow before the coastdown is initiated. Pretest calculations indicated that the temperature profiles in the fuel at the time of cladding melting were primarily independent of the initial flow rate. The time saved, however, permits the experiment to be performed in the TREAT reactor within the existing capabilities.

The energy in the burst was planned so that the temperature of the fuel would remain below $3500^{\circ} \mathrm{C}$, in keeping with the objective to limit fuel vapor pressure as a driving force for fuel dispersal. The corresponding TREAT energy to achieve this goal, with a sample calibration factor of about $4.5 \mathrm{~kJ} / \mathrm{kg}$ per MJ, was about $210 \mathrm{MJ}$. The desired TREAT transient could be obtained by inserting about $1 \% \Delta \mathrm{k} / \mathrm{k}$ as a step at the time of cladding melting. The resulting burst would reach a peak power level of about $500 \mathrm{MW}$, corresponding to a factor of about 12 above the $36-\mathrm{kW} / \mathrm{m}$ value at the nominal power. Setting the scram at $600 \mathrm{MJ}$ enables the required energy to be generated in the sample, with the energy generated after scram being a margin available for covering uncertainties. The actual L5 TREAT transient fell below the target value in peak power level, although the reactor did achieve the 600-MJ energy at scram.

Test L5 provided a basis of an evolutionary extension of the ANL program examining fuel motion with preirradiated, mixed-oxide fuel. Most noteworthy among these extensions were that, for the first time, a test with irradiated fuel included: 
1. Timing of a burst dependent on a defined state in test fuel (incipient cladding melting).

2. Adjustment of a plenum gas pressure of a preirradiated fuel element (by laser drilling and rewelding in a hot cell at HEDL).

3. Use of irradiated, mixed-oxide fuel having a near-prototype length of active fuel column.

4. Presetting the loop system pressure at operating conditions without jeopardizing the pressure-containment capability of the loop.

5. Testing of a permanent-magnet flowmeter in core on the lower bend of the Mark-IIC loop.

\section{INSTRUMENT AND TEST -ELEMENT CALIBRATIONS}

\section{A. Calibrations of Test-vehicle Instrumentation}

1. The rmocouples

Test-section thermocouples were of the Chromel-Alumel type. Reduction of the output signal to temperature was based on tabulated values related to $65.5^{\circ} \mathrm{C}$ reference junction.

\section{Pressure Transducers}

Statham, unbonded strain-bridge pressure transducers, Model PG $732 \mathrm{TC}-2.5 \mathrm{M}-350$, were used at the test-section inlet and outlet. This transducer model met the requirement for loop pressure containment of $34 \mathrm{MPa}$ without bursting, although its pressure-sensitive diaphragm would be damaged. At $5-\mathrm{V}$ excitation, the calibration constant for the transduce $r$ model is about $840 \mathrm{pV} / \mathrm{Pa}$ in the range 0-17 MPa. Because of space and temperature limitations, the transducers were mounted on the loop with $\mathrm{NaK}$ standoffs. The standoff design included a bellows to separate the NaK from the loop sodium.

Manufacture - supplied calibration information was verified with the transducers mounted on the loop, at operating temperatures, using a known pressure source in the range 0-1.5 MPa with a 5-V -dc excitation. For the tests in the reactor, the excitation source was switched to a $5-\mathrm{V}, 5-\mathrm{kHz}$ source to eliminate potential ionization-current effects in the resistance-bridge circuit. At the time of the test, the transducer bridge was balanced to null its output with the loop in the reactor at the initial equilibrium thermal conditions for sodium of about $400^{\circ} \mathrm{C}$ as specified for the experiment. At this point the loop could not be pressurized to recheck the pressure-transducer calibrations, since the expansion bellows on the test train would collapse. The transducer calibrations were therefore based on the earlier calibration verification and on the specification above the range for which the calibrations had been verified. Pressure pulses above the verified range were not necessarily expected. 


\section{Flowmeters}

The lower (inlet) electromagnetic flowmeter was calibrated by measuring its output ( 1 -A coil current) as a function of the pressure drop across a $5-\mathrm{mm}$-dia orifice before the fuel-bearing test section was loaded into the loop. The orifice was calibrated separately in a water loop to relate flow rate to pressure drop. When the no-flow, zero-shift signal output of the inlet electromagnet flowmeter was subtracted from its total output, a calibration constant of about $600 \mathrm{~cm}^{3} / \mathrm{s} \cdot \mathrm{mV}$ was obtained at sodium temperatures between 260 and $540^{\circ} \mathrm{C}$.

The upper (outlet) flowmeter and inlet permanent magnet were calibrated after the loaded test train was inserted into the loop, using the inlet flowmeter as the reference at a sodium temperature of $400^{\circ} \mathrm{C}$. The sensitivity of the outlet flowmeter was usually poorer than that of the inlet by a factor of 2-3. The inlet permanent magnet gave about a 50\% larger signal than the inlet electromagnet flowmeter at the same flow rate.

\section{B. Power-calibration Experiments \\ 1. Calibration Test Objectives}

The execution of a TREAT fuel-motion test using the Mark-II loop involves a requirement to "calibrate" the power generated in the test fuel. The se calibrations relate the power being generated in each fuel element in the test cluster to a detection device external to the test region. The detection device needs to be continuously recorded during the test for purposes of reactor control and posttest evaluation. The relationship between the detection device and the approximate reactor power level also needs to be known so that the acceptability of the transient can be established on reactor operational grounds.

Although various possibilities exist, it has been the practice at TREAT to use either a reactor power or a reactor power integrator channel for this detector. In Test L5, calibrations were based on "Integrator No. 1," an ion chamber (uncompensated). Calibration factors were determined for each element in the cluster. The value of a calibration factor is expressed as the specific power generated in the sample per megawatt of TREAT power; its peak axial value is generally quoted. The precise power level of the reactor need not be known so long as the instrument calibration, the core loading, and control-rod configuration a re the same for the calibration and the actual tests.

The calibration factor must be known sufficiently in advance of the test to both plan the transient and evaluate the experiment safety. For example, a test fuel element with $200 \mathrm{~g} / \mathrm{m}$ of fuel and a calibration factor of $4 \mathrm{~kW} / \mathrm{kg}$ per megawatt will generate heat at $40 \mathrm{~kW} / \mathrm{m}$ when TREAT operates at $50 \mathrm{MW}$. The knowledge of these calibration factors and of the associated 
internal radial and axial power distributions is essential to the planning, execution, and analysis of TREAT fuel-motion tests. Unfortunately, only values for the calibration factors with intact fuel geometry can be measured. These factors will change once fuel motion occurs, and no experimental or analytical method has, as yet, been devised to treat the detailed changes once the original fuel geometry is lost.

The schematic diagram shown in Fig. 4 illustrates the sequence of events that represent a TREAT test program such as for Test L5. Calibration experiments may not be required in all fuel-motion tests, since previous calibrations may apply with minor calculational corrections. Several possible alternatives, identified in Table V, might have been used to obtain an acceptable calibration result. Each alternative depends either on a radiochemical

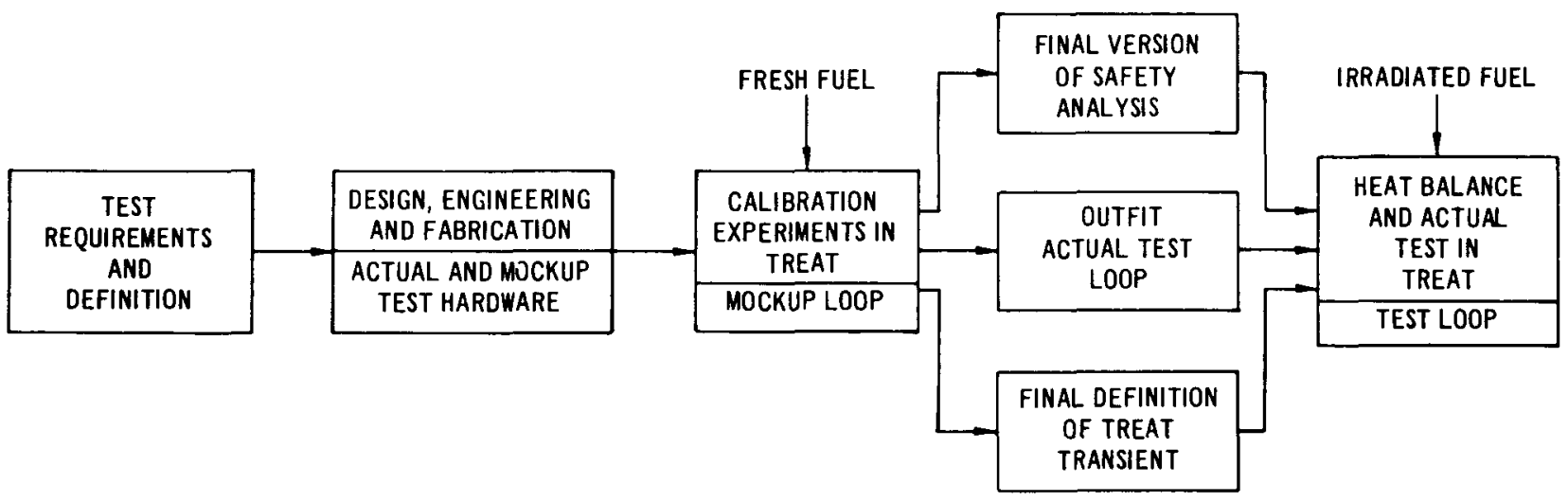

Fig. 4. Conduct of Typical Fuel Dynamics Test Using Mark-II Integral Sodıum Loop in TREAT. ANL Neg. No. 900-5735.

TABLE V. Alternative Ways to Determine Calıbratıon Factors

\begin{tabular}{|c|c|c|c|}
\hline & Option & Pro & Con \\
\hline 1 & $\begin{array}{l}\text { Fresh fuel in mockup } \\
\text { with planned tran- } \\
\text { sient. No sodium } \\
\text { present (dry). }\end{array}$ & $\begin{array}{l}\text { All factors nearly } \\
\text { identical to test } \\
\text { conditions. }\end{array}$ & $\begin{array}{l}\text { Fuel would fail and } \\
\text { could not be analyzed } \\
\text { easily. Safety in } \\
\text { question }\end{array}$ \\
\hline 2. & $\begin{array}{l}\text { Fresh fuel in mockup } \\
\text { with clipped transient } \\
\text { (dry) }\end{array}$ & $\begin{array}{l}\text { Conditions similar } \\
\text { to an actual test } \\
\text { transient. }\end{array}$ & $\begin{array}{l}\text { High risk of failing } \\
\text { fuel unless factors } \\
\text { known well enough }\end{array}$ \\
\hline 3. & $\begin{array}{l}\text { Fresh fuel in mockup } \\
\text { at low power level. } \\
\text { Correct to transient } \\
\text { using monitor-wire } \\
\text { ratios (dry). }\end{array}$ & $\begin{array}{l}\text { Low risk of fuel } \\
\text { failure. Readily } \\
\text { accomplished after } \\
\text { shaping-collar config- } \\
\text { uration determined }\end{array}$ & $\begin{array}{l}\text { Approach may not be } \\
\text { adequate to predict } \\
\text { "transient correction." }\end{array}$ \\
\hline 4. & $\begin{array}{l}\text { Fresh fuel in loop } \\
\text { at constant flow } \\
\text { (heat balance). }\end{array}$ & $\begin{array}{l}\text { Test approaches actual } \\
\text { test conditions. }\end{array}$ & $\begin{array}{l}\text { No time available to } \\
\text { commit loop. Sodium } \\
\text { handling required } \\
\text { Safety analysis } \\
\text { required. }\end{array}$ \\
\hline 5. & $\begin{array}{l}\text { Irradiated fuel in } \\
\text { loop at constant flow } \\
\text { (heat balance). }\end{array}$ & $\begin{array}{l}\text { Highly desirable and } \\
\text { usually performed } \\
\text { (done for L5). }\end{array}$ & $\begin{array}{l}\text { Usually performed } 1 \text { day } \\
\text { before test and data not } \\
\text { available for pretest } \\
\text { analysis. }\end{array}$ \\
\hline
\end{tabular}


determination of the sample fission rate or on calorimetry (temperature and flow measurements). Option 3 in the table was selected for Test L5 primarily because of schedule considerations.

Option 3 is based on the assumption that the ratio of the calibration factor for fuel in the test region to a monitor-wire factor for similar reactor transients is invariant. In addition, this ratio is assumed to remain constant, even though the reactor is operated at very low, steady power levels which do not involve significant control-rod motions or sample power generation. If this were indeed true, then the calibration factor for fuel during a transient could be inferred by measuring its value for fuel irradiated at a low power level without coolant present and then predicting its value for the failure transient by using the ratio of monitor-wire activations, or fission rate, per megajoule. The actual conduct of previous tests with both this procedure (Option 3) and the heat-balance (calorimetry) transients performed before the transient (Option 5) indicate agreement within experimental uncertainties $( \pm 10 \%)$.

The use of Option 3 also greatly simplified TREAT operations for the L5 calibrations since only fresh (unirradiated) fuel and monitor wires were required. The absence of sodium and its associated handling procedures were also desirable. In summary, the calibration procedure for fresh-fuel calibrations involved:

a. Analysis of selected pellets from fuel elements for fissions $/ \mathrm{kg}$ (four elements of seven) using the Ba-La pair.

b. Analysis of monitor wires for fission rate to determine transient correction.

c. Computation for estimated sample-to-reactor coupling.

d. Partial verification by heat balance with actual test fuel in sodium loop before TOP simulation (Option 5, Table V).

In addition to the normal calibration requirements, the axial power profile for the three test elements needed to be tailored to a specific experimental requirement. These axial shaping experiments preceded the final calibrations.

\section{Results of Calibration Tests}

The calibration factors for the L5 test elements are based on the results of calibration experiments performed in February and March 1974. A more complete discussion of the calibration results is incorporated in Appendix B. Monitor-wire measurements were used to approximate the ratio of the calibration factor for the final transient to the value obtained for the irradiations with fuel elements at low level. This ratio was measured to be 1.18. An additional correction was made to consider the effect of burnup from the 
GETR irradiations. Based on the calibration-test results with the appropriate corrections, the cluster-average value for the peak axial calibration factor was $4.52 \mathrm{~kW} / \mathrm{kg}$ per megawatt. Each element in the L 5 cluster was within $3 \%$ of this value, indicating that each event taking place within the test zone could reasonably be treated as a single-channel representation. Similarly, the axial power profile for each element was nearly identical, each distribution having a peak-to-average value of about 1.22 .

As intended, the axial power distribution was not symmetric about the fuel-column midplane; the distribution was somewhat skewed, the lower portion of the element generating a higher percentage of the power than the upper part. This type of power distribution represents a reactor case in which control rods have been withdrawn to positions in the upper half of the core. The portion of the fuel column between values of axial position/length of 0.3 and 0.55 measured from the bottom of the element generated power at about the peak axial value; i.e., the distribution function was almost a constant over this portion of the fuel column. Further refinements in improving the characteristics of the axial power distribution we re judged to provide little further benefit consistent with the difficulties involved in meeting the originally limited objectives.

Internal radial power distributions within selected pellets at the midplane locations of the calibration elements were obtained by counting cylindrical (annular)sections. The sections were obtained by an ultrasonic trepan-

ning technique described by Yaggee and Dragel. ${ }^{4}$ The internal peak-to-average values did not exceed about 1.5 for an individual element. These distributions are reported in Appendix B. A recommended radial power distribution for a single-channel, azimuthally symmetric model is also given in Appendix $B$. Extensive thermal-neutron filtering would be required to reduce the radial peak-to-average value below the 1.5 value obtained in the loop without a filter.

\section{RESULTS OF HEAT-BALANCE TEST}

Test L5 consisted of a heat-balance (nonfailure) transient and the loss of-flow simulation transient. These transients were conducted on consecutive days in November 1974 at the TREAT Reactor at the ANL site of the Idaho National Engineering Laboratory. This section deals with the results of the heat-balance test, designated L5-1. The heat-balance test was conducted primarily as a check on the consistency of the power-calibration factors of the fuel elements and as an operational test of the loop.

\section{A. Comparison of Results with Thermal Analysis}

A partial check of the consistency of flow and sample power-calibration data was provided by the results from the $L 5$ heat-balance test. In a TREAT heat-balance test, the reactor is operated by the transient program control to 
obtain a constant power over a specified time interval. The loop is operated at a constant flow rate. Because the experimental apparatus lacks a heat exchanger, the energy generated increases the temperatures of both the bulk sodium coolant and the loop wall. The time at full power was therefore limited so that the estimated energy generated in the loop would keep cladding temperature well below the temperature believed to cause changes in cladding properties.

The L5-1 transient is shown in Fig. 5. The sodium temperatures, measured by thermocouples mounted on the outside of the flow tube, are also
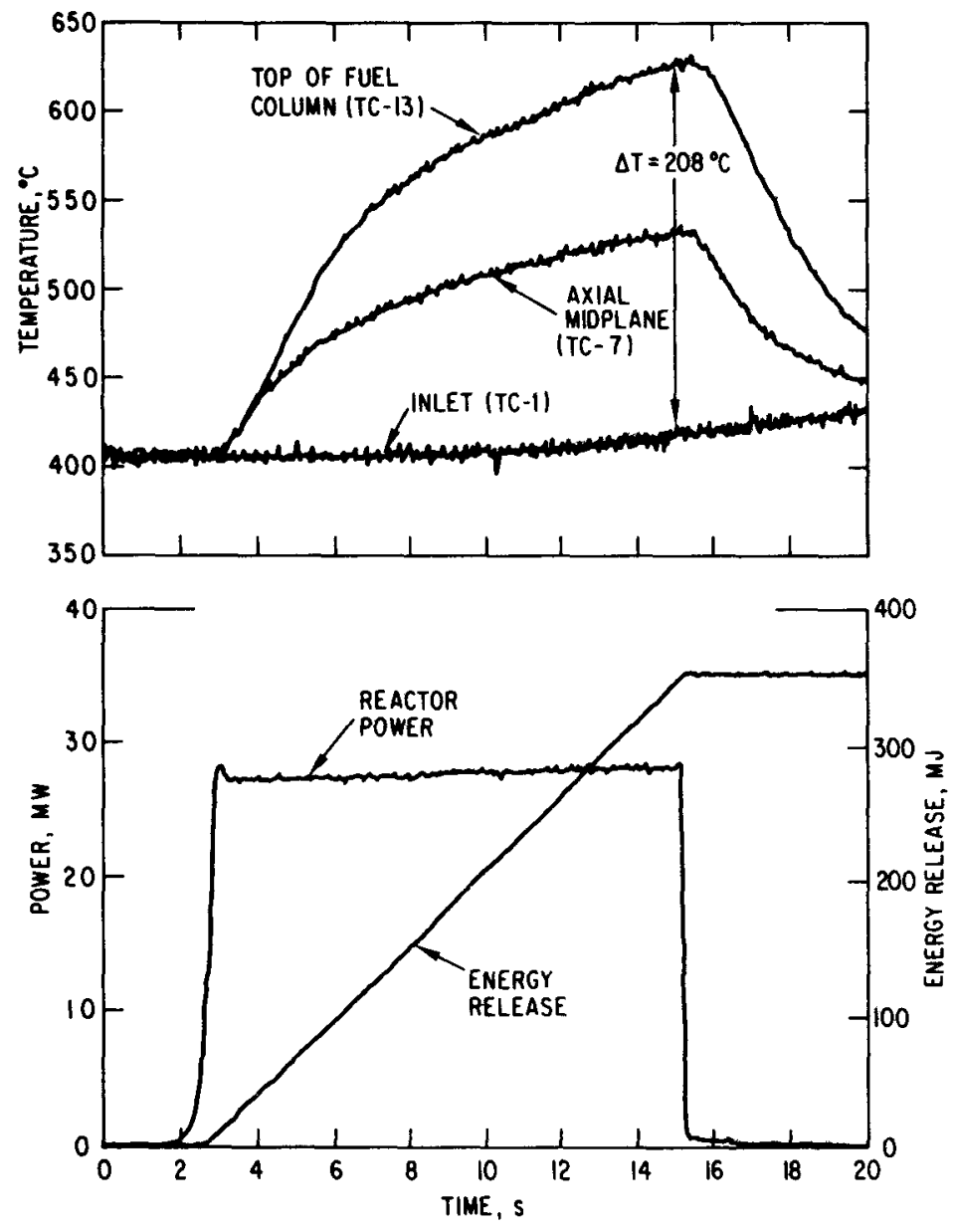

Fig. 5. TREAT Transient for L5 Heat-balance Test. ANL Neg. No. 900-77-533. shown in the figure. The transient consisted of about a 12 -s interval at a constant power of about $28 \mathrm{MW}$. The initial sodium flow rate was set at $225 \mathrm{~cm}^{3} / \mathrm{s}$ at $400^{\circ} \mathrm{C}$. As based on the cali bration factor determined from the calibration tests, the test region should have generated $51 \mathrm{~kW}$. The coolant temperature rise at the constant flow rate of $225 \mathrm{~cm}^{3} / \mathrm{s}$ is about $195^{\circ} \mathrm{C}$. The measured coolant temperature rise of about $208^{\circ} \mathrm{C}$ shown in Fig. 5 is within $7 \%$ of the estimate. Additional calculations with the SAS code were made in a further effort to esti mate the experiment heattransfer parameters. These results are reported in Sec. VII.

B. Instrument Responses

The heat-balance test also offered the opportunity to examine the instrument response to a relatively simple reactor transient. The pressure transducer signals, shown in

Fig. 6, indicated that the inlet transducer responded to the radiation and thermal environment at its location, since no pressure changes in the loop should have occurred. Similar observations were made in other Mark-II loop tests. Subsequent study of this phenomenon has identified the cause of the problem as the radiation response of the cables with the electronic circuitry used. The output signal from the lower transducer failed to return to its initial value of zero during the data-recording period of 2 min. The outlet (upper) transducer was nearly unaffected by the transient. 
The flowmeter data for the first $20 \mathrm{~s}$ into the transient are also shown in Fig. 6. Both lower (inlet) flowmeters indicated a decline in flow during the
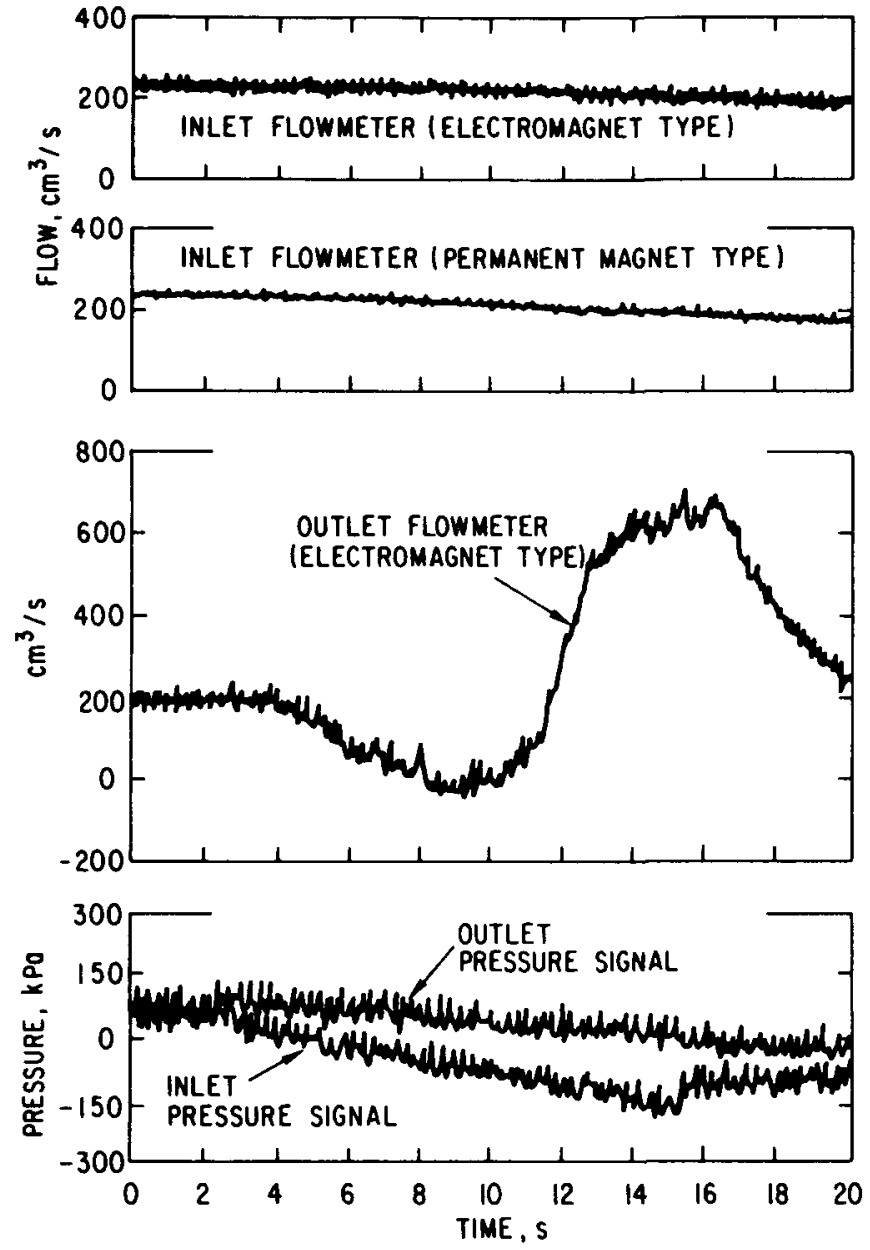

Fig. 6. Responses of Flowmeters and Pressure Transducers in L.5 Heat-balance Test. ANL Neg. No. 900-77-537. time when the reactor was at $28 \mathrm{MW}$ and for at least $4 \mathrm{~s}$ thereafter. During this time, the pump voltage was held constant, which ordinarily results in a constant flow rate. A more erratic behavior was exhibited by the outlet flowmeter. These anomalous behavior characteristics have been observed in other Mark-II loop experiments in TREAT. However, no phenomenon has, as yet, been identified to explain unambiguously the observed behavior of the flowmeter signal. Nevertheless, it is believed that the flow was constant during the test, but that the indicated flow change was a result of the radiation response.

Additional graphical displays of the data obtained from the heatbalance test are presented in Appendix $C$. These data were unavail able for review when the transient test was conducted. No opportunity was therefore available to examine the anomalous behavior of instrumentation more closely before conducting the final transient.

The hodoscope was also operated during the heat-balance test so that, in the event of a malfunction leading to fuel-element failure, the resulting fuel-motion data would not be lost. Since the transient for the heat balance was executed as planned, these hodoscope data were not analyzed. 


\section{TRANSIENT TEST RESULTS}

\section{A. Test Transient Characteristics}

The loss-of-flow test (L5-2) was conducted on November 7, 1974 (TREAT Transient 1606). The actual transient attained is shown in Fig. 7.

The transient consisted of a constant-

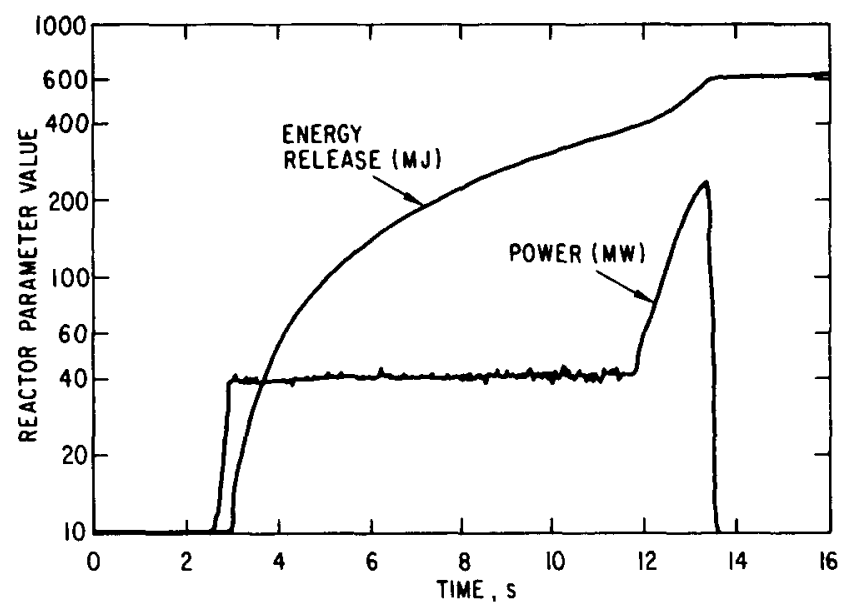

Fig. 7. TREAT Transient 1606 for Loss - of-flow Test L5. ANL Neg. No. 900-77-536. power portion of about $42 \mathrm{MW}$ for about $9 \mathrm{~s}$, followed by a power burst initiated at $11.84 \mathrm{~s}$ from the start of the control program. Figure 8 shows the transient in an expanded time scale in the interval of the burst. The actual transient reached a peak power of about $240 \mathrm{MW}$ at about $13.4 \mathrm{~s}$, when the reactor energy release was about $600 \mathrm{MJ}$. The total energy release for the transient was $628 \mathrm{MJ}$, about $240 \mathrm{MJ}$ of energy being contained in the burst. The power shape, indicated in Fig. 8, was substantially asymmetric, with an average period in the rising portion of about $835 \mathrm{~ms}$. The time between the half-power points was $800 \mathrm{~ms}$, although the asymmetry of the burst renders this parameter nearly useless as a measure of the burst characteristics.

The actual transient differed from both the planned transient and the trial transient. The peak power for the actual transient was about half the value attained in the trial. The energy release at the scram setting was reached just about at the same time of peak reactor power, leading to the high degree of asymmetry in the burst portion of the transient once scram occurred. Apparently, the rate of reactivity insertion at the time of the burst initiation did not correspond to the the value obtained in the trialtransient. Although unplanned, the total energy deposited in the test ele-

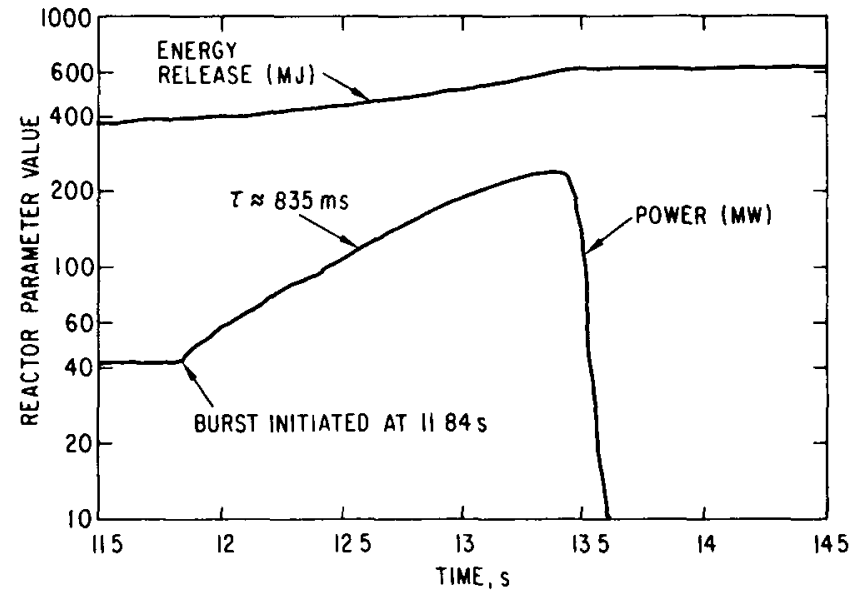

Fig. 8. TREAT Transient for Loss-of-flow Test L5 in Time Interval of Power Burst. ANL Neg. No. $900-77-530$. ments at the actual rate of deposition was just about sufficient to cause a mild fuel dispersal, leaving portions of the fuel below the melting transition. The results obtained from the postmortem examinations therefore take on special significance, since a full range of microstructural transitions could be expected. 
The flow coastdown was initiated at about $175 \mathrm{MJ}$ or at a time of $7 \mathrm{~s}$ from the initiation of the control program. Figure 9 shows the flow coastdown and resulting postvoiding flow oscillations in relation to the reactor transient. The flowmeter data indicate that the coastdown occurred in about five steps
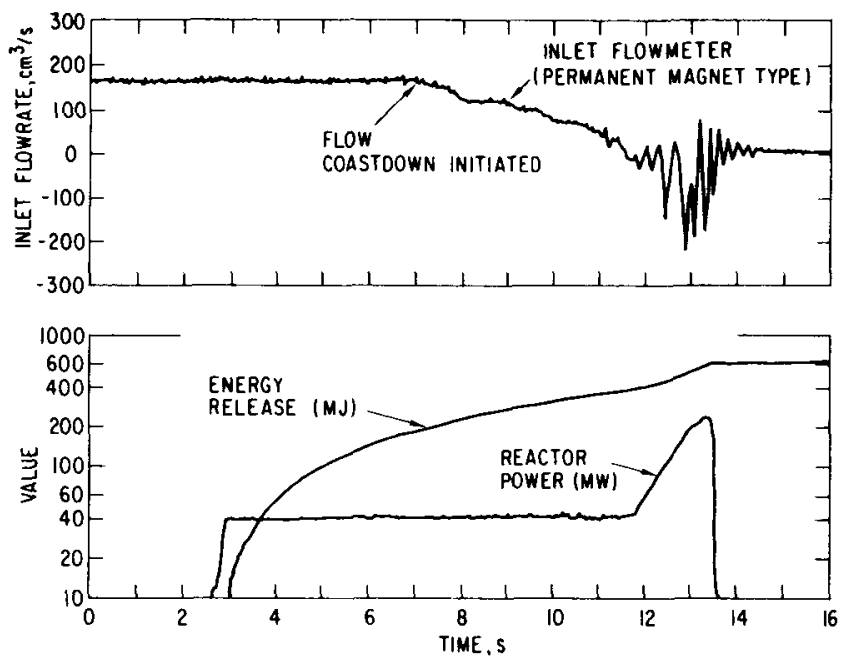

Fig. 9. Test L5 Loss-of-flow Transient and Flow Coastdown. ANL Neg. No. 900-77-542. rather than as a continuous function of time. This stepwise coastdown occurred because of the way in which the pump power supply was controlled using the Data-Trak and Variac. Calculations using SAS indicated that this stepwise flow coastdown was adequate to meet the test objectives.

B. Results from Test Instrumentation

\section{Comments on Data Ac- quisition and Reduction}

Data from the test-vehicle thermocouples, pressure transducers, and flowmeters were recorded on

separate channels of analog magnetic tapes and on a CRT Visicorder after amplication with NEFF high-gain amplifiers to the desired levels. A clock channel was recorded on each tape unit using pulses generated from a $\mathrm{l}-\mathrm{kHz}$ oscillator. Hodoscope data were recorded independently using a high-speed camera in conjunction with a binary light-array system. Timing signals for the hodoscope system were recorded with the light-array frames using a separate clocking system. The relationship for timing of events among the data-acquisition units was computed by counting pulses from the start of the control-program sequence. In some cases, the clock pulses might be nonuniform; therefore a different discriminator setting could potentially result in a small timing error. Such timing errors were probably of no consequence for interpretations of $L 5$ results because of the longer time intervals between major events.

Data-reduction procedures for test-vehicle instrumentation produced graphical displays during time periods of interest. The CRT Visicorder record served as the primary qualitative basis for ensuring that the datahandling procedure did not, by itself, produce an erroneous result. The analog signal on the tape unit typically contained both random noise and a $60-\mathrm{Hz}$ pickup. Flowmeter signals were particularly prone to significant $60-\mathrm{Hz}$ pickup and noise levels because the flowmeters being used had a low sensitivity. A typical output signal from a flowmeter for Test L5 was no greater than $400 \mu \mathrm{V}$. Removal of noise and $60-\mathrm{Hz}$ pickup by digital averaging was used, where necessary, to reveal the data trend. Electronic filtering with a $60-\mathrm{Hz}$ notch filter and an averaging amplifier yielded essentially the same result as the 
analog-to-digital conversion with digital filtering. The point to be recognized is that the graphical data may depend on the method used to convert and filter the data from the true record stored on the magnetic tape. In no case was it apparent that the data-reduction techniques had influenced the interpretation of a test result.

The data-reduction techniques used to obtain hodoscope-detector count-rate data were more complicated. After film development, the lightarray record on each film frame was converted to a digital tape record using the ALICE flying-spot detector system. Techniques developed for other tests were used to identify the condition of the array lights (on or off) and to reject apparently spurious records. Subsequent analysis of the hodoscope data from the processed signal data involved several corrections, such as for detector efficiency, dead time, and nonlinearity The primary objective of the hodoscopedata evaluation was to identify changes in fuel density within the viewing area The interpretations of hodoscope data were somewhat more difficult than for previous fuel-motion tests because, in Test L5, an appreciable quantity of fuel was originally located outside the hodoscope view. A more complete description of the techniques used to analyze the fuel motion in Test L5 is given by Stewart. ${ }^{5}$

\section{Results from Test-vehicle Instrumentation}
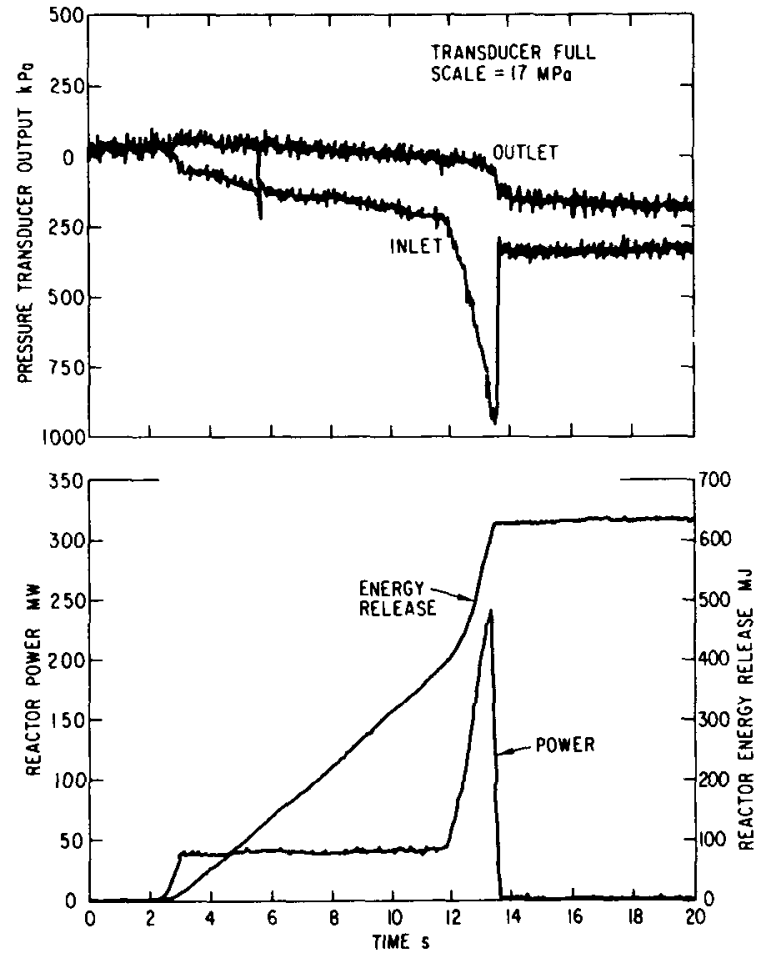

Fig. 10. Signals from Inlet and Outlet Pressure Transducers in L5 Loss-of-flow Transient. ANL Neg. No. 900-77-538.
The outputs from the pressure transducers are shown in Fig. 10 Neither transducer recorded any pressure pulses. The inlet pressure transducer did experience a shift in its signal to about $6 \%$ of its full-scale value as the radiation field in the test region increased This radiation response depended on both the type of cabling used and the excitation source The effect on the outlet pressure transducer was negligible because its cabling did not pass through the active core region Had any pressure events occurred, the pressure pulses would have been superimposed on the drifted transducer signals. Other than the lack of pressure pulses, the transducer data provided no further useful information

The outputs from the three flowmeters installed for Test L5 loss-offlow are shown in Fig. 11 for analog data averaged over about $20 \mathrm{~ms}$. The output from the outlet flowmeter shows 


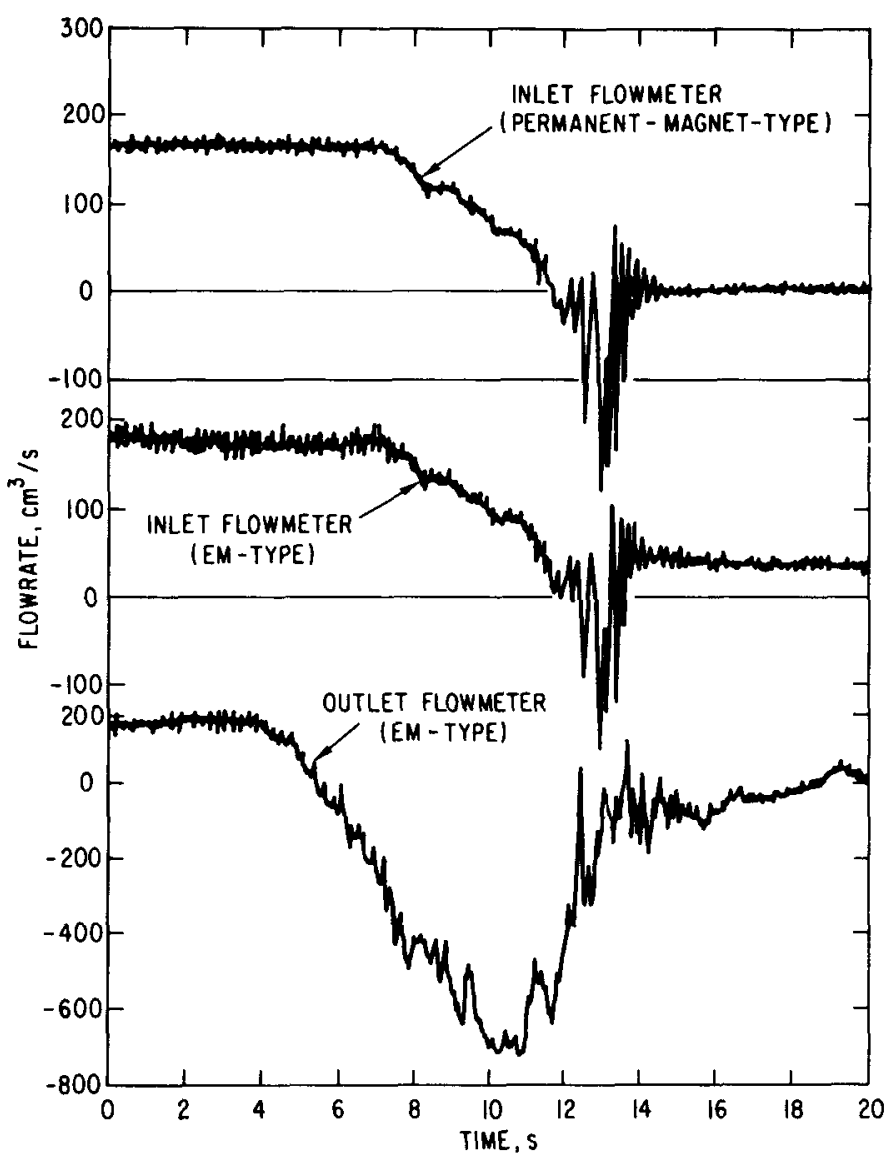

Fig. 11. Flowmeter Signals in L5 Loss-of-flow Transient. ANL Neg. No. 900-77-541. the same erratic behavior recorded during the heat-balance transient, illustrated in Fig. 6. Because of this pronounced erratic behavior, no significant interpretations could be as sociated with the data from the outlet flowmeter. The inlet permanent-magnet-type flowmeter showed essentially the same characteristic patterns observed with the inlet electromagnetic-type instrument. The permanent-magnet flowmeter did, however, demonstrate little, or no, zero drift (or shift) during the test. The permanent-magnet calibration is ordinarily sensitive to temperature increases. The measured temperature increase of only $12^{\circ} \mathrm{C}$ was, however, insufficient to cause any significant reduction in the flow sensitivity of the permanent-magnet flowmeter.

Although difficult to determine from Fig. 11 alone, both the inlet flowmeters indicate a deviation from the coastdown pattern

at $11.2 \mathrm{~s}$. This deviation might be associated with a bulk boiling in the test region. The oscillations occurring after voiding had an approximate frequency of $5 \mathrm{~Hz}$. This frequency is probably more a parameter of the loop hydraulics rather than a characteristic of an LMFBR subassembly.

Some of the principal sensor data recorded during the test are shown in Figs. 12 and 13. Figure 12 covers the transient during the full $13.5 \mathrm{~s}$ of reactor operation at significant power levels; Fig. 13 shows these data during the time of the burst. The boiling plateau at about $938^{\circ} \mathrm{C}$ is observable in these figures. The thermocouple at the top of the fuel column (TC13) indicates test-section voiding at about $11.5 \mathrm{~s}$, which is about $300 \mathrm{~ms}$ before the initiation of the burst.

The data shown in Fig. 13 provide an expansion of the plotting scale in the time interval of the burst just about the time that the inlet flowmeter indicated flow reversal. Data from thermocouples $7,9,11$, and 13 represent typical results from other thermocouples similarly mounted on the outside of the flow tube. Once voiding occurs, a considerable time lag will occur between the time of events at the cladding surface or in the flow channel and the time 
these thermocouples will record the event. Because of current engineering limitations, it has not been possible to mount thermocouples in positions needed to monitor cladding events directly. From the data, the temperatures indicated by these thermocouples all rise rapidly at, or before, $13.4 \mathrm{~s}$ into the transient, the point of peak power. Both coolant dryout and/or molten material impinging on the flow tube could have caused this rapid rise. The first thermocouples to fail were located at, or above, the original fuel-column midplane; the failures occur after the time of peak power. Note that a thermocouple could fail either by overheating its junction or by a melthrough of its output lead when the fluted (flow) tube melts through. The timing of thermocouple failures suggests that considerable heat transfer to the flow tube was still occurring well after the transient.

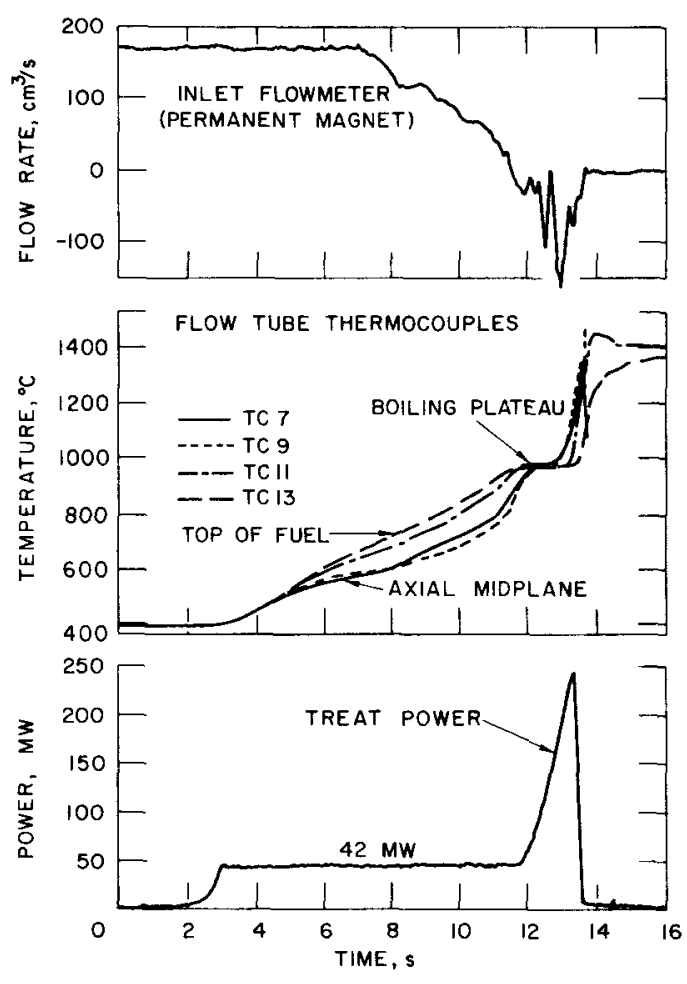

Fig. 12. Flow and Temperature Features of Loss-of-flow Test L5. ANL Neg. No. 900-77-532.

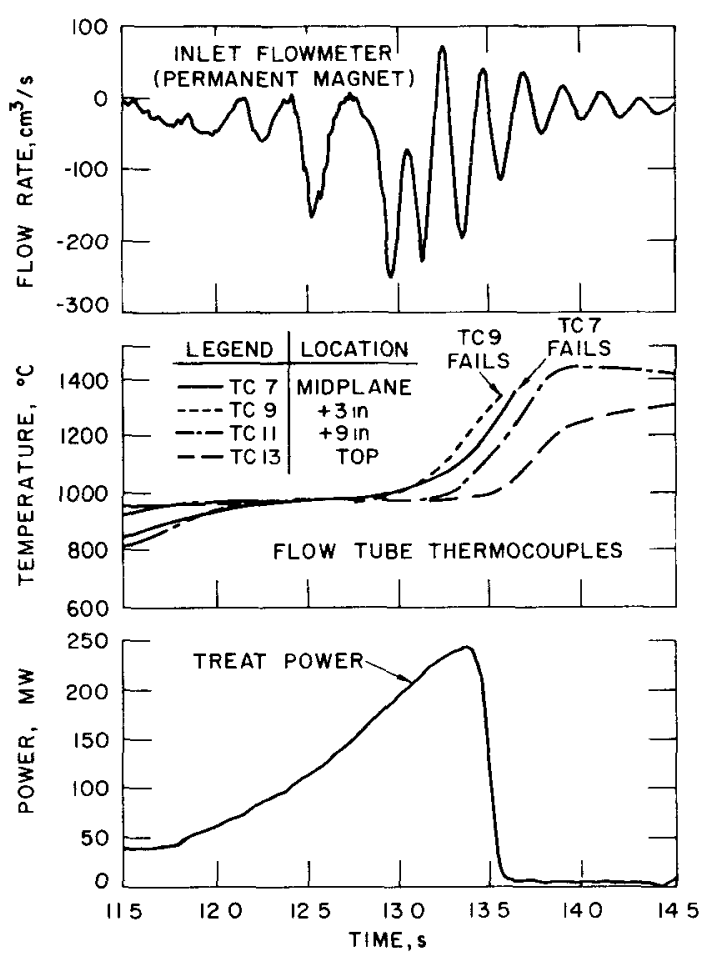

Fig. 13. Flow and Temperature Data in Time Interval of L5 Burst. ANL Neg. No. $900-77-535$.

Once flow reversal occurred, the data from the inlet flowmeter did not necessarily indicate the absolute flow rate, since the output signal had not been calibrated for a two-phase mixture. Noncondensible gasses could be present after fuel-pin failure or when the flow tube is breached by molten fuel. [The adiabatic section surrounding the flow tube was originally filled during its construction with $0.1 \mathrm{MPa}(1 \mathrm{~atm})$ of helium at room temperature.] Nevertheless, the oscillations exhibited in the flowmeter signal output indicate the characteristics expected in a voided assembly that is still generating heat. 
Additional data obtained from the test-vehicle sensors are presented in Appendix D. Little additional data could be extracted from the test-vehicle sensors because these sensors become substantially "decoupled" from the fuel zone once sodium voiding occurs. The fuel-motion scenario is therefore dependent on the analysis of the hodoscope data and postmortem examinations.

C. Summary of Fuel-motion Results

Final evaluation ${ }^{5}$ of hodoscope data for L5 revealed only minor fuelmotion effects before scram, indicating that the major fuel redistribution observable in the post-transient radiograph occurred after scram. This fuel redistribution occurred as an upward dispersal.

At about $4.0 \mathrm{~s}$ into the transient, just after preheat and well before the power burst, the lower half of the fuel column started and continued to bend westward until about $11.8 \mathrm{~s}$. Sodium boiling had occurred by $11.5 \mathrm{~s}$. The power burst was initiated at $11.8 \mathrm{~s}$, at which time the lower half of the fuel column abruptly shifted eastward and the portion above the midplane shifted westward.

Beginning at $11.8 \mathrm{~s}$, while the fuel elements maintained their cylindrical geometry, much bending, displacement, or buckling of the fuel elements apparently occurred at some points, as is indicated by small localized increases and decreases comparable to the estimated uncertainties.

Between 13.7 and $13.9 \mathrm{~s}$, there was a significant decrease in fuel density in the hodoscope lower-half region of view, which corresponded to the region near the midplane (to about $190 \mathrm{~mm}$ below the midplane). The apparent fuel movement was upward at about $3 \mathrm{~m} / \mathrm{s}$ and emanated from the westmost region of the test section originally occupied by the element HEDL-59-23.

The data showed no collapse of the fuel-element bundle, such as occurred in the fresh-fuel loss-of-flow Tests L2 and R6. The total amount of fuel dispersed was estimated to be about one-fourth of that originally viewed by the hodoscope, or $15 \%$ of the test fuel. The supporting analysis and evaluation of the hodoscope data are included in Ref. 5. 


\section{POSTTEST EXAMINATIONS}

The posttest examination of the L5 test train consisted of a determination of the macro- and microscopic aspects of fuel and steel motion. Quantitative stereology techniques were used to study the axial redistribution of fuel and steel, and the evolution of fuel microstructure during the transient. This section discusses the results of the posttest examination and the probable fuel-motion sequence that led to the observed structures.

\section{A. Pretest Characterization}

The three fuel elements used in Test L5 had been previously irradiated in the thermal-neutron spectrum of the General Electric Test Reactor (GETR). Because of the large axial variation of neutron flux in GETR, both burnup and linear heating rate were strong functions of axial position. Figure 14 shows the axial distribution of the ${ }^{106} \mathrm{Ru}$ gamma-ray intensity of the elements, which approximates the burnup and heating-rate profiles. The gamma-scan data in Fig. 14 were summed over all three HEDL- 59 elements and normalized by dividing by the length-averaged intensity.

No sibling elements of the HEDL-59 type were available for a detailed destructive characterization. As a result, direct information about the microstructure of the elements in the as-irradiated condition was unavailable.

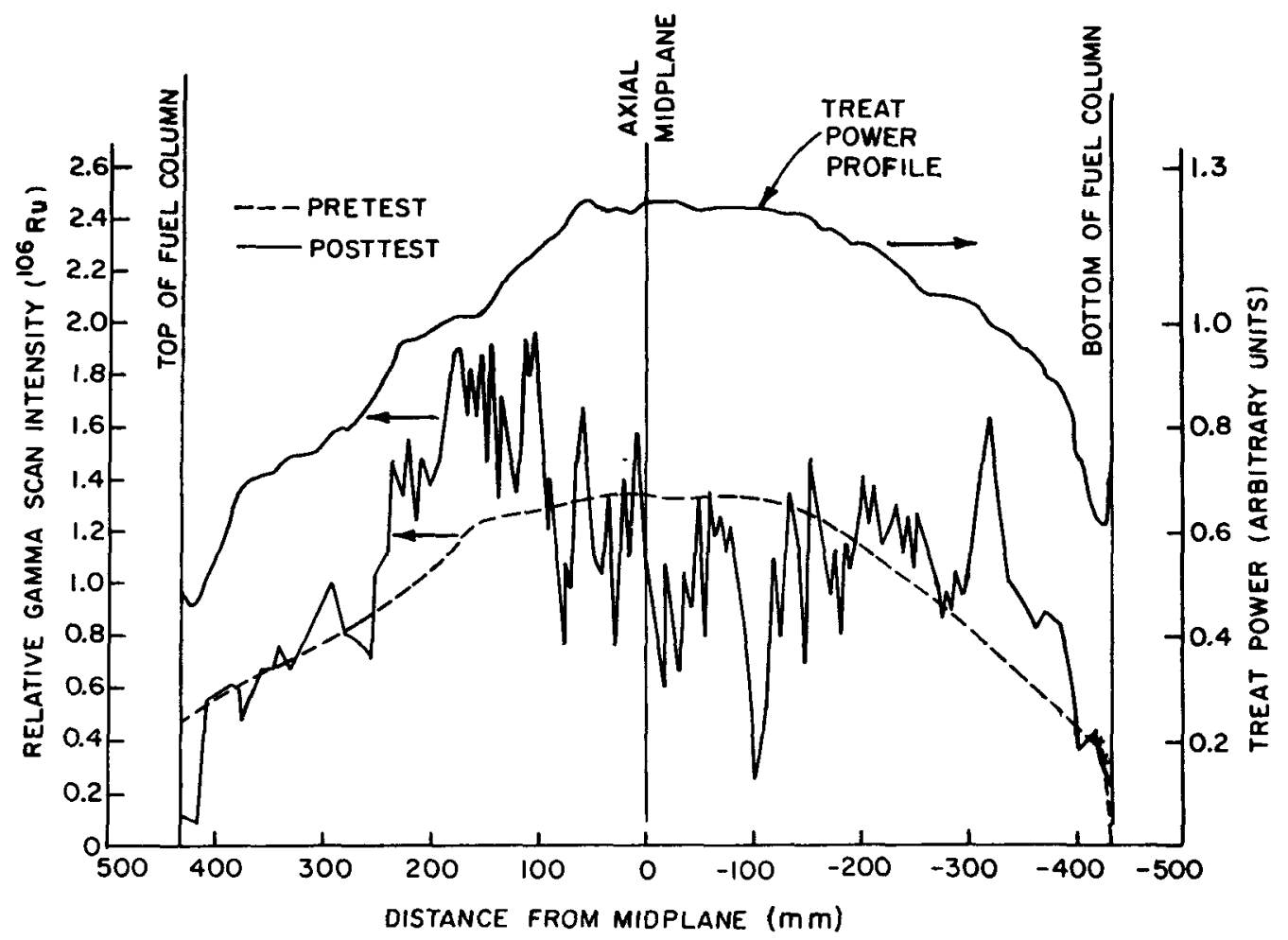

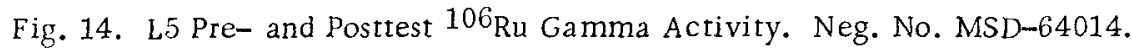


Indirect information was available from two sources. The first source was a group of fuel fragments found in the $L 5$ posttest remains. The microstructures of these fragments are considered to have been unaffected by the transient.

The second source of data was a group of elements (type PNL-59) irradiated in GETR under conditions similar to the HEDL-59 irradiation. Some of the results of the HEDL postir radiation examination of the PNL-59 elements were made available to ANL. Typical microstructures of element PNL-59-7 are reproduced in Figs. 15-17. The higher-power-structure region of the element shown in Figs. 15 and 16 has a well-developed central void region and a columnar-grain region. The lower-power-structure region has a central region of large grains that are elongated in the radial direction. The lowpower microstructure also has a series of circumferential cracks that separate the central from the outer zones. The lower-power-structure regions of the PNL-59 elements are microstructurally similar to the PNL-17 elements used in Tests $\mathrm{H} 3$ and $\mathrm{H} 5$.

Table VI summarizes the variation of the microstructural zone radii observed in element PNL-59-7. The smooth variation of zone radii with position in this element is disrupted at a fractional fuel-column height of 0.68 by a metallic-disc restrictor that separated the fuel column into two sections. No central void was observed above the position of the restrictor. However, the values reported for the lower half of the PNL-59-7 fuel column should be representative of the corresponding values for the L 5 test elements.

Direct information about the axial extent of the central void in the HEDL- 59 test elements is available from pretest neutron radiographs, which indicated that the void extended from 0.25 to 0.75 (fractional fuel-column heights). These values are consistent with the information shown in the PNL-59-7 element micrographs.

The high fissile content of the HEDL-59 elements was the cause of a substantial radial depression of neutron flux during irradiation in the thermal flux. The effect of the resulting radial fission-density profile on the fissionproduct distribution in the L5 test elements is not known.

A cross section of the L5 test train with the test elements in place is shown in Fig. 2. The positions of the elements relative to the plane containing the pump and hodoscope are also indicated in the figure.

\section{B. Posttest Neutron Radiography}

The posttest neutron radiograph in Fig. 18 shows that the fuel elements failed over nearly the entire length of the fuel column. The pretest geometry is maintained only in two short zones: just below the fuel-column top and just above the fuel-column bottom. Fuel has apparently moved away from the axial midplane of the fuel column, and collected in two regions that extend from 
+80 to $+140 \mathrm{~mm}$ and from -300 to $-340 \mathrm{~mm}$, measured from the midplane. The positive sign refers to distances above the midplane and the negative sign to distances below it. In the lower region, the fluted tube ruptured; fuel moved outward and appeared to be in contact with the intermediate tube in the adiabatic section.
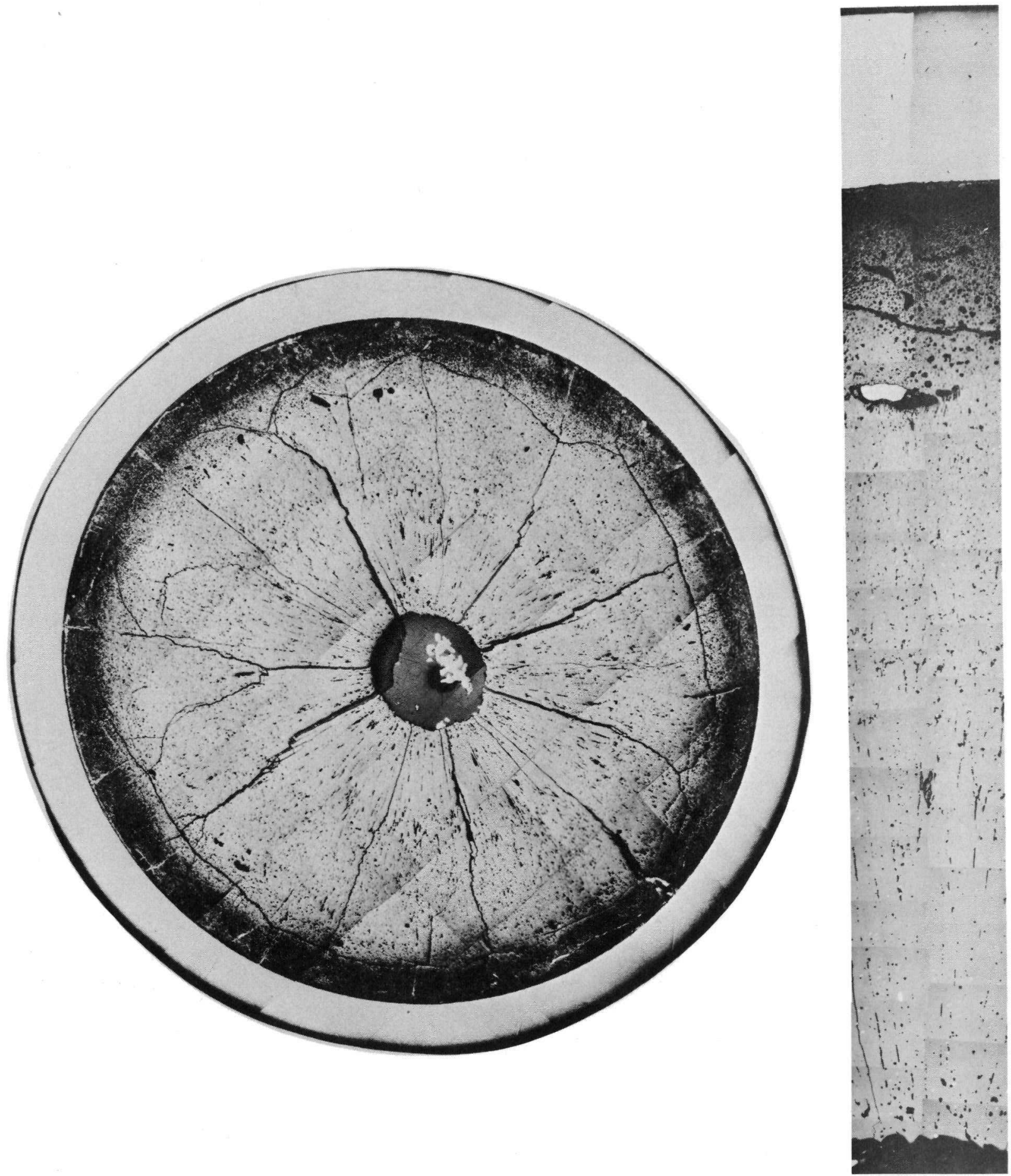

Fig. 15. Microstructure in Pin PNL-59-7 at Fractional Fuel-column Height of 0.48. Neg. No. MSD-188964. 


$$
\text { Q. }
$$



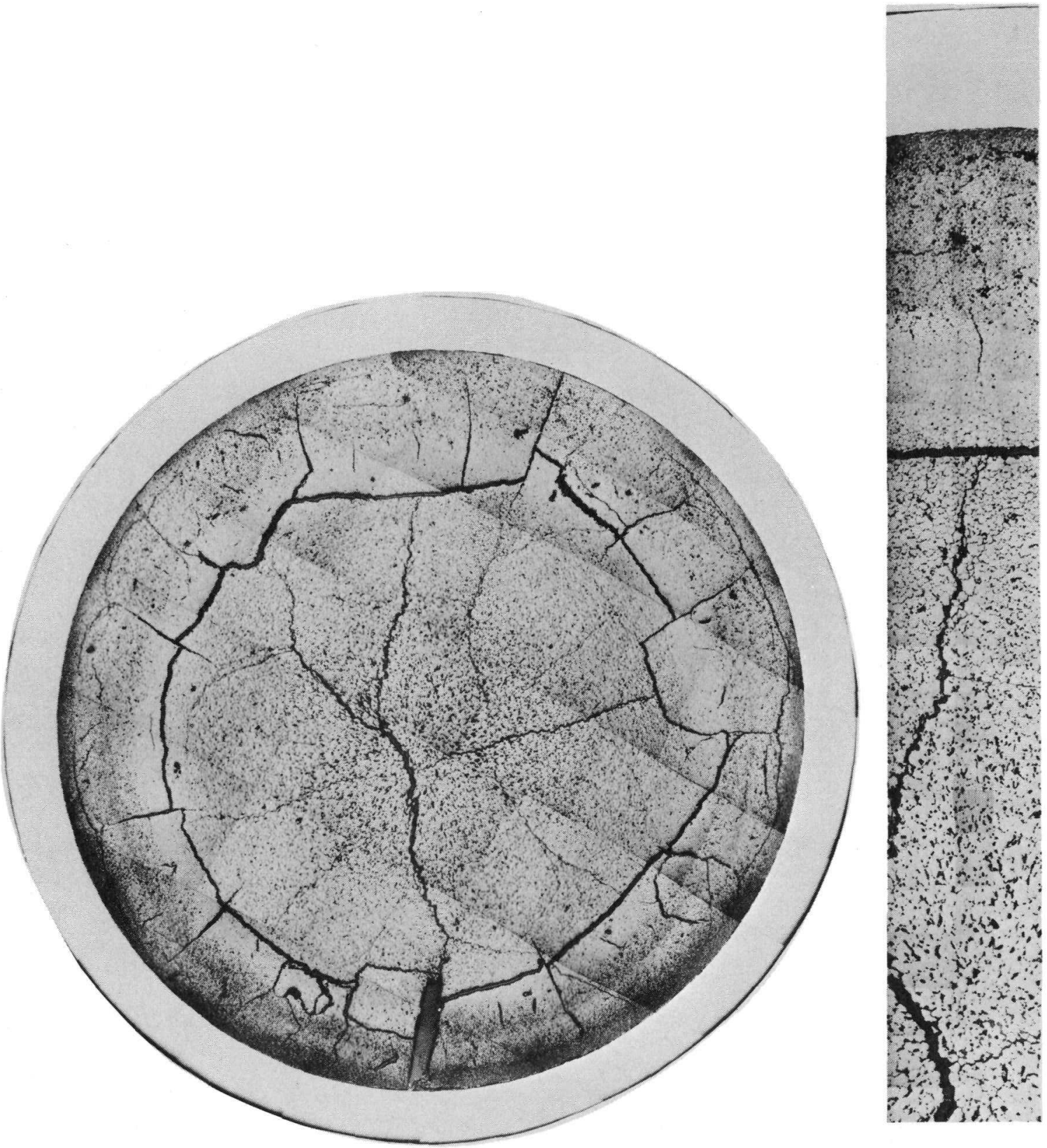

Fig. 17. Microstructure in Pin PNL-59-7 at Fractional Fuel-column Height of 0.87. Neg. No. MSD-188966.

TABLE VI. Restructuring Zone Radii in Pin PNL-59-7

\begin{tabular}{cccc}
\hline $\begin{array}{c}\text { Fractional Fuel- } \\
\text { column Height }\end{array}$ & $\begin{array}{c}\text { Fractional Central- } \\
\text { void Radius }\end{array}$ & $\begin{array}{c}\text { Fractional Columnar- } \\
\text { zone Radius }\end{array}$ & $\begin{array}{c}\text { Fractional Equiaxed- } \\
\text { zone Radius }\end{array}$ \\
\hline 0.05 & 0 & - & - \\
0.36 & 0.11 & 0.63 & 0.76 \\
0.48 & 0.18 & 0.73 & 0.86 \\
0.65 & 0.17 & - & - \\
$0.68^{\mathrm{a}}$ & 0 & $\sim 0.3^{b}$ & 0.8 \\
0.87 & 0 & - & - \\
0.97 & 0 & & \\
\hline
\end{tabular}

${ }^{a}$ Location of restrictor; columnar grains were not observed above this position.

$\mathrm{b}_{\mathrm{Grains}}$ were elongated in the radial direction, but not truly columnar. 


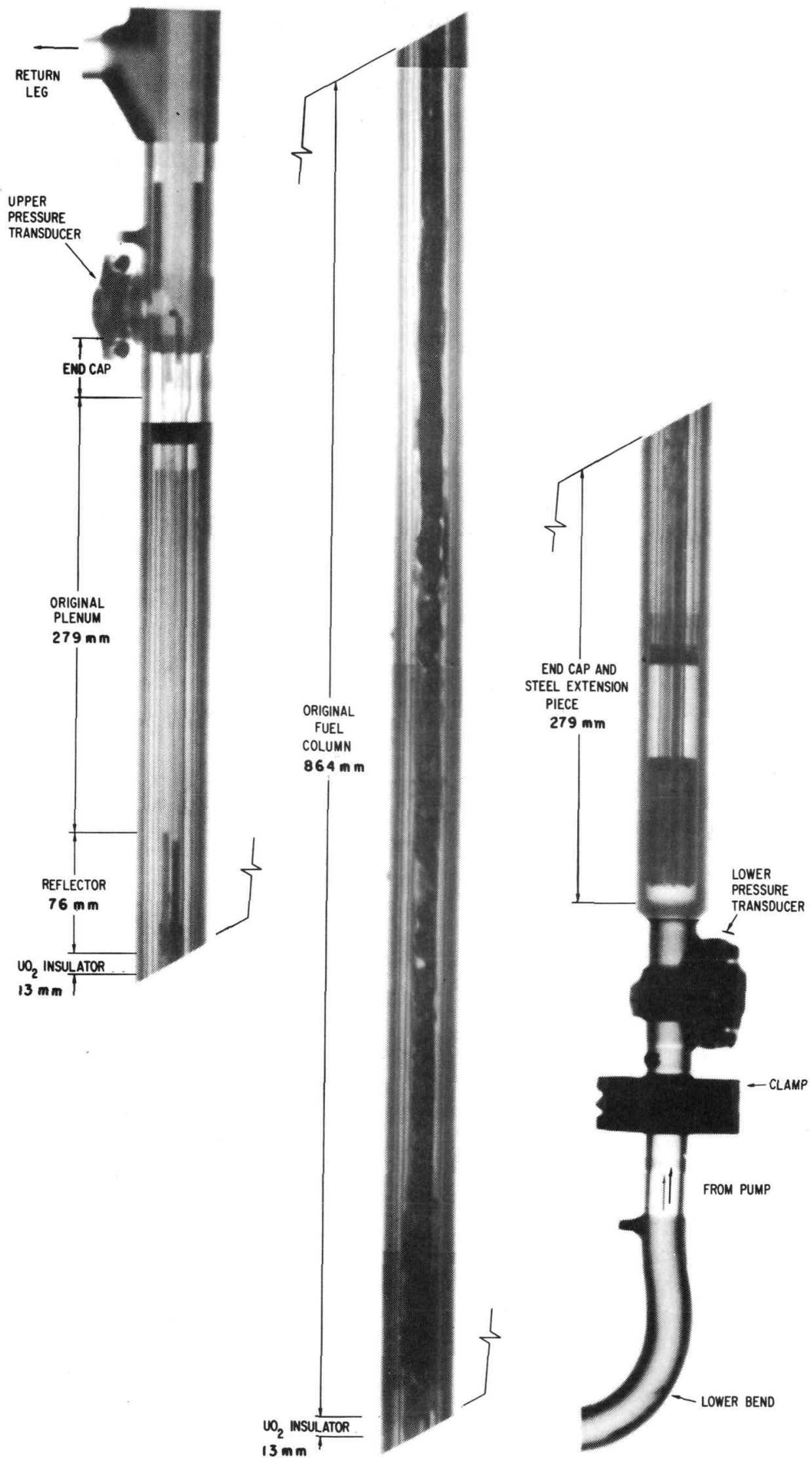

Fig. 18. Posttest Neutron Radiograph of L5 Test Section. ANL Neg. No. 900-76-107. 
Fuel was more thinly distributed in the region of the fuel column between the upper and lower accumulations. Several prominent patches in this region appear to be nearly free of neutron-absorbing material. An accumulation of neutron-absorbing material, probably fuel, was in contact with the intermediate tube in the region from +85 to $+140 \mathrm{~mm}$.

Some neutron-absorbing material was evident in the flow channel just above and below the boundaries of the original fuel column. This material extended for $45 \mathrm{~mm}$ above the fuel column top and $105 \mathrm{~mm}$ below the fuelcolumn base.

The radiograph also indicated that the upper insulator pellets, the upper reflector rods, and the tops of the fuel elements experienced varying amounts of axial motion during the transient. In addition, the entire test train moved about $11 \mathrm{~mm}$ upward, so that its base was no longer located in the tapered seat in the loop body. Table VII summarizes the posttest displacements of the various parts of the test train, as determined from the neutron radiograph and the destructive examination.

\begin{tabular}{lccc} 
TABLE VII. Axial Displacements of Upper Components of L5 Test Elements \\
\hline Component & HEDL-59-22 & HEDL-59-23 & HEDL-59-24 \\
\hline Top end plug and cladding, mm & 6 & 17 & 17 \\
Reflector rod, mm & 12 & 7 & 2 \\
Insulator pellet, $\mathrm{mm}$ & 12 & 7 & 2 \\
\hline
\end{tabular}

${ }^{a}$ All displacements were upward relative to the initial positions.

There was no evidence in the neutron radiograph to indicate that melting or deformation occurred in the region outside the intermediate tube. In particular, the intermediate tube did not appear to be fused or bonded to the outer shell tube. No extraneous neutron-absorbing material was present in any part of the loop outside the test train.

C. Disassembly

The initial stripping and disassembly of the L5 loop were performed in HFEF. After the neutron filters were removed, the test section was separated from the loop by cutting just below the outlet flowmeter and unbolting the bottom flange clamp. The inlet and outlet pressure transducers and the inlet thermocouple feedthrough were then removed from the test section. Only the portion of the loop containing the test train was shipped to the alphagamma hot-cell facility (AGHCF).

At the AGHCF, the test train was cut transversely at three locations, shown in Fig. 19, into pieces of a convenient size for gamma-scanning. The topmost piece (159A4) contained the upper ends of the fuel elements, the compression springs, spacer tubes, upper reflector rods, upper insulator pellets, 
and about $147 \mathrm{~mm}$ of the fuel column. The second piece from the top (159A3) contained about $510 \mathrm{~mm}$ of the fuel column. The third piece (159A2) contained the bottom $206 \mathrm{~mm}$ of the fuel column, the lower insulator pellets, the bottom end plug, and the fuel-element extensions. The bottom piece (159Al) was a short length of sodium-filled inlet pipe. The loop wall sections were slid off of all pieces except 159A1, and the outer shell of the adiabatic holder was removed from 159A3, again by sliding. The sections were heated to melt the sodium in order to remove the loop wall and outer shell parts. The heat applied was kept to a minimum to minimize the redistribution of sodium and loose material within the test-train pieces.

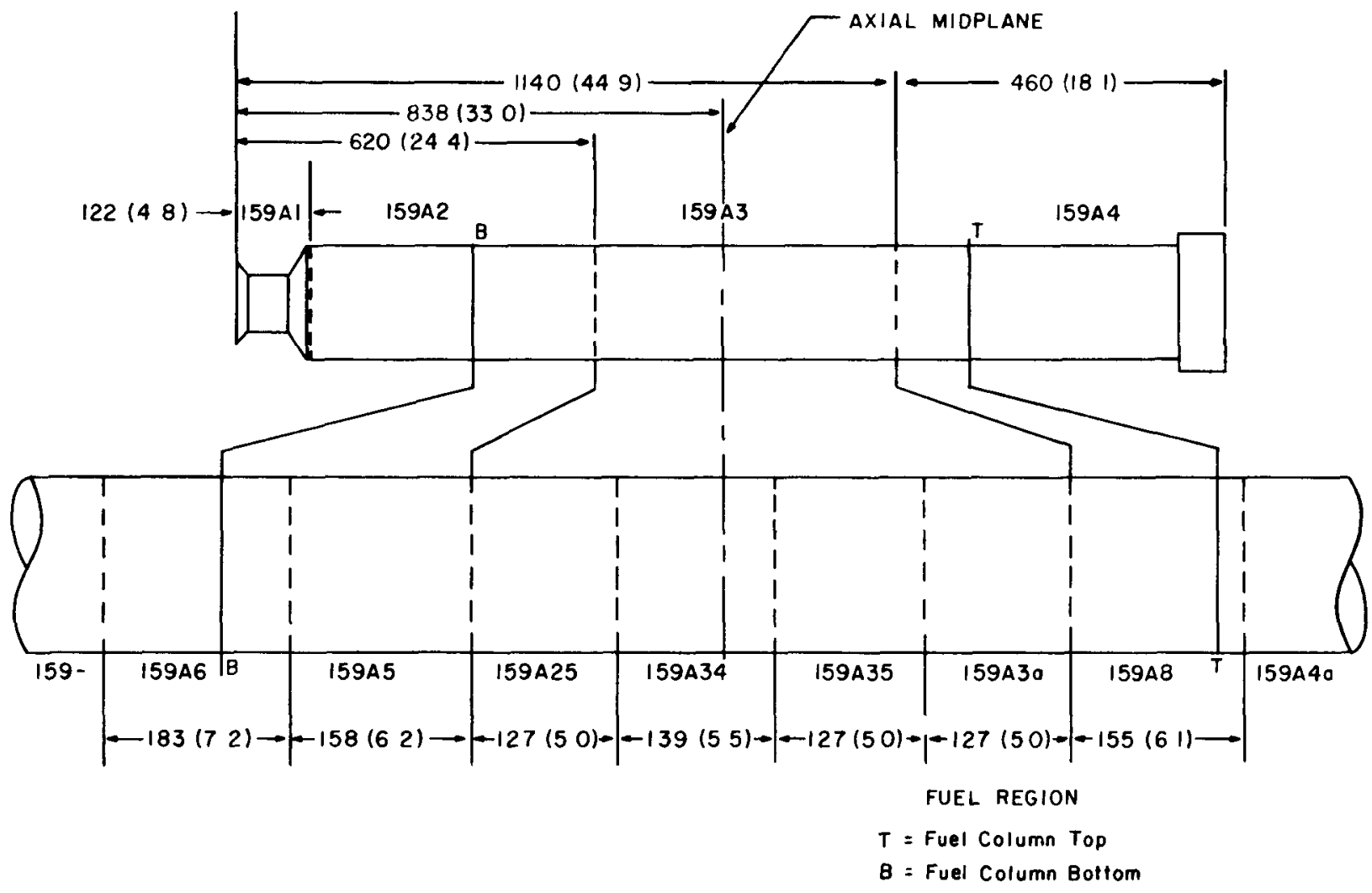

Fig. 19. L5 Inıtıal Cuttıng Scheme. Lengths in millimeters (inches).

The four pieces were scanned for gamma rays while most of the sodium was still in place to determine the axial profile of the gross ${ }^{106} \mathrm{Ru}$, and ${ }^{137} \mathrm{Cs}$ activities. The gross activity consisted of counts detected in the energy range $0.1-2.0 \mathrm{MeV}$. The $0.513-\mathrm{MeV}$ gamma of ${ }^{106} \mathrm{Rh}$ and the $0.662-\mathrm{MeV}$ gamma of ${ }^{137 \mathrm{~m}} \mathrm{Ba}$ were used to detect the presence of ${ }^{106} \mathrm{Ru}$ and ${ }^{137} \mathrm{Cs}$, respectively. The gamma scans were used primarily as guides for determining the positions of cuts for the detailed macro- and microexamination. The ${ }^{106} \mathrm{Ru}$ activity, which can correlate with the presence of either irradiated fuel or metallic fission-product ingots, was found to be particularly useful.

After gamma-scanning, the disassembly process was resumed. Sections of the outer shell tube were separated from sections $159 \mathrm{~A} 2$ and $159 \mathrm{~A} 4$ by 
making circumferential cuts through the shell near the upper and lower headers that join the fluted and outer shell tubes. The outer shells were then slid off from these sections after heating to melt the sodium. The intermediate tube was removed from section $159 \mathrm{~A} 4$, exposing the fluted tube. The resulting sections are identified in Fig. 19 as $159 \mathrm{~A} 8$ and 159A4a. The fluted tube was removed from 159A4a by holding the fluted tube in a vise and tapping the tops of the fuel elements. The fuel elements in this region were fused together by a mass of melted steel at the base of $159 \mathrm{~A} 4 \mathrm{a}$.

Two sections, labeled $159 \mathrm{~A} 5$ and $159 \mathrm{A6}$ in Fig. 19, were cut from section 159A2. The upper of the two, 159A5, contained the fuel column from 218 to $376 \mathrm{~mm}$ below the midplane. A lump of solidified fuel that fell out of the upper end of this section is shown in Fig. 28 (later). The intermediate tube could not be removed from 159A5, even after prolonged heating to melt out most of the sodium, and after cleaning in an alcohol-water mixture to remove the remainder.

The second section cut from 159A2, i.e., 159A6, contained the bottom $56 \mathrm{~mm}$ of the fuel column, the lower insulators, bottom end plugs, and $98 \mathrm{~mm}$ of the fuel-element extension rods. The intermediate tube was pried off of the two halves of $159 \mathrm{~A} 6$ after it was split longitudinally.

Section 159A3 was cut into four sections, each about $128 \mathrm{~mm}$ long. These sections are labeled in Fig. 19 as 159A3a, 159A35, 159A34, and 159A25. The intermediate tube was removed from the lower two sections, 159A34 and 159A25, after sodium removal. The intermediate tube was firmly attached to 159A3a and 159A35, however.

After sodium removal and before further cutting, sections $159 \mathrm{~A} 8$, 159A3a, 159A34, 159A25, and 159A 5 were potted in epoxy to fix the position of any loose material. The final sectioning of these pieces produced specimens for the detailed macro- and microexamination. For the most part, transverse sections were examined, although longitudinal sections were made in a few cases, especially where the major sense of fuel and steel motions was expected to be in the axial direction. The sections selected for metallographic examination were vacuum-impregnated with epoxy at least once to minimize pullout during the grinding and polishing operations.

Sodium samples were collected from several locations in the test train for possible future analysis. The solid residue (fines) collected from the rest of the sodium that was melted out of the sections was saved for posible analysis of particle size, density, and chemical composition. 


\section{Examination Results}

\section{Gamma Scanning}

The axial profile of the posttest ${ }^{106} \mathrm{Ru}$ gamma intensity is superimposed on the pretest gamma-scan data and the L5 axial power profile in Fig. 14. The ${ }^{106} \mathrm{Ru}$ intensity may be used as a qualitative indicator of the presence of irradiated fuel. The posttest profile suggests that fuel has moved away from the axial midplane and collected in two regions that extend from +100 to $+250 \mathrm{~mm}$ and from -300 to $-400 \mathrm{~mm}$. There is a pronounced minimum in the gamma intensity at $-100 \mathrm{~mm}$. There is considerable short-range variation in the ${ }^{106} \mathrm{Ru}$ trace in addition to the long-range trends. The gamma scans indicate that little or no fuel was present above or below the original fuel region. The qualitative description of fuel distribution from the gamma-scan results is in relatively good agreement with the neutron-radiography results.

Cesium-137 was found throughout the fuel column as an inhomogeneous distribution. No long-range trends in cesium distribution were observed within the fuel region. Large amounts of cesium were found outside the fuel region. Cesium was concentrated on the horizontal surfaces of the test train, e.g., on the headers that joined the fluted and outer shell tubes. Cesium-134 and ${ }^{137} \mathrm{Cs}$, but no other fission-product isotopes, were found in the sodium that filled the inlet pipe section (159Al). Part of the cesium activity observed in the rest of the test train was probably associated with sodium. Not all the cesium could have been dissolved in sodium, however, since high cesium activity was observed in several small sections, even after careful cleaning to remove the sodium.

An attempt was made to determine the axial profile of ${ }^{60} \mathrm{Co}$ activity in the test train. Cobalt-60, formed during the thermal-neutron irradiation of the elements in the GETR, was expected to indicate the presence of cladding concentrations. Unfortunately, the count rates obtained were so small that complete axial profiles could not be determined in reasonable counting times. However, ${ }^{60} \mathrm{Co}$ activities were determined at selected positions in the test train. These measurements indicated that cladding concentrations were present in several regions that showed low ${ }^{106} \mathrm{Ru}$ activity. High ${ }^{60} \mathrm{Co}$ counts were also observed near the top and bottom of the fuel column, in the regions subsequently identified as the upper and lower cladding blockages. The upper cladding blockage also contained ${ }^{54} \mathrm{Mn}$, another isotope formed during the irradiation of stainless steel in a thermal-neutron flux.

\section{Macroexaminations}

Total blockages of the coolant flow channel were observed at the top and bottom of the fuel region. The upper flow blockage, shown in Fig. 20, was formed by the solidification of molten cladding in a region just above the top of the fuel column. The cladding was driven upward from lower levels in 


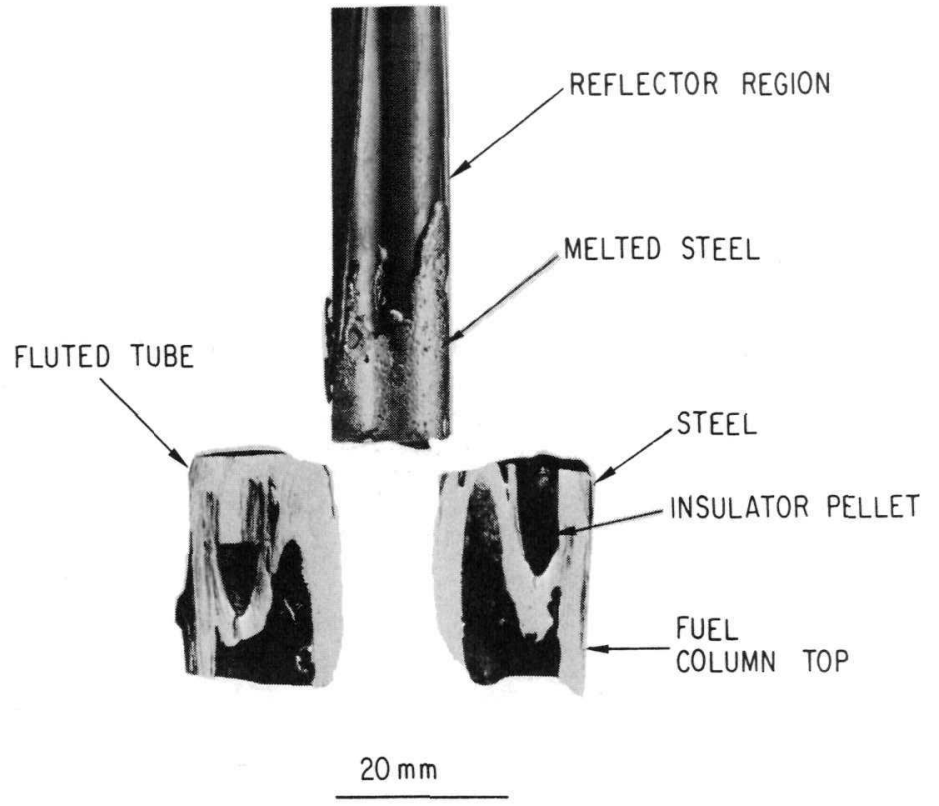

Fig. 20. L5 Upper Flow Blockage. ANL Neg. No. 900-76-647. the test train. The two lower photographs in Fig. 20 show mating halves of a longitudinal section through the base of the blockage; the spaces between the elements and between the elements and the fluted tube are filled with melted steel. The upper photograph shows melted steel in contact with the cladding in the reflector-rod region of the elements, i.e., just above the section shown in the lower photographs. (The fluted tube was removed from the reflector region to make the melted steel visible.)

The highest penetration of melted steel was to $50 \mathrm{~mm}$

above the top of the fuel column. The flow channel was completely or almost completely blocked from 7 to $33 \mathrm{~mm}$ above the fuel column top. The upward steel penetration had a distinctive outline that may be characterized as a group of upward-flowing dribbles. The fact that this flow pattern is preserved in the posttest remains is evidence that the steel froze in place rapidly after reaching the reflector region.

Mating halves of a longitudinal section through the lower flow blockage are shown in Fig. 21. The blockage extended from 8 to $25 \mathrm{~mm}$ above

Fig. 21

L5 Lower Flow Blockage. ANL Neg. No. 900-76-646.
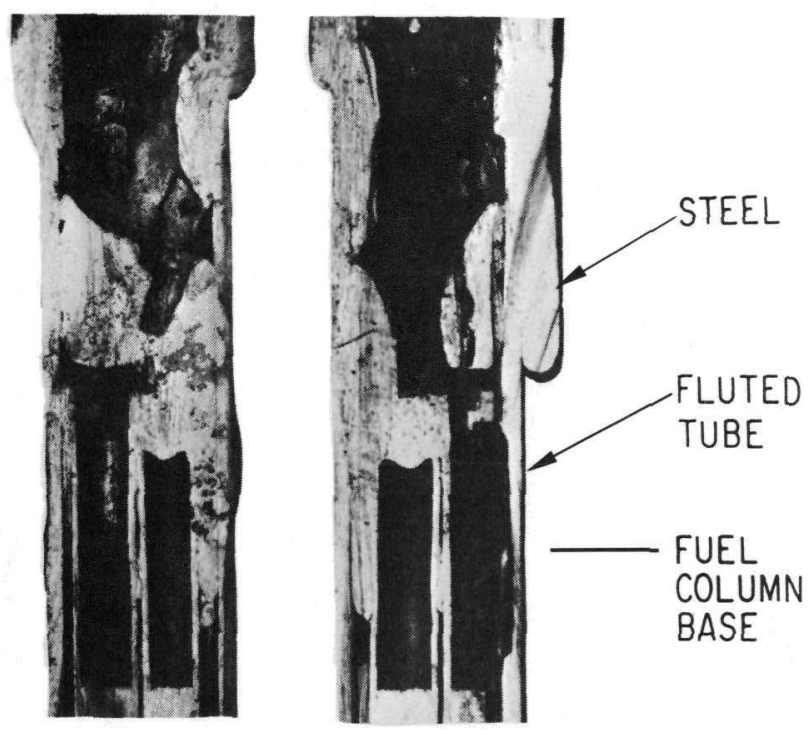

$20 \mathrm{~mm}$ 
the fuel-column base. In addition to the major portion of the blockage, isolated dribbles of steel penetrated as far as $25 \mathrm{~mm}$ below the fuel-column base. The cladding tubes were intact below the blockage, but were completely destroyed above it. The fuel pellets fell out of the region below the flow blockage during sectioning. As a result, the cladding tubes shown in Fig. 21 are empty.

Both the destructive examination and the neutron radiograph indicate that no fuel was driven into the region below the lower blockage, and that the fuel initially present in this region was undisturbed. A substantial fuel deficit was observed in the steel blockage, however. Since no fuel was added to the region below the blockage, the fuel that was displaced from the blockage region must have moved upward, i.e., toward the midplane of the fuel column. This example of motion toward the midplane is contrary to the trend of net fuel motion away from the midplane that was observed in the rest of the fuel column.

The upper and lower blockages differed in that the upper blockage is the result of steel filling the flow channel around elements that (locally) had retained their initial geometry, while the lower blockage consisted of a mass of melted steel that plugged nearly all the fluted-tube cross section, including most of the area originally occupied by fuel.

Between the upper and lower flow blockages, the fuel-element cladding was completely melted. The fuel in this region showed evidence of fragmentation, swelling, melting, and interaction with the fluted and intermediate tubes. Cladding material was entrained in the fuel, as a coating of variable thickness against the inner wall of the fluted tube, and mixed with melted fluted-tube material. Some of the details of the posttest appearance of the fuel region are discussed in the following paragraphs.

Figure 22 a shows a transverse section through the fuel column at $417 \mathrm{~mm}$ above the axial midplane. The cladding at this level had melted from the elements and was observed as a coating on the inner surface of the fluted tube. The fuel had broken up into chunks that were evenly distributed in the flow channel. In Fig. 22a, the chunks are embedded in a matrix of epoxy resin and fuel dust from the cutting operation. The fluted tube at this level was not deformed or melted during the transient.

As the fuel-column midplane was approached from the level shown in Fig. 22a, the appearance of the test train changed rapidly. One obvious change was the appearance of local meltthroughs in the fluted tube. This effect is shown in Fig. 23, which presents views of the three sides of the fluted tube in the region from 380 to $320 \mathrm{~mm}$ above the midplane. The holes are in the concave portion (when viewed from the outside) of the fluted tube. The amount of fluted-tube melting appeared to be largest in the bottom portion of this section; several thermocouple sheaths were fused to the fluted tube near the base of the section. 


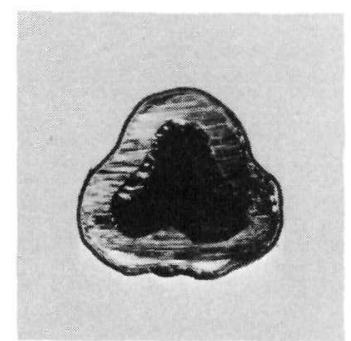

A. $+417 \mathrm{~mm}$ (MSD-185970)

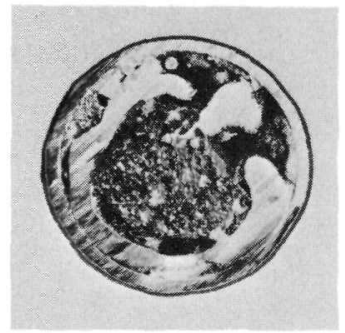

C. $+175 \mathrm{~mm}$ (MSD-186018)

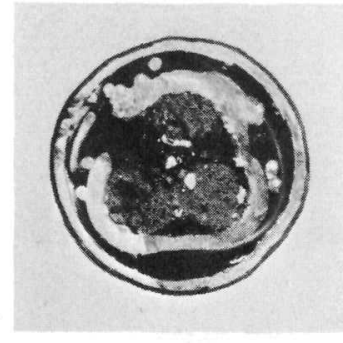

B. $+239 \mathrm{~mm}$ (MSD-186085)

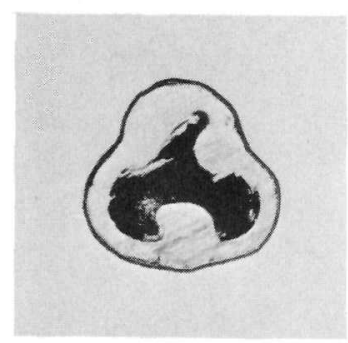

D. $-91 \mathrm{~mm}$ (MSD-185953)

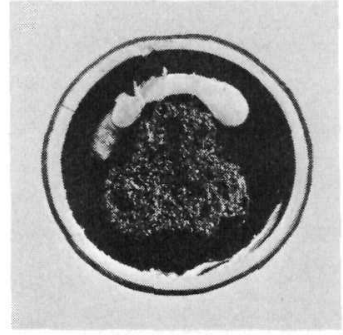

E. $-218 \mathrm{~mm}$ (MSD-185749)

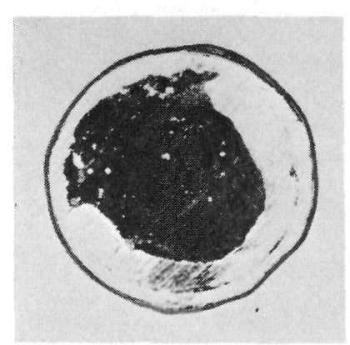

G. $-312 \mathrm{~mm}$ (MSD-185808)

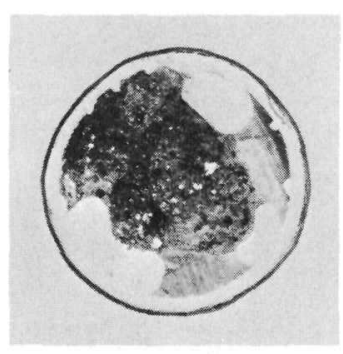

F. $-300 \mathrm{~mm}$ (MSD-185810)

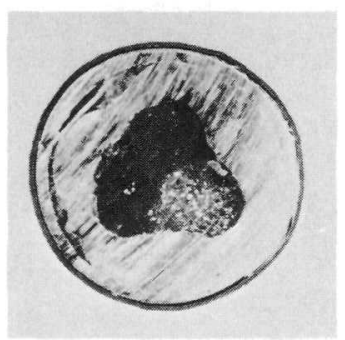

H. $-363 \mathrm{~mm}$ (MSD-185817) $20 \mathrm{~mm}$

Fig. 22. Macrophotos of Transverse Sections through L5 Test Train. Neg. Nos. MSD-188967 and -188968.

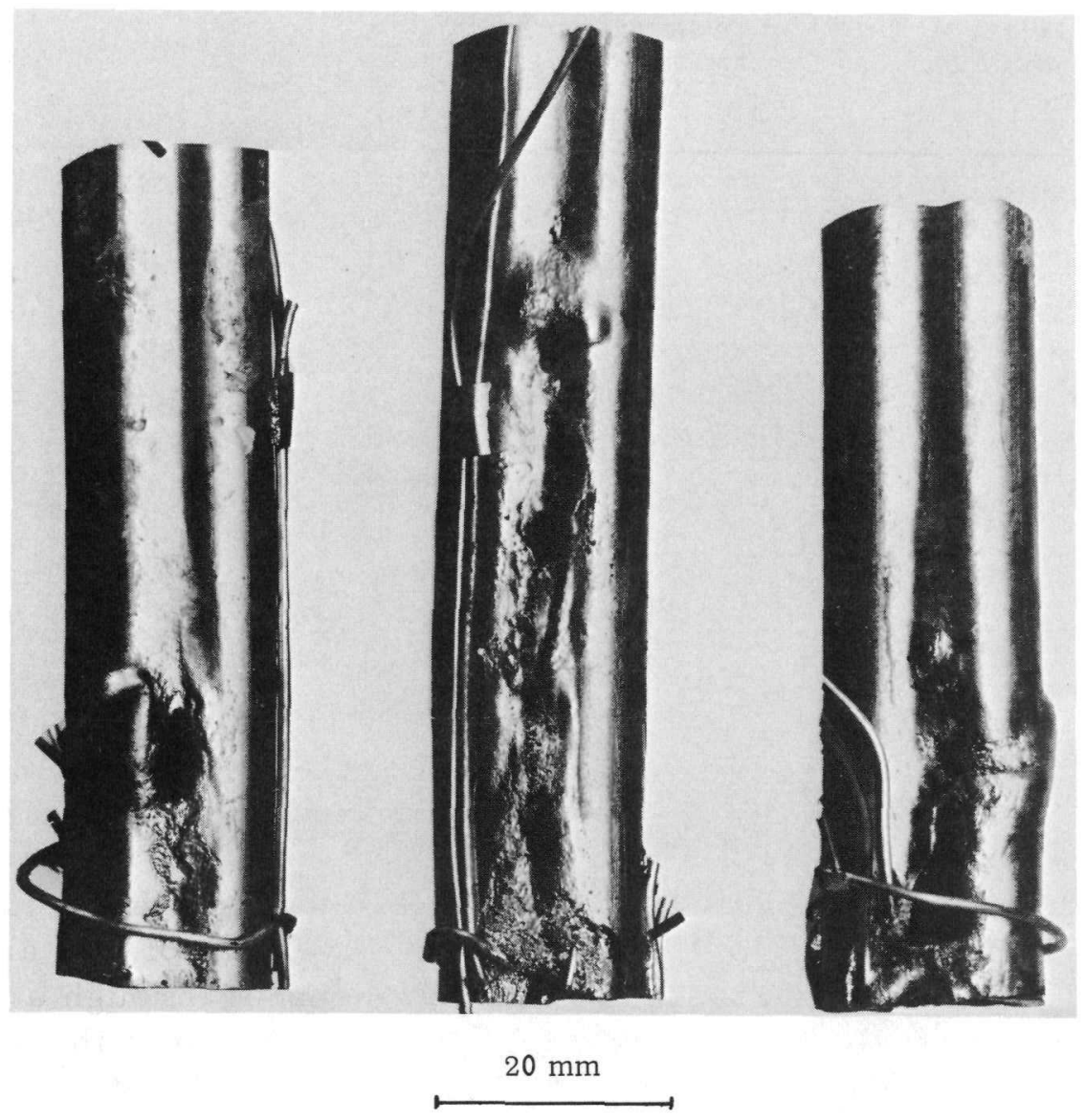

Fig. 23. Three Views of Fluted Tube Exterior in Region between +320 and $+380 \mathrm{~mm}(+12.6$ and +15.0 in.). Neg. No. MSD-188969. 
A longitudinal section through this region is shown in Fig. 24. The sectioning plane passes through one of the holes in the fluted tube. Be-
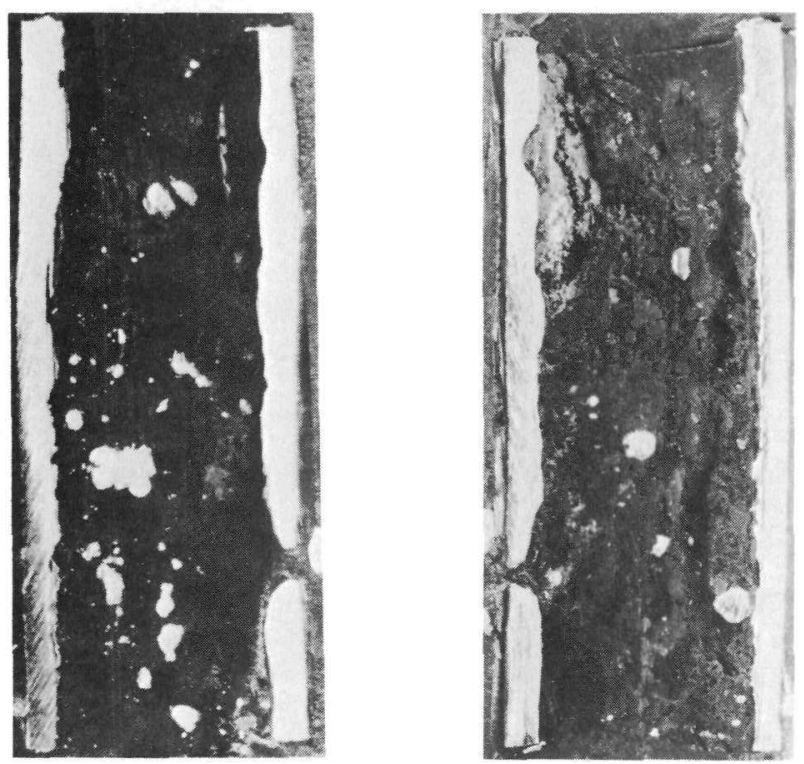

$20 \mathrm{~mm}$

Fig. 24. Longitudinal Section through Base of Region Shown in Fig. 23. Neg. No. MSD-188970. cause the section was impregnated with epoxy, it is difficult to see the details of the fuel structure. However, a few chunks similar to those in Fig. 22a are visible. In addition, porous fuel is present in the section of Fig. 24 next to the fluted tube on the side opposite the rupture. Particles of steel are also observed to be entrained in the fuel.

The most easily observed change in fuel appearance in the top $200 \mathrm{~mm}$ of the fuel column is that of macroscopic swelling, shown in Fig. 22b, a transverse section at the +239-mm level. The fuel swelled so that the three fuel columns were in contact. Increases of fuel-pellet diameter of 15-45\% were observed on this section. Most of the cladding had drained away, although some melted steel, presumably cladding,

was entrained in the fuel. The fluted tube was deformed and partly melted away; the meltthroughs had again occurred in the concave portion of the fluted tube.

Nearer to the axial midplane, melting and deformation of the test-train components occurred to a large extent. An example of a transverse section at $+175 \mathrm{~mm}$ is shown in Fig. 22c. Because of the extreme swelling, the original fuel columns are no longer recognizable. Pores with maximum caliper diameters greater than $2 \mathrm{~mm}$ are visible in the fuel. Subsequent metallographic examination revealed that the fuel at this level melted. The fuel occupied essentially all the area originally enclosed by the fluted tube. The fluted tube was extensively deformed and melted, and had moved outward radially to contact the intermediate tube. A small amount of melted fuel had moved outside the fluted tube to contact the intermediate tube. Transverse sections similar in appearance to that in Fig. $22 \mathrm{c}$, but with varying amounts of fuel and steel, were observed in the interval between +200 and $-250 \mathrm{~mm}$.

In a region extending from 85 to $140 \mathrm{~mm}$ above the fuel-column midplane, evidence of a high-velocity lateral movement of fuel and steel was observed. This material exited from the flow channel through a hole in the fluted tube on the side opposite the pump. Figure 25 shows the appearance of the intermediate tube in this region after longitudinal slitting to expose the 
inner surface. The droplets of steel visible in the photograph apparently spattered against the intermediate tube, suggesting that the molten material moved with a relatively large lateral velocity. Cobalt-60 was not detected in the gamma-emission spectrum of the steel spatter; this result indicated that the melted steel visible in Fig. 25 originally came from the fluted tube and not from the cladding.

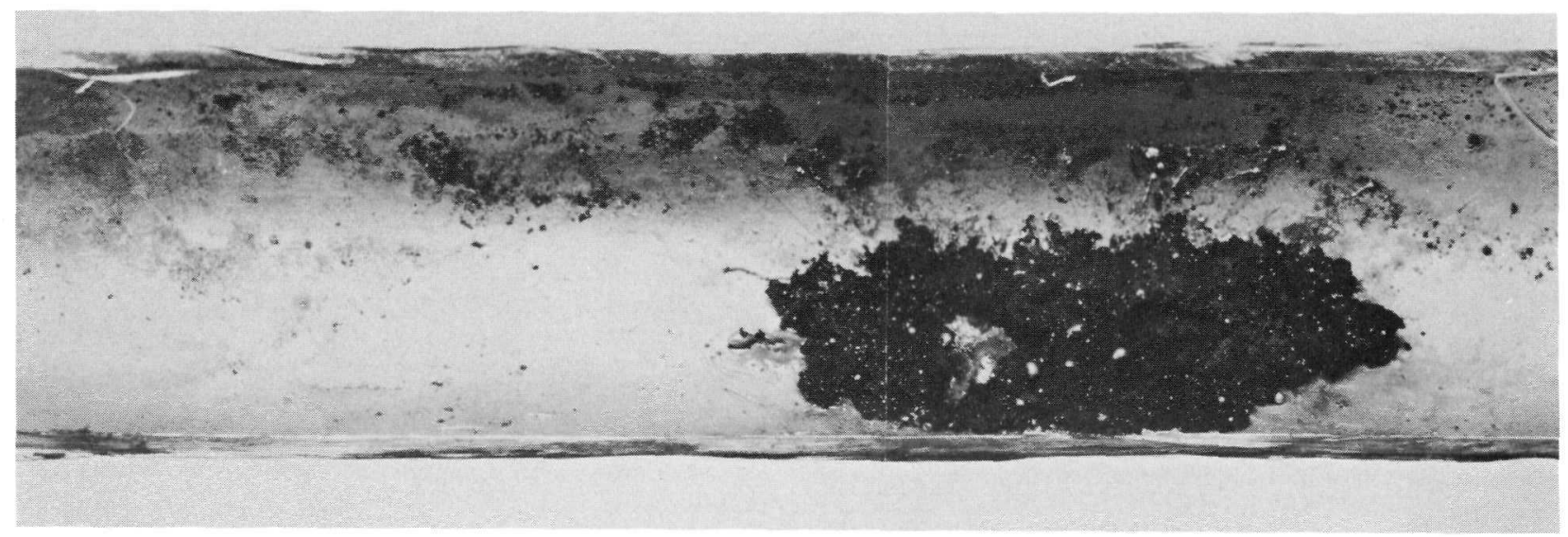

$20 \mathrm{~mm}$

Fig. 25. Fuel and Steel Spatter on Inner Surface of Fluted Tube. Neg. No. MSD-188974.

A composite micrograph of a transverse section through the fuelsteel deposit is shown in Fig. 26. The fuel layer had a maximum thickness of about $3.6 \mathrm{~mm}$. The density of fuel varied with position in the deposit, but averaged 0.41 of theoretical. The estimated total amount of fuel in the deposit was $700 \mathrm{mg}$. Significant reaction of the deposit with the intermediate tube or melted material from the intermediate tube was not observed; the deposit apparently cooled and solidified shortly after contact.

Lateral motion of fuel to locations outside the fluted tube occurred in a limited number of regions in the fuel column. In addition to the region just described, this phenomenon was observed at +250 and between -290 and $-340 \mathrm{~mm}$. A more characteristic behavior for the test train in the central third of the fuel column was exhibited by sections 159A34 and 159A25, which extended from +46 to $-218 \mathrm{~mm}$. Three views of section 159A34 (+46 to $-79 \mathrm{~mm}$ ) after removal of the intermediate tube are shown in Fig. 27. These photographs illustrate the confinement of melted fuel within the original flow area, and the melting pattern on the three sides of the fluted tube.

Melting of the fluted tube was most severe in its concave portions, i.e., the flutes. The convex portions showed less melting, and had formed ribs that supported the melted steel and fuel. At any given axial level, the melting of the flutes was usually confined to one or two sides of the fluted tube. Single flutes were melted through continuously over lengths of 40-70 $\mathrm{mm}$. In most 


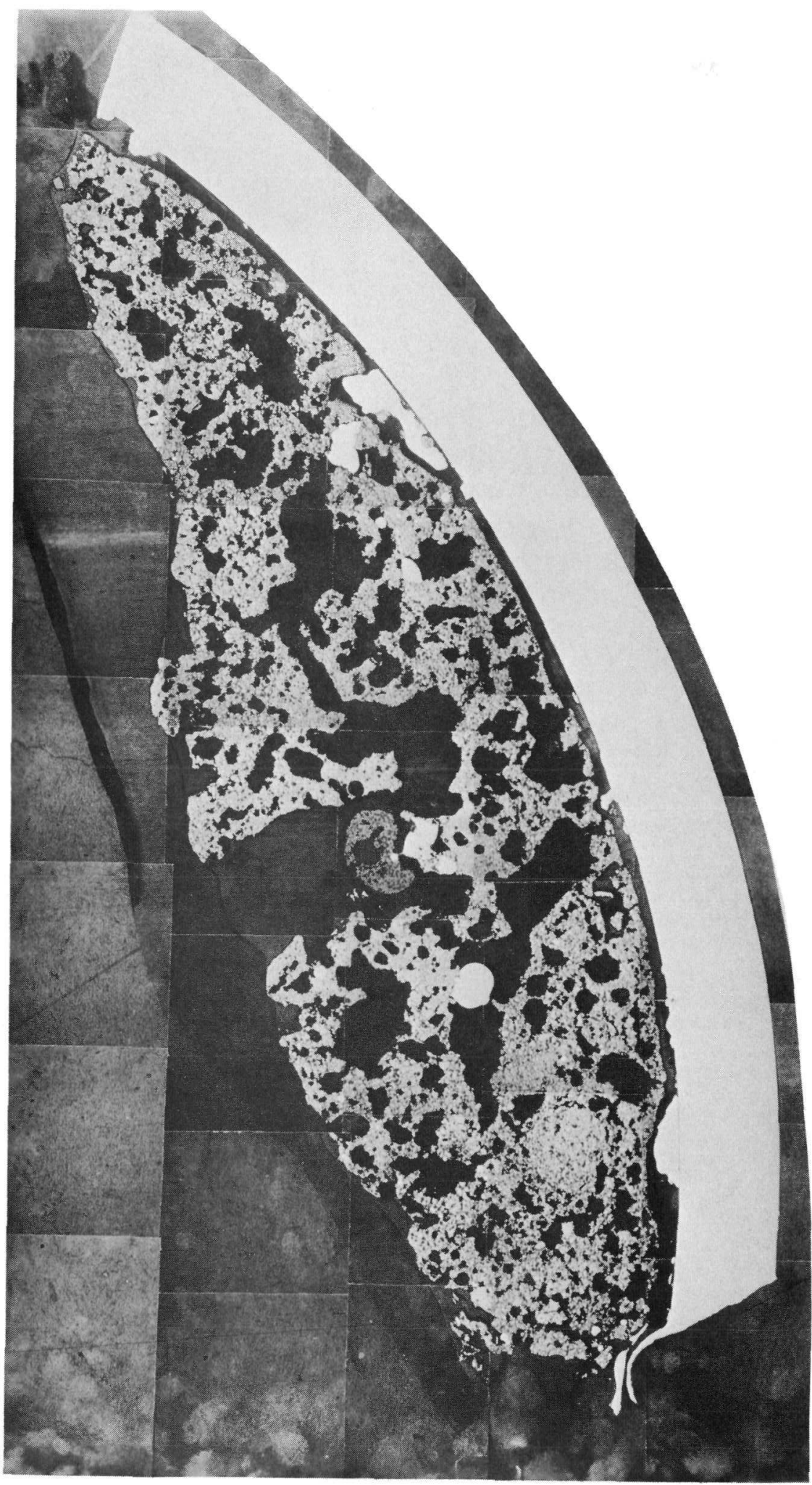

$1 \mathrm{~mm}$

Fig. 26. Transverse Section through Fuel Deposit Shown in Fig. 25. Neg. No. MSD-186912. 


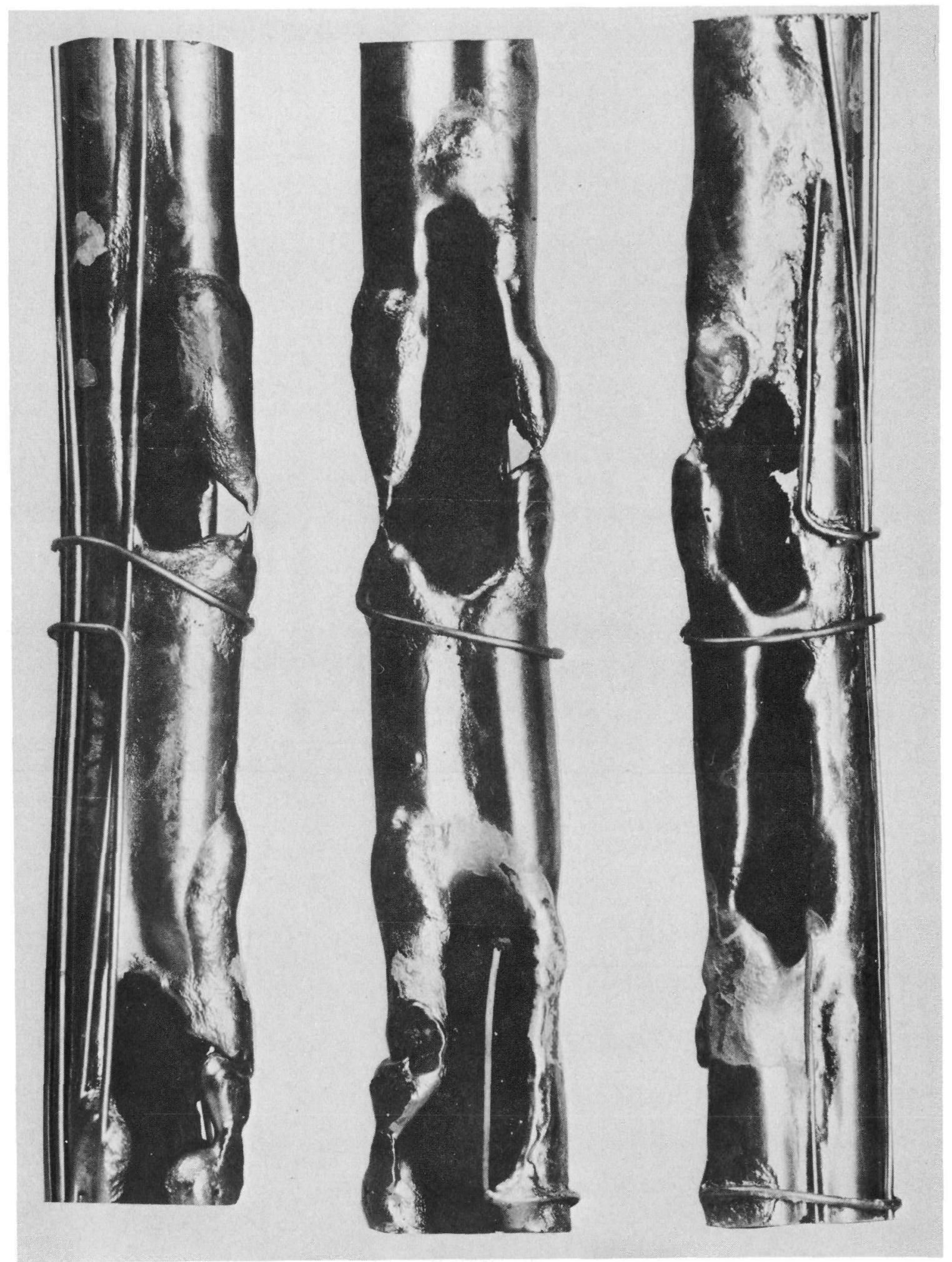

$20 \mathrm{~mm}$

Fig. 27. Three sides of Fluted Tube in Section 159A34 [+46 to $-79 \mathrm{~mm}$ $(+1.8$ to -3.1 in. $)$. Neg. No. MSD -188971 . 
cases, the termination of a melted through region in one of the flutes was associated with the initiation of a meltthrough in an adjacent flute. This pattern suggests that, during the transient, the fuel assumed an S- or spiralshaped configuration and melted the fluted tube by contact at various positions around the circumference. However, the fuel in this section did not move laterally through the holes in the fluted tube; no evidence was found that fuel had ever been in contact with the intermediate tube or in the gap between the fluted and intermediate tubes.

A likely explanation for the apparent effectiveness of the fluted tube in retaining molten fuel is suggested by the appearance of Fig. 22e, a transverse section $218 \mathrm{~mm}$ below the axial midplane. The fuel at this level swelled outward, contacted the fluted tube, assumed its cross section, and then melted the fluted tube. The heat loss that occurred as a result of melting the fluted tube was sufficient to reduce the temperature of the fuel below its melting point. After the molten fluted tube drained away, the solidifying fuel retained the three-lobed shape of the fluted tube. During the disassembly of the test train, several lumps of fuel, each with the characteristic three-lobed cross section, fell out of the sections immediately above and below the cut surface shown in Fig. 22e. Several of these chunks of fuel are shown in Fig. 28.
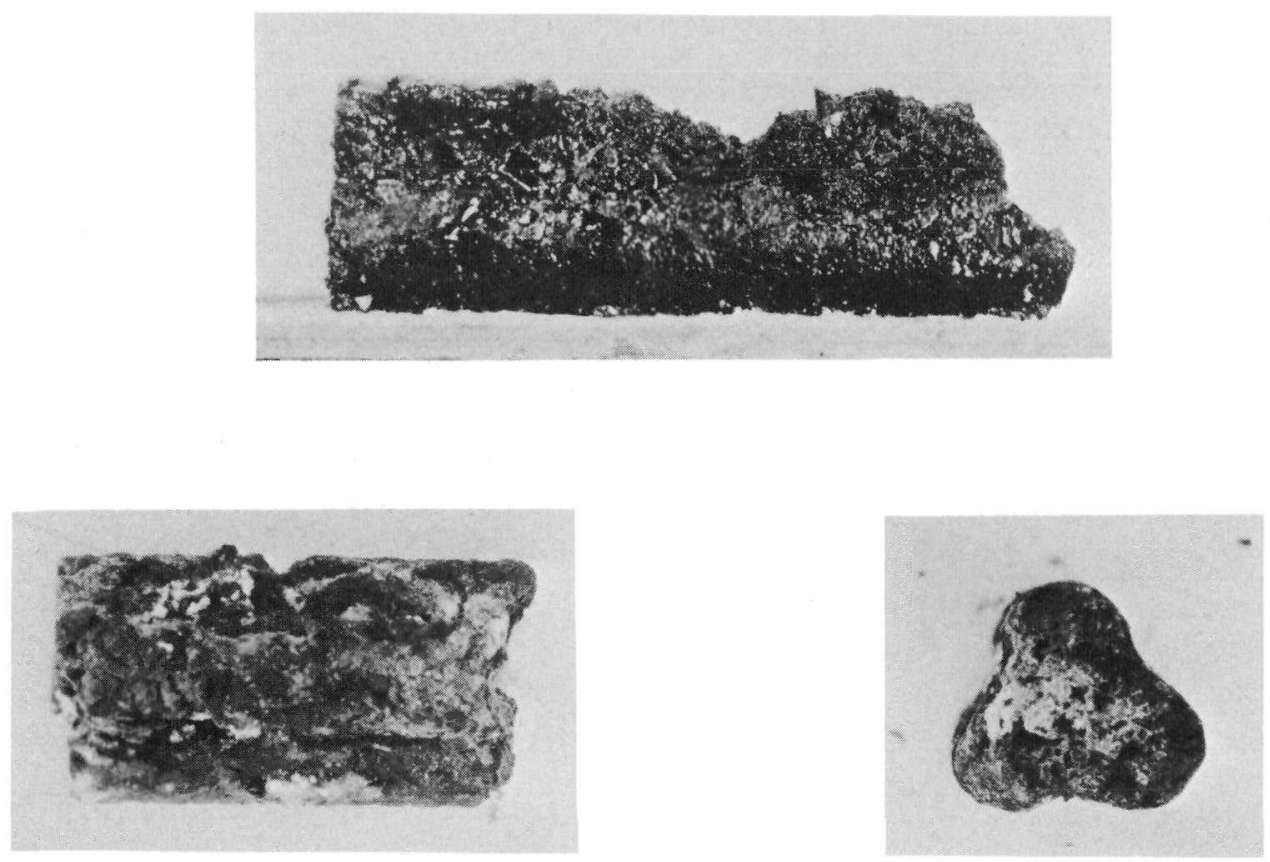

$20 \mathrm{~mm}$

Fig. 28. Large Lumps of Fuel Recovered from $-220 \mathrm{~mm}$. Neg. No. MSD-188972.

An extreme example of the variation in the extent of fuel and steel in the test train is shown in Fig. 22d, a transverse section at $-91 \mathrm{~mm}$. The 
relatively large amount of melted steel present at this level was identified as primarily cladding material by its high ${ }^{60} \mathrm{Co}$ activity. This section is near the pronounced minimum in the ${ }^{106} \mathrm{Ru}$ gamma-activity profile at $-100 \mathrm{~mm}$ of Fig. 14.

In the region between 290 and $340 \mathrm{~mm}$ below the midplane, lateral motion of fuel to locations outside the fluted tube was observed. Two transverse sections from this region, separated by $12 \mathrm{~mm}$, are shown in Figs. $22 \mathrm{f}$ and $22 \mathrm{~g}$. Both fuel and fluted tube had moved outward to contact the intermediate tube in these sections. Although all three flutes of the fluted tube are missing in Fig. 22f, lateral fuel motion occurred through only one of the openings. In Fig. $22 \mathrm{~g}$, only $12 \mathrm{~mm}$ lower in the fuel column than Fig. 22f, the fluted tube had an opening on only one side, but had opened outward to form a distorted $C$ shape. Fuel had moved laterally through this opening. Because the intermediate tube was not removed from this section, it could not be determined if the lateral fuel motion occurred as a sudden burst, as was inferred for the structure shown in Figs. 25 and 26.

In the bottom $80 \mathrm{~mm}$ of the fuel column, a substantial buildup of excess melted steel was observed. This phenomenon is shown in Fig. $22 \mathrm{~h}, \mathrm{a}$ transverse section $363 \mathrm{~mm}$ below the midplane. The space between the fuel and intermediate tube had almost completely filled with melted steel, including both material that was initially present at this level and steel that $r$ an down from higher positions. The appearance of the steel rundown in the vicinity of the lower flow blockage is shown in Fig. 29. These photographs represent the reverse side of the pieces shown in Fig. 21.

After fuel-element integrity was destroyed during the transient, the upper ends of the elements were free to move axially. The net displacements of the upper components of the elements are summarized in Table VII. The tops of elements HEDL-23 and -24 were in contact with a thermocouplemounting bracket that prevented further upward motion. The displacements of the reflector and insulator were larger than the cladding displacement for HEDL-22; the opposite was observed for HEDL-23 and -24 . In addition, the entire test train was displaced upward by $11 \mathrm{~mm}$. An attempt was made to remove the compression springs from the fuel elements. However, all three springs were firmly attached to the claddings.

\section{Mic roexamination}

The microscopic examination was performed to determine the extent of and mechanisms for fuel and cladding motion and, if possible, to determine the time sequence of the major transient events. The problem of reconstructing the events of the transient from the posttest examination was complicated by the long fuel column (put simply, the re was a great deal of material to look at) and by the pronounced axial variations in pretest fuel microstructures that implied differences in response to an applied transient. 
Because a preliminary microscopic examination indicated that the posttest microstructures were complex with a significant axial variation, a detailed characterization of the microstructure was needed to provide baseline information for discussing the fuel-motion processes.

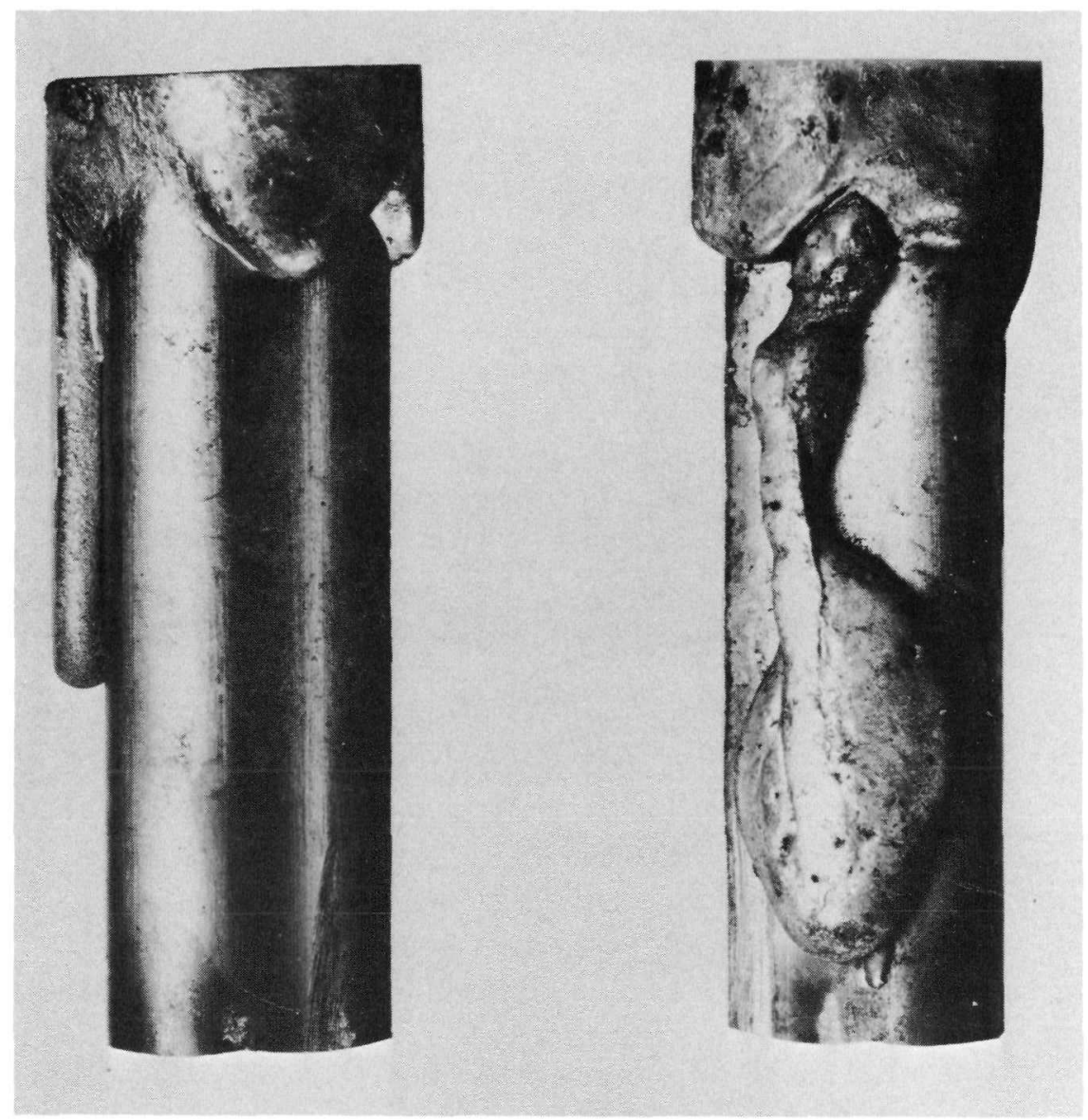

$20 \mathrm{~mm}$

Fig. 29. Rundown of Steel on Outside of Fluted Tube at Base of Fuel Column. Neg. No. MSD-188973.

The techniques of quantitative stereology was used to perform the necessary characterization. The results of these analyses included a quantitative description of the net displacement of fuel and steel, and the extent and location of regions of fuel-steel mixing. In addition, four distinct types of fuel microstructure were observed in the test remains; the density, grain size, and axial variation in extent were determined for each microstructural type. The implications concerning the fuel-motion sequence provided by these results are discussed in Sec. VI.E below.

The sections selected for detailed microstructural examination represented the extremes as well as the intermediate states of fuel behavior. The selections were made on the basis of information obtained from the macroexamination, the gamma scans, and the neutron radiograph. 
Before the quantitative stereology results are presented, the microstructural states observed in the test remains will be described quali-

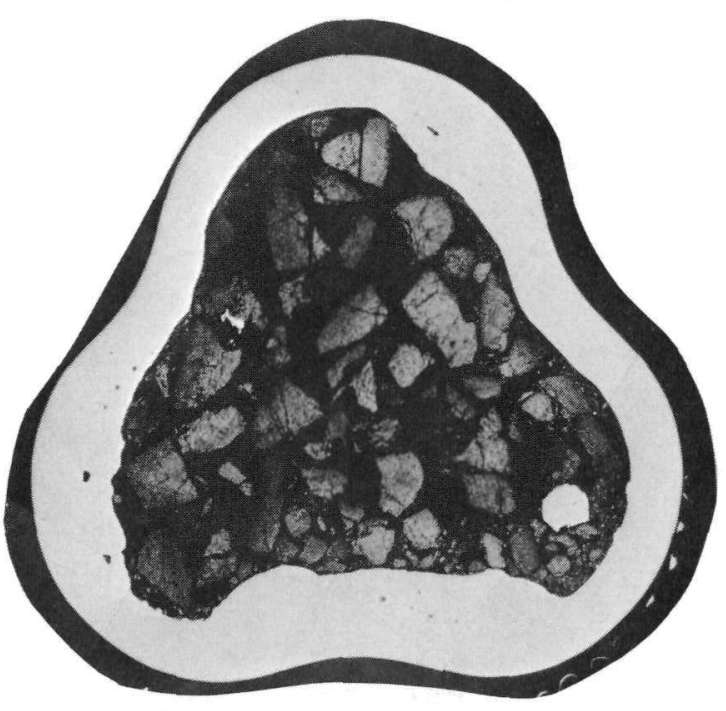

$2 \mathrm{~mm}$

Fig. 30. Transverse Section through Test Train at $+388 \mathrm{~mm}$. Neg. No. MSD-188958. tatively. The gross features of the microstructure will be described first, followed by the fine-scale features.

The appearance of the trans verse section shown in Fig. 30 is characteristic of the upper $50 \mathrm{~mm}$ of the fuel column. The most prominent feature of this structure is the large number of chunks into which the fuel pellets fragmented. The chunks, which had maximum caliper diameters of $0.5-3.0 \mathrm{~mm}$, moved enough so that, in most cases, it was not possible to identify from which fuel element the individual fragments came. Some of the fragments showed portions of the original pellet outline. Because the fragments had tumbled around, either during or after the transient, the traces of the pellet surfaces on the sectioning plane were usually not circular. The grain size and volume fraction of intergranular pores of the fragments at this level had probably not changed from the pretest values. A moderate amount of fission-gas precipitation and bubble coalescence had occurred, however; these phenomena are described in later paragraphs.

Steel, originally from the cladding and spacer wires, was deposited against the inner surface of the fluted tube. Nearly all the melted steel present at this level was so deposited; only a small portion mixed with the fuel fragments. Except for the coating of melted steel, the fluted tube appeared to be unaffected by the transient.

A somewhat different appearance is presented in Fig. 31, a transverse section $287 \mathrm{~mm}$ above the axial midplane. Fuel reached higher temperature levels at this position than the fuel shown in Fig. 30, and a more advanced degree of microstructural evolution is observed. Although separation of the fuel pellets into chunks or fragments is still evident, particularly in the central portion of the flow channel, most of the fuel in the outer lobes of the cross section shows gross swelling and large, distended voids. Highmagnification examination of this structure indicated that portions of the swelled fuel had been heated above the solidus. 


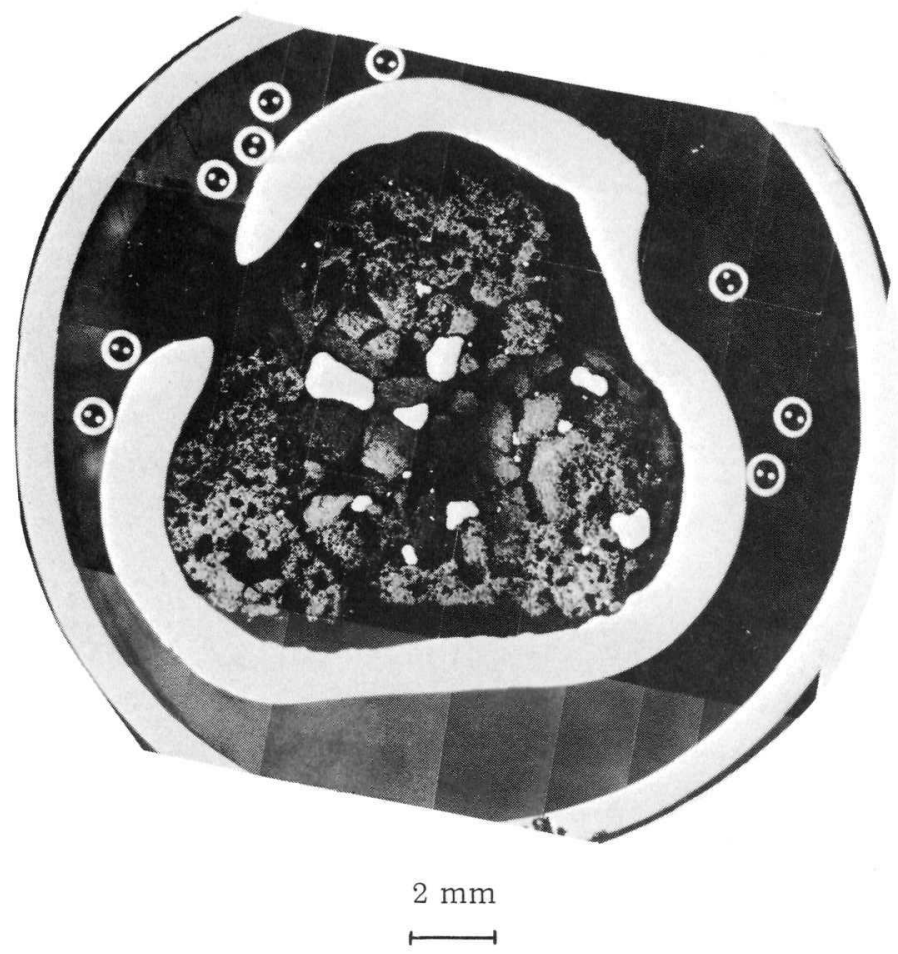

Fig. 31. Transverse Section at $+287 \mathrm{~mm}$. Neg. No. MSD-188960.

Blobs of steel with maximum caliper diameters as large as $2 \mathrm{~mm}$ are scattered throughout the fuel; several of the steel particles are molded into the interstices between unmelted fuel fragments. The fluted tube is deformed and has melted through in one spot.

At $250 \mathrm{~mm}$ above the midplane, extensive fuel swelling and melting have all but obliterated the prior pellet-fragment structure. Enough vestiges of fuel fragments are present, however, to indicate that the fuel must have separated into chunks at this level. The outline of the fragments can be seen more easily on the original composite micrograph than on the reproduction in Fig. 32. In view of the proximity of the two sections shown in Figs. 31 and 32 (their axial separation is $37 \mathrm{~mm}$ ), the microstructure of Fig. 31 is probably characteristic of a precursor state through

Fig. 32

Transverse Section at $+250 \mathrm{~mm}$. Neg. No. MSD-188962.

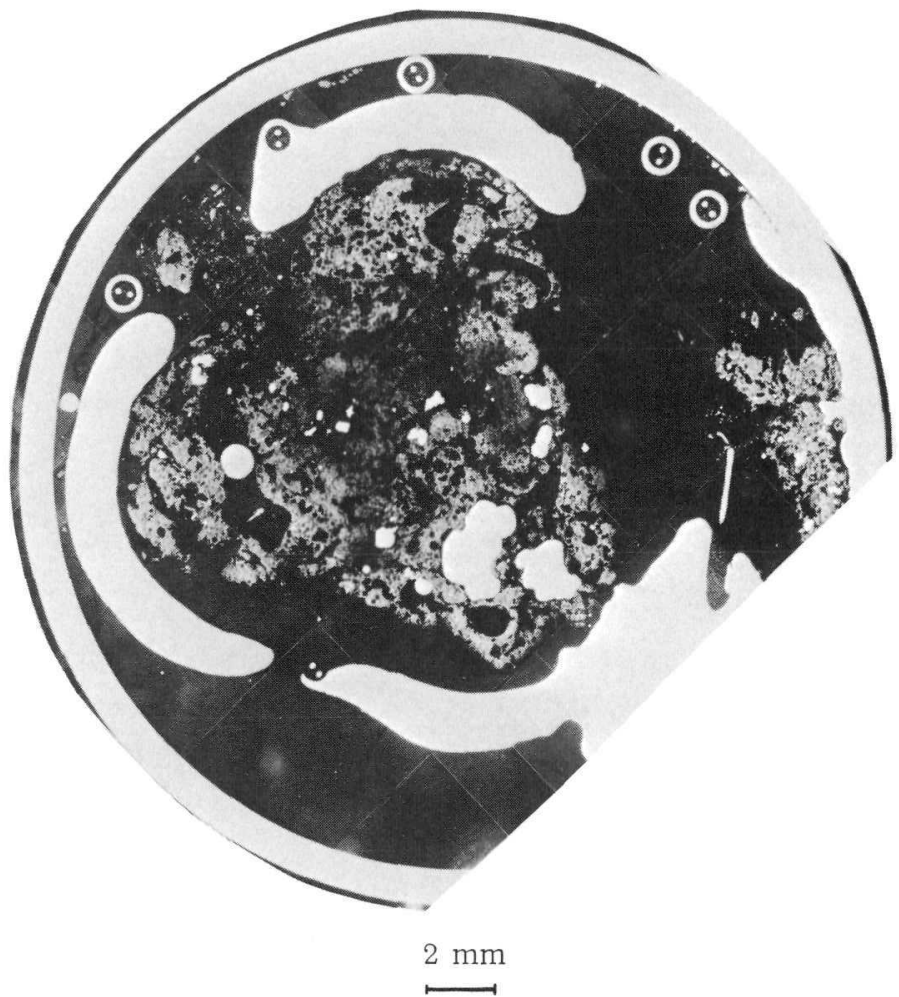


which the fuel at the $250-\mathrm{mm}$ level (see Fig. 32) passed before attaining its final structure. If this supposition is correct, the observed differences between the two reflect the higher temperatures and longer time at temperature for the fuel at the lower axial position.

The sectioning plane of Fig. 32 passed through an isolated deposit of fuel and steel against the intermediate tube. The fuel in this deposit was

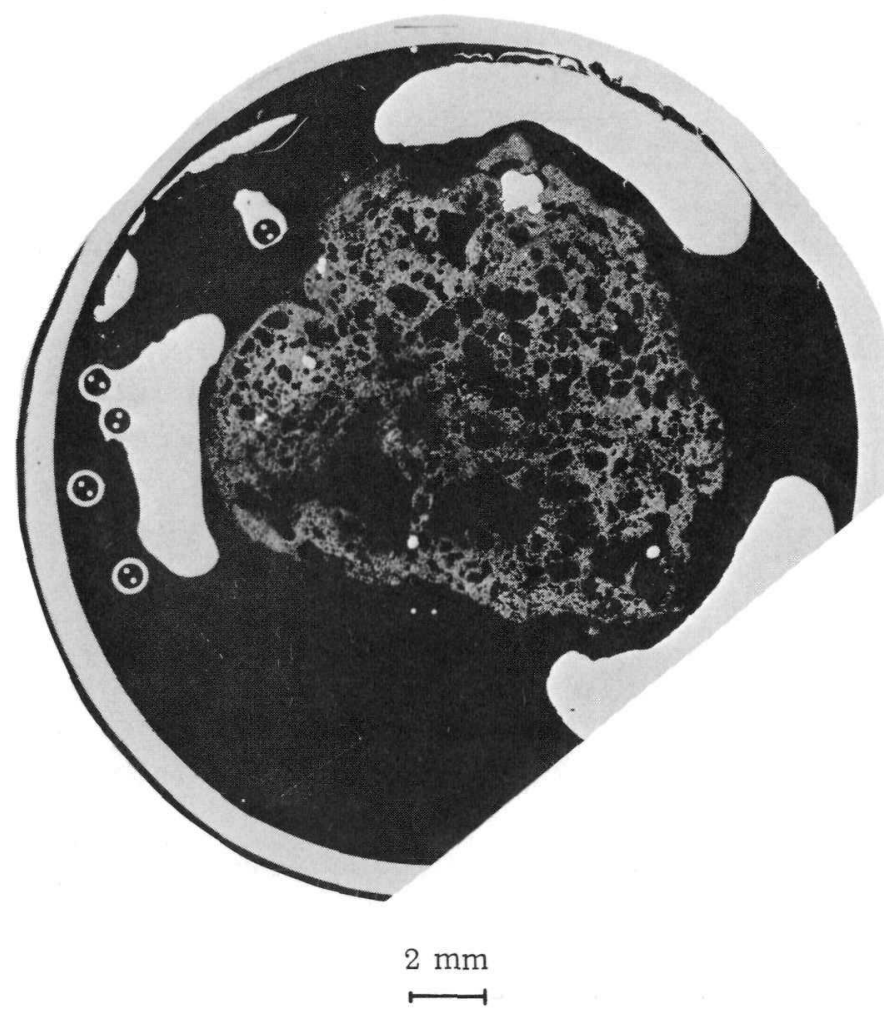

Fig. 33. Transverse Section at $+175 \mathrm{~mm}$. Neg. No. MSD-188963. liquid during the transient; at high magnification, its microstructure is similar to that of the deposit shown in Fig. 26.

The fuel microstructure of Fig. 33, a transverse section $175 \mathrm{~mm}$ above the midplane, is typical of that observed in the region between +200 and $-250 \mathrm{~mm}$. All the fuel in this region was heated to above the solidus, but, as described earlier, differences in the amounts of fuel and steel present at the various axial levels were observed. The lateral fuel motion shown in Fig. 33 is confined to an area roughly bounded by the original outline of the fluted tube, even though large areas of the fluted tube are missing. A possible explanation for this phenomenon was presented in the discussion of Fig. 22e.

The axial variation of microstructure in the bottom $175 \mathrm{~mm}$ of the fuel column shows a pattern similar to the behavior of the upper $200 \mathrm{~mm}$. As distance below the midplane increased, and maximum temperature and time at temperature decreased, the extent of fuel melting decreased, and the features found in the upper portion of the fuel column began to reappear. The transverse sections shown in Figs. 34 and 35 are representative of the microstructures observed in the bottom portion of the fuel column. In Fig. 34, $302 \mathrm{~mm}$ below the midplane, a large amount of melted fuel is present. However, small islands of unmelted material are also observed, often near the regions of melted fuel. Melted steel particles are distributed through the cross section. The spatial distribution of unmelted and melted fuel and melted steel in this section suggests that considerable mixing of these constituents occurred. The pattern observed in this section may be contrasted with that of Figs. 31 and 32, in which the unmelted and melted fuel constituents are grouped into separate regions with minimum overlap. The section shown in Fig. 34 had the largest amount of fuel outside the fluted tube of any section examined in L5 postmortem. 


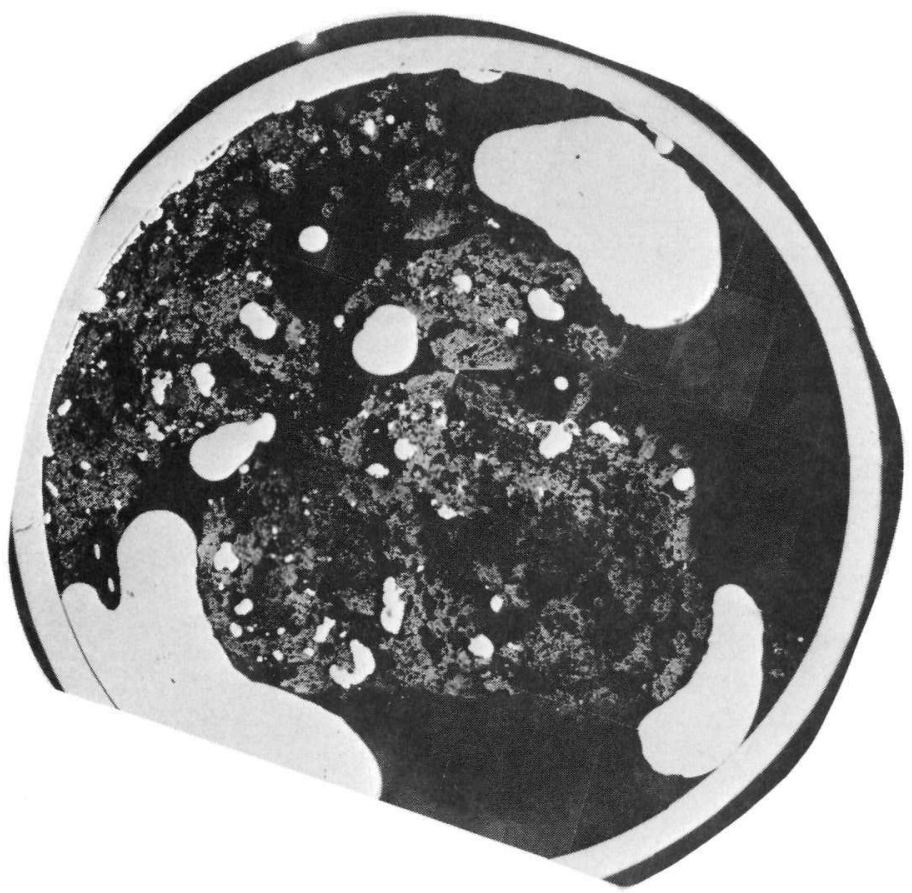

Fig. 34

Transverse Section at $\mathbf{- 3 0 2} \mathrm{mm}$.

Neg. No. MSD-188961.

$2 \mathrm{~mm}$

Fig. 35

Transverse Section at $-355 \mathrm{~mm}$.

Neg. No. MSD-188959.

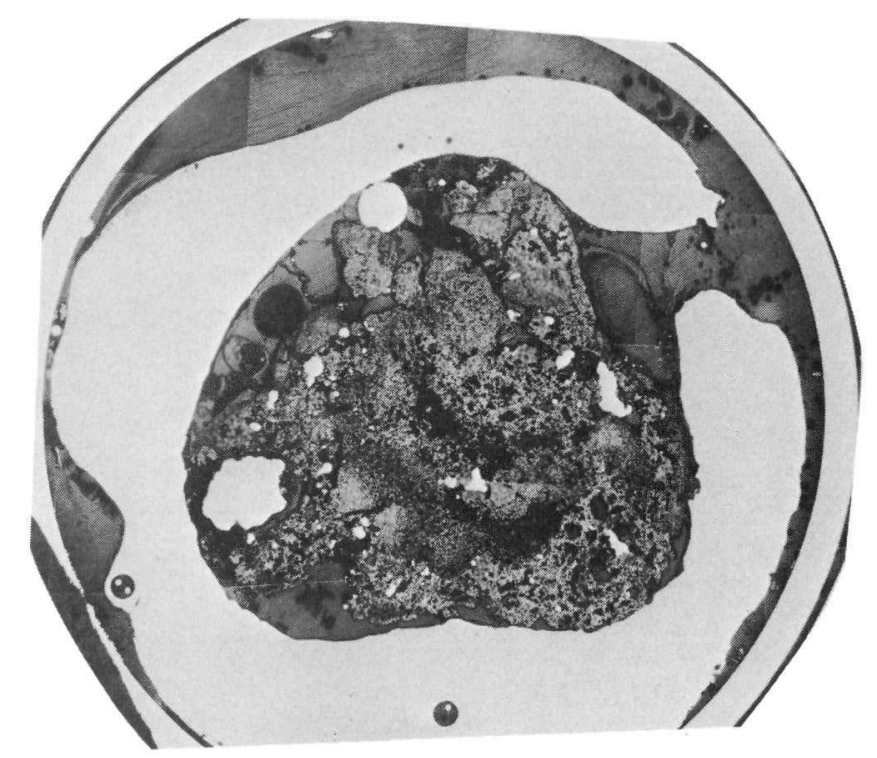

$2 \mathrm{~mm}$

The structure shown in Fig. 35, $355 \mathrm{~mm}$ below the midplane, represents the continued progression to structures characteristic of lower transient temperatures. The same types of features are observed in Figs. 34 and 35 , but a smaller amount of melted fuel and a larger amount of unmelted fuel are observed at the lower axial position. Chunks of unmelted fuel are prominent in Fig. 35. 
Low-power micrographs of the type shown in Figs. 30-35 were used to make quantitative determinations of the amount of fuel and steel present at several axial positions in the test train. The data presented in Table VIII and Fig. 36 were obtained by the quantitative stereology techniques

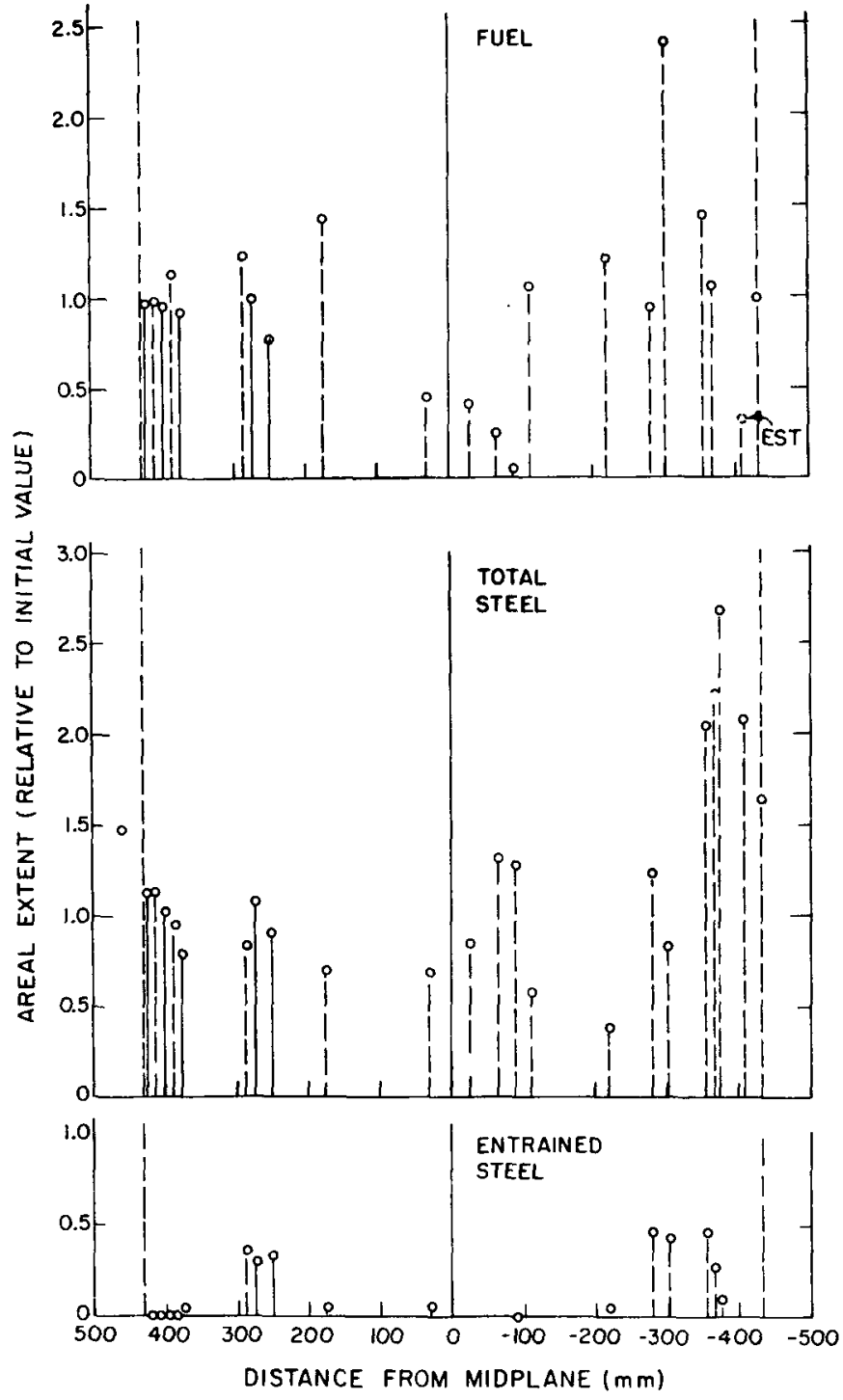

Fig. 36. Axial Profile of Posttest Concentrations of Fuel, Steel, and Total Steel. Neg. No. MSD-64013. of point counting and area measurement. The three curves in Fig. 36 show the axial variation of the relative amounts of fuel, total steel, and entrained steel. The measurements of fuel include melted and unmelted material from both inside and outside the fluted tube. Total steel includes the contribution from the fuel-element claddings, spacer wires, and fluted tube, these being the only (steel) test-train components from the fuel region that melted and moved axially. Entrained steel refers to the isolated particles of steel that were mixed in with the fuel.

All particles greater than $30 \mu \mathrm{m}$ in maximum caliper diameter were counted as entrained steel. This limit was established because previous experience (microprobe examination of melted metallic particles from the L4 test remains) indicated that the very fine particles are largely composed of metallic fission products. In any case, the $30-\mu \mathrm{m}$ cutoff excluded less than $3 \%$ of the total metallic-particle volume from the reported values of entrained steel.

The measured areas of fuel and total steel were normalized by dividing by the areas that would have been occupied by fuel and steel, respectively, in sections through the pretest test train. Thus, for fuel, a value of one represents an area equivalent to that occupied by the fuel in the three elements before the transient; for total steel, one corresponds to the sum of the pretest area contributions of the claddings, spacer wires, and fluted tube. The entrained-steel areas were normalized by dividing by the original area occupied by the cladding and spacer wires. The latter normalization factor reflects the fact that much of the entrained steel was originally part of the fuel elements. For comparison, the pretest area occupied by cladding plus spacer wires equals $22.8 \%$ of the total steel area. 
TABLE VIII. Summary of Quantıtative Stereology Measurements

\begin{tabular}{|c|c|c|c|c|c|c|c|c|c|c|c|}
\hline \multirow[b]{2}{*}{$\begin{array}{c}\text { Sample } \\
\text { No. } \\
159-\end{array}$} & \multirow[b]{2}{*}{$\begin{array}{c}\text { Distance to } \\
\text { Midplane } \\
\text { mm }\end{array}$} & \multirow[b]{2}{*}{$\begin{array}{l}\text { Euel } \\
\text { Area, } \\
\mathrm{mm}^{2}\end{array}$} & \multirow[b]{2}{*}{$\begin{array}{l}\text { Normalized } \\
\text { Fuel Area }\end{array}$} & \multirow[b]{2}{*}{$\begin{array}{c}\text { Total Steel } \\
\text { Steel Area, } \\
\mathrm{mm}^{2}\end{array}$} & \multirow[b]{2}{*}{$\begin{array}{c}\text { Normalized } \\
\text { Total Steel } \\
\text { Area }\end{array}$} & \multirow[b]{2}{*}{$\begin{array}{l}\text { Entrained } \\
\text { Steel Area, } \\
\mathrm{mm}^{2}\end{array}$} & \multirow[b]{2}{*}{$\begin{array}{l}\text { Normalized } \\
\text { Entrained } \\
\text { Steel Area }\end{array}$} & \multicolumn{4}{|c|}{ Fractional Amounts of } \\
\hline & & & & & & & & $\begin{array}{c}\text { As-irradiated } \\
\text { Fuel }\end{array}$ & $\begin{array}{c}\text { Bubble- } \\
\text { precipitated } \\
\text { Fuel }\end{array}$ & $\begin{array}{l}\text { Spongy } \\
\text { Fuel }\end{array}$ & $\begin{array}{l}\text { Melted } \\
\text { Fuel }\end{array}$ \\
\hline A52 & +457 & 0 & 0 & 143.3 & 1.48 & 0 & 0 & - & - & - & - \\
\hline A31 & +425 & 51.0 & 0.99 & 110.5 & 1.14 & 0 & 0 & 1.0 & 0 & 0 & 0 \\
\hline A30 & +412 & 51.3 & 0.99 & 109.9 & 1.14 & 0 & 0 & 1.0 & 0 & 0 & 0 \\
\hline A29 & +400 & 49.9 & 0.96 & 100.1 & 1.03 & 0 & 0 & 1.0 & Trace & 0 & 0 \\
\hline A28 & +388 & 58.7 & 1.14 & 93.0 & 0.96 & 0 & 0 & 0.53 & 0.47 & 0 & 0 \\
\hline A 27 & +375 & 48.1 & 0.93 & 77.6 & 0.80 & 1.0 & 0.05 & 0.29 & 0.47 & 0.24 & 0 \\
\hline A55L & +334 & - & - & - & - & - & - & 0.12 & 0.19 & 0.31 & 0.38 \\
\hline A $24 \mathrm{~L}$ & +308 & - & - & - & - & - & - & 0 & 0.15 & 0.37 & 0.49 \\
\hline A.46 & +287 & 63.8 & 1.23 & 82.7 & 0.86 & 8.0 & 0.36 & 0.09 & 0.17 & 0.12 & 0.62 \\
\hline A 49 & +275 & 51.4 & 1.00 & 104.7 & 1.08 & 6.7 & 0.30 & - & - & - & - \\
\hline A 51 & +250 & 40.4 & 0.78 & 89.4 & 0.92 & 7.5 & 0.34 & 0 & 0 & 0.26 & 0.74 \\
\hline A62 & +175 & 69.8 & 1.35 & 67.5 & 0.70 & 1.1 & 0.05 & 0 & 0 & 0 & 1.00 \\
\hline A41 & +30 & 23.8 & 0.46 & 66.7 & 0.69 & 1.4 & 0.06 & 0 & 0 & 0 & 1.00 \\
\hline A 45 & -30 & 21.1 & 0.41 & 82.7 & 0.85 & 0 & 0 & 0 & 0 & 0 & 1.00 \\
\hline A 48 & -68 & 12.8 & 0.25 & 127.8 & 1.32 & 0 & 0 & 0 & 0 & 0 & 1.00 \\
\hline A36 & -95 & 3.3 & 0.06 & 125.0 & 1.29 & 0 & 0 & 0 & 0 & 0 & 1.00 \\
\hline A38 & -116 & 55.0 & 1.06 & 56.1 & 0.58 & 0 & 0 & 0 & 0 & 0 & 1.00 \\
\hline A $5 \times 1$ & -220 & 62.7 & 1.21 & 38.7 & 0.40 & 1.0 & 0.05 & 0 & 0 & 0 & 1.00 \\
\hline A $5 \times 2$ & -238 & - & - & - & - & - & - & 0 & 0 & 0 & 1.00 \\
\hline A23 & -280 & 49.0 & 0.95 & 120.1 & 1.24 & 10.5 & 0.48 & 0 & 0.02 & 0.56 & 0.42 \\
\hline A.21 & -302 & 123.4 & 2.40 & 84.2 & 0.87 & 9.6 & 0.44 & 0 & Trace & 0.47 & 0.53 \\
\hline A 17 & -355 & 74.9 & 1.45 & 198.7 & 2.05 & 10.3 & 0.47 & 0.12 & 0.12 & 0.28 & 0.48 \\
\hline A16 & -367 & 55.2 & 1.07 & 214.5 & 2.22 & 6.1 & 0.28 & - & - & - & - \\
\hline A9R & -375 & - & - & 259.3 & 2.68 & 2.1 & 0.09 & - & - & - & - \\
\hline A6R & -408 & $17.2^{\mathrm{a}}$ & 0.33 & 202.0 & 2.09 & - & - & - & - & - & - \\
\hline A6R & -432 & $51.7^{\mathrm{a}}$ & 1.00 & 158.7 & 1.64 & - & - & $1.0^{\mathrm{a}}$ & 0 & 0 & 0 \\
\hline
\end{tabular}

a Estimated. 
The sections on which the measurements were performed were selected to include the extremes of fuel and cladding deposition. Therefore the data points in Fig. 36 accurately represent the true magnitudes and axial positions of the maxima and minima in the fuel and total-steel curves.

More sampling sites were selected at the ends of the fuel column than in the central regions. This selection procedure allowed a detailed examination of unmelted fuel structures from which the evolution of microstructure during the transient was determined. As a result, the axial profile in fuel concentration in Fig. 36 shows more detail near the ends of the fuel column than near the center. However, enough sites were examined from the latter region to illustrate the important features of the fuel-concentration profile. Note that the selection procedure did not affect the profile of microstructure variation in Fig. 47 (see below) since all the fuel from the central region melted.

The axial redistribution of fuel is shown in Fig. 36 by the fuel deficits at +30 and $-90 \mathrm{~mm}$ and surpluses at $+287,+175,-220$, and $-302 \mathrm{~mm}$. The point in the figure identified as FUEL EST is an estimate of the fuel present in the lower flow blockage. The amount of fuel was estimated from the size of the hole left in the section after the fuel fell out during sectioning. The largest concentration of fuel is at $-302 \mathrm{~mm}$ and corresponds to about 2.4 times the pretest fuel concentration; this section is shown in Fig. 34. The lowest fuel concentration is at $-90 \mathrm{~mm}$ and corresponds to about 0.06 times the initial value. The positions of the local maxima and minima are in good correspondence with several of the prominent maxima and minima in the ${ }^{106} \mathrm{Ru}$ gamma-scan curve shown in Fig. 14. A comparison of Figs. 14 and 36 indicates that, when properly interpreted, the ${ }^{106} \mathrm{Ru}$ gamma scan is useful as a qualitative guide to the axial redistribution of fuel and as a means of studying the short-range variations in fuel concentration. However, the quantitative stereology methods have the advantage of providing absolute magnitudes for the extent of fuel redistribution.

Because of the mixing of material from the various steel components, the posttest distribution of the fuel-element claddings and spacer wires could not be determined unambiguously. As an alternative, the distribution of total steel (fluted tube, cladding, and spacer wire) was measured. The data obtained show surpluses with maxima at $+445 \mathrm{~mm}$, in the upper flow blockage above the fuel column top; at $-68 \mathrm{~mm}$, close to the most prominent fuel deficit; at $-280 \mathrm{~mm}$; and at $-375 \mathrm{~mm}$ or about $32 \mathrm{~mm}$ above the lower flow blockage. The largest steel excess, at the $-375-\mathrm{mm}$ level, equaled about 2.7 times the pretest steel concentration. Most of the excess at this level is the result of steel rundown in the space between the fluted and intermediate tubes, and is shown in Fig. 29. The amount of steel outside the fluted tube is much less at the level of the lower flow blockage. Even though the inside of the fluted tube is blocked with steel at the latter position, the total amount of steel is only about 2.1 times the initial value, or somewhat less than the maximum. 
The data for entrained steel show maxima centered at +275 and $-315 \mathrm{~mm}$. The maxima correspond to about 0.4 times the initial amount of cladding and spacer wires. The relatively small values are an indication that most of the molten cladding and spacer wires moved either upward to form the upper flow blockage or laterally to mix with the fluted tube and then flow downward. Little entrained steel was observed between the two maxima, i.e., in the central portion of the fuel column. The axial profile of entrained steel distribution suggests that steel particles may have been swept away from the midplane by axially moving fuel. Alternatively, the moving fuel may have stripped steel particles from the fluted tube walls.

The path of microstructural evolution during the transient was studied by examining four distinct types of fuel microstructure identified in the posttest remains. The qualitative and quantitative characteristics of each type of microstructure were determined, including the axial variation of the relative amount of each structure. The microstructural characteristics are discussed in the order of increasing severity of transient heating effects.

The first microstructure is representative of the condition of the equiaxed and unrestructured zones of the as-irradiated fuel. An example of this structure, taken from a transverse section at $+412 \mathrm{~mm}$, is shown in

Fig. 37. Approximately half of a

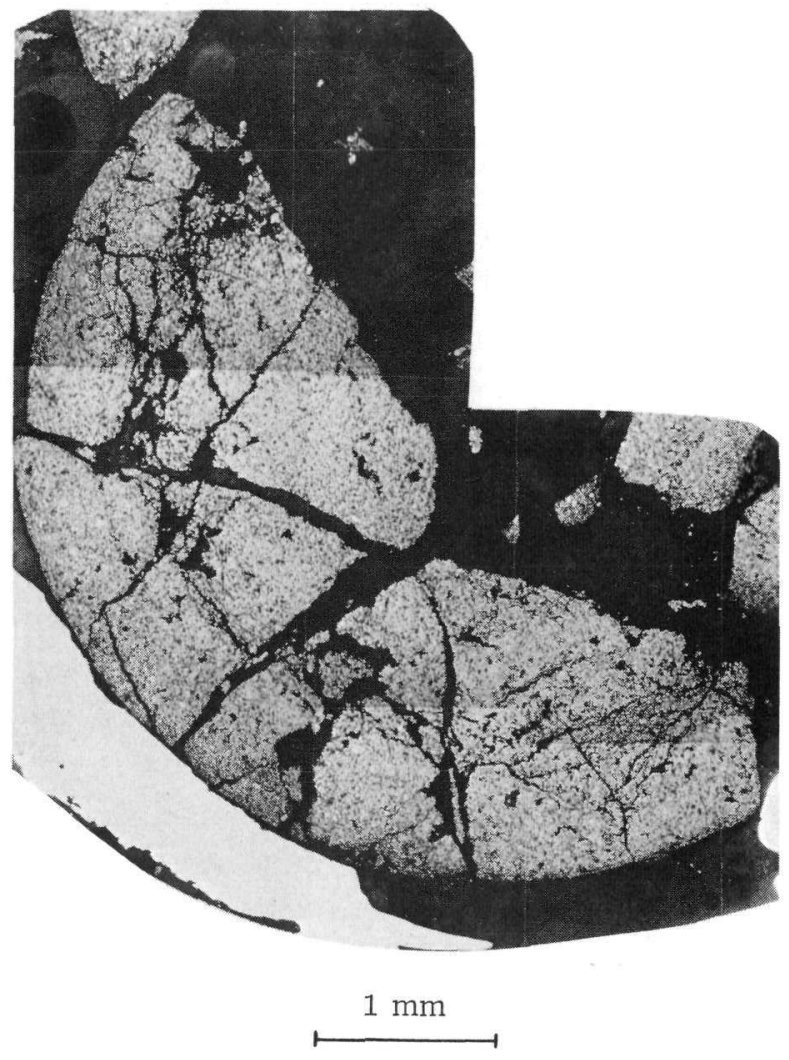

Fig. 37. As-irradiated Microstructure at $+412 \mathrm{~mm}$. Neg. No. MSD-187030. pellet is represented in this fragment, based on its semicircular outline as well as the radial and circumferential crack pattern. Both the unrestructured (with a mean grain intercept of $7 \mu \mathrm{m}$ ) and equiaxed (with a mean grain intercept of $9 \mu \mathrm{m}$ ) zones are present. Equiaxed fuel from other fragments at slightly lower axial levels had mean grain intercepts of about $16 \mu \mathrm{m}$. The latter figure is probably more typical of the grain size of equiaxed fuel in the HEDL-59 type. Both equiaxed and unrestructured zones were observed in the fuel chunks shown in Fig. 30. The as-irradiated structure is characteristic of fuel from the upper $100 \mathrm{~mm}$ of the fuel column. No remnants of columnar-grained fuel were observed in the test remains, apparently because fully restructured fuel was initially present only in the central portion of the fuel column. All the columnar-grained fuel must have melted during the transient. As shown 


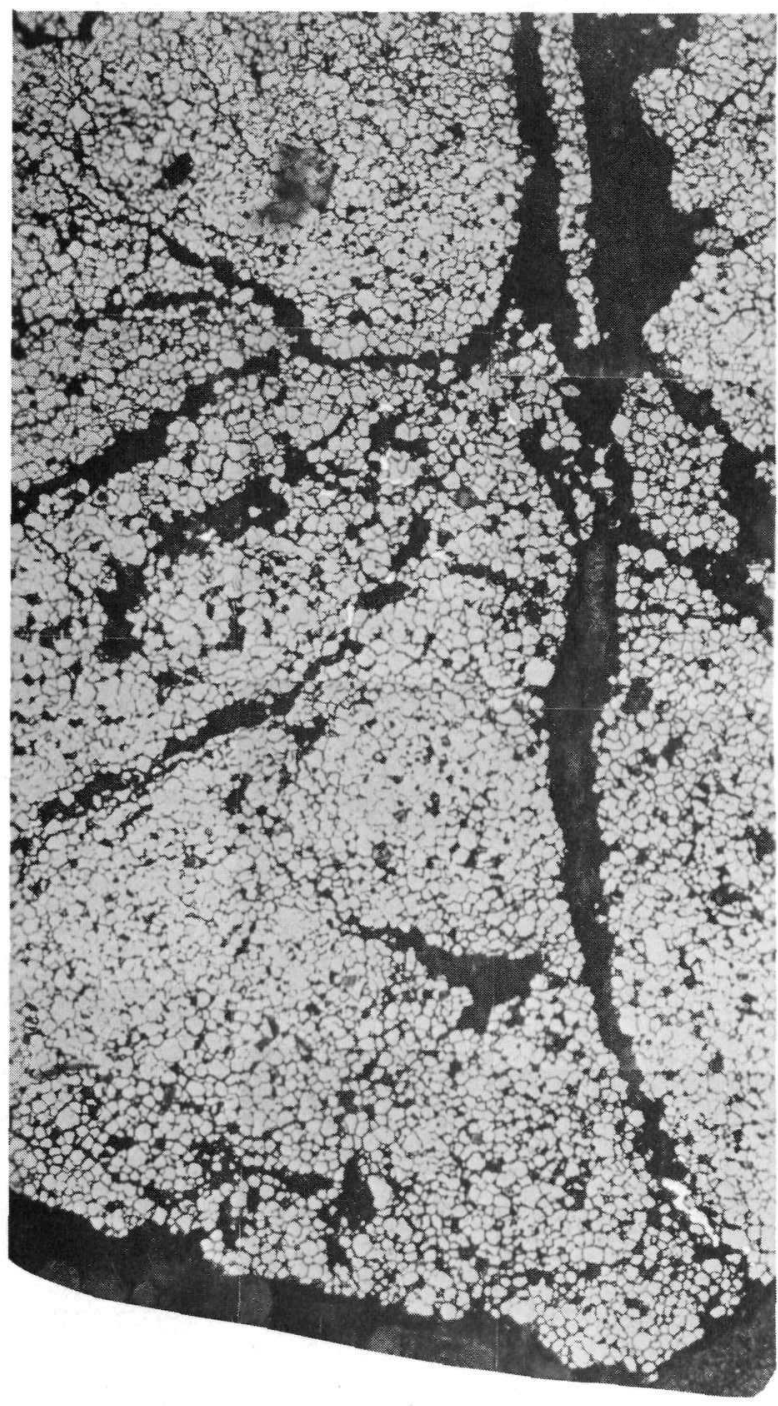

$200 \mu \mathrm{m}$

Fig. 38. As-irradiated Fuel at $+412 \mathrm{~mm}$. Neg. No. MSD-187012. in the higher magnification in Fig. 38, the as-irradiated fuel was nearly free of intragranular porosity.

The second microstructural class is the first type of fuel microstructure that exhibits effects of transient heating. Intragranular fission-gas bubbles are visible in this fuel, which is otherwise similar to the as-irradiated type. Figures 39 and 40 show two examples of this type of structure containing different levels of fission-gas precipitation. Although the smaller bubbles are not resolved at this magnification, they are evident in the dirty gray shading of the grains. This appearance may be contrasted with that of the bubble-free grains in Fig. 38.

The fuel shown in the righthand edge of the fragment in Fig. 40 exhibits intergranular swelling, apparently because it was contacted by hotter, melted fuel. Individual bubbles are resolved in the high-magnification micrographs of the bubble-precipitated structures shown in Fig. 41. Apparent bubble diameters in these micrographs range from 0.2 to $3 \mu \mathrm{m}$. The smaller bubbles are usually spherical; the larger ones are often irregularly shaped.

The volume fraction of intergranular bubbles measured with respect to grain volume averaged 0.34. Individual grains with bubble volume fractions greater than 0.5 were observed. The mean grain intercept for bubble-precipitated fuel was about $12 \mu \mathrm{m}$.

The continuous nature of the transition between the as-irradiated and bubble-precipitated structures is illustrated by the series of micrographs in Fig. 41. A transition state observed in the upper portion of the fuel column, in Fig. 4la, has a low density of relatively small-diameter bubbles. The grain size of this fuel indicates an origin in the equiaxed zone of the pretest fuel structure. The intragranular bubbles distinguish this material from the asirradiated fuel shown in Fig. 38. A more fully developed bubble-precipitated 


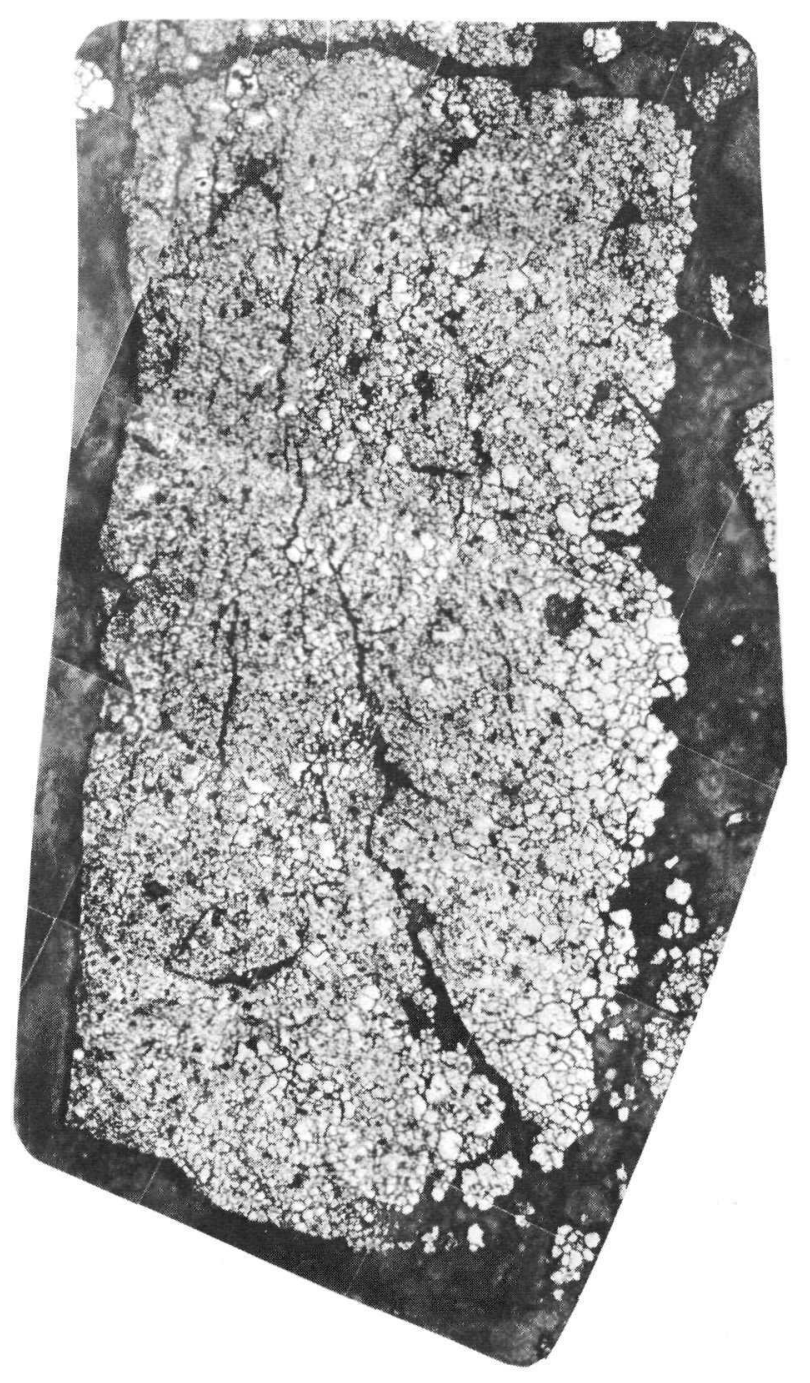

$200 \mu \mathrm{m}$

Fig. 39. Bubble-precipitated Structure at $+388 \mathrm{~mm}$. Neg. No. MSD-188612.

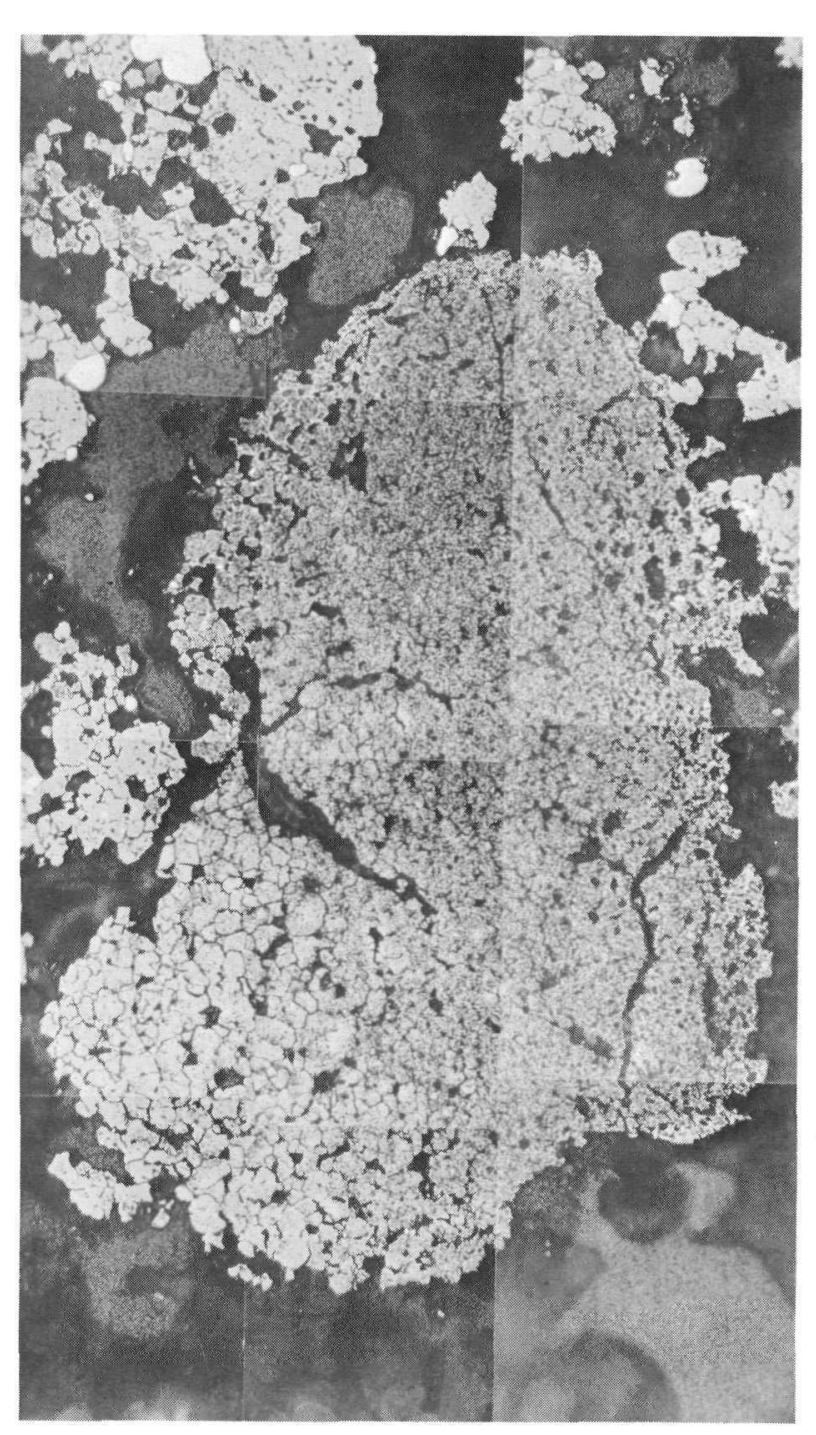

$200 \mu \mathrm{m}$

Fig. 40. Bubble-precipitated Structure at $-302 \mathrm{~mm}$. Neg. No. MSD-187158. 


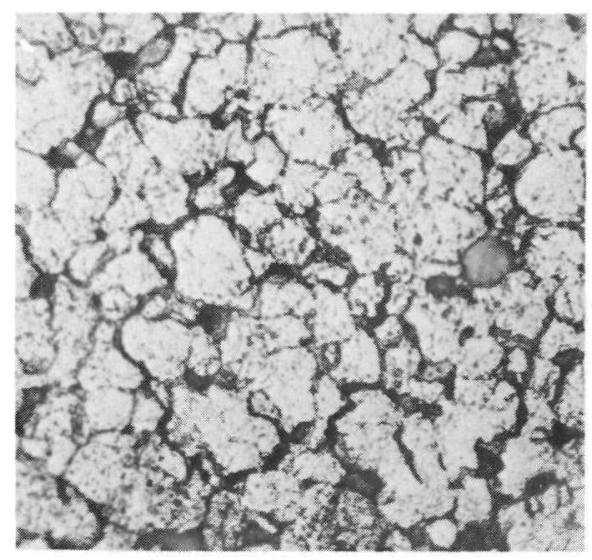

A. MSD- 187176

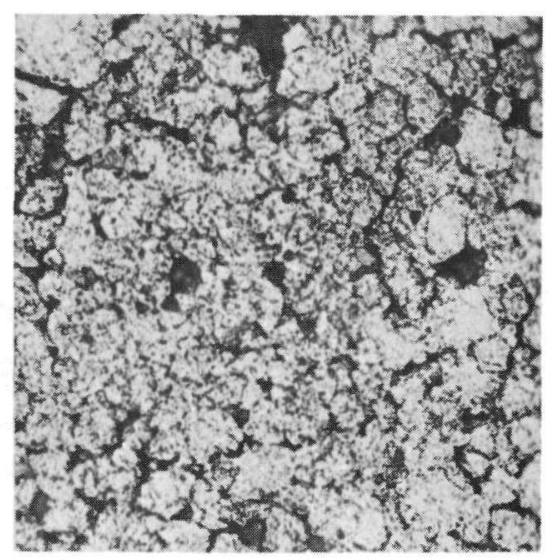

B. MSD- 187175

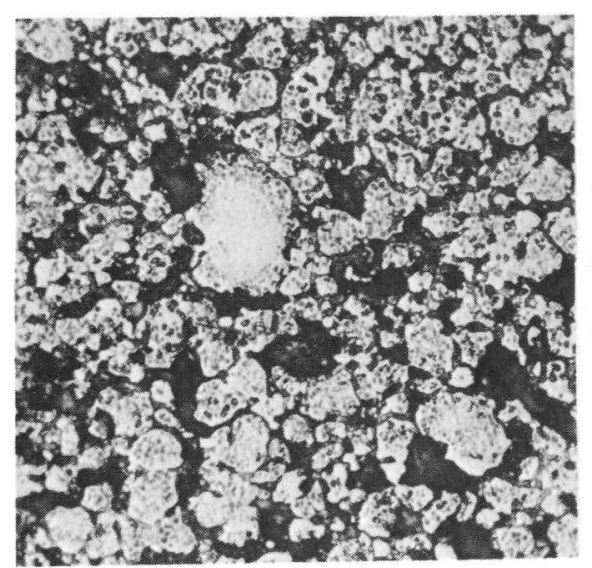

C. MSD- 186902

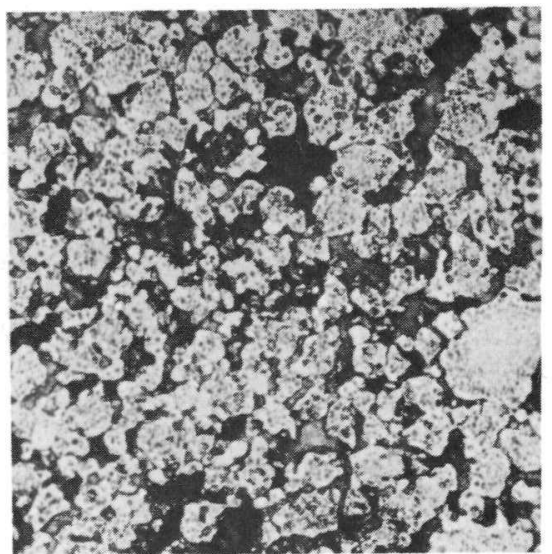

D. MSD- 187293
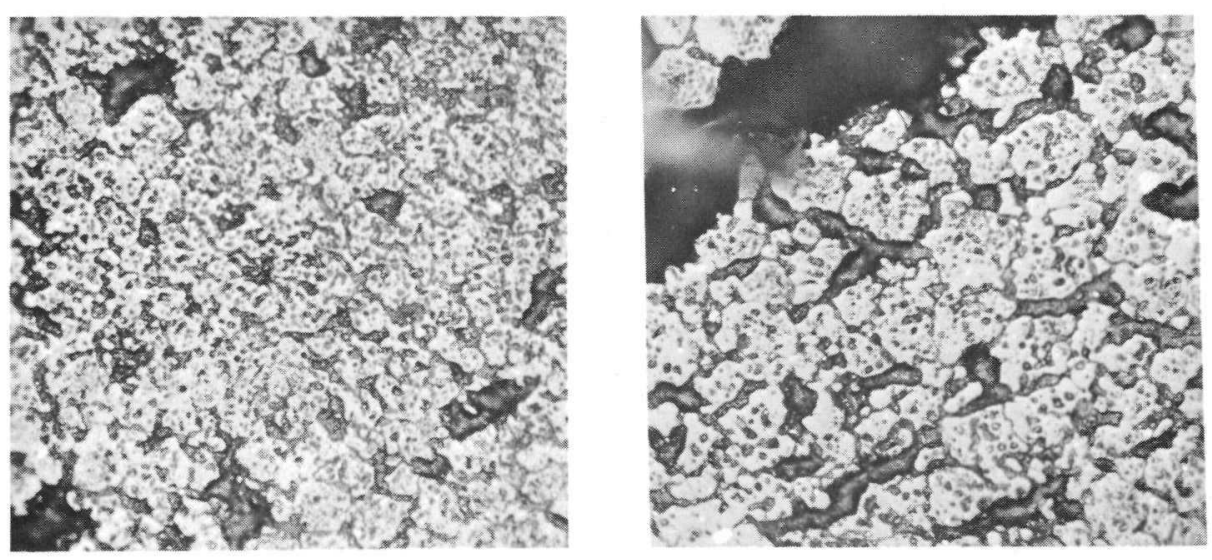

$50 \mu \mathrm{M}$

E. MSD- 187238

F. MSD- 187240

Fig. 41. Examples of Bubble-precipitated Fuel. Neg. Nos. MSD-188975 and -188976. 
structure is shown in Fig. $41 \mathrm{~b}$. Bubble densities are much higher than in Fig. $41 \mathrm{a}$, but bubble diameter is still small. Some intergranular swelling has occurred in this structure. Note that some of the grains are missing, an artifact of the metallographic preparation.

Figures $4 \mathrm{lc}$ and $4 \mathrm{ld}$ show fuel with lower bubble densities; the bubbles are of much larger sizes than the bubbles shown in Fig. 4lb. The coarse intragranular bubbles evidently were formed by the coalescence of fine bubbles, such as those in Fig. $41 \mathrm{~b}$.

A final stage in the development of intragranular bubble precipitation is shown in Figs. $41 \mathrm{e}$ and $41 \mathrm{f}$. In these structures, the continued bubble coalescence led to the formation of wormhole porosity, i.e., sinuous (and possibly multiply connected) channels of porosity. In Fig. $41 \mathrm{e}$, the initial grain size was small compared to the distance over which bubble interlinkage occurred. As a result, most of the wormholes have vented to the intergranular porosity. This phenomenon occurred to such a large extent that recognizing the original grain outlines is difficult. By way of contrast, the grains in Fig. $41 \mathrm{f}$ originating from an equiaxed zone are large enough to encompass most of the interlinked channels. Large-scale venting of the intragranular bubbles did not occur.

No detailed study was made of the amount of swelling resulting from the intragranular bubble precipitation. However, the increase in the linear dimensions of the grains was much less than would be predicted on the basis of the bubble volume fraction. As a result, the intragranular bubbles must have been highly pressurized.

Intragranular bubble precipitation was more pronounced for unrestructured than for equiaxed fuel; an example of this effect is shown in Fig. 40. The large-grained fuel in the fragment shown in Fig. 40 originated from the equiaxed zone. The fragment shows little bubble precipitation compared to the adjacent fine-grained unrestructured material.

The unrestructured zone of the as-irradiated fuel is unique in that it contains a dispersion of isolated large grains in a matrix of finergrained material. These grains, visible by a close examination of the section shown in Fig. 37, are about twice the size of the surrounding material. In the bubble-precipitated structure, the large grains are particularly prominent because they are usually free of precipitate bubbles, except for the bubbles found in a band around the grain peripheries. The latter effect is seen in Figs. 4lc and 4ld. Since the outer band containing the bubbles often does not encircle the bubble-free interior, this phenomenon may be an effect of biased bubble migration. However, no completely satisfactory explanation for the large, relatively bubble-free grains has yet been advanced.

In the third type of microstructure, extensive grain-boundary separation and intergranular swelling is superimposed on the intragranular 
bubble precipitation described earlier. The microstructure is referred to as "sponge." A transition stage between the bubble-precipitated and spongy structures is illustrated in Fig. 42. The grains of fuel have begun to separate along the boundaries, forming fissures that extend for several grain diameters. A comparison of the transition structure with the fully developed sponge structure typified in Fig. 43 suggests that the intergranular swelling occurred by the formation of additional intergranular fissures and the puffing up of those fissures not connected to the outside of the fuel fragment. Large amounts of swelling would be expected for this transient because the individual fragments were unconstrained after the loss of the cladding restraint. The pore volume fraction for the intergranular porosity of the sponge structure was variable; values in the range 0.49-0.64 were observed.

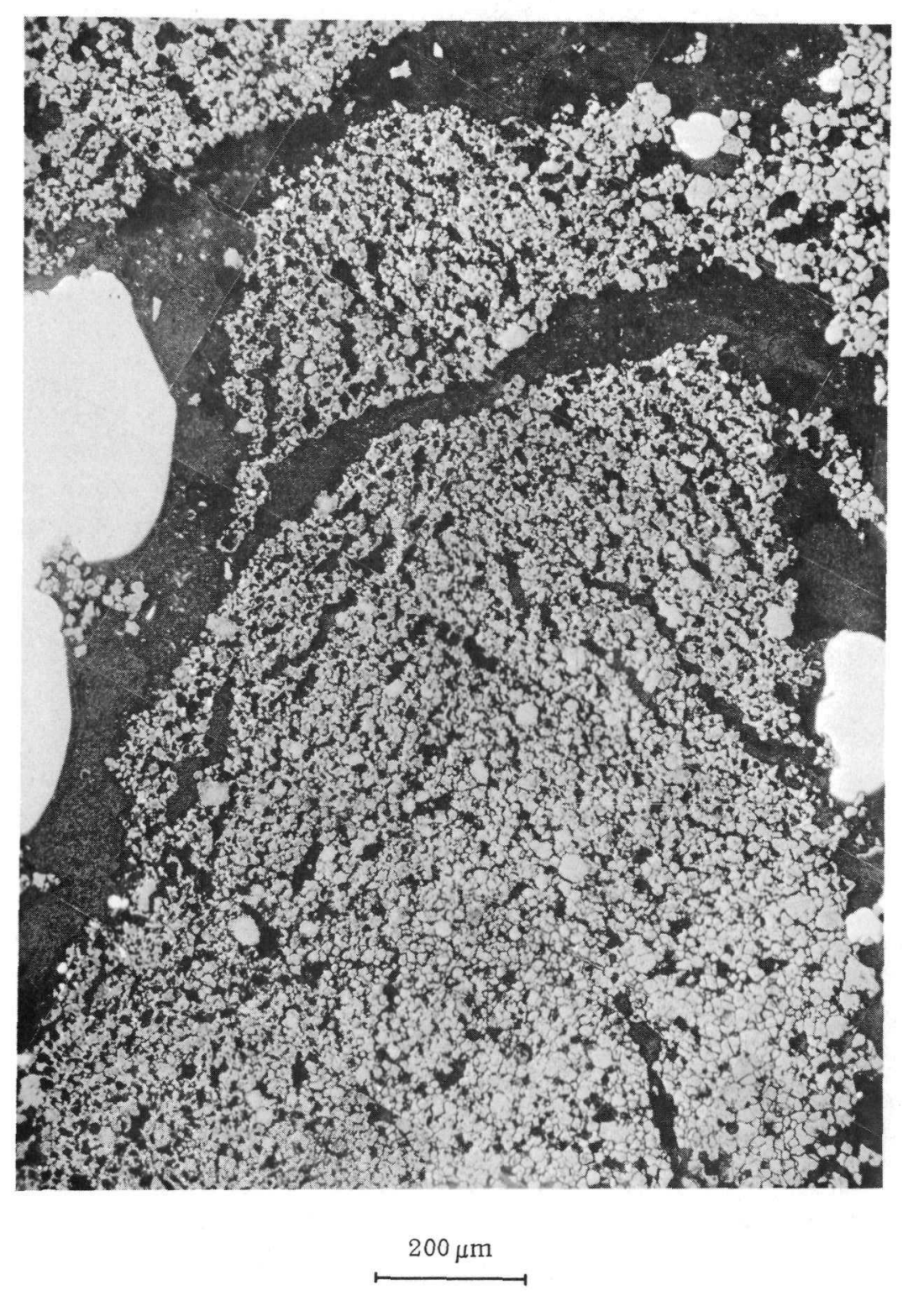

Fig. 42. Grain-boundary Fissures Marking Transition between the Bubbleprecipitated and Spongy Structures. Neg. No. MSD-188979. 


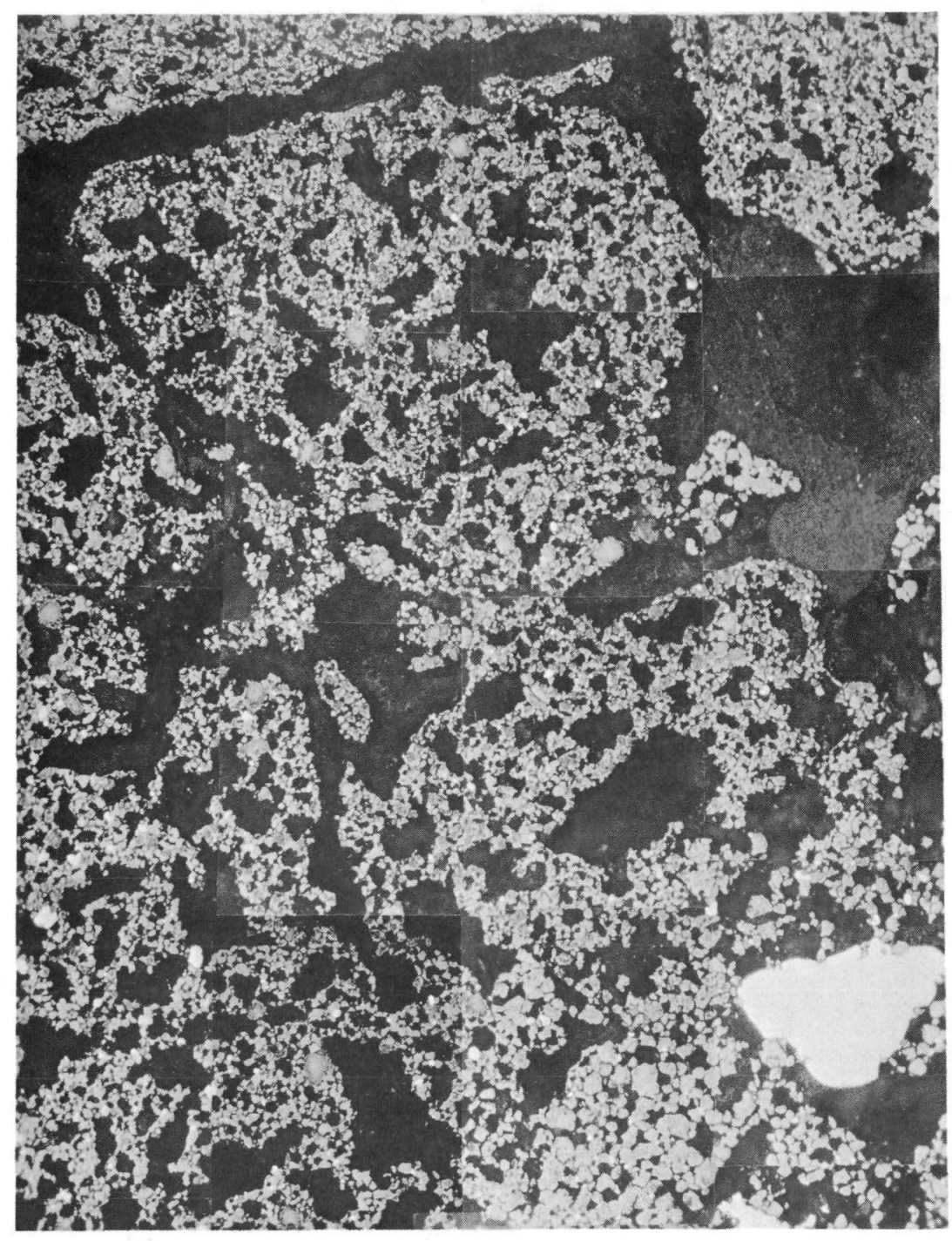

$200 \mu \mathrm{m}$

Fig. 43. Spongy, Unmelted Fuel. Neg. No. MSD-188977.

It is important to emphasize that the sponge microstructure represents fuel that did not melt during the transient. The major evidence for this conclusion comes from the fine details of the microstructure. Upon close inspection, the individual grains in Fig. 43 are similar to the grains in Figs. 39-42. The intragranular bubbles for the spongy fuel are nearly identical to those in the bubble-precipitated structure; in fact, several examples of the large grains containing an outer band of bubble precipitation are also present in the spongy fuel of Fig. 43. These details of the microstructure would not have been preserved if the spongy fuel had melted. Rather, the spongy microstructure represents an unmelted structure that formed from bubbleprecipitated material in a gradual evolutionary process. 
Fuel of the fourth type of microstructure was heated beyond the solidus, i.e., melted fuel. This material is characterized by (1) relatively large grains (about $21 \mathrm{\mu m}$ for the mean grain intercept) that are nearly free of intragranular bubbles, (2) large intergranular bubbles that were frozen as they percolated through the molten fuel, and (3) irregular globs of steel and metallic fission products. A typical melted fuel structure is shown in Fig. 44. Unlike the bubble-precipitated and sponge structures, the melted structure was not formed by gradual evolution from a specific precursor state. Rather, melted fuel was formed discontinuously from a variety of unmelted structures. This point is illustrated in Figs. 45 and 46, which show the melting of fuel with bubble-precipitated and sponge structures, respectively. In both cases there is a sharp discontinuity in microstructure at the boundary between the unmelted and melted fuel. A third transition, not shown in the figures, was observed for fuel that was originally equiaxed. In the latter transition, equiaxed fuel melted directly with little or no bubble precipitation and no froth formation.

Both the microstructural state and the fission-gas retention of a fuel fragment in the instant before melting depend on the pretransient structure

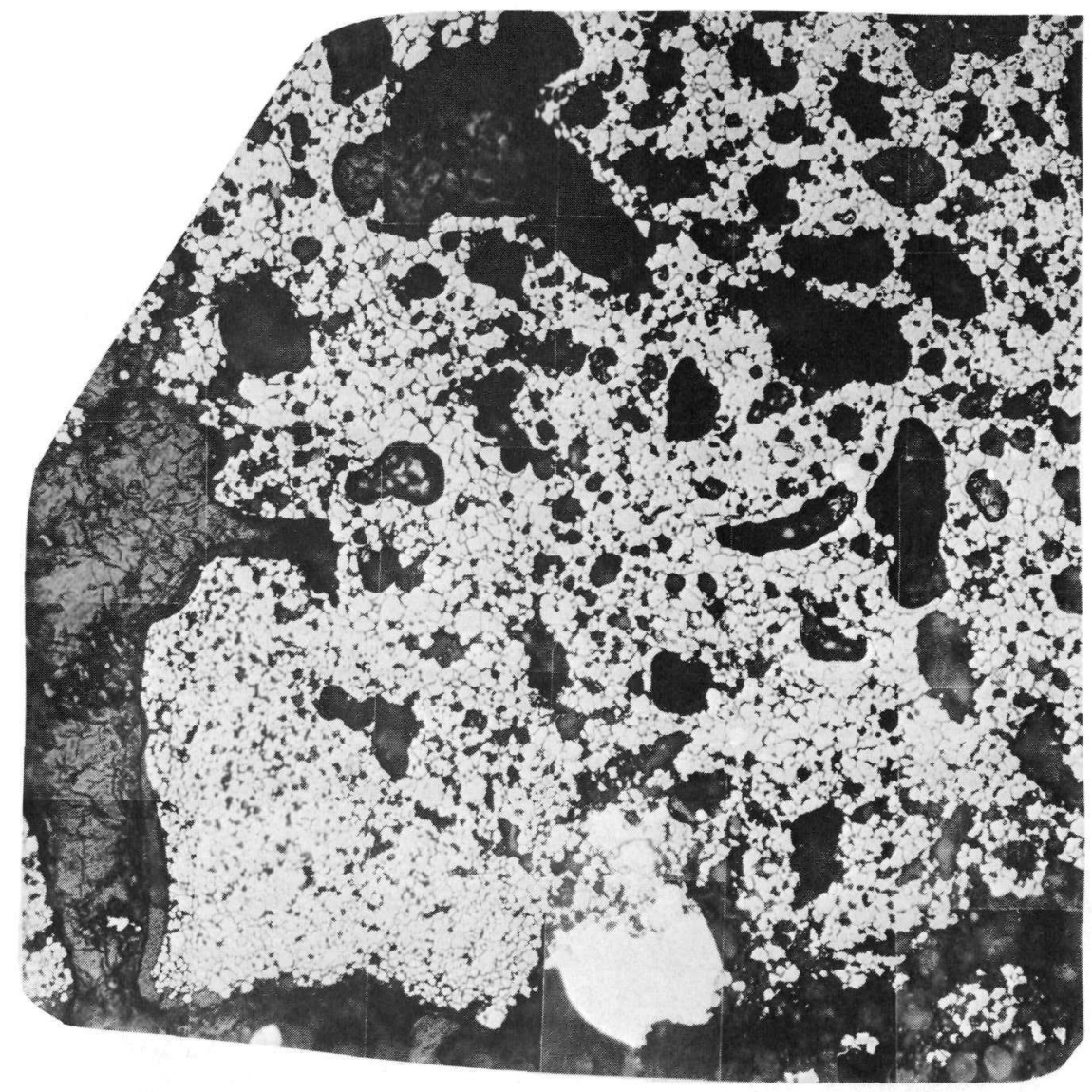

$200 \mu \mathrm{m}$

Fig. 44. Melted Fuel. Neg. No. MSD-187027. 


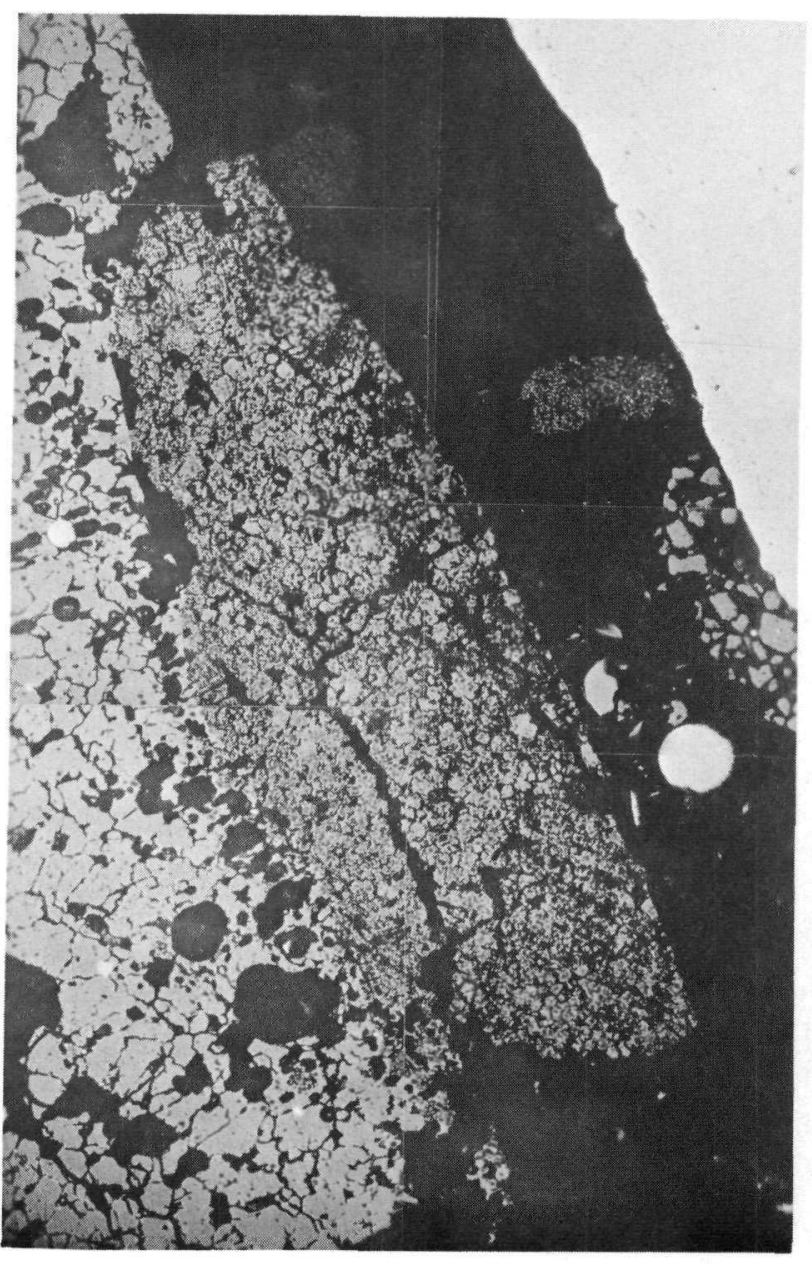

$100 \mu \mathrm{m}$

Fig. 45. Melting of Bubble-precipitated Fuel. Neg. No. MSD-187163.

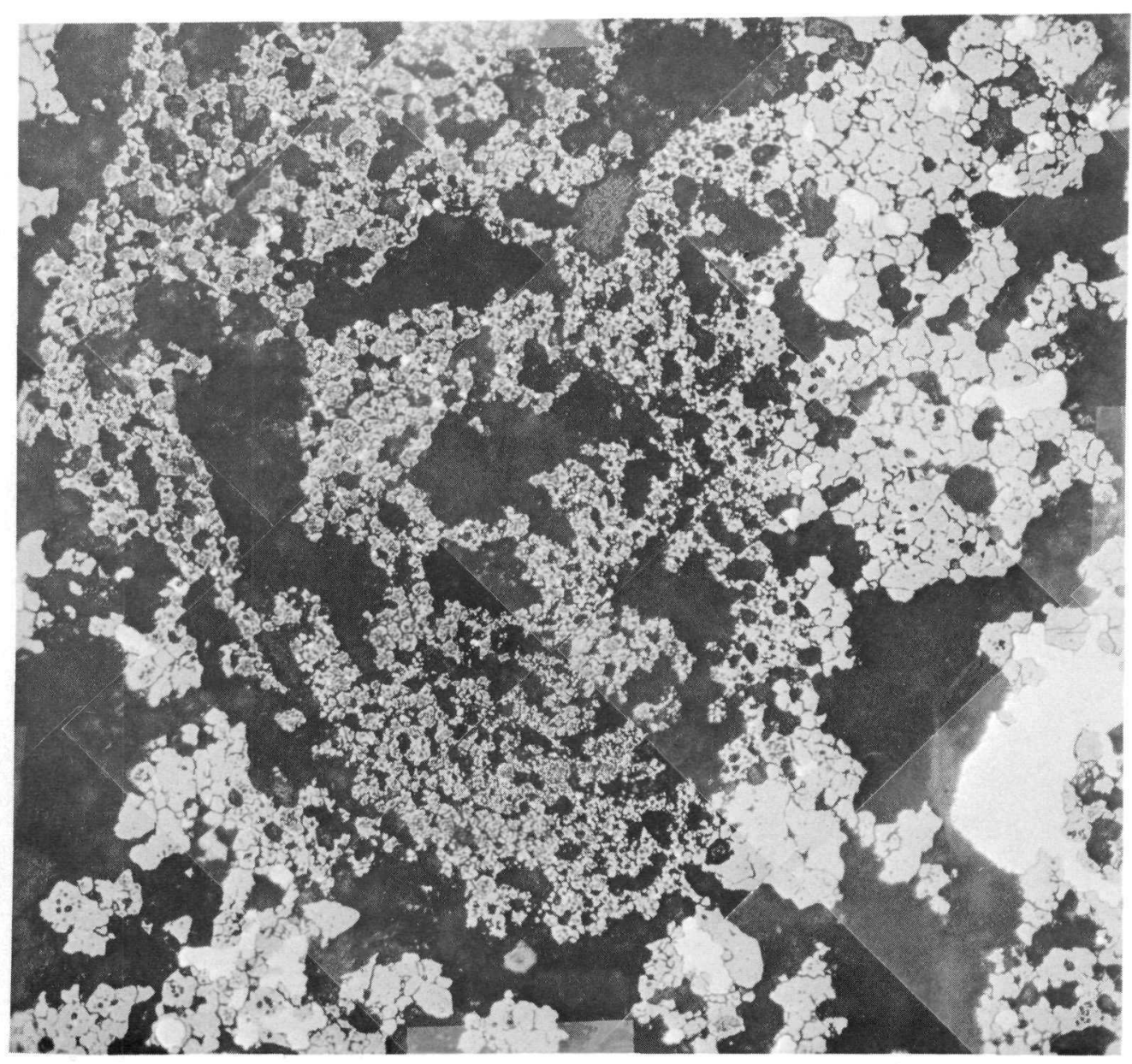

$100 \mu \mathrm{m}$

Fig. 46. Melting of Spongy Fuel. Neg. No. MSD-188978. 
and gas content, and on the local thermal history during the transient. The melting of spongy fuel, i.e., the condition shown in Fig. 46, predominated in L5. Therefore, as a result of sponge formation, large amounts of gas were probably released before melting. In contrast, the bubble-precipitated structure retained much of its fission-gas burden in the interval up to melting; this gas, released upon melting, formed a line of bubbles along the boundary of the melt zone, as shown in Fig. 45.

The microstructures exhibited by once-molten fuel are so complex as to make it impossible to determine unambiguously whether melted fuel has been heated above the liquidus or to the temperature regime between the solidus and liquidus. There is, however, a marked difference between the melted-fuel microstructures of $\mathrm{L} 5$ and those observed in the posttest remains of experiments such as $F 1$ and F2. The grain size of once-molten fuel is smaller, and the pore volume fraction is larger in L5 than that observed in Fl or F2. In addition, portions of the fuel in Fl and F2 showed a dendritic solidification structure not observed for L5. This comparison of the microstructures indicates that if any of the L5 fuel was heated above the liquidus, the time interval was too short to permit the percolation of significant amounts of gas out of the liquid fuel. As a result, the dense masses of solidified fuel characteristic of F1 and F2 never formed in L5.

Most of the melted fuel in $L 5$ may never have reached the liquidus. The relatively high viscosity of a partially molten state would have slowed the motion of gas bubbles and helped retain the bubbled-up state shown in Fig. 44. A partially molten state is also consistent with the small grain size of the L5 structure compared to the grain sizes characteristic of Fl and F2. To summarize, the $L 5$ posttest melted-fuel microstructures are representative of fuel that was either held below the liquidus or heated above the liquidus only for a relatively short time.

The axial variation of the amount of each of the microstructural types is presented in Table VIII and Fig. 47. At each axial position the amounts are expressed as fractions of the total fuel concentration at that level. As a result, the sum of the fractional amounts of the four fuel types is equal to one at every axial position. The data were obtained by performing systematic point counts on $15 X$ composite photomicrographs. A few regions on the sections examined had microstructures corresponding to transition states between as-irradiated and bubble-precipitated, or between precipitated and spongy structures. When these regions were selected by the random sampling process of the point count, an arbitrary decision was made to assign the area sampled to one of the microstructural classes. The maximum error attributable to such decisions is small compared to the uncertainty associated with the point-counting procedure. The coefficients of variation for the values in Fig. 47 ranged from 0.02 to 0.05 . 

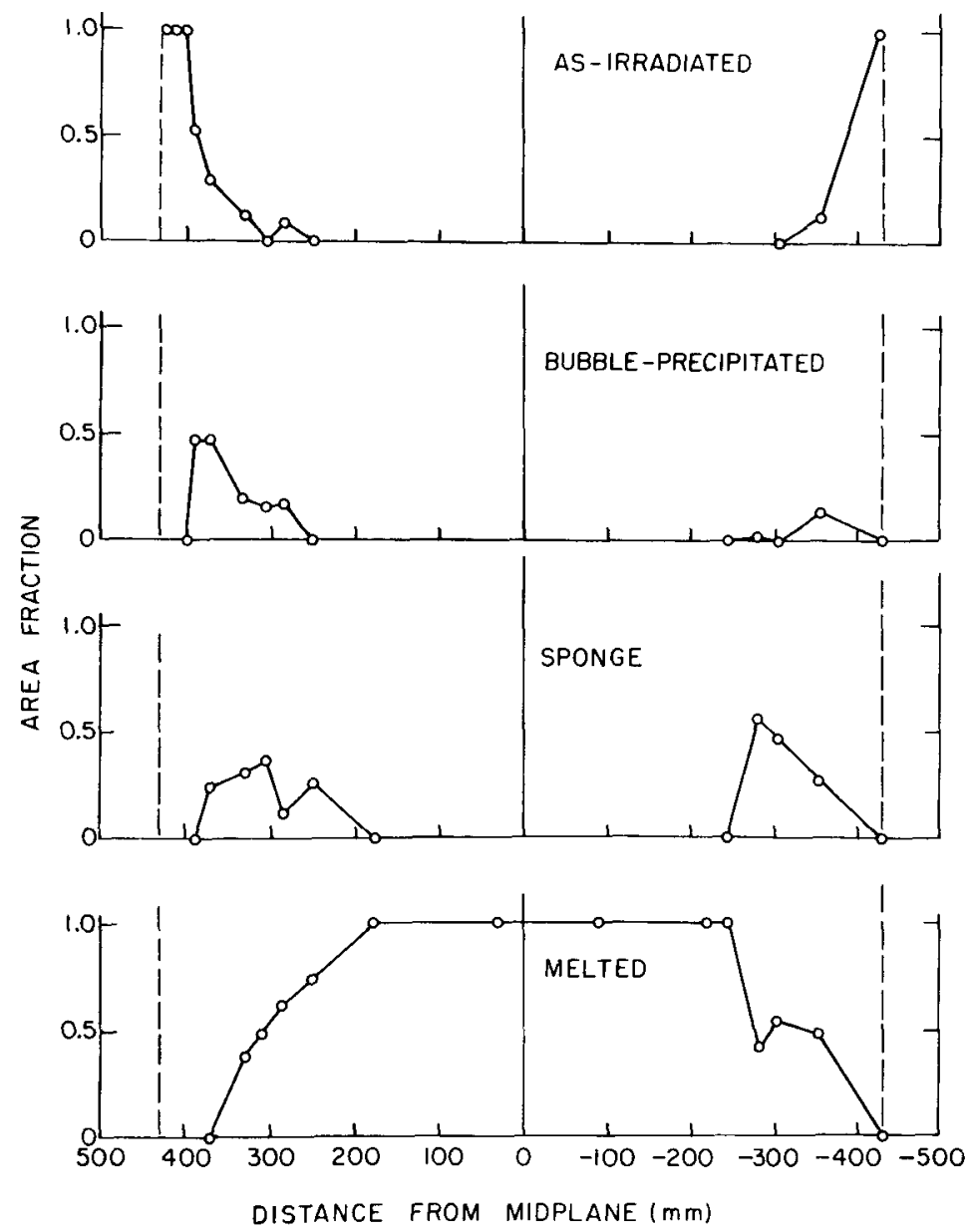

Fig. 47. Axial Profile of Four Microstructural Types of Fuel. Neg. No. MSD-64012.

In the top $30 \mathrm{~mm}$ of the fuel column, all the fuel has the as ir radiated structure. Below $+400 \mathrm{~mm}$, the relative amount of as-irradiated fuel decreases and goes to zero at $+250 \mathrm{~mm}$. In the upper half of the fuel column, the amounts of bubble-precipitated and spongy fuel reach maximum values near +375 and $+305 \mathrm{~mm}$, respectively. At its maximum extent, the bubble-precipitated structure accounts for $44 \%$ of the total fuel, while the spongy fuel reaches a maximum of $36 \%$ of the total. Melted fuel was first observed at $+330 \mathrm{~mm}$; the relative amount of melted material increased steadily with decreasing separation from the midplane, until it reached $100 \%$ of the total at $+175 \mathrm{~mm}$. Between +275 and $-245 \mathrm{~mm}$, all the fue 1 melted. In the bottom portion of the fuel column, the relative amounts of the various types of fuel exhibited a pattern that was an approximate mirror image of the behavior in the top half. Fewer sections were examined in the bottom portion, however, so that there is considerable uncertainty as to the positions and values of the maxima in the bubble-precipitated and sponge values.

When considered as a whole, the axial variation of fuel microstructure shown in Fig. 47 is a strong confirmation of the earlier description 
of microstructural evolution during the transient. The argument is as follows. At the top of the fuel column, where fuel temperatures during the transient were lowest, the details of the microstructure were unaltered from the pretransient condition. At lower levels in the fuel column, corresponding to higher transient temperatures, the amount of unaffected fuel decreased, as transient heating effects in the form of intragranular bubble precipitation were observed. At levels where the spongy structure first appeared, the amount of bubble-precipitated fuel was determined by several competing effects. Additional bubble-precipitated material is formed from as-irradiated fuel; existing bubble-precipitated material is consumed by the formation of sponge and by melting. As the distance to the midplane decreased and transient temperatures increased, the sponge formation and melting processes began to dominate. As a result, the relative amount of bubble-precipitated fuel went through a maximum and then decreased. By an analogous argument, the maximum in the spongy fuel profile can be explained as an effect of a competition between sponge formation from bubble-precipitated fuel and sponge destruction by melting.

The preceding explanation of the axial variation in fuel microstructure does not allow for the mixing of fuel microstructures due to axial fuel motion. It is significant, therefore, that the two regions in which the microstructural variation departs from the pattern predicted by the axial temperature distribution are coincident with major fuel surpluses due to axial fuel motion, as seen in Fig. 36. The pattern is disrupted in the region between +300 and $+250 \mathrm{~mm}$ and between -250 and $-300 \mathrm{~mm}$. In the former region, the sponge fraction is anomalously low and the as-irradiated and bubble-precipitated fractions are high; in the latter region, the melt fraction shows a local maximum. These results indicate that the axial profile of microstructural makeup is a function of both the temperature distribution and fuel-motion effects.

E. Discussion of Results

\section{Evolution of Microstructure}

For any process involving the evolution of structure, the path of microstructural change (PMC) may be defined as the sequence of microstructural states through which a system passes as the process occurs. The fuel in Test L5 experienced several PMC's because of the variety of initial microstructural states and transient thermal conditions. Originally unrestructured fuel was observed to evolve by two PMC's. In the first of these, as-irradiated fuel transformed by intragranular-bubble precipitation; the bubble-precipitated material then swelled intergranularly to form the sponge structure; finally, the spongy material melted. This sequence may be abbreviated by as ir radiated $\rightarrow$ bubble-precipitated $\rightarrow$ spongy $\rightarrow$ molten, or AI $\rightarrow$ BP $\rightarrow S \rightarrow M$. 
In the second PMC observed for originally unrestructured material, the sponge structure did not develop; i.e., the PMC AI $\rightarrow$ BP $\rightarrow$ M occurred. Originally equiaxed fuel transformed by three PMC's: (1) $\mathrm{AI}^{\prime} \rightarrow \mathrm{BP}^{\prime} \rightarrow \mathrm{S}^{\prime} \rightarrow \mathrm{M}$; (2) $\mathrm{AI}^{\prime} \rightarrow \mathrm{BP}^{\prime} \rightarrow \mathrm{M}$; (3) $\mathrm{AI}^{\prime} \rightarrow \mathrm{M}$. Primes are used for the unmelted structures to indicate that the PMC depends on the pretransient microstructure. Primes are omitted from molten fuel (M) because the precursor state could not be distinguished for the melted fuel observed in the test remains.

Since all the originally columnar-grained fuel melted during the transient, direct evidence of the PMC for this material was not available. However, because of its low gas content, the columnar-grained material probably transformed by the PMC AI" $\rightarrow$ M.

It is not possible to determine whether the PMC's inferred from the posttest examination results occurred during the TREAT power pulse or after scram.

The variety of microstructures observed in L5 was present in some of the other TREAT tests. Since the RAS-TREAT experiments are usually not designed to study only the phenomena surrounding fuel-element failure and the early stages of fuel motion, the tests are usually carried beyond the fuel-melting stage, and little of the as-irradiated structure or potential intermediate structures (e.g., bubble-precipitated or spongy) remains.

A review of the posttest microstructures from several prior TREAT experiments yielded several examples of the structural types observed in L5. The H4 and Fl test remains contained small amounts of fuel with a spongy structure. This structure may also have been produced in Test E8. The micrographs from Tests H5, E6, and Fl show regions that exhibit the bubble-precipitated structure. The structures in the E6 test remains indicate that the $\mathrm{PMC} \mathrm{AI} \rightarrow \mathrm{BP} \rightarrow \mathrm{M}$ occurred in this test. In addition, the test remains of the HOP 3-3C/3-3A transient ${ }^{6}$ contained fuel that exhibited the bubble-precipitated structure as well as grain-boundary fissuring similar to that shown in Fig. 42. In none of these experiments were the intermediate structures as prominent as in L5, however. It is not clear whether the large amounts of bubble-precipitated and spongy fuel observed in the L5 test remains are due to the large quantity of unmelted fuel in this experiment or to differences in fuel behavior between L5 and the other TREAT tests.

A potentially important mechanism for gas release was observed in the L5 test remains. The mechanism, a result of which is illustrated in Fig. 4le, consists of the interlinkage and venting to the grain surface of intragranular bubbles. The lattice diffusion distance for gas atoms released in this manner can be significantly less than in mechanisms that require the diffusion of gas atoms to the grain boundaries. 
The large grains with an outer band of gas bubbles (see Figs. 4lc and $4 \mathrm{ld}$ ) are apparently unique to Test L5. However, grains of similar size (but without intragranular bubbles) were observed in the unrestructured zones of the PNL-59 fuel. This observation suggests that the grains may have been formed during fuel fabrication, possibly as a result of plutonium inhomogeneity.

\section{Sequence of Transient Events: Early Stages}

Test L5 was designed so that melting of the cladding and spacer wires and formation of the upper and lower flow blockages would precede appreciable fuel motion. This sequence was predicted by the SAS computer calculations discussed in Section VII and is supported by indirect evidence from the posttest examination. The most important evidence is that no motion of fuel to positions above the upper blockage occurred. In addition, the appearance of the upper and lower flow blockages is similar to several of the R-series experiments in which cladding melting and draining and blockage formation are known to have preceded fuel motion. In particular, the thick mass of steel that formed the L5 lower blockage resembles the lower blockage in R $4 .^{7}$

Once the cladding had melted and began to drain, motion of the fuel external to the fuel-element dimensions was possible. The initial fuel motion almost certainly consisted of the localized crumbling of an unrestrained pellet stack into chunks of fuel, as shown in Figs. 30 and 31 . As a result of the irradiation in GETR, the individual fuel pellets were probably already broken into a number of smaller pieces. Once the radial restraint of the cladding was removed, these pieces were able to move around. Both radial and rotational displacements of the fragments were observed. The time at which motion of the fragments occurred was variable. The fragments shown in Fig. 31 probably did not move until swelling and melting of the other portions of the fuel pellets occurred. At the higher levels along the fuel-column height, the evidence suggests that motion of individual fragments preceded swelling or occurred at levels where gross swelling was not observed. Considerable motion of the fragments in the very top of the fuel column may have occurred during the posttest handling. Some motion must have occurred during the test, however.

Breakup of fuel into chunks was observed at all axial positions above about $+250 \mathrm{~mm}$ and below $-280 \mathrm{~mm}$. It was not possible to determine whether chunk breakup occurred between these levels because the fuel melted in this region. Because the L5 test fuel contained a fresh set of shutdown cracks at the time of the transient, the chunk-breakup phenomenon may have occurred to a greater extent than would be expected during an accident in an operating reactor. 


\section{Sequence of Transient Events: Later Stages}

The onset of microstructural evolution occurred in the same time interval as the motion of fuel chunks, as evidenced by the orientation of fuel chunks with respect to the assumed local temperature profile. In some regions, solid fuel chunks that had moved to contact masses of molten fuel showed preferential swelling on the side nearest the molten fuel, an apparent implication that motion of the chunk preceded microstructural change. In other sections, chunks of fuel that were originally part of a single pellet and showed comparable patterns of microstructural evolution had moved apart from one another. The close similarity in the microstructure of these chunks strongly suggests that the structural changes occurred before the observed displacements.

The PMC followed in any region of the fuel column was largely determined by the retained fission-gas burden and the local rate of temperature increase. In general, the solid-state swelling processes are favored by a high gas burden and low temperature ramp rates. At high ramp rates, the PMC can be terminated by melting before significant solid-state swelling occurs. Therefore, in the highest power region of the test section from about +60 to $-130 \mathrm{~mm}$, where the ramp rate was highest, the amount of solid-state swelling was probably smaller than at any other axial elevation. Although there apparently was an inverse relationship between the TREAT power level and the amount of microstructural evolution before melting, we could not determine how much swelling and gas release preceded melting and the consequent release of the remaining gas.

Once the gas was released by melting, sponge formation, or venting of multiply connected intragranular tunnels, the gas was available to produce axial fuel motion. Fuel temperatures were low enough to rule out vapor pressure as a driving force; steel vapor pressure may have been important, but its effect could not be assessed from the posttest examination. The fuel from the highest-power region was probably liquid when motion occurred. Near the ends of the fuel column, where chunk breakup occurred, the motion of at least some of the chunks preceded melting. The posttest examination did not provide a conclusive answer as to whether the fuel from intermediate-power regions (from about +60 to $-200 \mathrm{~mm}$ and from about -130 to $-250 \mathrm{~mm}$ ) was liquid or solid when axial motion occurred.

The pressure supplied by released fission gas was uniform in all directions and therefore could force fuel to move both axially and laterally. The fact that minor amounts of fuel were observed outside the flow tube indicates that the flow tube must have been intact to restrain lateral motion during the major fuel-motion events. Therefore, the large holes observed in the flow tube, such as the holes shown in Fig. 27, must have been formed after the bulk of the axial fuel motion ceased. The minor deposits of fuel and steel against the intermediate tube are probably the result of secondary fuel-motion events. 
The melting of the fluted tube extracted enough heat from the fuel to solidfy large portions of the fuel column. This phenomenon helped fix the axial distribution of fuel and thus aided the interpretation of the posttest examination results.

The axial fuel motion is believed to be responsible for disrupting the pattern of microstructural evolution that is otherwise explainable on the basis of the axial temperature profile, as indicated in the discussion of Fig. 47. It is not possible to state with certainty the specific mechanisms that acted to produce the observed disruption. Several potential mechanisms may be outlined, however. The unpredicted variation in microstructural makeup may be due to turbulent mixing of microconstituents caused by escaping gases and moving fuel. This effect may have been augmented by the heat transfer from melted fuel moving axially to cause microstructural evolution in fuel that might otherwise not have been transformed.

\section{Suggestions for Future Study}

Test L5 is a particularly good example of the wide variety of microstructural transitions that can occur in fuel-motion experiments. Information that might be of additional usefulness to the understanding of fuelmotion behavior is contained in the test remains, but was not extracted during the present posttest examination. Additional characterizations that would be helpful to modelers include determination of bubble-size distributions for the various microstructures, careful measurements of the contribution of intragranular bubble precipitation to fuel swelling, and fission-gas analysis by laser sampling. Microprobe studies of the volatile fission-product distribution and of the unique, large unrestructured grains should also be considered. Finally, the interpretation of some of the observations of posttest examination would be aided when the examination of fuel elements with irradiation histories similar to the L5 test elements is completed.

F. Summary and Conclusions from the Postmortem Examinations

1. The flow channel was completely blocked with cladding material just above the fuel-column top and above the fuel-column bottom. The melting and axial motion of the claddings and spacer wires preceded the evolution of fuel microstructure and fuel motion. The claddings were completely destroyed between the positions of the blockages. Steel from the cladding and spacerwire was also found as a coating on the inner surfaces of the fluted tube, mixed with melted portions of the fluted tube, and as isolated particles entrained in the fuel.

2. A chunk-breakup mode of fuel-pin disruption occurred near the ends of the fuel column. The chunks separated along the preexisting system of startup and shutdown cracks. 
3. Fuel moved axially out of the central portion of the fuel column, and collected in regions that extended from about +120 to $+320 \mathrm{~mm}$ and from about -150 to $-370 \mathrm{~mm}$. The axially moving fuel stripped liquid steel particles from the walls of the fluted tube, and produced the mixtures of microstructurally diverse fuel masses and steel particles observed in the regions that contained fuel surpluses.

The formation of the lower cladding blockage produced an upward displacement of most of the fuel originally in this region. This example of motion toward the midplane contrasts with the general trend of motion away from the midplane observed in the posttest remains. Axial fuel motion to positions outside the original fuel column was not observed.

4. With a few exceptions, lateral fuel motion was confined to positions within the fluted tube. Most of the extensive meltthroughs of the fluted tube were formed after the major pressure-driven fuel-motion events had ended.

5. The evolution of fuel microstructure took place concurrently with chunk breakup and fuel motion. Three types of microstructure, called the asirradiated, bubble-precipitated, and sponge structures, were generated by gradual processes that did not involve fuel melting. The evolutionary sequence of microstructural change was terminated by fuel melting at a stage that depended on the local thermal history. The axial concentration profiles for each microstructural class were explainable on the basis of the maximum transient temperature profile, except in the regions in which surpluses and the mixing of fuel with differing mic rostructures were observed.

The bubble-precipitated and sponge structures are examples of the solid-state swelling processes that occurred as a result of the transient. The coalescence of intragranular bubbles of the bubble-precipitated structure did not produce large amounts of volume swelling. However, volume increases above $100 \%$ were observed as a result of the intergranular swelling that led to the sponge structures. 


\section{THERMAL-HYDRAULIC ANALYSIS}

A. Introduction

Since no test instrumentation was located within the fuel-element bundle, the thermal and hydraulic conditions within the bundle had to be estimated through calculations. Most of the calculations for this test were performed with the SAS3A computer code ${ }^{2}$ by using experimentally measured parameters such as sodium flow rate, reactor power, and axial and radial power distributions.

B. Description of SAS3A Computer Code and Accuracy of Its Calculations

The SAS3A code, a product of the SAS-series computer codes, is an integrated accident-analysis code that calculates the initial consequences of an accident from steady-state, preaccident conditions up to the point of largescale fuel motion or disassembly. The code performs a steady-state thermalhydraulic calculation to initialize the fuel temperatures, fuel and cladding thermal expansions, and the coolant temperatures, pressures, and flow rates. The code then calculates transient temperatures in fuel, cladding, and coolant consistent with user-specified perturbations in power level and flow rate. Transient stresses and strains in the fuel and cladding, and transient coolant pressures and flow rates are also calculated, as well as sodium boiling, film dryout, cladding melting, and fuel melting. Neutron kinetics is handled with a point-kinetics approximation, with reactivity feedback from the Doppler effect, fuel thermal expansion, sodium voiding, fuel slumping, and scram reactivity, as well as user-specified programmed reactivity.

SAS3A handles up to 10 channels, each channel representing a large group of similar fuel elements and associated coolant. The multichannel treatment allows for variations in element power, coolant flow rate, and irradiation across the reactor core.

The multibubble slug-ejection coolant-voiding model in SAS3A treats either boiling or voiding caused by the release of fission-product gas from failed fuel elements. Axial pressure gradients within vapor bubbles are treated. SAS3A includes models that allow an integral treatment of both transient-overpower and loss-of-flow accident sequences through fuel failure and subsequent core disruption.

The accuracy of SAS3A calculations depends upon many factors, including the accuracy of phenomenological models of the mechanisms involved. Uncertainties also exist in most test parameters, such as the space- and timedependent power input, thermal properties of fuel, and fuel-cladding gap conductance. The uncertainty in the power calibration factor for the test elements is about $\pm 10 \%$. Also, fuel-density changes and restructuring may alter the radial power distributions from the radial profiles determined experimentally with fresh fuel and create an additional uncertainty in the variation of thermal conductivity as a function of radius. 
There are also considerable uncertainties in the physical properties for fuel used in the computations. Properties of fuel above the solidus are largely based on theoretical extrapolations. Consequently, the properties of irradiated fuel were assumed to be the same as those for fresh fuel. Properties of molten fuel were assumed to be temperature-invariant and identical to properties at the solidus. The principal parameter for the model of fuelcladding gap conductance is the gap size between the fuel and cladding. The gap size depends upon thermal-expansion coefficients of the fuel and cladding and upon fission-gas-induced fuel swelling. The fuel-swelling phenomenon is poorly known, leading to potential errors in the computation of the gap conductance.

\section{Calculated Thermal History}

The input parameters for SAS3A calculations for L5 are given in Appendix E. The axial power profile of the fuel is from calibration test L5M 2.1 ; the radial power profile was based on the results from the core-drilled specimens in the same test. The TREAT reactor power profile and flow rate were based on Transient 1606 for Test L5-2.

To verify the consistency of the input parameters for the thermalhydraulic calculation ( $\mathrm{such}$ as a cold gap conductance of $0.283 \mathrm{~W} / \mathrm{cm}^{2} \cdot{ }^{\circ} \mathrm{C}$ ), a calculation was performed with the TREAT power profile and flow rates under the conditions for the heat-balance test for L5. Figure 48 shows the calculated and measured sodium-temperature difference between the midplane and the inlet and between the top of fuel and the inlet, as a function of time. The agreement between the measured data and the calculated results is within the uncertainty of the input parameters.
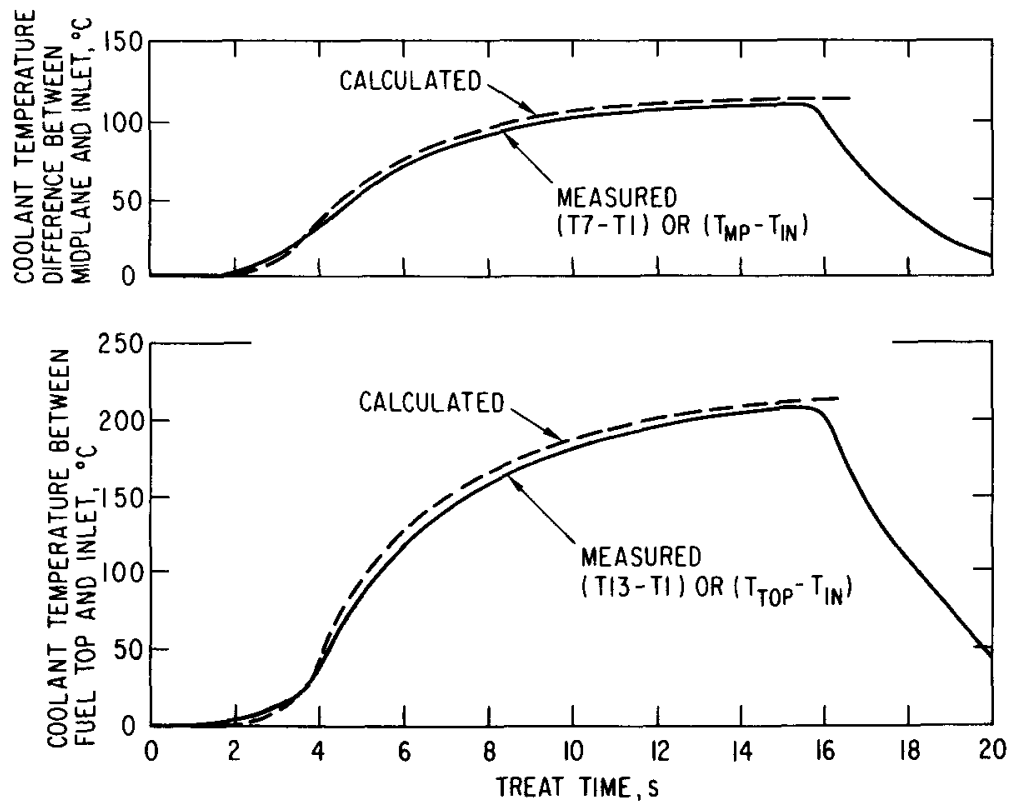

Fig. 48. Coolant-temperature Difference between Fuel Top and Inlet and between Fuel Midplane and Inlet 
The calculated results for the loss-of-flow Test L5-2 show that the first bubble was formed at $10.9 \mathrm{~s}$, using the TREAT clock time. Inlet flow reversal in the test section began at $11.0 \mathrm{~s}$. The cladding at $200 \mathrm{~mm}$ above the midplane of the fuel column began to melt at $11.9 \mathrm{~s}$. A $246-\mathrm{mm}-\mathrm{long} \mathrm{sec}-$ tion of cladding at $160 \mathrm{~mm}$ above the midplane was completely melted at $12.4 \mathrm{~s}$. Cladding motion then began. At $13.0 \mathrm{~s}$, the cladding in the fueled portion of the test elements was almost completely melted, and substantial move ment toward both ends occurred. This calculational result is in good qualitative agreement with observations from postmortem examination, which showed upper and lower molten-cladding blockages. The fuel began to melt at the midplane at $12.6 \mathrm{~s}$. At $13.1 \mathrm{~s}, 50 \%$ of the pellet cross section was at, or through, the heat of fusion. In the absence of a definitive microstructure based on a sibling examination, this 50 -areal percentage was considered the fuel-motion criterion for initiation of the SLUMPY calculations.

The calculated results are plotted in Figs. 49-57. Figure 49 shows the oscillation of the inlet and outlet flow subsequent to $10.8 \mathrm{~s}$ after reactor startup. Figure 50 shows the formation of sodium vapor. The vertically hatched area represents sodium voiding; the crosshatched area represents film dryout; the blank area represents the cladding melting. Figure 51 shows the temperatures of the coolant, cladding, and structure, and the molten fraction of the cladding near the axial center of the element. Figure 52 shows the molten fraction and temperatures of the centerline, mass average, and surface of the fuel near the axial center. Figure 53 shows the conditions of the cladding at the early stage of its motion. Figure 54 shows the cladding conditions at the beginning of fuel motion. Figure 55 shows the location and size of the upper and lower flow blockages at $13.48 \mathrm{~s}$. Figure 56 shows the fuel distribution at the beginning of fuel dispersing, and Fig. 57 shows the dispersing fuel at $13.56 \mathrm{~s}$, which is $0.46 \mathrm{~s}$ after the onset of its major axial motion. In Figures 56 and 57 , the density of the shade approximates the fuel density.

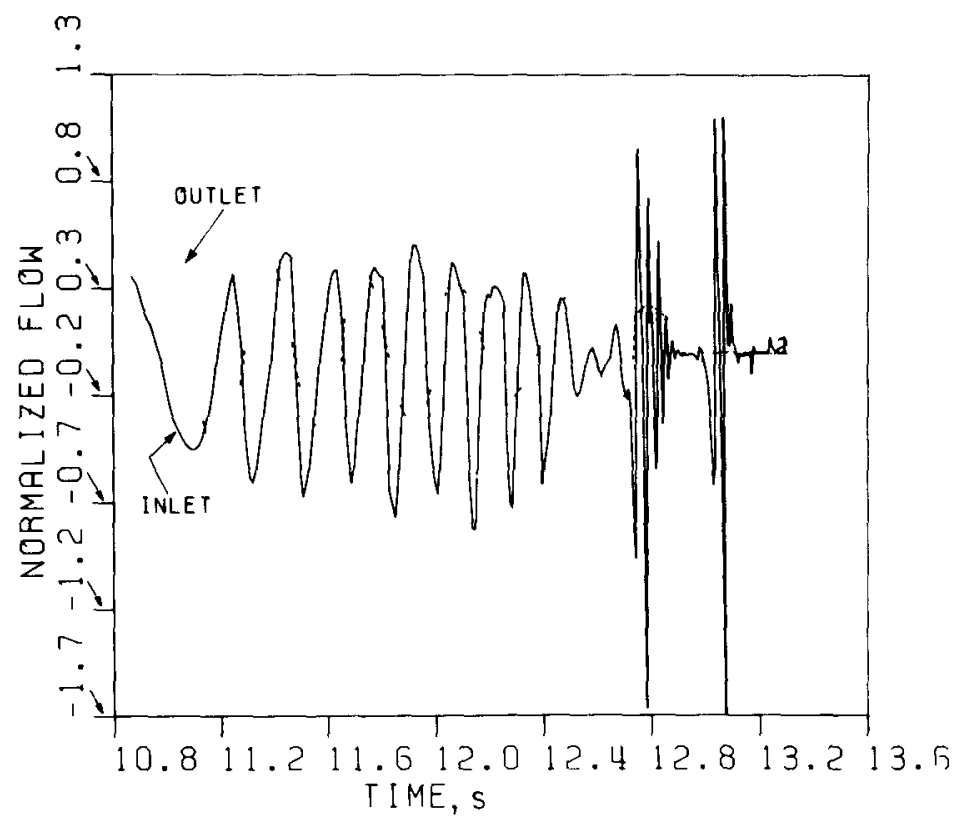

Fig. 49

Inlet and Outflow at Test Section TIME, S 


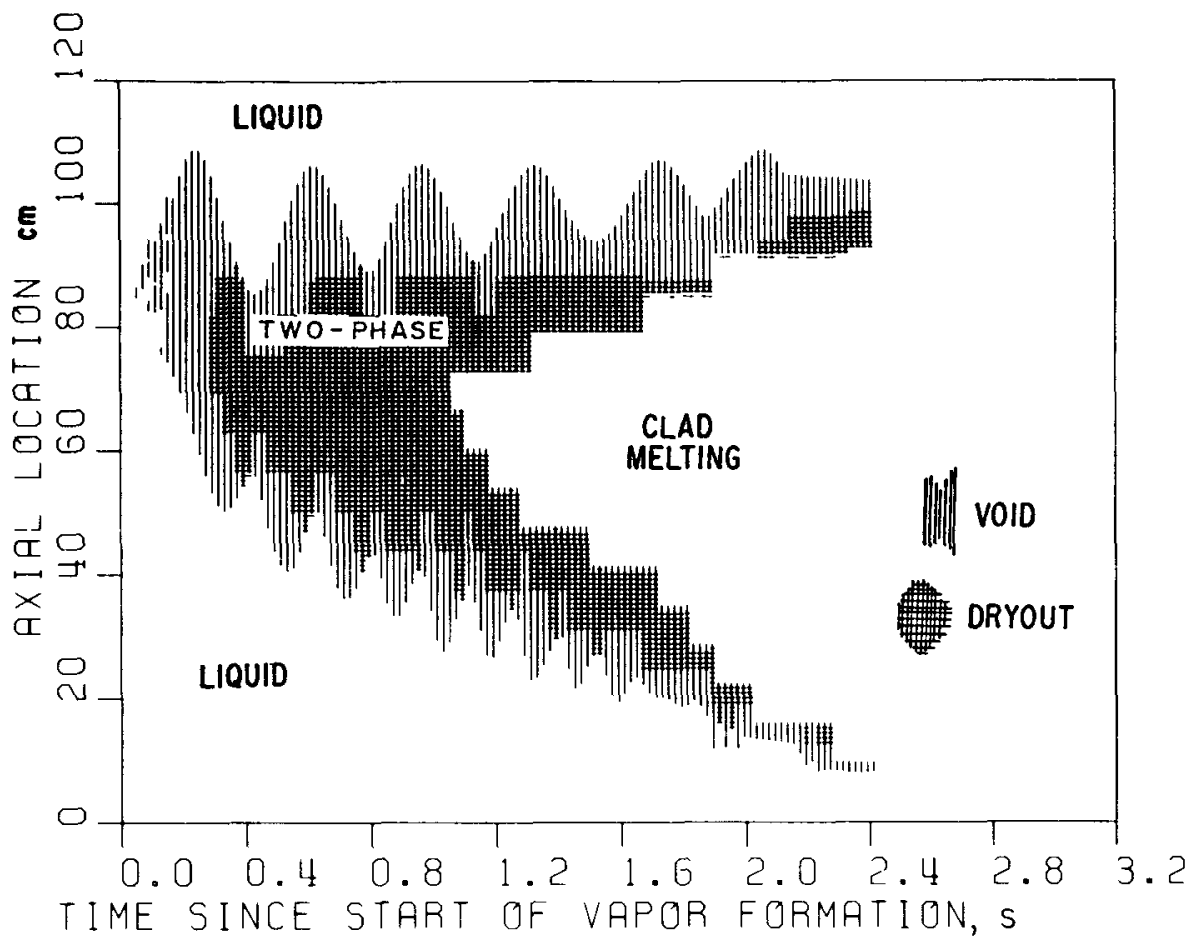

F1g. 50. Formation of Sodıum Vapor in Channel

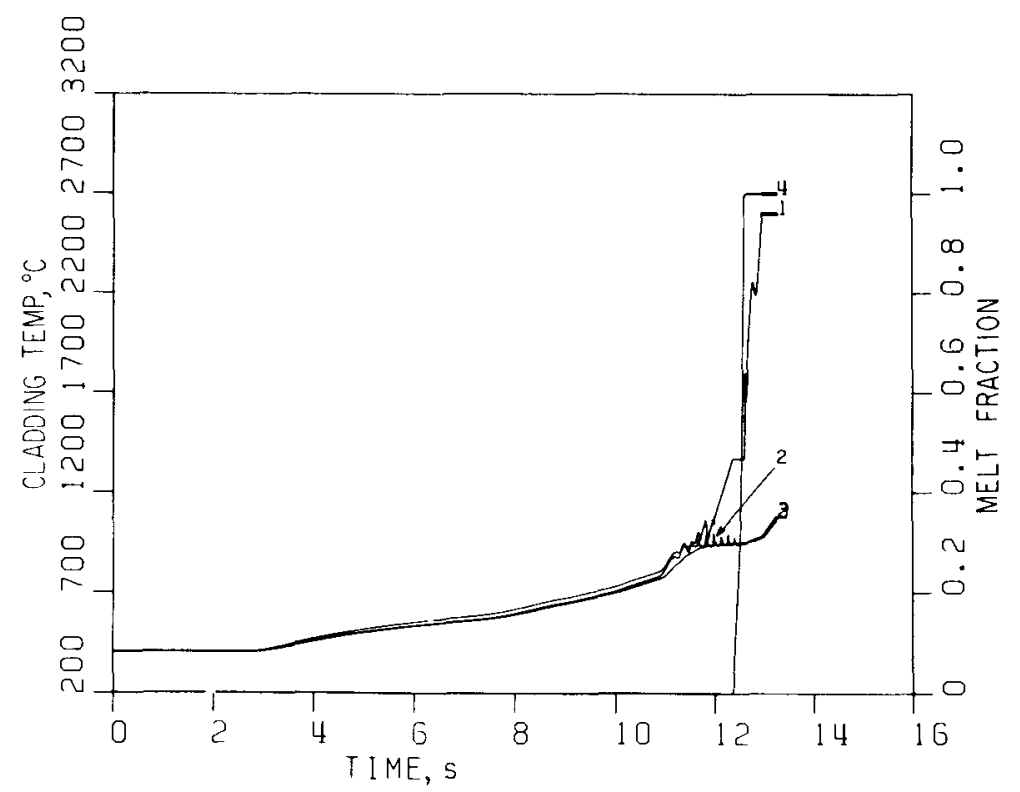

Fig. 51. Coolant, Cladding, and Structure Temperatures, and Molten Fraction of Cladding. 1 , clad; 2 , coolant; 3 , structure; 4 , molten fraction. 


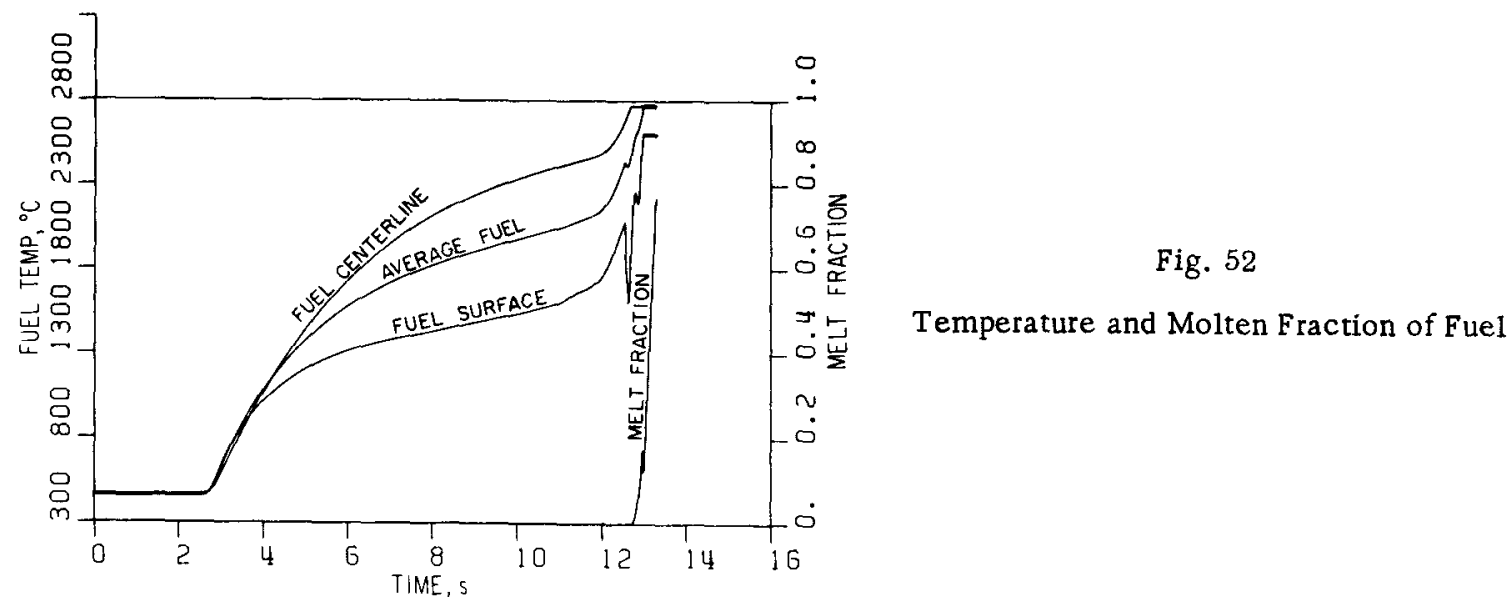

Fig. 53

Beginning of Cladding Motion

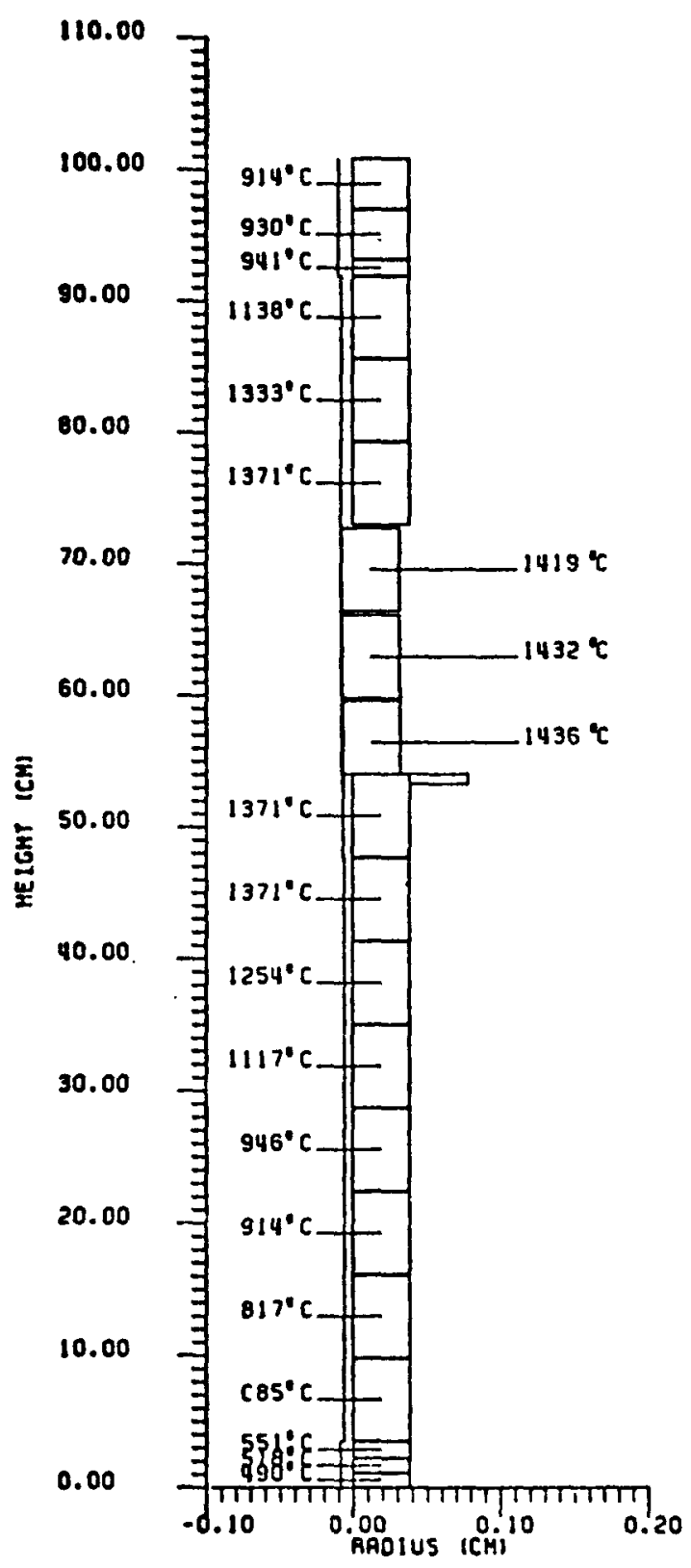




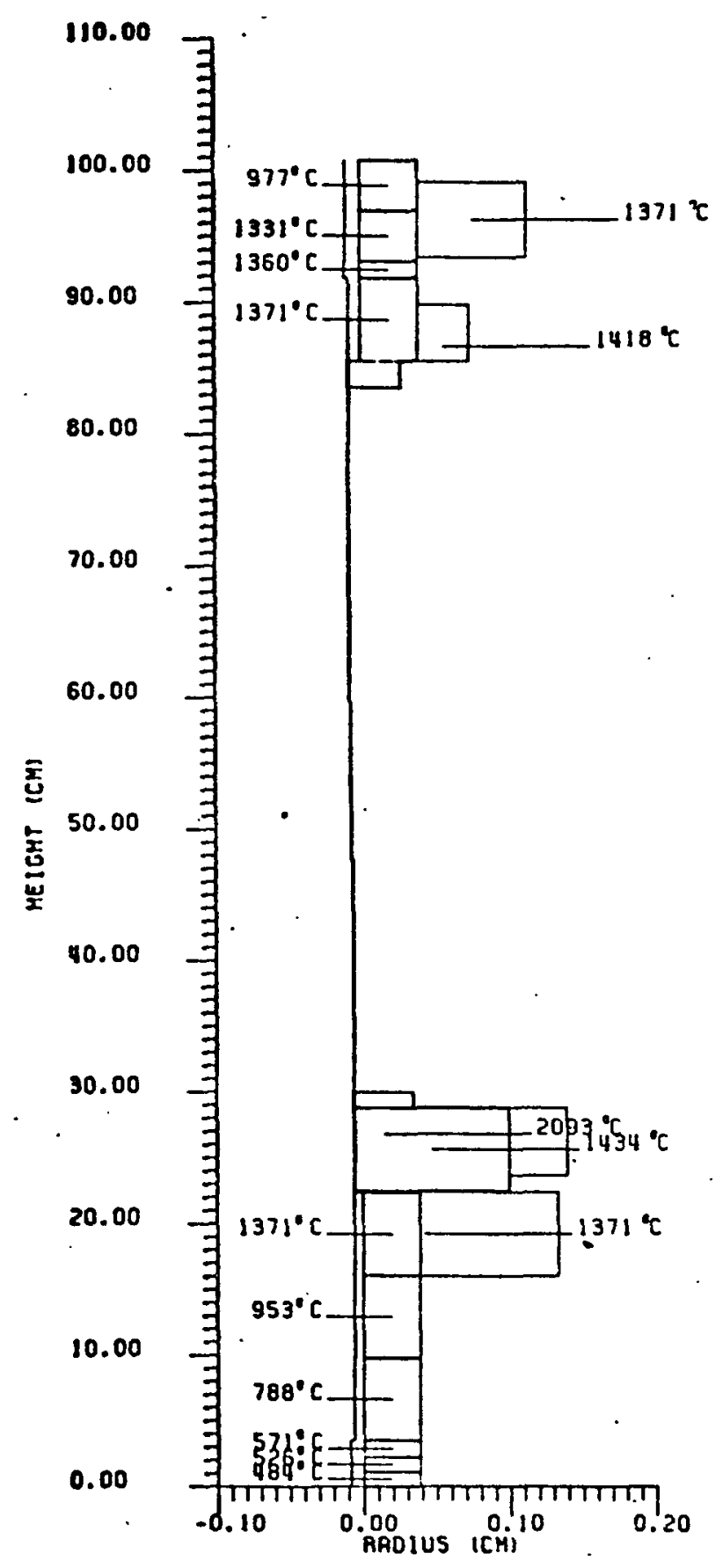

Fig. 54. Cladding Condition at Beginning of Dispersal of Fuel

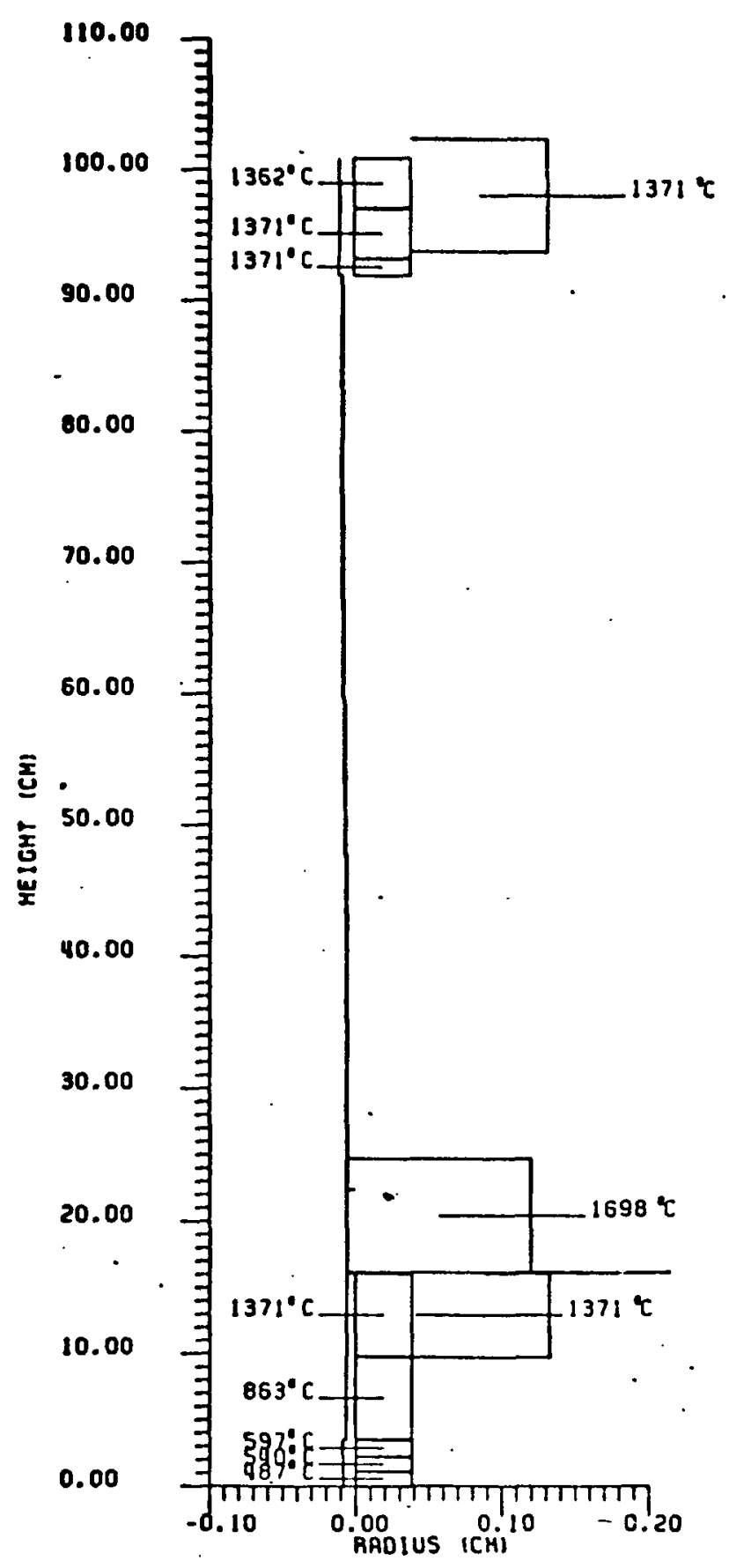

Fig. 55. Upper and Lower Blockages 


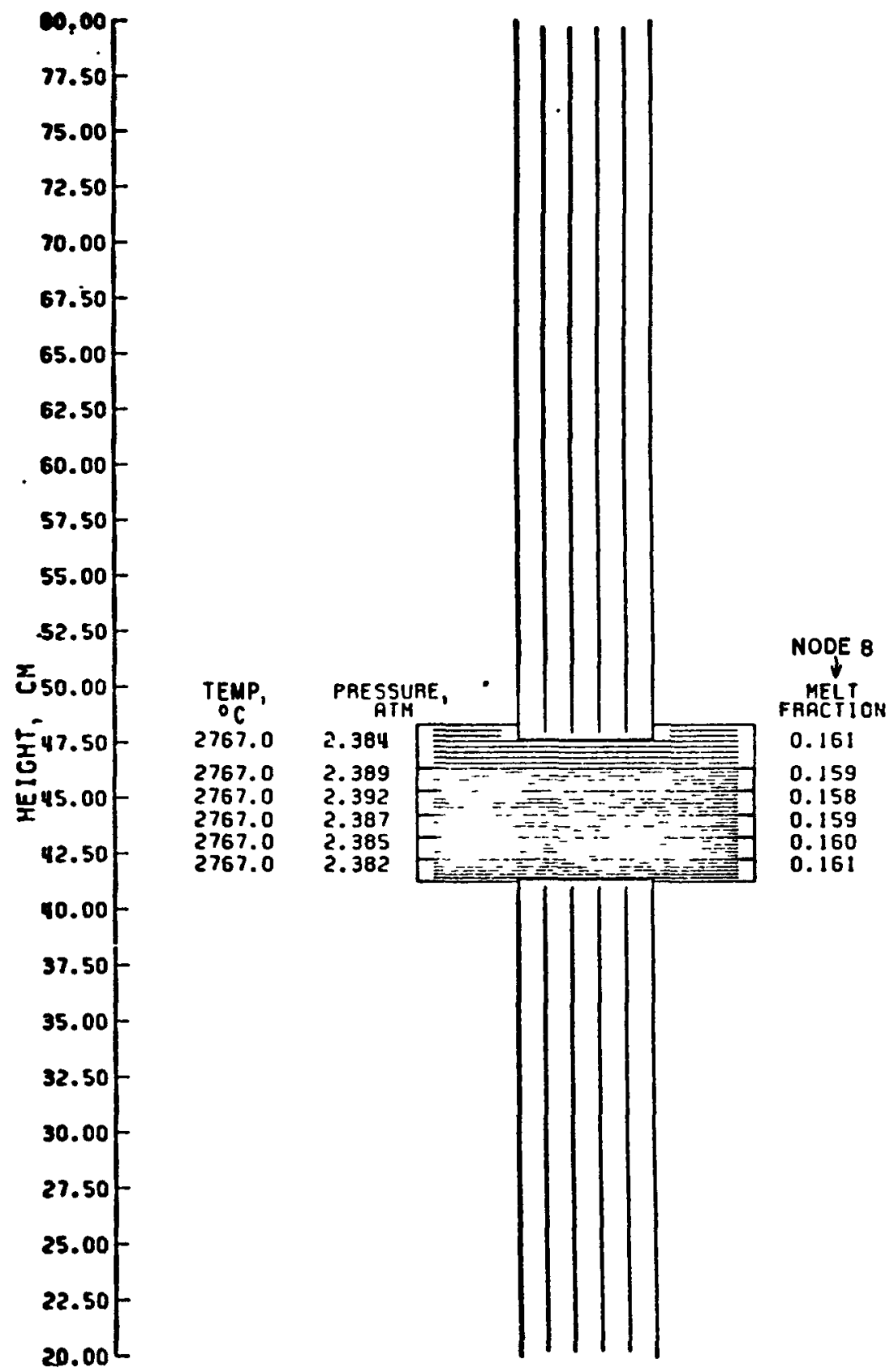

Fig. 56. Fuel Dispersal at $12.98 \mathrm{~s}$. Conversion factor: $1 \mathrm{~atm}=0.1 \mathrm{MPa}$. 


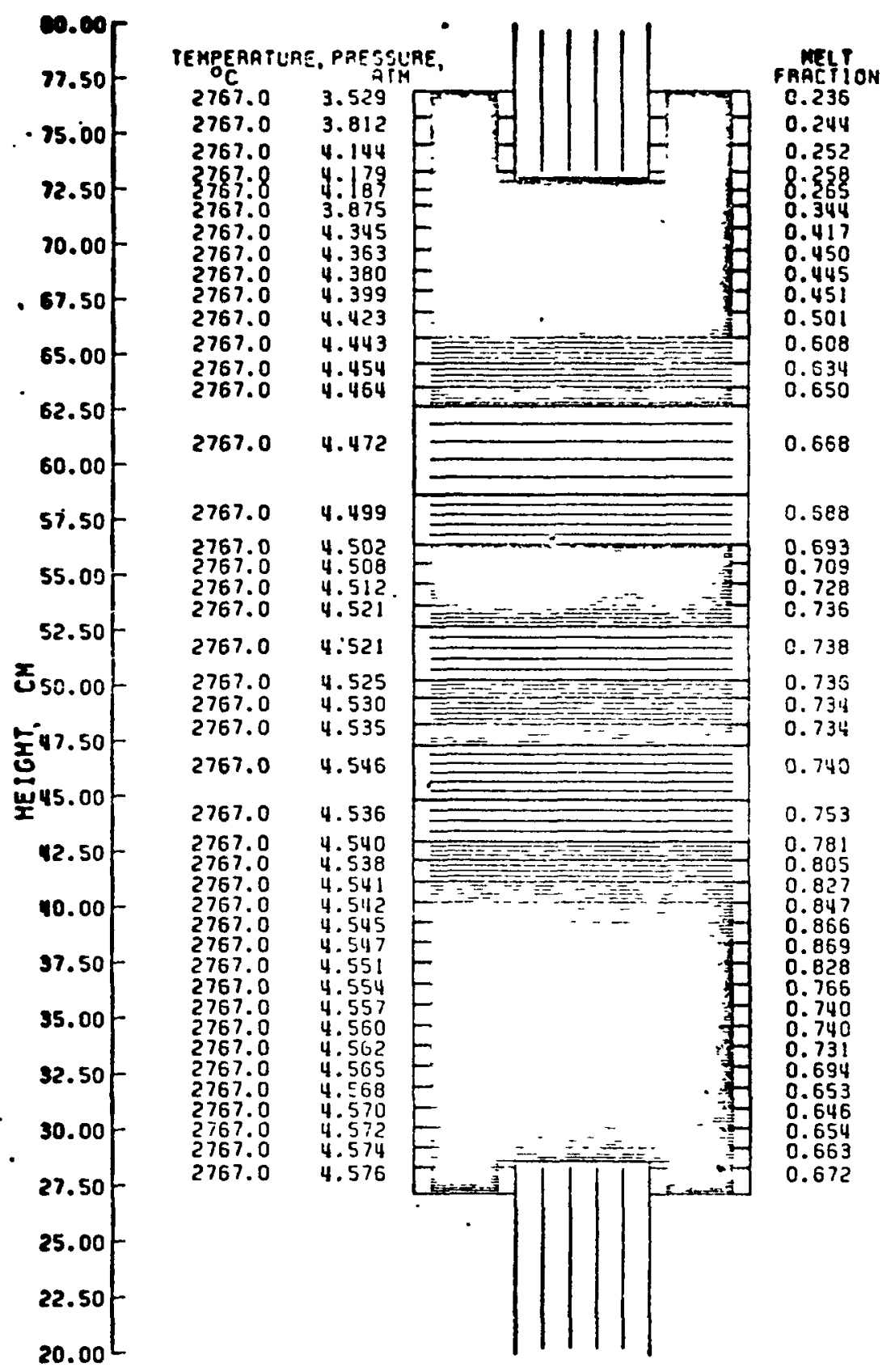

Fig. 57. Fuel Dispersal at End of Transient. Conversion factor: 1 atm $=0.1 \mathrm{MPa}$. 


\section{Concluding Remarks}

Although sodium-vapor streaming carried some molten cladding up ward, most of the calculated cladding movement was a downward drain. In contrast, the fuel segments were dispersed upward and downward in approximately equal proportions. The calculations show that the average axial fuel temperatures in the central portion of the fuel column reached temperatures in the range $3340-3490^{\circ} \mathrm{C}$, exceeding the liquidus temperature of $3300^{\circ} \mathrm{C}$. The maximum fuel temperature reached $3600^{\circ} \mathrm{C}$. Even at $3600^{\circ} \mathrm{C}$, the fuel vapor pressure is only about $0.25 \mathrm{MPa}(2.5 \mathrm{~atm})$. Such a low vapor pressure of fuel was probably not responsible for the observed fuel motion since the test re mains showed that the calculations were probably overestimating the energy retention in the fuel. The release of the fission gas retained in the fuel at the time of fuel motion must have been the mechanism that produced fuel motion in the test. The calculations also showed that the top and bottom $60 \mathrm{~mm}$ of fuel segment did not reach the fuel solidus temperature of $2767^{\circ} \mathrm{C}$ by the end of the transient, consistent with the postmortem results.

\section{SUMMARY AND CONCLUSIONS}

The results of the test observations with the loop instrumentation and fast-neutron hodoscope are compared with the SAS3A calculations in Table IX. Analysis of the hodoscope data showed that the onset of the major axial fuel motion occurred after scram. The net motion was dispersive, away from the midplane of the original fuel column. The SAS calculation indicates initiation of fuel motion at about $13.1 \mathrm{~s}$, about $0.25 \mathrm{~s}$ before the peak power and $\mathrm{scram}$, when a criterion for fuel motion of $50 \%$ areal melt fraction is used. The thermal calculation indicated that the top and bottom $60 \mathrm{~mm}$ of fuel would not have reached the solidus by the end of the transient. The calculation is therefore reasonably consistent with postmortem observations. The postmortem examinations found the fuel at the top of the fuel column in its as-irradiated state, an indication it had not exceeded its solidus temperature.

The calculations also indicated that the maximum fuel temperature in the fuel column did not exceed about $3600^{\circ} \mathrm{C}$. At this temperature, the fuel vapor pressure is only about $0.25 \mathrm{MPa}(2.5 \mathrm{~atm})$. Consequently, in accord with one of the original test goals, the fuel vapor pressure was probably not responsible for the observed fuel motion. Although the transient energy deposition was apparently within the desired pretest objectives, the fuel motion after scram was unexpected. This observation indicated that the fuel-motion criterion and/or the heat-transfer model probably did not accurately describe the actual sequence of test events. It was estimated that an additional $15 \%$ reduction in the power generation rate would be required before the $50 \%$ fuelmotion criterion (see Sec. VII.C) would be met at the time of reactor scram. A theory of extensive radial swelling when fuel reaches the solidus would explain some of the deviations and is consistent with postmortem observations for both L 5 and F1. 
TABLE IX. Sequence of Events in TREAT Loss-of-flow Test L5

\begin{tabular}{|c|c|c|c|}
\hline \multirow[b]{2}{*}{ Event } & \multicolumn{3}{|c|}{ Time, $\mathbf{s}$} \\
\hline & $\begin{array}{l}\text { Experiment } \\
\text { Sensors }\end{array}$ & $\begin{array}{l}\text { Fast-neutron } \\
\text { Hodoscope }\end{array}$ & $\begin{array}{c}\text { SAS } \\
\text { Calculations }^{a}\end{array}$ \\
\hline Reactor control program initiated & 0 & 0 & 0 \\
\hline $\begin{array}{l}\text { Reactor power reached } 42 \mathrm{MW} \\
(36 \mathrm{~kW} / \mathrm{m} \text { per element })\end{array}$ & 3.0 & - & 30 \\
\hline $\begin{array}{l}\text { Flow coastdown initiated } \\
\text { (flow initially } 170 \mathrm{~cm}^{3} / \mathrm{s} \text { ) }\end{array}$ & 7.0 & - & 7.0 \\
\hline $\begin{array}{l}\text { First indication of coolant-channel } \\
\text { voiding }\end{array}$ & 11.5 & - & 10.9 \\
\hline Flow reversal of test-section inlet & 11.6 & - & 11.0 \\
\hline $\begin{array}{l}\text { Power burst initiated at } 390-\mathrm{MJ} \\
\text { energy release }\end{array}$ & 11.8 & - & 11.8 \\
\hline Incipient cladding melting & - & - & $11.9^{\mathrm{b}}$ \\
\hline Flow coastdown ended (flow of $23 \mathrm{~cm}^{3} / \mathrm{s}$ ) & 12.0 & - & 12.0 \\
\hline Localized fuel motion observed & - & $121^{\mathrm{c}}$ & - \\
\hline Cladding melted & - & - & 12.4 \\
\hline Upper cladding blockage formed & $\mathrm{d}$ & - & 12.7 \\
\hline Beginning of fuel melting & - & - & 12.6 \\
\hline Peak power reached (240 MW) & 13.4 & - & 13.4 \\
\hline Onset of major axial fuel motion & - & 13.5 & $13.1^{\mathbf{e}}$ \\
\hline Reactor scram settıng $(600 \mathrm{MJ})$ & 13.4 & - & - \\
\hline
\end{tabular}

a Based on single-element model using cluster-averaged parameters.

b $200 \mathrm{~mm}$ above midplane of fuel column.

At about $125 \mathrm{~mm}$ above midplane of fuel column and also at $100 \mathrm{~mm}$ below midplane

${ }^{d}$ Sensor data showed no clear indication of the time a cladding blockage could have

formed.

e $50 \%$ a real melt fraction.

The observed fuel motion behavior at, or after, scram occurred when the power level was significantly below the level required to determine dispersive rates accurately. The se postscram observations were based on delayedneutron emissions for which counting statistics were low. To achieve an acceptable, statistically significant count rate required longer time intervals, so that only gross axial fuel relocation was observable. The hodoscope analysis was further complicated because the $500-\mathrm{mm}$ vertical view of the collimator missed a significant part of the fuel present in the test. Normalization of the hodoscope count rate to fuel quantities and their variations was therefore dependent on assumptions concerning the magnitude of the fuel moving into, and out from, the limited view a rea.

The key results from Test L 5 are summarized as follows:

1. Fuel underwent a mild dispersal at, or after, the scram. The dis persal rate was statistically indeterminant since the fuel motion began after scram.

2. The fuel motion was initiated in the absence of significant vapor pressure of fuel. 
3. Calculations based on the best available thermal parameters indicated that the onset of the fuel motion occurred well after the attainment of $50 \%$ areal melt fraction as defined in SAS. Inability of the calculation to de scribe extensive radial fuel swelling may be a shortcoming of the computation.

4. No fuel was found outside the region occupied by the original fuel column. A cladding blockage was observed in the postmortem examinations at both the inlet to, and the outlet from, the test region.

5. No pressure events or FCI's were observed.

6. The calculated timings of events differ from the experimental values by about $0.3-0.6 \mathrm{~s}$. In view of the complexity involved in the mathematical modeling and the uncertainty in physical parameters, variations of the se parameters within the uncertainty limits might improve the correspondence between the calculations and the observations. 
The assembly drawing for the L5 test train is shown in Fig. A.l. Except where noted, all dimensions are those at room temperature. As-fabricated dimensions might be somewhat different from those indicated on the drawings. The total flow area in the flow tube of the test train was measured by alcohol displacement. The irradiated fuel elements were not conveniently available so that the net flow area with the fuel elements was estimated from the dimensions of the fresh elements. The net flow area was about $0.63 \mathrm{~cm}^{2}$. A precise knowledge of this flow area was not required since no flow or fuel-motion parameter could be identified for which a flow-area deviation would cause a major perturbation in the phenomena under study.

The test-train seating was accomplished by tailoring the dimensions of the test train to the actual loop. Belleville washers located at the exit gland provided a preload at room temperature. When the loop was heated from electric heaters surrounding the primary vessel, differences in thermal expansion could be accommodated by the relaxation of the Belleville washers. In the event the test train became completely unseated, about $50 \%$ of the flow could bypass the test region in the $0.76-\mathrm{mm}$ gap separating the outer wall of the adiabatic section of the test train from the inner diameter of the loop-body weldment. Although not an absolute assurance, the seat was checked in the pretest radiography.

The loop wall (about 9-mm-thick Type 316 stainless steel) at the testsection location provided sufficient heat-capacity protection to accommodate the meltthrough defined for the Mark-II test vehicle. The loop pressure rating is not limited by the test-section wall thickness; the rating is apparently dependent on the pump tube (manufactured from Inconel), where the objective of minimizing the ALIP gap requires a minimum wall thickness. At this location, the meltthrough problem is somewhat less stringent than at the test-section side of the loop. 


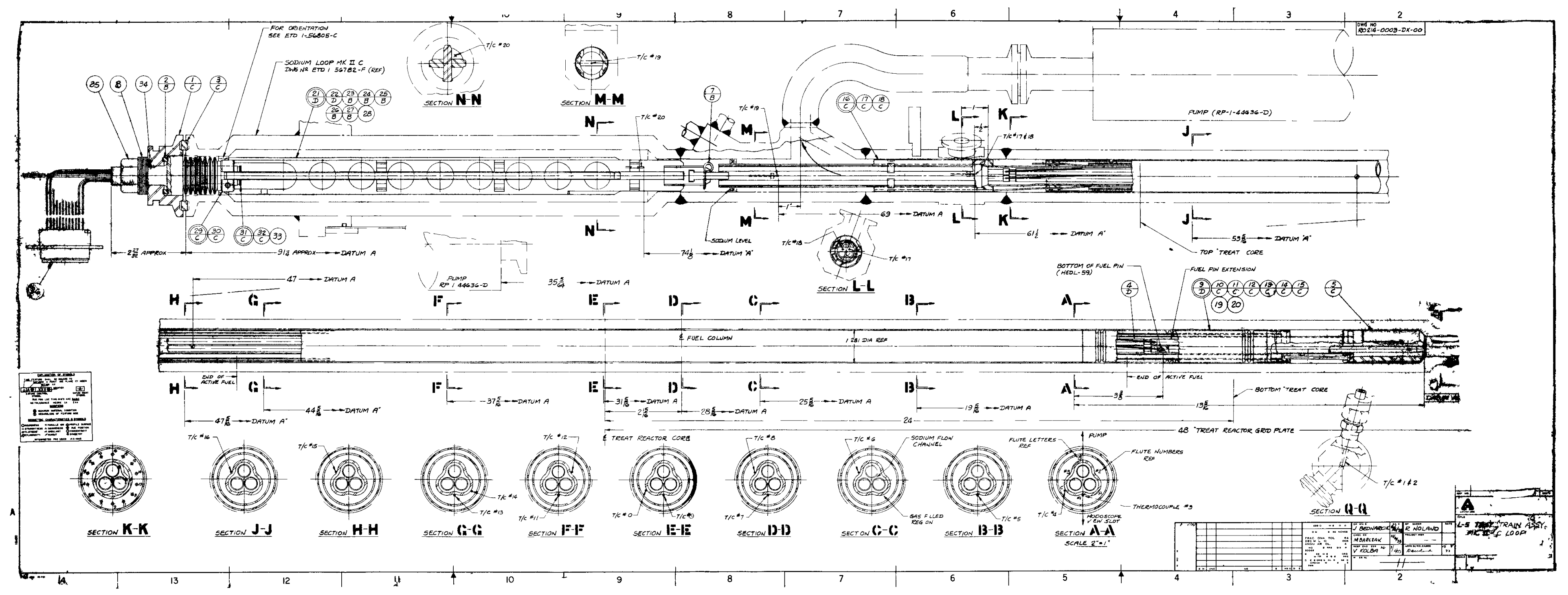

Fig. A.1. L5 Test-train Assembly. ANL drawing RO214-0003-DX. 


\section{APPENDIX B}

\section{Results of Power-calibration Tests}

1. Introduction

The sample power-calibration constants for Test L5 are based on calibration tests performed in TREAT in March 1974. These calibration tests were conducted in a neutronic equivalent of the L5 test loop and test train using fresh fuel, but in the absence of sodium. Transients were conducted in the mockup loop without fuel. Monitor wires in these transient tests were used as the basis for converting calibration constants for fuel at low power ( $50 \mathrm{~kW})$ to transient conditions. In addition, the axial power distributions were "shaped" to meet a desired distribution by shifting and adding dysprosium metal placed on the outside of the test section. The designations for these transient tests are given in Table B.1. The test results discussed in this appendix deal only with the tests on which the final results are based; the shaping tests are not included.

TABLE B 1. Summary of L5 Calibration Tests in TREAT

\begin{tabular}{lcccccc}
\hline $\begin{array}{c}\text { Test } \\
\text { Designation }\end{array}$ & $\begin{array}{c}\text { TREAT } \\
\text { Transient }\end{array}$ & $\begin{array}{c}\text { Date } \\
\text { Performed }\end{array}$ & $\begin{array}{c}\text { Number of } \\
\text { Fuel Elements }\end{array}$ & $\begin{array}{c}\text { Number of } \\
\text { Monitor } \\
\text { Wires }\end{array}$ & $\begin{array}{c}\text { Energy } \\
\text { Release, } \\
\text { MJ }\end{array}$ & Description \\
\hline L5M-1.1A & - & $2-15-74$ & 3 & 2 & 81.5 & Axial shaping \\
L5M-1.1B & - & $2-20-74$ & 3 & 2 & 93.3 & Axial shaping \\
L5M-1 1C & - & $2-26-74$ & 3 & 2 & 93.3 & Axial shaping \\
L5M-1.2 & - & $3-1-74$ & 3 & 2 & 93.3 & $\begin{array}{c}\text { Axial-shaping } \\
\text { confirmation }\end{array}$ \\
L5M-2.1 & - & $3-8-74$ & 3 & 2 & 93.3 & Low-level \\
L5M-3.1 & - & $3-5-74$ & 0 & 2 & 93.3 & Low-level \\
L5M-3.2 & 1545 & $3-5-74$ & 0 & 2 & 360 & Constant power \\
L5M-3.3 & 1546 & $3-6-74$ & 0 & 659 & L5-type \\
\end{tabular}

2. Theory

No method has been devised as yet to directly measure all the required parameters for preirradiated fuel. The method used for the L5 calibration used fresh (unirradiated) fuel, monitor-wire irradiations, and calculations (for burnup corrections) in an attempt to infer the sample-to-reactor power-calibration factor for the test fuel. A consistency check (heat balance) was also conducted before the final test transient to establish that the interpretation obtained from the calibration tests with fresh fuel was sufficient to proceed with the actual test. This approach was acceptable for previous transient-overpower tests in TREAT. 
The two principal parameters needed to run a TREAT test are the axial power distribution and the calibration factor for each element in the cluster. The axial power distributions for the fresh fuel were obtained by counting relative pellet activity. The calibration factor for each fresh element destructively examined was determined by:

a. Inferring the fission rate from ${ }^{140}$ La activity by counting three pellets from the element,

b. Using monitor-wire corrections to account for differences between transient and steady-state behavior at the sample and at the detector.

The calibration factor CF for the element (peak axial value) was calculated by

$$
(C F)_{t}=(C F)_{s s} A_{t} / A_{s s}
$$

where

$(\mathrm{CF})_{\mathrm{t}}=$ calibration factor for the fuel element in a transient, $\mathrm{W} / \mathrm{g} \cdot \mathrm{MW}$;

$(C F)_{s s}=$ calibration factor for the fueled, steady-state experiment, $\mathrm{W} / \mathrm{g} \cdot \mathrm{MW}$;

$A_{t}=$ activity of a monitor wire in the test region for the transient, fissions $/ \mathrm{g} \cdot \mathrm{MJ}$;

$\mathbf{A}_{\mathbf{s} \text { S }}=$ activity of a monitor wire in the test region for steady-state, fissions $/ g \cdot M J$.

The above relationship is equivalent to assuming that the ratio of fissions in the fuel to fissions in a monitor wire for the same transient will be the same for all similar transients and, also, when the reactor is operated at a much lower power defined as at steady state. If the steady-state irradiations for fuel and monitor wires are conducted at the same indicated power level and for the same time duration, then the energy release of the reactor at steady state cancels in the equation, and the exact energy release therefore, need not be known. Similarly, the energy release for the transient monitor-wireirradiation test need not be known exactly, as long as the same instrumentcalibration constant is used when the actual transient is conducted. Indeed, there may be no need to define a transient correction if the local reactor power levels could be defined using the reactor instrumentation alone.

The values obtained from these calibration tests apply to fresh fuel. The factors must therefore be corrected before the test for any differences in either the fuel or test configuration, such as for the burnup associated with the test fuel. 


\section{Transient-correction Factor}

The relationship between the low-level power-calibration factor and the value that would be obtained during a transient was estimated by means of monitor-wire activations. No fuel was present during a calibration transient and reliance must be placed on monitor-wire results alone. In these tests, monitor wires were irradiated at low level. [The monitor wires used were $50-\mathrm{mm}$-long segments of $0.76-\mathrm{mm}$-dia zirconium-uranium wire (3.5 wt \% U; $\left.\left.93 \%{ }^{235} \mathrm{U}\right).\right]$ These wires were then removed and fresh wires of the same type inserted for an irradiation in transients similar to those desired for the actual Test L5. These irradiations were accomplished with the L5 mockup loop hardware designed and fabricated for these calibrations. The monitor-wire activity was based on the ${ }^{140} \mathrm{Ba}$ activity in the wire specimens related to fissions per gram of wire using a calibrated source. The procedure was deemed acceptable since only the relative fission rate for the irradiated monitor wires was required.

The transient correction $\left(A_{t} / A_{s s}\right)$ for the transient relative to the lowlevel, steady-state irradiation was computed in Table B.2 as 1.18 for the monitor wires placed in the test section at about the location of the TREAT core midplane. The factor was determined by dividing the indicated wire fissions/ $\mathrm{g} \cdot \mathrm{MJ}$ for the transient case by the value for monitor wires obtained for the irradiation in the low-level, steady-state case. Since the control-rod configurations in the low-level irradiations of monitor wires and elements were essentially identical, no further correction caused by differences in control-rod positioning was required. Also, the results indicate that the same transient correction may be used for heat-balance-type transients.

TABLE B.2. Transient-correction Factor for L5 Based on Monitor-wire Results from Test Section

\begin{tabular}{cccccc}
\hline Test & $\begin{array}{c}\text { Wire } \\
\text { Serial } \\
\text { No, }\end{array}$ & $\begin{array}{c}\text { Wire } \\
\text { Activity, } \\
10^{12} \text { fissions/g }\end{array}$ & $\begin{array}{c}\text { Energy } \\
\text { Release, } \\
\text { MJ }\end{array}$ & $\begin{array}{c}\text { Relative Wire } \\
\text { Activity, } \\
10^{10} \\
\text { fissions/g・MJ }\end{array}$ & $\begin{array}{c}\text { Transient } \\
\text { Correction }\end{array}$ \\
\hline L5M-3.1 & ZR-2-01 & 3.8 & 93.3 & 4.07 & - \\
L5M-3.2 ${ }^{a}$ & ZR-2-03 & 17.4 & 360 & 4.83 & 1.18 \\
L5M-3.3 & ZR-2-05 & 31.7 & 659 & 4.81 & 1.18 \\
\hline
\end{tabular}

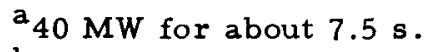

$\mathrm{b}_{\mathrm{T}}$ ransient with burst added to $\mathrm{L} 5 \mathrm{M}-3.2$.

The indicated data for TREAT energy release were based on Integrator No. 1. The monitor wires had been examined for uniformity by counting the individual wire specimens actually used in the test. All wires were uniform within $\pm 1.5 \%$ at the $2 \sigma$ level in ${ }^{235} \mathrm{U}$ content per unit weight. 
Monitor wires were also placed in a guide tube adjacent to the test section within the secondary containment can at the elevation of the TREAT core midplane. Although the monitor wires placed at this location were not in the test section, the results for these wires, listed in Table B.3, nevertheless gave nearly the same transient correction.

TABLE B.3. Transient-correction Factor for L5 Based on Monitorwire Results from Secondary-containment-can Guide Tube

\begin{tabular}{cccccc}
\hline Test & $\begin{array}{c}\text { Wire } \\
\text { Serial } \\
\text { No. }\end{array}$ & $\begin{array}{c}\text { Wire } \\
\text { Activity, } \\
\text { fissions/g }\end{array}$ & $\begin{array}{c}\text { Energy } \\
\text { Release, } \\
\text { MJ }\end{array}$ & $\begin{array}{c}\text { Relative Wire } \\
\text { Activity, } \\
\text { fissions/g·MJ }\end{array}$ & $\begin{array}{c}\text { Transient } \\
\text { Correction }\end{array}$ \\
\hline L5M-3.1 & ZR-2-02 & 5.38 & 93.3 & 5.76 & - \\
L5M-3.2 & ZR-2-04 & 24.2 & 360 & 6.72 & 1.17 \\
L5M-3.3 & ZR-2-06 & 43.7 & 659 & 6.63 & 1.15 \\
\hline
\end{tabular}

4. Results of Power Calibration for Unirradiated Fuel at Low-level TREAT Power

In calibration Test L5M-2.1, three fresh HEDL-59-type elements were irradiated at about $50 \mathrm{~kW}$ in the calibration mockup loop. After the irradiation, the three-element cluster was removed from the loop for radiochemical analysis. Axial power distributions for each element were obtained by counting about

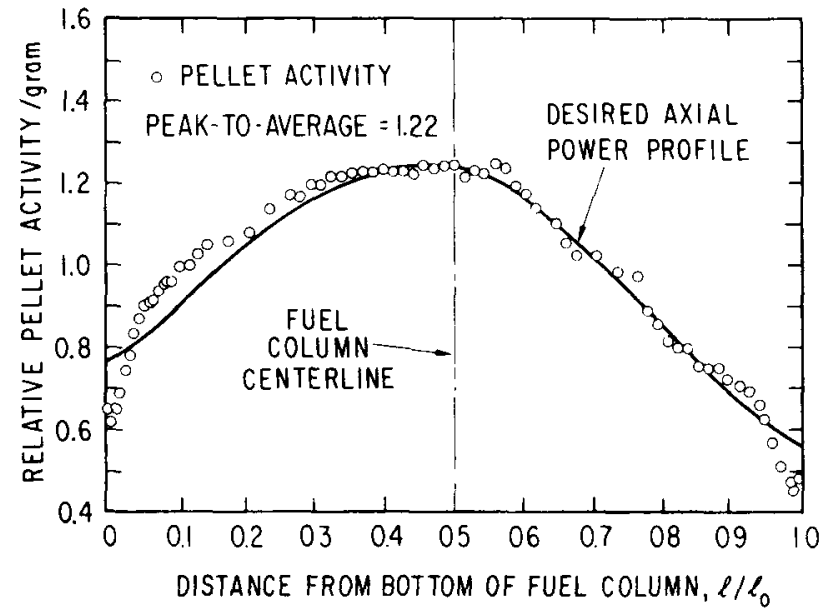

Fig. B.1. Average Axial Power Distribution for L5 Analysis. ANL Neg. No. 900-77-539.
60 individual pellets per element for gamma-ray activity in the energy range 0.45-0.80 MeV with a NaI gamma-ray spectrometer. The distributions of axial pellet activities were essentially identical, each with a peak-to-average value of about 1.22. An average distribution, recommended for use in analysis of L5, is shown in Fig. B.1.

The absolute value of the sample power-calibration factor for each element was determined by analyzing three pellets per element for $\mathrm{Ba}-\mathrm{La}$ (by dissolution techniques) and applying the appropriate conversion constants to account for decay, fission yield, and

fission energy. Pellet numbers 73, 74, and 78 from the 154-pellet stack (numbered starting at the bottom) of elements L5C-3, L5C-6, and L5C-7 were selected for this analysis based on the gamma scans. The correspondence between element designation and cluster position is given in Fig. B.2. 


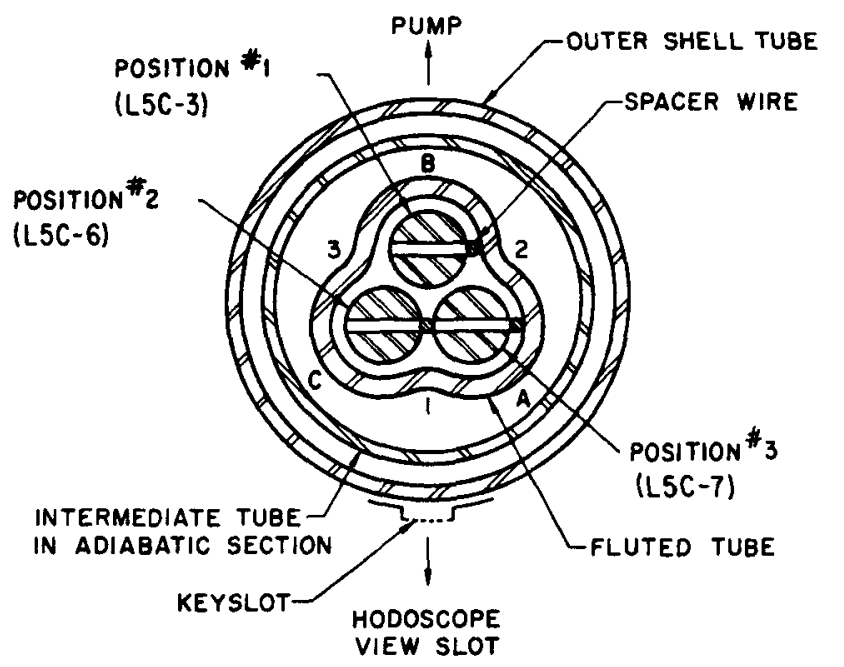

Fig. B.2

Location of Calibration Elements Relative to Test-element Positions for $L 5$

Absolute fission determinations for the pellets were based on the $\mathrm{Ba}$ La pair by counting ${ }^{140}$ La-gamma-ray emissions with a calibrated NaI gammaray spectrometer. The determinations were first averaged by weighting the experimental values with the pellet gamma-ray counts (from the axial power determinations) to estimate the peak value for the element. A value of $5.92 \%$ was used for the effective yield of barium from the mixed-oxide fuel in TREAT. The values of fissions per gram oxide were converted to peak axial calibration factors at low-level TREAT power by:

a. Multiplying by $28.6 \mathrm{pJ} /$ fission.

b. Dividing by the indicated TREAT energy release.

The experimental results for the calibration elements are listed in Table B.4. Note that the calibrations indicate that each element will be within about $\pm 4 \%$ of the average for the cluster.

TABLE B.4. Experimental Radiochemical Values for Lowlevel Calibration Factors for L5 (Peak axial values)

\begin{tabular}{ccccc}
\hline $\begin{array}{c}\text { Element } \\
\text { Designation }\end{array}$ & $\begin{array}{c}\text { Pellet 73, } \\
\text { W/g.MJ }\end{array}$ & $\begin{array}{c}\text { Pellet 74, } \\
\text { W/g.MJ }\end{array}$ & $\begin{array}{c}\text { Pellet 78, } \\
\text { W/g・MJ }\end{array}$ & $\begin{array}{c}\text { Average, } \\
\text { W/g.MJ }\end{array}$ \\
\hline L5C-3 & 4.19 & 4.08 & 4.08 & 4.11 \\
L5C-6 & 4.09 & 4.37 & 4.44 & 4.29 \\
L5C -7 & 4.37 & 4.42 & 4.25 & 4.35 \\
\hline
\end{tabular}

5. Conversion to Test Elements

The data from the calibration tests with fresh elements were used to characterize the calibration factors for the test elements. The three test elements were characterized based on their positions in the cluster relative to the calibration elements. The match between elements is indicated in Table B.5. 
TABLE B.5. Correspondence between Test and Calibration Elements

\begin{tabular}{lcl}
\hline Test Element & Calibration Element & \multicolumn{1}{c}{ Cluster Location } \\
\hline HEDL-59-22 & L5C-3 & Nearest Pump Leg \\
HEDL-59-24 & L5C-6 & Nearest Hodos cope Slot (LHS) \\
HEDL-59-23 & L5C-7 & Nearest Hodos cope Slot (RHS) \\
\hline
\end{tabular}

Once the correspondence between the test and calibration elements was established, the following three possible factors were considered:
a. A transient correction.
b. A burnup correction.
c. An assessment for fuel-batch differences.

Correction $c$ turned out to be insignificant. The transient correction of 1.18 was assumed to apply equally to all elements in the cluster. The burnup correction for each element was based on an approximate computation for the reduction in fissile content, which was about $10 \%$ for the GETR burnup of 8 at. \%. The final result for each test element is given in Table B.6. The cluster-averaged value for $\mathrm{L} 5$ was about $4.52 \mathrm{~W} / \mathrm{g} \cdot \mathrm{MW}$.

TABLE B.6. Sample Power-calibration Factors for L5 Test Elements (Peak axial values)

\begin{tabular}{cccccc}
\hline $\begin{array}{c}\text { Element } \\
\text { Position }\end{array}$ & $\begin{array}{c}\text { Element } \\
\text { Designation }\end{array}$ & $\begin{array}{c}\text { Fresh-element } \\
\text { Value, W/g.MW }\end{array}$ & $\begin{array}{c}\text { Transient } \\
\text { Correction }\end{array}$ & $\begin{array}{c}\text { Burnup } \\
\text { Correction }\end{array}$ & $\begin{array}{c}\text { Calibration } \\
\text { Factor, W/g.MW }\end{array}$ \\
\hline 1 & HEDL-59-22 & 4.11 & 1.18 & 0.90 & 4.36 \\
2 & HEDL-59-24 & 4.29 & 1.18 & 0.90 & 4.56 \\
3 & HEDL-59-23 & 4.35 & 1.18 & 0.90 & 4.62 \\
- & Average & 4.25 & 1.18 & 0.90 & 4.52 \\
\hline
\end{tabular}

6. Internal Radial Power Distributions

The radial power distribution within an element is a parameter needed for the heat-transfer calculations. In L5, this distribution was obtained as a histogram by drilling concentric specimens from selected pellets in the fuel column. Unfortunately, only four points could be obtained by this technique because the pellets were so fragile. Also, only the azimuthally averaged value is represented by the shell counted. Attempts to use foils to estimate azimuthal asymmetries have not always proven acceptable. The data for Tests L5 and E8 were the first such experimental information on radial power distributions; all 
previous TREAT test analysis relied on calculations alone. Subsequent TREAT tests now use the ultrasonic trepanning technique developed originally for these calibration tests to obtain the concentric sections for estimates of the radial power distribution.

The dimensions of the core-drilled specimens, given in Table B.7, indicate that about $30 \%$ of the original pellet was lost in the cutting process. Tables B.8-B.10 give the count rates obtained by counting the core-drilled specimens from L5C-3, -6 , and -7 , respectively. Note that the largest peakto-average value was about 1.5. The true distribution would have a larger peak-to-average value at the cluster edge than is represented by the coredrilled results.

TABLE B.7. Dimensions of Core-drilled Specimens from Mixed-oxide Fresh-fuel Pellets in Calibration Experiments

\begin{tabular}{ccccc}
$\begin{array}{c}\text { Ring } \\
\text { Designation }\end{array}$ & $\begin{array}{c}\text { Specimen } \\
\text { Inside Diameter, } \\
\text { mm }\end{array}$ & $\begin{array}{c}\text { Specimen } \\
\text { Outside Diameter, } \\
\text { mm }\end{array}$ & $\begin{array}{c}\text { Fraction of Pellet } \\
\text { Cross-sectional Area }\end{array}$ & $\begin{array}{c}\text { Fraction of } \\
\text { Total Counted }\end{array}$ \\
\hline 0 & - & 1.65 & 0.112 & 0.158 \\
1 & 1.91 & 2.77 & 0.166 & 0.234 \\
2 & 3.20 & 3.89 & 0.200 & 0.282 \\
3 & 4.32 & 4.93 & 0.232 & 0.326 \\
sum & - & - & 0.710 & 1.000 \\
\hline
\end{tabular}

${ }^{a}$ For ring designation, see sketch in Fig. B.3.

TABLE B.8. Azimuthally Averaged Radial Power Distribution Measured for Calibration Element L5C-3

\begin{tabular}{|c|c|c|c|c|}
\hline \multirow{2}{*}{$\begin{array}{c}\text { Ring } \\
\text { Designation }\end{array}$} & \multicolumn{3}{|c|}{${ }^{95} \mathrm{Zr}$ Activity, counts/s per $\mathrm{g}$} & \multirow{2}{*}{$\begin{array}{c}\text { Relative } \\
\text { Distribution }\end{array}$} \\
\hline & Pellet 75 & Pellet 80 & Average & \\
\hline 0 & 459.4 & 427.7 & 443.5 & 1.000 \\
\hline 1 & 468.7 & 471.6 & 470.2 & 1.060 \\
\hline 2 & 635.4 & 638.2 & 636.8 & 1.436 \\
\hline 3 & 938.3 & 872.2 & 905.3 & 2.041 \\
\hline Average & & & & $1.476^{\mathrm{b}}$ \\
\hline
\end{tabular}

${ }^{2}$ Uncertainty based on deviation between specimen count rates for pellets 75 and 80 is about $\pm 6 \%$.

${ }^{b}$ Average computed by weighting distribution values for each core-drilled specimen by its fraction of the total sample counted based on cross-sectional area. 
TABLE B.9. Azimuthally Averaged Radial Power Distribution Measured for Calibration Element L5C-6

\begin{tabular}{|c|c|c|c|c|}
\hline \multirow{2}{*}{$\begin{array}{c}\text { Ring } \\
\text { Designation }\end{array}$} & \multicolumn{3}{|c|}{${ }^{95} \mathrm{Zr}$ Activity, counts/s per $\mathrm{g}$} & \multirow{2}{*}{$\begin{array}{c}\text { Relative } \\
\text { Distributiona }\end{array}$} \\
\hline & Pellet 75 & Pellet 80 & Average & \\
\hline 0 & 453.7 & 439.2 & 446.5 & 1.000 \\
\hline 1 & 532.8 & 587.2 & 560.0 & 1.254 \\
\hline 2 & 630.9 & 637.7 & 634.3 & 1.420 \\
\hline 3 & 881.2 & 126.7 & 107.4 & 2.405 \\
\hline Average & & & & $1.636^{\mathrm{b}}$ \\
\hline
\end{tabular}

${ }^{a}$ Uncertainty based on deviation between specimen count rates for pellets 75 and 80 is about $\pm 22 \%$. Based only on Rings 0,1 , and 2 , the uncertainty on the distribution for these rings reduces to $\pm 7 \%$.

$\mathrm{b}_{\text {Average computed by weighting distribution values for each }}$ core-drilled specimen by its fraction of the total sample counted based on cross-sectional area.

TABLE B.10. Azimuthally Averaged Radial Power Dis tribution Measured for Calibration Element L5C-7

\begin{tabular}{|c|c|c|c|c|}
\hline \multirow{2}{*}{$\begin{array}{c}\text { Ring } \\
\text { Designation }\end{array}$} & \multicolumn{3}{|c|}{${ }^{95} \mathrm{Z}$ r Activity, counts/s per $\mathrm{g}$} & \multirow{2}{*}{$\begin{array}{c}\text { Relative } \\
\text { Distributiona }\end{array}$} \\
\hline & Pellet 75 & Pellet 80 & Average & \\
\hline 0 & 460.8 & 466.2 & 463.5 & 1.000 \\
\hline 1 & 545.0 & 515.2 & 530.1 & 1.144 \\
\hline 2 & 707.5 & 696.1 & 701.8 & 1.514 \\
\hline 3 & 102.5 & 104.5 & 103.5 & 2.233 \\
\hline Average & & & & $1.581^{b}$ \\
\hline
\end{tabular}

${ }^{2}$ Uncertainty based on deviation between specimen count rates for pellets 75 and 80 is about $\pm 4 \%$.

${ }^{b}$ Average computed by weighting distribution values for each core-drilled specimen by its fraction of the total sample counted based on cross-sectional area. 
Computer programs such as SAS cannot consider the differences in radial power distributions among the elements, since only a one-channel, azimuthally symmetric representation is possible. For this case, the distributions were averaged producing the radial power histogram shown in Fig. B.3. For additional radial nodal points, the rms value of the radius of the core-drilled specimen was used and points interpolated on a graph of $P(r)$ versus $\left(r / r_{0}\right)^{2}$. This final result is shown in Fig. B.4.

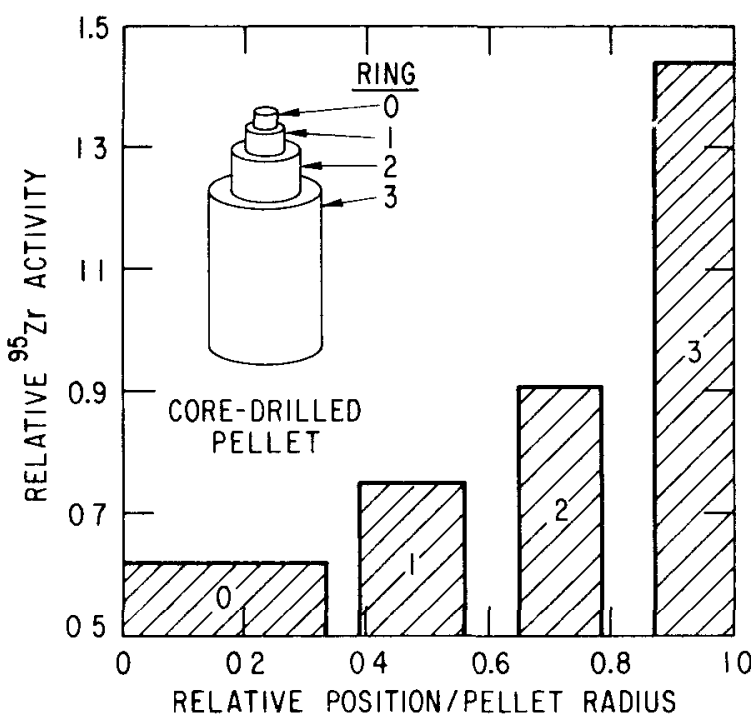

Fig. B.3. Radial Power Distribution (Histogram) Obtained from Core-drilled Specimens. ANL Neg. No. 900-5736.

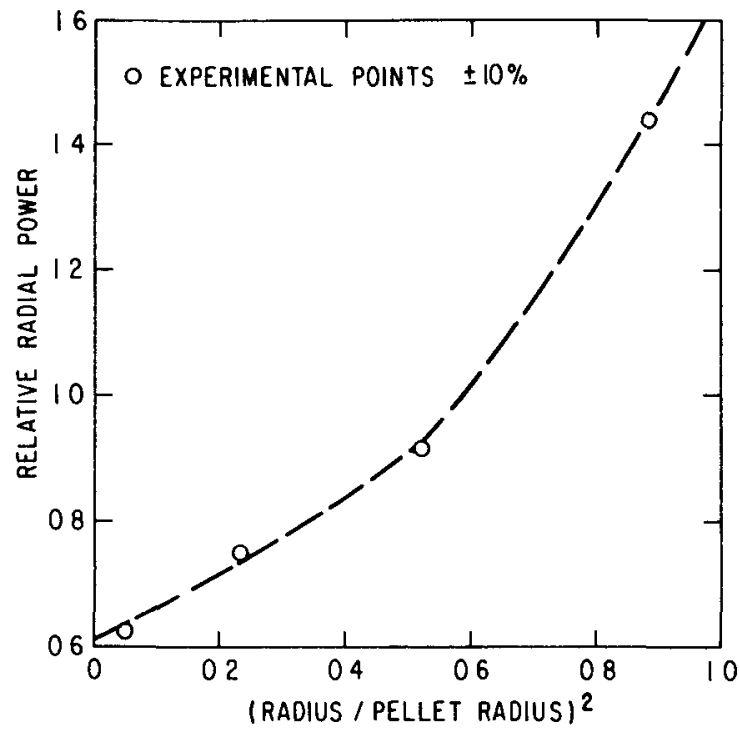

Fig. B.4. Radial Power Distribution Interpolated from Histogram. ANL Neg. No. 900-77-590. 


\section{APPENDIX C \\ Additional Data from L5 Heat-balance Test}

Data from the test-vehicle instrumentation were recorded on the analog tape units for $2 \mathrm{~min}$. The constant-power portion of the test was in the time interval of about 3-15 s, as shown in Fig. 5. The pressure and flow data, shown in Sec. IV, indicate the extent of the radiation response and recovery over the 2-min period of data acquisition. The erratic behavior of the outlet flowmeter was probably a result of its low sensitivity and proportionately greater radiation response relative to the inlet flowmeters. The ALIP current and power were essentially constant during the test. The pump behavior was therefore probably not responsible for the anomalous behavior of the outlet flowmeter. The transient heating had little affect on the temperature of the permanent magnet, which increased by only $5^{\circ} \mathrm{C}$.

Thermocouple signals recorded during the test are shown in Figs. C.1C.5. Note that the rise in the bulk sodium temperature, as represented by the inlet thermocouple, $\mathrm{d}_{1} \mathrm{~d}$ not exceed about $450^{\circ} \mathrm{C}$. At the end of $2-\mathrm{min}$ interval of data acquisition, the loop sodium temperature reduced slowly to $450^{\circ} \mathrm{C}$. The sodium temperatures at the test-region outlet peaked at about $625^{\circ} \mathrm{C}$ at the end of the full power operation. The loop system functioned as one might expect from a well-insulated thermal system without a heat exchanger.

Figures C.1-C.4 cover the time interval of 0-30 s, which includes the period of full reactor power operation. The behavior at $9.5 \mathrm{~s}$ of TC-19 (1n Fig. C.1), located at the elevation of the upper loop bend in the sodium

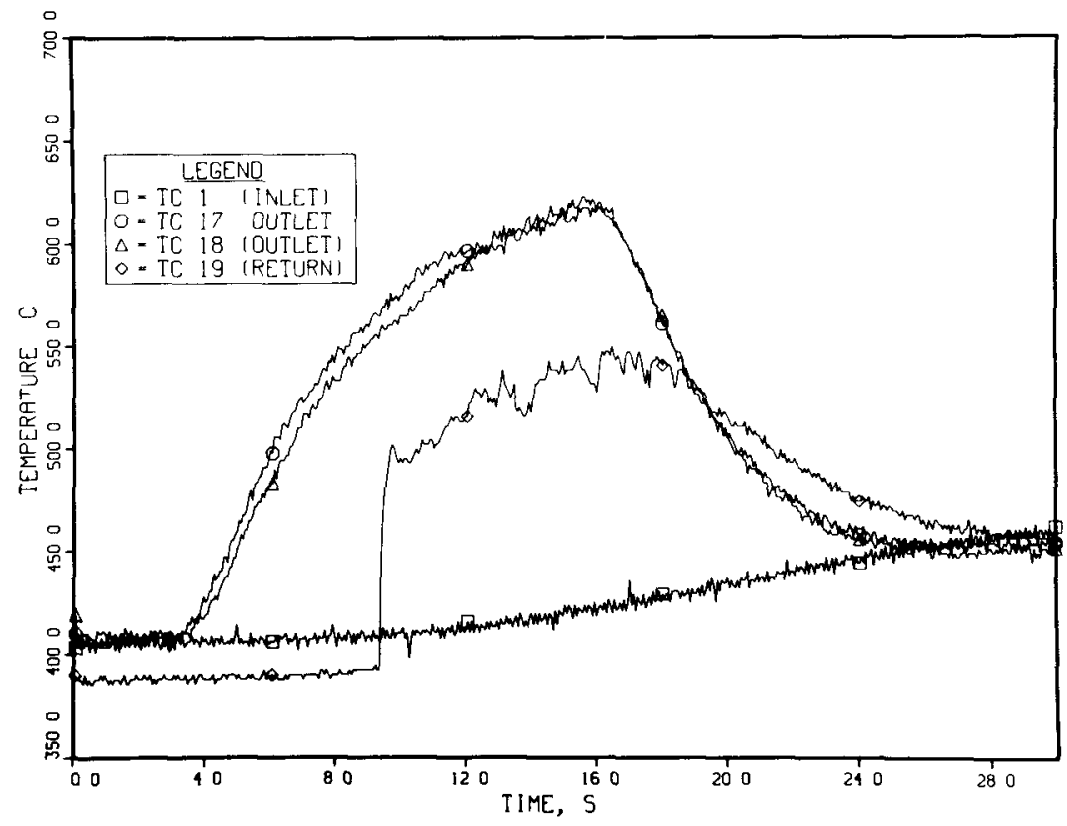

Fig. C.1 Coolant Temperatures during L5 Heat-balance Test. ANL Neg. No. 900-77-425. 


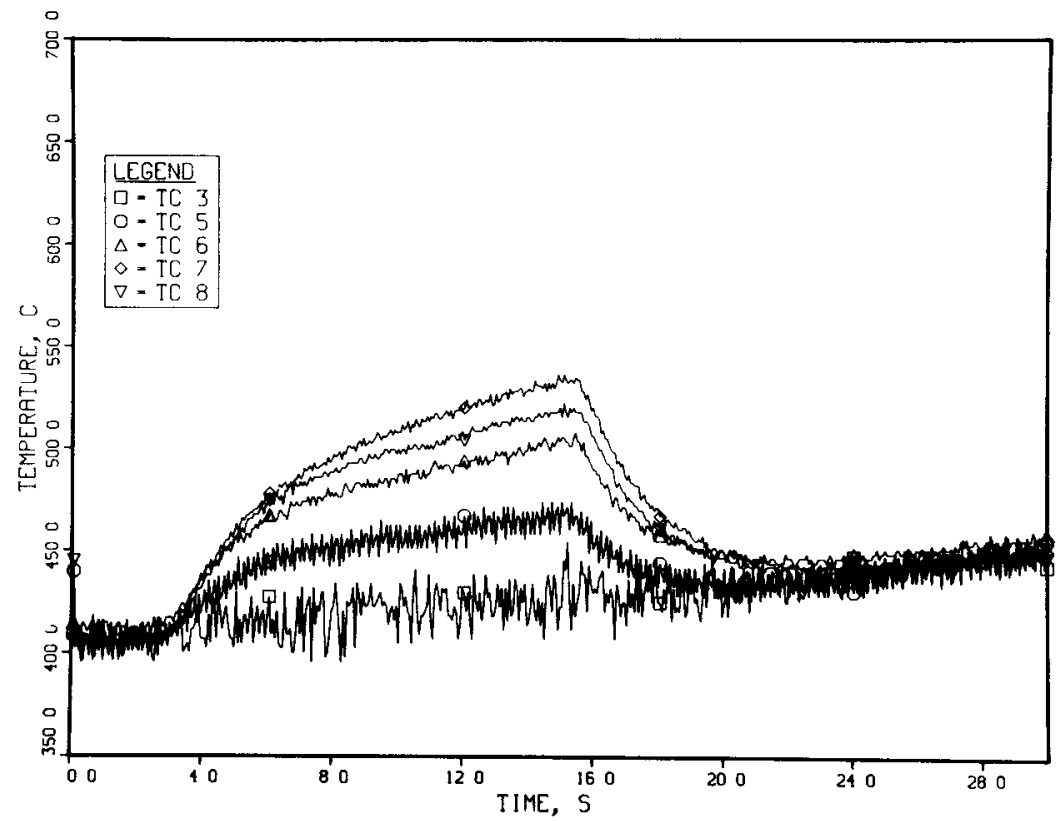

F1g. C.2. Temperatures Measured by Structure Thermocouples in Lower Fuel-column Region. ANL Neg. No. 900-77-422.

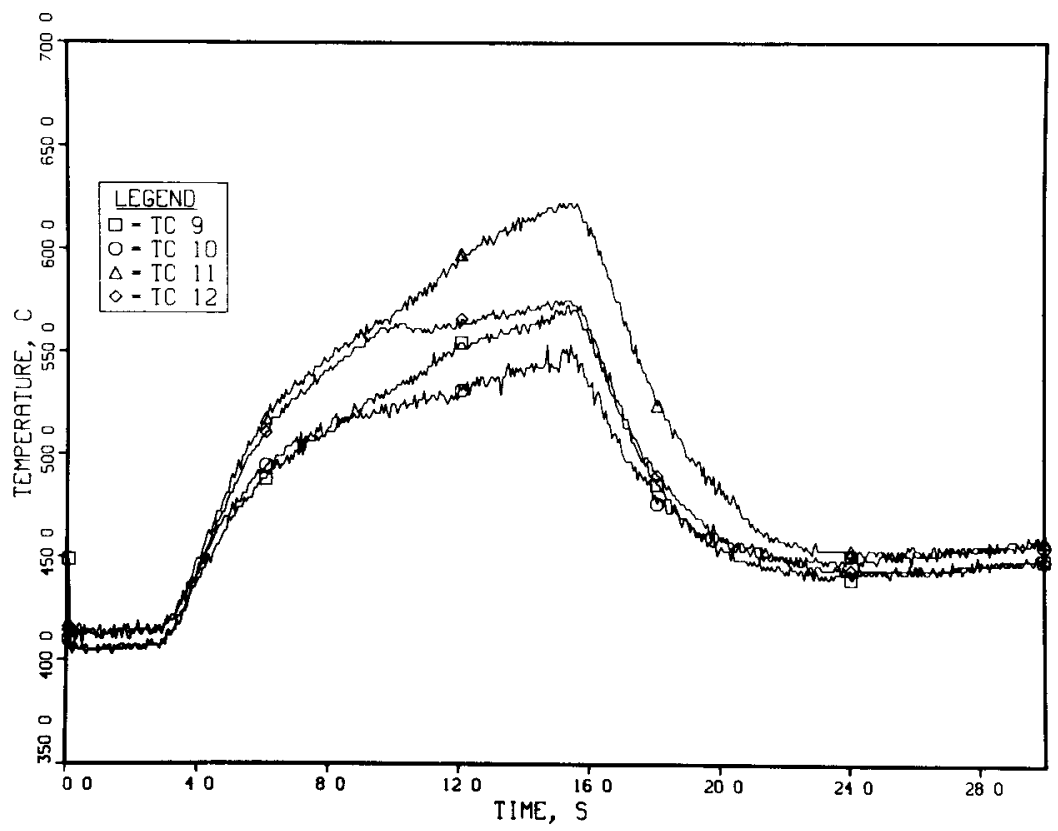

Fig. C.3. Temperatures Measured by Structure Thermocouples above Fuel-column Midplane. ANL Neg. No. 900-77-420. 


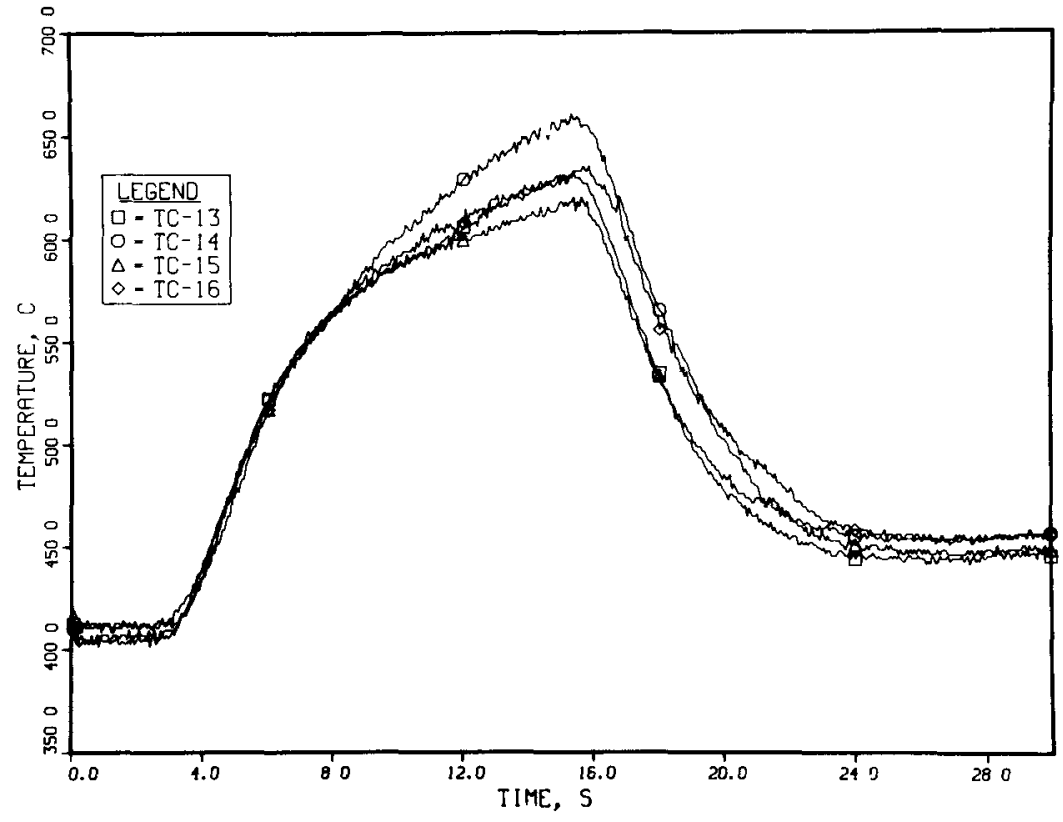

Fig. C.4. Temperatures Measured above Top of Fuel Column. ANL Neg. No. 900-77-423.

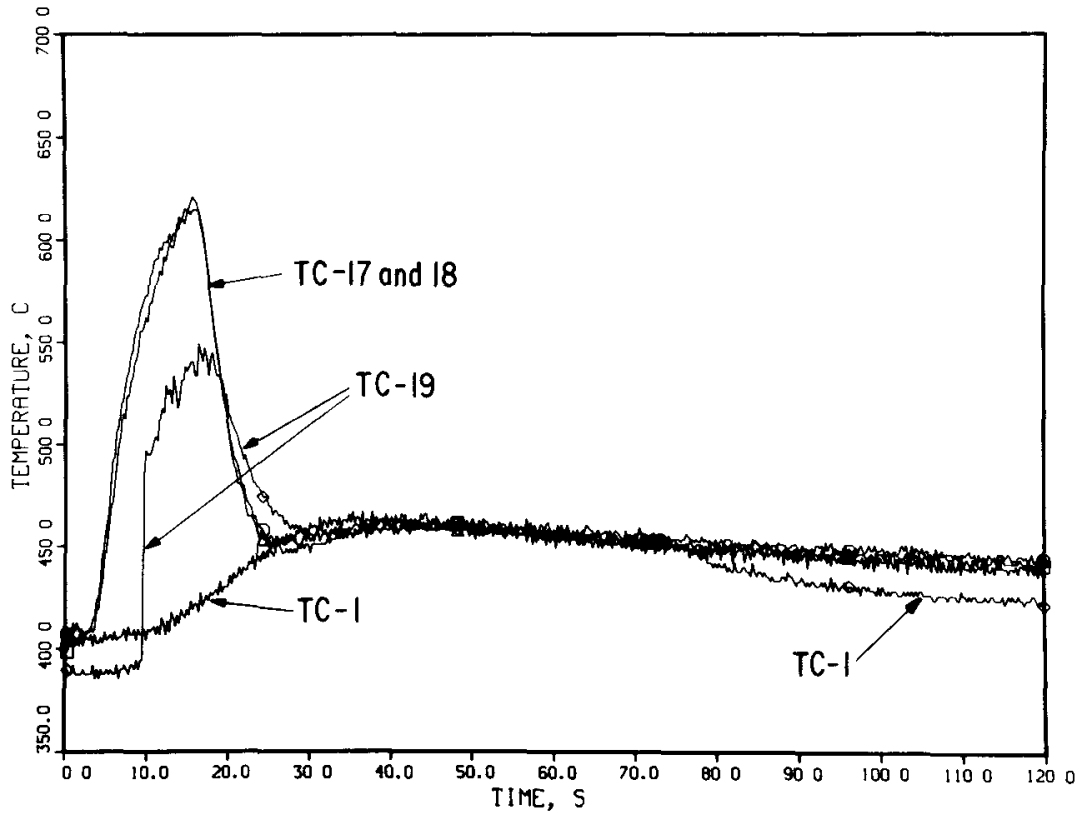

Fig. C.5. Coolant Temperatures in Heat-balance Test for 2-min Time Interval. ANL Neg. No. 900-77-432.

flowstream, was an apparent result of a lower-than-normal sodium level in the loop. Thermocouples TC -3 and -5 exhibited excessive noise during the transient, although pretest resistance measurements indicated that these the rmocouples were operative. 


\section{Additional Data from Loss-of-flow Test L5}

Figures D.1-D.6 show a complete set of thermocouple data recorded during Test L5. Once a thermocouple fails, the data recorded wander erratically; therefore, the data plotted in this appendix terminate in time when it is clear the thermocouple has failed. Estimated times of thermocouple failure are recorded in Table D.1. The inlet-and outlet-flowmeter data are given in Figs. D.7 and D.8. As noted in Sec. V, the outlet-flowmeter data appear erroneous, probably because radiation and thermal responses are more important at the outlet because the sensitivity of the outlet flowmeter is low. Because of the marked deviation of the outlet-flowmeter signal from any credible behavior in the test zone, no interpretation of its signal appeared meaningful.

TABLE D.1. Failure Times of L5 Thermocouples during Loss - of-flow Test

\begin{tabular}{cc|cc}
\hline $\begin{array}{c}\text { Thermocouple } \\
\text { No. }\end{array}$ & $\begin{array}{c}\text { Time of } \\
\text { Failure, s }\end{array}$ & $\begin{array}{c}\text { Thermocouple } \\
\text { No. }\end{array}$ & $\begin{array}{c}\text { Time of } \\
\text { Failure, s }\end{array}$ \\
\hline 3 & 13.7 & 9 & 13.4 \\
5 & 16.66 & 10 & $16.9^{\mathrm{b}}$ \\
6 & 15.34 & 11 & 16.98 \\
7 & 13.74 & 12 & 13.74 \\
8 & $17.94^{\mathrm{a}}$ & & \\
\hline
\end{tabular}

$\mathrm{a}_{\mathrm{TC}}-8$ may have failed at $13.9 \mathrm{~s}$.

$\mathrm{b}_{\mathrm{TC}} \mathrm{-10}$ may have failed at $14 \mathrm{~s}$.

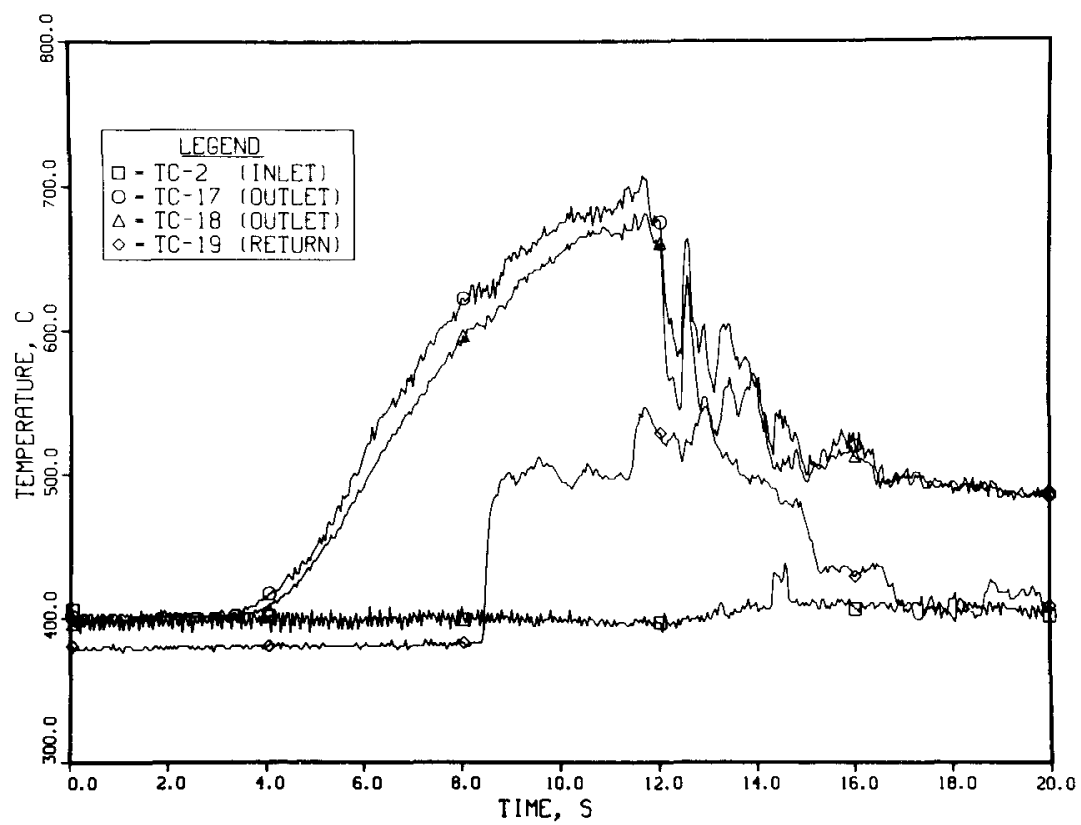

Fig. D.1. Coolant Temperatures in Loss-of-flow Test L5. ANL Neg. No. 900-77-429. 


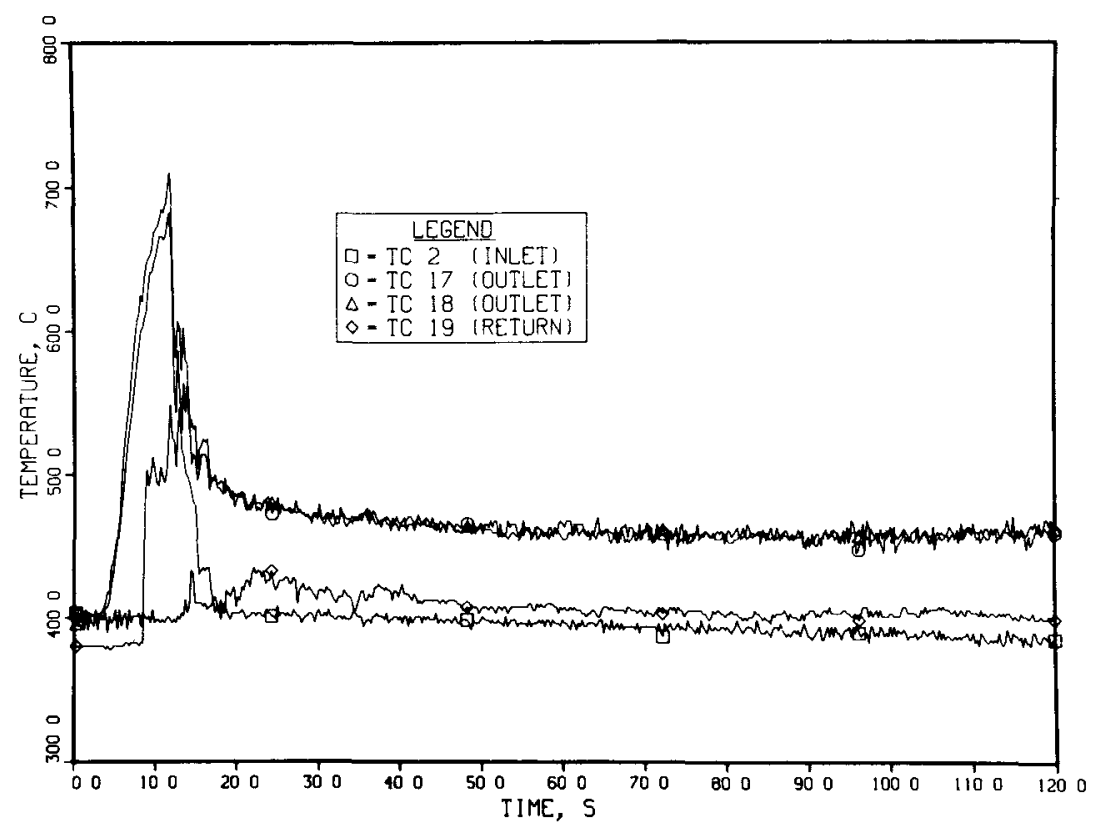

Fig. D.2. Coolant Temperatures in Loss-of-flow Test L5 during 2-min Interval of Data Acquisition. ANL Neg. No. 900-77-428.

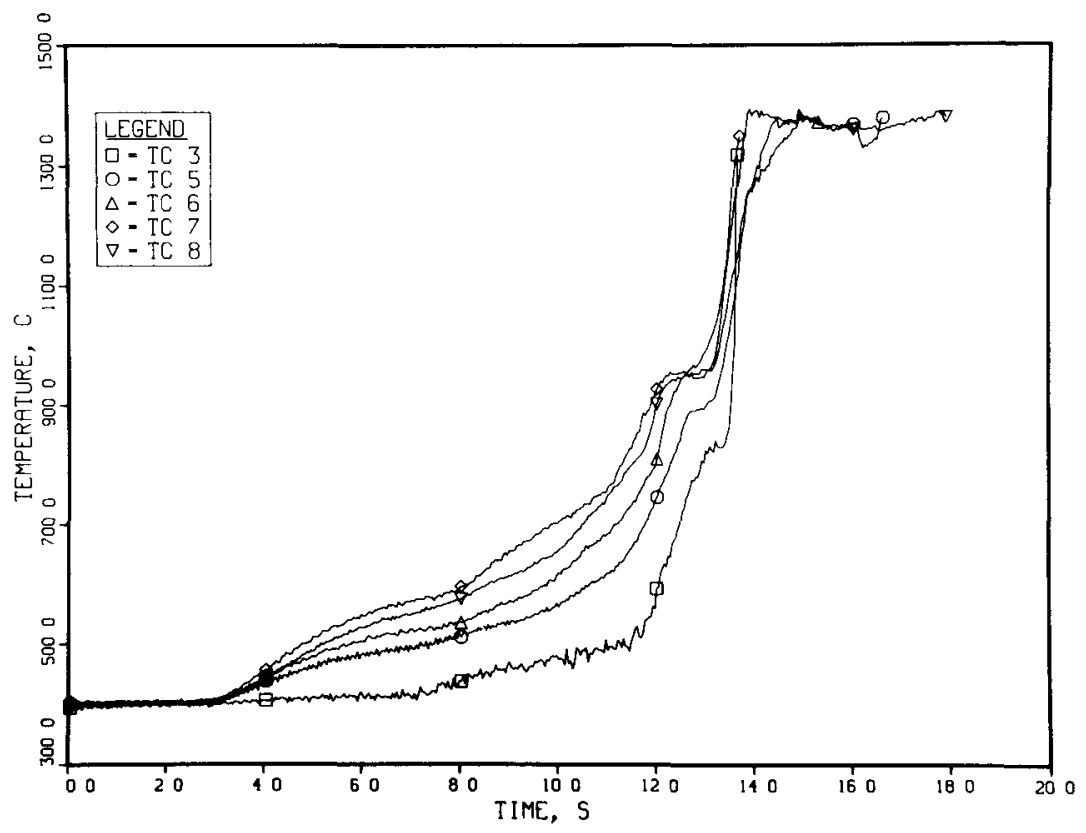

Fig. D.3. Temperatures of Structure Thermocouples in Loss-offlow Test L5. ANL Neg. No. 900-77-427. 


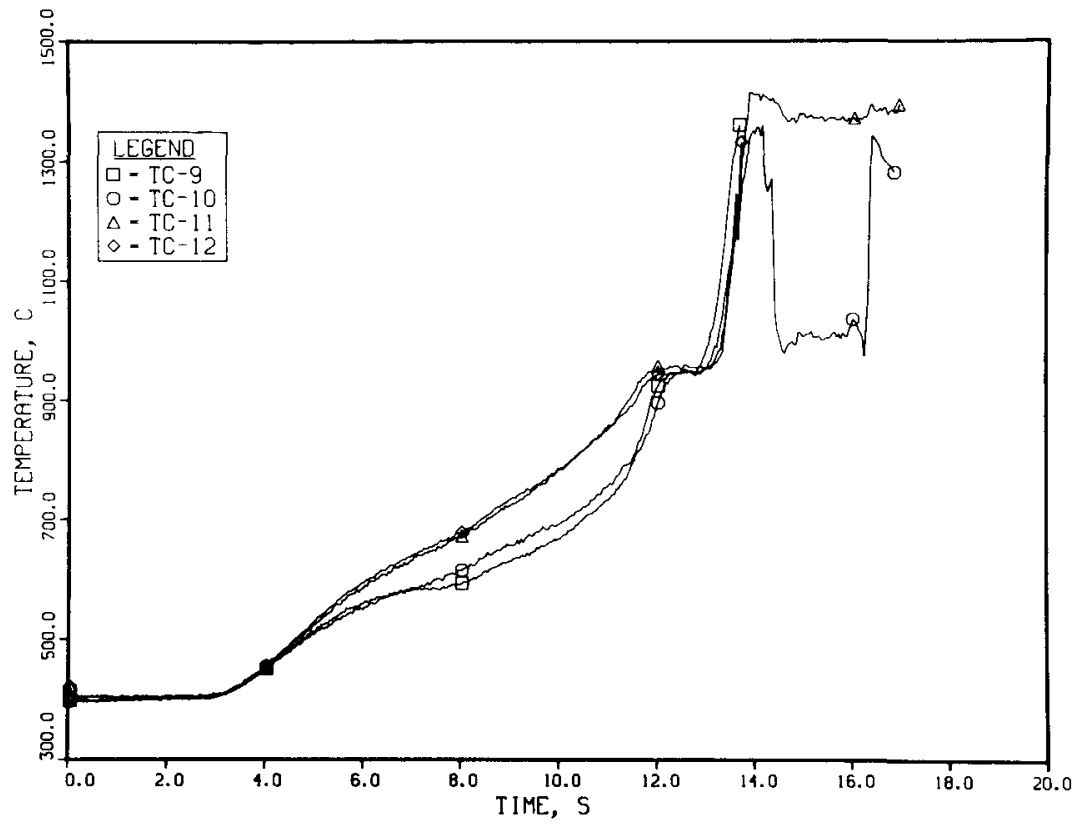

Fig. D.4. Temperatures of Structure Thermocouples above Fuel-column Midplane in Loss-of-flow Test L5. ANL Neg. No. 900-77-415.

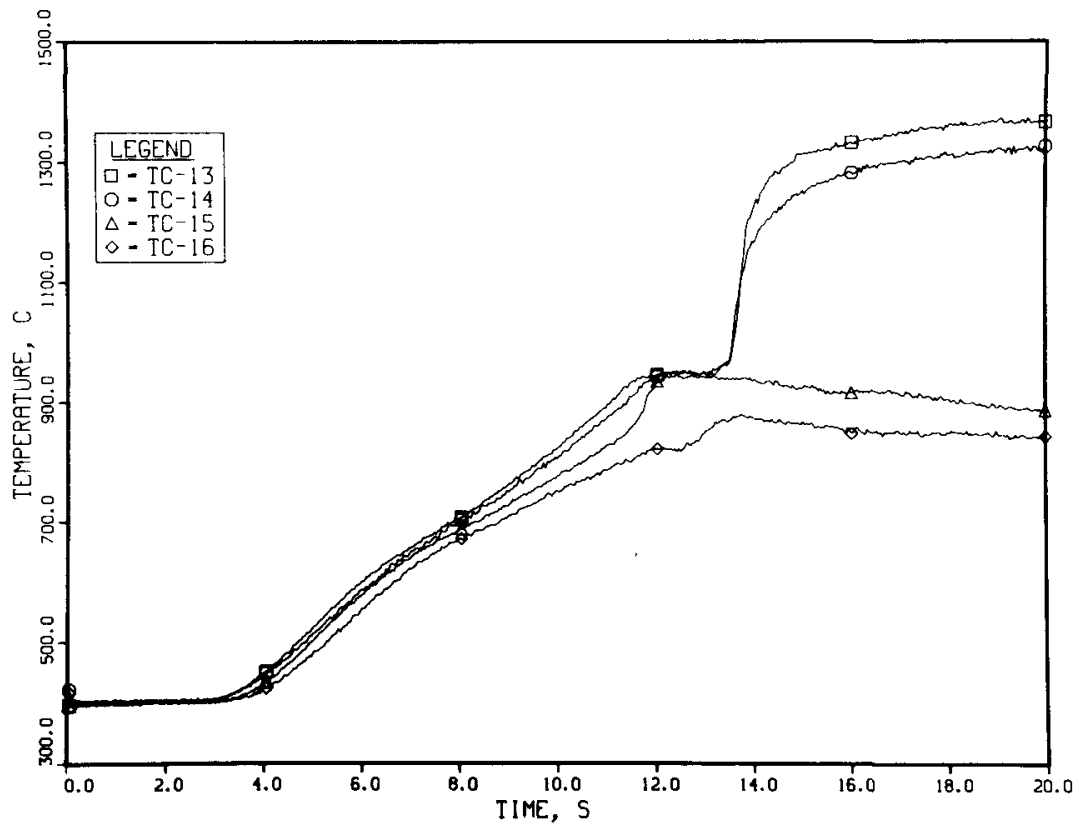

Fig. D.5. Temperatures of Structure Thermocouples at and above Top of Active Fuel Column. ANL Neg. No. 900-77-416. 


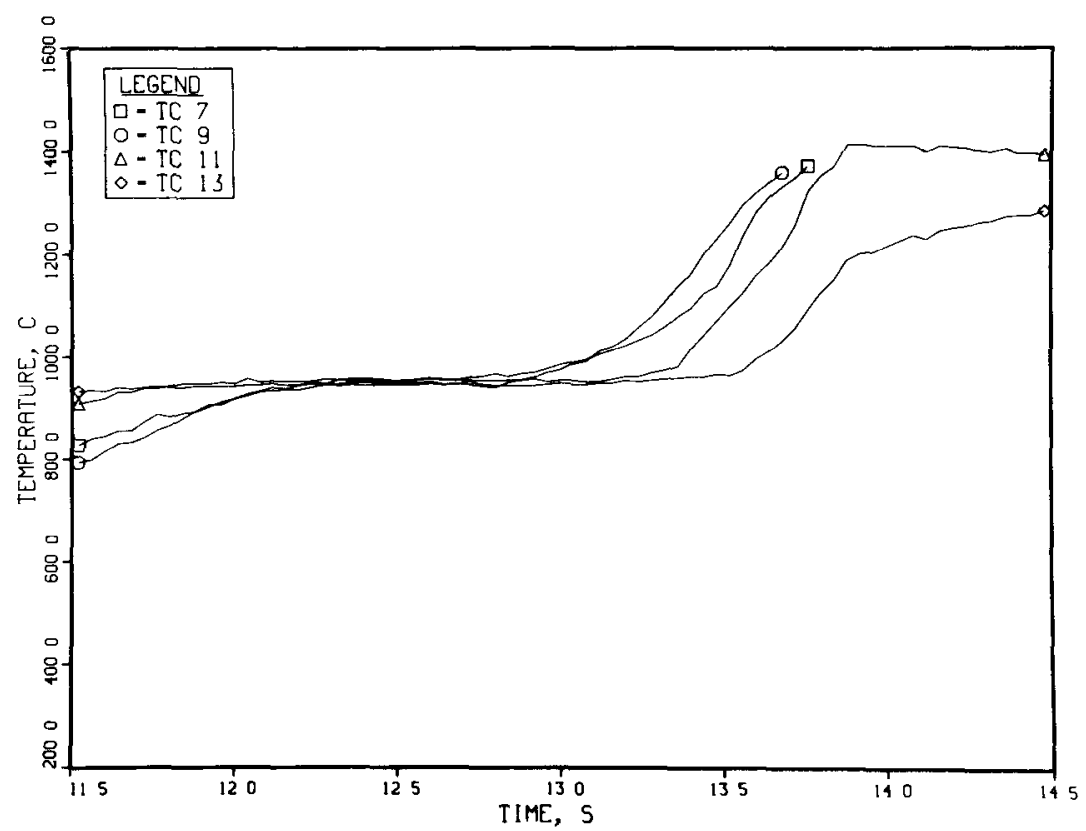

Fig. D.6. Temperatures of Selected Structure Thermocouples during the Time Interval of Burst. ANL Neg. No. 900-77-418.

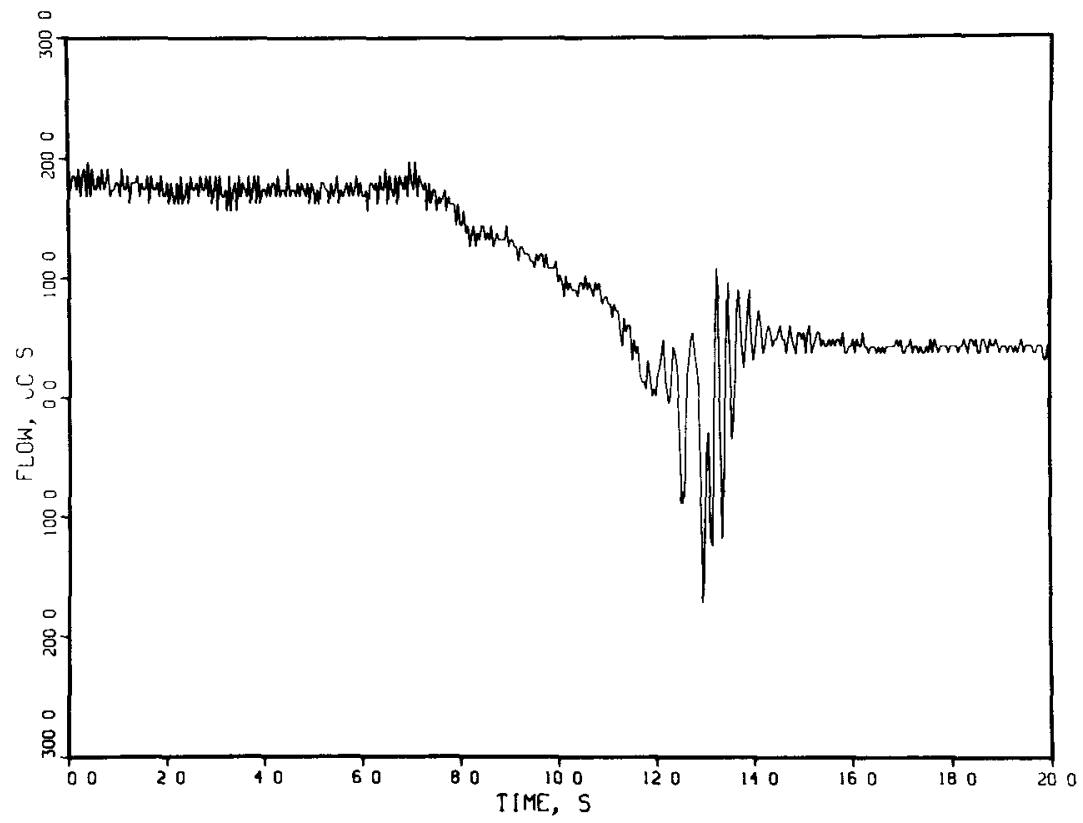

Fig. D.7. Flow Rate Measured by Inlet Electromagnetic Flowmeter in Loss-of-flow Test L5. ANL Neg. No. 900-77-430. 


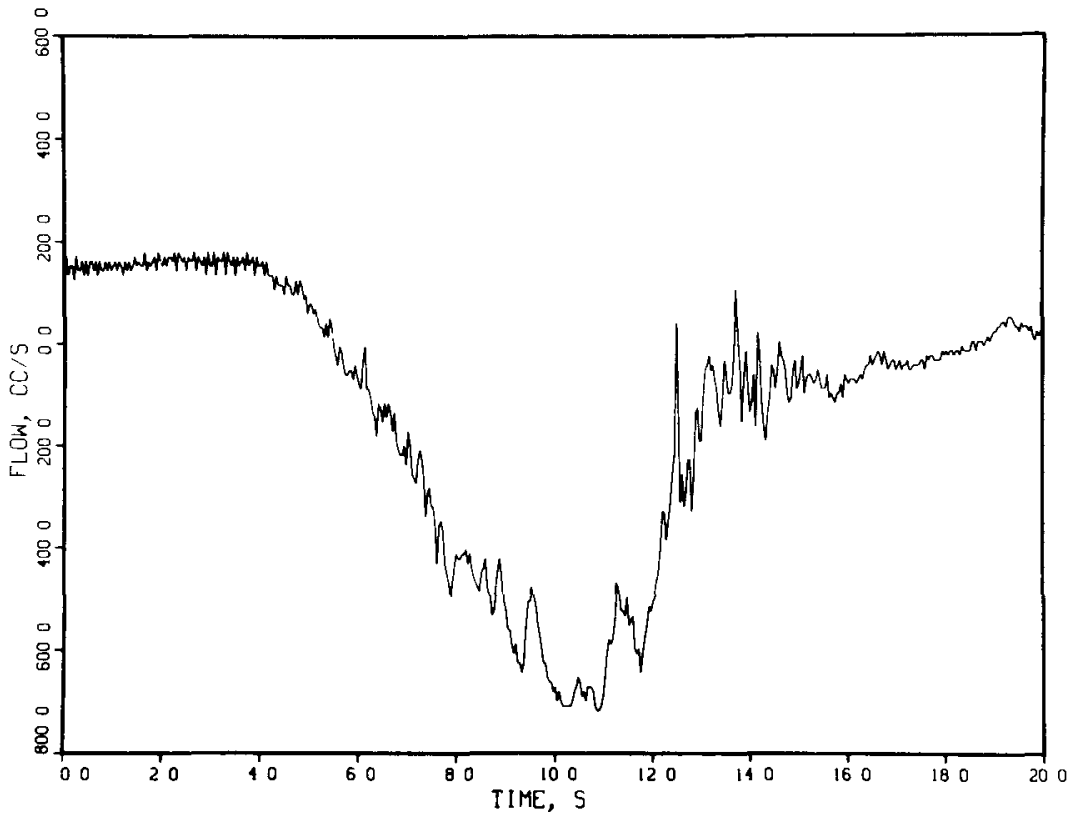

Fig. D.8. Outlet-flowmeter Data Recorded for Loss-offlow Test L5. ANL Neg. No. 900-77-431. 
Input data for calculations by the SAS3A code are listed in this appendix. No physical or geometric units are listed; the units are given in the input manual for the SAS3A code. 


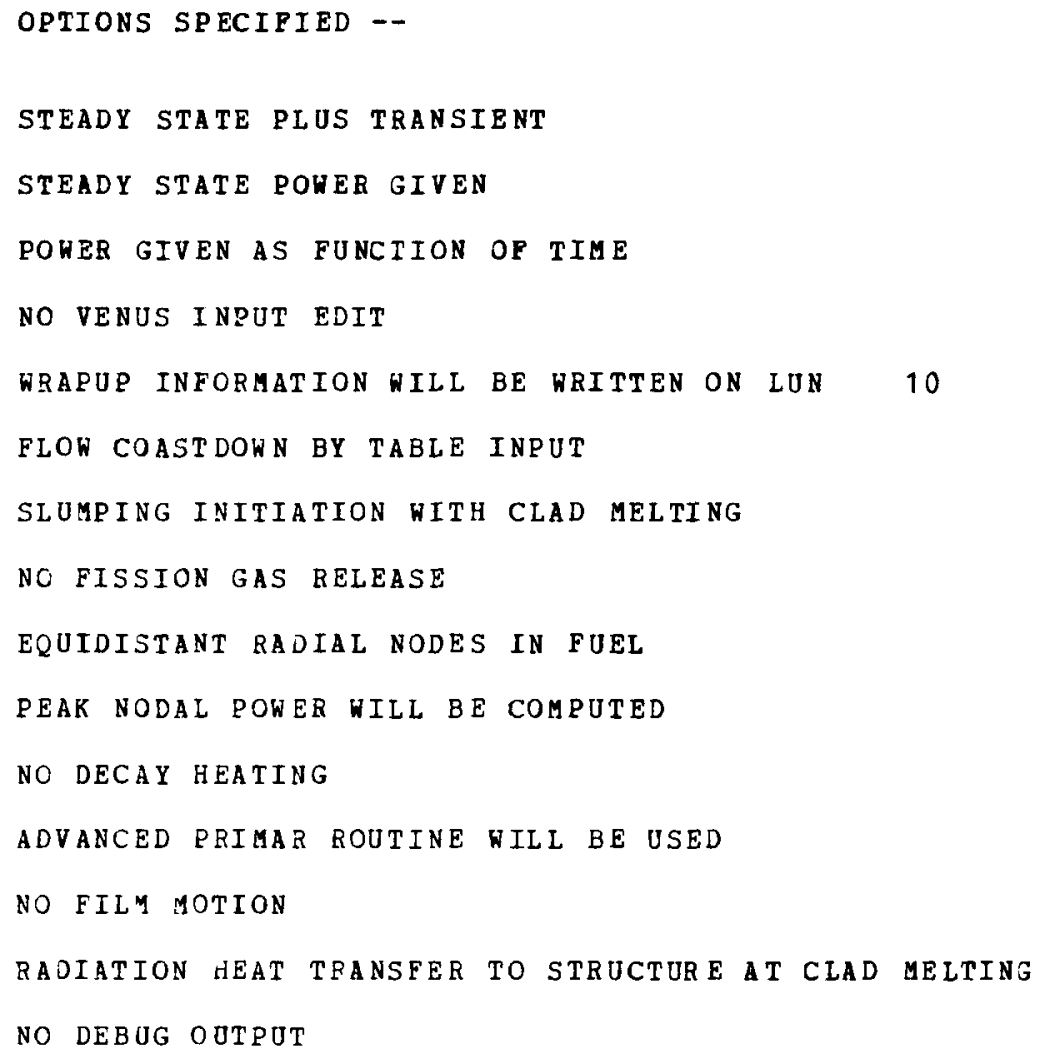

CHANNEL NUMBER

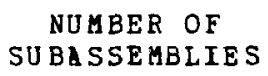

TOTAL NUBBER OP PINS

3
ZONE OP RESI DENCE 


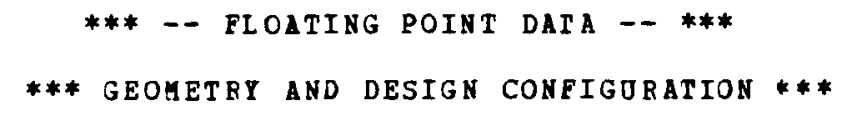

FRACTION OF TOTAL REACTOR POWER REPRESENTED

EXPLICITLY BY THE CHANNELS

FRACTION OF TOTAL COOLANT FLON REPRESENTED

HEIGHT OF PLENUM

EXPLICITLY BY THE CHANELS

HEIGHT OF LOWER REFLECTOR

HEIGHT OF UPPER REPLECTOR

MESH HEIGHT OF LONER REFLECTOR

MESH HEIGHT OF UPPER REFLECTOR

YESH HEIGHT OF PLENUM

NUMBER OF NODES IN LONER FEFLECTOR

NUMEER OF NODES IN UPPER REFLECTOR

NUMBER OF NODES IN PLENUM

REFERENCE DESIGN TEMPERATURE

COOLANT INLET TEMPERATURE

COOLANT EXIT PRESSUBE

GEOMETRY AND DESIGN FOR CHANNEL 1

STRUCT'JRAL THICKNESS

STRUCTURE-CLAD SURFACE AREA RATIO

VOLUME FRACTION OF COOLANT

LENGTH OF FUEL IN PIN

INERTIAI LENGTH ABOVE CORE

INERTIAL LENGTH BELON CORE

LENGTH OF COOLANT CONSIDERED

NOMINAL CLAD BADIUS USED FOR COOLANT

FRACTION OF PINS FROM GROUP 1

$\begin{array}{cl}\text { FUEL NODE } & \text { RADII } \\ \text { NUMBER } & \text { INNER } \\ 1 & 0.0 \\ 2 & 0.0 \\ 3 & 0.0 \\ 4 & 0.0 \\ 5 & 0.0 \\ 6 & 0.0 \\ 7 & 0.0 \\ 8 & 0.0 \\ 9 & 0.0 \\ 10 & 0.0 \\ 11 & 0.0 \\ 12 & 0.0 \\ 13 & 0.0 \\ 14 & 0.0 \\ 15 & 0.0 \\ 16 & 0.0 \\ 17 & 0.0 \\ 18 & 0.0 \\ 19 & 0.0 \\ 20 & 0.0\end{array}$

\begin{abstract}
OUTER FUEL
2.52100D-01

$2.52100 \mathrm{D}-01$

2. $52100 \mathrm{D}-01$

2.52100D-01

2. $52100 \mathrm{D}-01$

2.52100D-01

2.52100D-01

2. $52100 \mathrm{D}-01$

2. 52100D-01

2. $52100 \mathrm{D}-01$

2.52100D-01

2. $52100 D-01$

$2.52100 D-01$

2. 52100D-01

$2.52100 D-01$

2.52100D-01

2.52100D-01

2.52100D-01

2. $52100 \mathrm{D}-01$

2.52100D-01
\end{abstract}

1.00000000

1.00000000

$3.09900 \mathrm{D} 01$

$1.00000 \mathrm{D} 00$

$1.43778 \mathrm{D} 02$

$1.00000 \mathrm{D} 00$

1. $43778 \mathrm{D} 02$

6. 19800D 00

2

2

$2.70000 \mathrm{DO} 01$

3.98900002

$1.50000 \mathrm{D} 00$

1. 39700D-01

8. $41000 D-01$

4. $16330 \mathrm{D}-01$

9.87460001

5.34000000

$7.04000 \mathrm{D} 00$

$2.74515 \mathrm{D} 02$

2. $92000 D-01$

9. $80000 \mathrm{D}-01$

INNER =LAD

OUTER CLAD 2. 54000D-01

2. $54000 \mathrm{D}-01$

2. 54000D-01

2. $540000-01$

2. 54000D-01

2. $54000 \mathrm{D}-01$

2. 54300D-0 1

2. 540000-01

2. $54000 \mathrm{D}-01$

2. $54000 D-01$

2. $54300 D-01$

2. 54 J00D-01

2. 54J00D-0 1

2. 54 J00D-01

2. $54300 D-01$

2. 543000-01

2. $540000-01$

2. 54000D-0 1

2. $54000 \mathrm{D}-01$

2. $54300 \mathrm{D}-01$
2.92000D-0 1

2. $92000 \mathrm{D}-01$

2. $92000 \mathrm{D}-01$

2. $920000-01$

2. $92000 \mathrm{D}-01$

2. $92000 \mathrm{D}-01$

2. $92000 \mathrm{D}-01$

2. $920000-01$

2. $92000 \mathrm{D}-01$

2. $92000 \mathrm{D}-01$

2. $92000 \mathrm{D}-01$

2. $92000 \mathrm{D}-01$

2. $92000 \mathrm{D}-01$

2. $920000-01$

2. $920000-01$

2. $920000-01$

2. $92000 D-01$

2. $92000 \mathrm{D}-01$

2. $92000 D-01$

2. $92000 \mathrm{D}-01$ 
FUEL NODES

NU Y BER
1
2
3
4
5
6
7
8
9
10
11
12
13
14
15
16
17
18
19
20

$$
\begin{gathered}
\text { HEIGHT OF CENTEB } \\
5.55000 \mathrm{D}-01 \\
1.66500 \mathrm{D} 00 \\
2.85500 D 00 \\
6.57450 \mathrm{D} 00 \\
1.27435 \mathrm{D} 01 \\
1.89125 \mathrm{D} 01 \\
2.50815 \mathrm{D} 01 \\
3.12505 \mathrm{D} 01 \\
3.74195 \mathrm{D} 01 \\
4.35885 \mathrm{D} 01 \\
4.97575 \mathrm{D} 01 \\
5.59265 \mathrm{D} 01 \\
6.20955 \mathrm{D} 01 \\
6.82645 \mathrm{D} 01 \\
7.44335 \mathrm{D} 01 \\
8.06025 \mathrm{D} 01 \\
8.67715 \mathrm{D} 01 \\
9.04910 \mathrm{D} 01 \\
9.30310 \mathrm{D} 01 \\
9.68410 \mathrm{D} 01
\end{gathered}
$$

ALL FUEL NODES OF FUEL TYPE
MASS

1.73272000

$1.73272 \mathrm{D} \quad 00$

2.54796000

$1.23757 \mathrm{D} 01$

1.23767001

$1.23767 \mathrm{D} 01$

$1.23767 \mathrm{D} 01$

1.23767001

1.23767001

1.23767001

$1.23767 \mathrm{D} 01$

$1.23767 \mathrm{D} 01$

1.23767D 01

1.23767001

$1.23767 \mathrm{D} 01$

1.23767001

1. $23757 \mathrm{D} 01$

$2.54796 \mathrm{D} 00$

$5.947+4 \mathrm{D} 00$

$5.94744 \mathrm{D} 00$
L EN GT H

1. $11000 \mathrm{D} \mathrm{OO}$

1. $11000 \mathrm{D} \mathrm{OO}$

$1.27000 \mathrm{D} 00$

$6.16900 \mathrm{D} 00$

6.16900D 00

6. $16900 \mathrm{D} 00$

6. $16900 \mathrm{D} 00$

6. $16900 \mathrm{D} 00$ $6.16900 \mathrm{D} 00$

$6.16900 \mathrm{D} 00$

$6.16900 \mathrm{D} 00$

$6.16900 \mathrm{D} 00$

6. $16900 \mathrm{D} 00$

6. $16900 \mathrm{D} 00$

$6.16900 \mathrm{D} 00$

$6.16900 \mathrm{D} 00$

6. $16900 \mathrm{D} 00$

1. $27000 \mathrm{D} 00$

$3.81000 \mathrm{D} 00$

3.81000000

BLANKETS OP FUEL TYPE 2

$2.31000 \mathrm{D} 02$
* * Material PROperties ***

FUEL

MEITING TEMPERATJRE

LATENT HEAT OF MELTING

MOLECULAR WEIGHT

PUISSONS RATIO

EMISSIVITY OF THE PUEL

AXIAL RESTRAINT SPRING CONSTANT FOR CHANNEL 1

AXIAL RESTEAINT SPEING CONSTANT FOR CHANNEL

PRESSURE TO CRACK FUEL

YOUNGS MODULUS

* fuel type $1 *$

LIQUID FUEL BULK MODJLUS

YOUNGS MODULUS

* FUEL TYPE 2 *

LIQUID FUEI BULK MODULUS

MATERIAL PROPERTIES CONTINUED....

MINIMUY BOND CONDUCTANCE

* fuel clad interface for channel 1 *

BOND CONDJCTANCE PARAMETER

DAXIMOM BOND CONDUCTANCE (NO PEESSORE)

SLCPE OF BOND CONDUCTANCE VERSUS PRESSURE

STEFAN BOLTZMANNS CONSTANT * EMMISIVITY
$2.76700 \mathrm{D} 03$

$2.80000 \mathrm{D} 02$

$2.70000 \mathrm{D} 02$

2. $85000 \mathrm{D}-01$

$5.000000-01$

1.00000006

0.10000013

1.00000012

1. 10000012

5. $86000 \mathrm{D} \mathrm{Og}$

$5.86000 \mathrm{D} 09$

0.0

$2.28800 \mathrm{D}-04$

1.00000000

0.0

$4.56800 \mathrm{D}-12$ 
MATERIAL PROPERTIES CONTINUED....

* CladDing *

MEITING TEUPERATURE

COEFFICIENT OF LINEAR EXPANSION

SPECIFIC HEAT * DENSITY

THERMAL CONDUCIIVITY

POISSONS RATIO

IATENT HEAT OF MELTING

SPECIFIC HEAT

AVERAGE DENSITY

THERMAL RESISTANCE AT CLAD MELTING

PRICTION COEFEICIENT

BLOCKAGE PARAMETER

VISCOSITY OF CLAD AT IIQUIDUS

VISCOSITY OF CLAD AI SOLIDUS

EFFECTIVE VISCOSITY OF SOLID CLAD

* Clad coolant interface*

HEAT TRANSFER CONDUCTANCE AT CLAD BURNOUT

COEFFICIENTS IN FILM CONDUCTANCE EQUATION

$1.00000 D-02$

$1.603000-02$

8. $60000 \mathrm{D}-01$

4. $55000 \mathrm{D} 00$

* Coolant*

$\begin{array}{ll}\text { LIQUID FRICTION FACTOR COEFFICIENTS } & \text { AFR } \\ & \text { BFE } \\ \text { VAPOR FRICTION FACTOR COEFFICIENTS } & \text { AFR } \\ & \text { BPR } \\ \text { FILM FRICTION FACTOR COEFFICIENTS } & \text { AFR } \\ \text { BRIMAKI LOOP FRICTION COEFFICIENTS } & \text { AFR } \\ & \text { BFR }\end{array}$

1. $99220 \mathrm{D}-01$

$-2.00000 D-01$

3. $16000 \mathrm{D}-01$

$-2.50000 \mathrm{D}-01$

3. $16000 \mathrm{D}-01$

$-2.50000 D-01$

1. $99220 \mathrm{D}-01$

$-2.00000 \mathrm{D}-01$

DEGREES OF SUPERHEAT

INITIAL FILM THICKNESS ON CLAD

MINIMUM FILM THICKNESS ON CLAD

INITIAL FIL THICKNESS ON STRUCTORE

MINIMUY FILM THICKNESS ON STRUCTURE

CONDENSATION HEAT TEANSFER CONDUCTANCE

FLOW CONTRACTION HEAD LOSS COEPFICIENT

FLOW EXPANSION HEAD LOSS COEFFICIENT

MINIMUM INITIAL SLJG LENGTH

BUBBLE LENGTH FOR START OF PRES. GRAD. CALC.

FRACTION OF TWO - PHASE FRICTION

RATIO OF INITIAL FILA/LIQUID SLJG VELOCITIES

EMISSIVITY OF THE COOLANT

MINIMUM BUBBLE LENGTH FOF FILM FLOW

5.00000000

$1.00000 D-02$

$6.67000 \mathrm{D}-03$

$1.00000 D-02$

$6.670000-03$

6.30000000

1.00000000

$1.00000 \mathrm{D} 00$

6.00000D-01

5.00000000

1. 00000000

3. $000000-01$

2. $.000000-01$

1.00000000

MATEEIAL PROPERTIES CONTINUED.....

* coolant*

CHANNEL NUMBER 1

LOWEB REFLECTOR HYDRAULIC DIAMETER

1. $90500 \mathrm{D} 00$

2. $26271 \mathrm{D}-01$

1. 90500000

7. 50000000

7. $50000 \mathrm{D} 00$

UNBLOCKED ORIFICE PRESSURE DROP COEFFICIENT

BLOCKED ORIFICE PRESSURE DROP COEFFICIENT

ORIFICE BLOCKING TIUE

0.0 
MATERIAL PROPERTIES CONTINOED.....

* Structure*

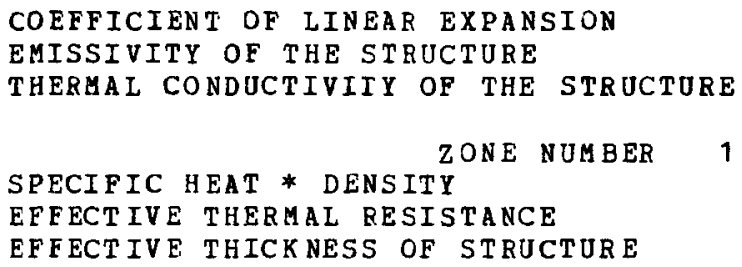

* REFLECTOR *

THERMAL CONDUCTIVITY OF THE REFLECTOR

2. $18070 \mathrm{D}-01$ EFFECTIVE KEFLECTOR THICKNESS

EFFECTIVE REFLECTOR THERMAL RESISTANCE

$1.46000 \mathrm{D}-01$

3. $347550-01$

SPECIFIC HEAT * DENSITY OF REFLECTOR

STRUCTURE-REFLECTOK EFFECTIVE TRANSIENT TIME

4. $77900 \mathrm{D} 00$

4.00000000

* plenum gas *

CHANNEL NUMBER 1

SPECIFIC HEAT * DENSITY OF PLENUM GAS

THERMAL RESISTANCE OF PLENUM GAS

1. $25000 \mathrm{D}-02$

6. 00000002

*** PEIMARY COOLANT LOOP DATA ***

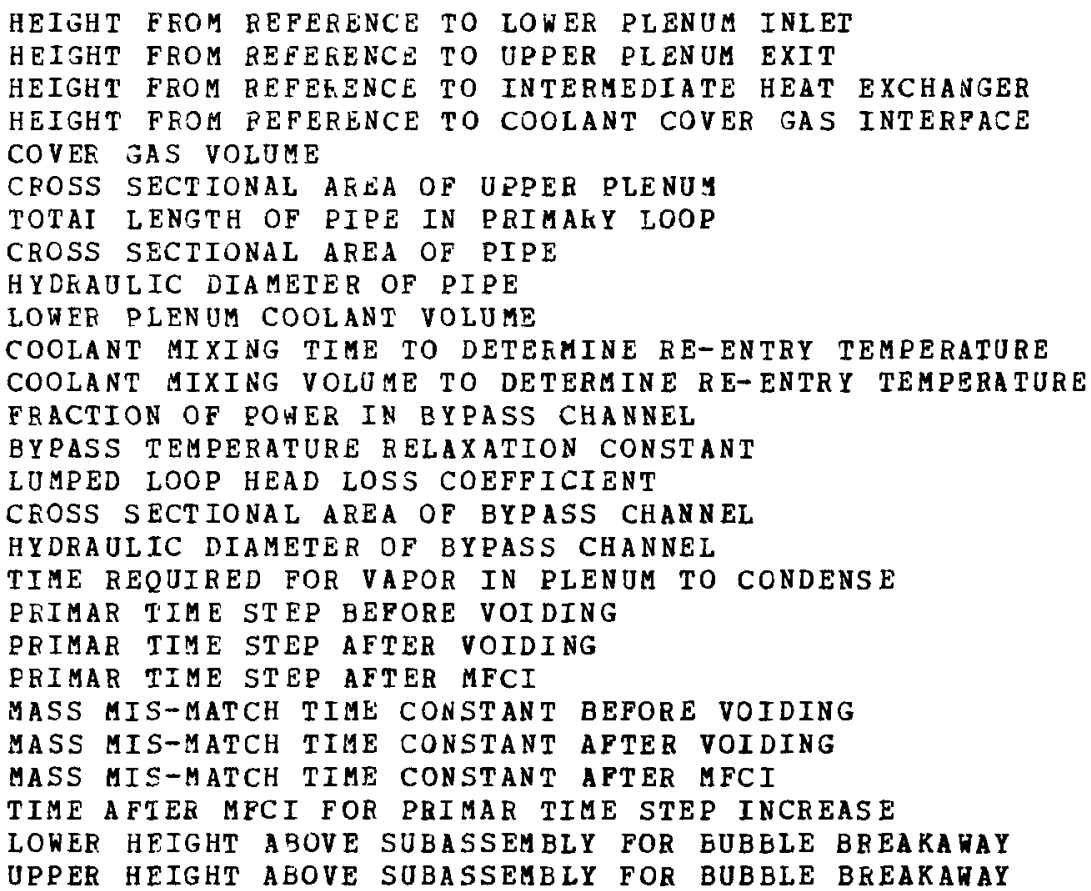

$1.00000 \mathrm{D} 01$
$1.77700 \mathrm{D} 02$
$1.18100 \mathrm{D} 02$
$1.86600 \mathrm{D} 02$
$1.01680 \mathrm{D} 03$
$2.03000 \mathrm{D} 01$
$1.11800 \mathrm{D} 02$
$5.81000 \mathrm{D}-01$
$1.54000 \mathrm{D}-01$
$2.85000 \mathrm{D} 01$
0.0
0.0
0.0
0.0
$5.00000 \mathrm{D}-01$
$1.00000 \mathrm{D}-20$
$1.00000 \mathrm{D}-10$
$1.00000 \mathrm{D} 00$
$5.00000 \mathrm{D}-02$
$2.00000 \mathrm{D}-02$
$2.00000 \mathrm{D}-02$
$1.00000 \mathrm{D}-01$
$5.00000 \mathrm{D}-02$
$2.00000 \mathrm{D}-02$
$1.00000 \mathrm{D}-01$
$1.00000 \mathrm{D} 01$
$2.50000 \mathrm{D} 01$


STEADY STATE PONER IN THE PEAK NODE

TOTAL REACTOR POWER

FRACT. OF TOTAL POHER IN DIRECT HEATING OF CLAD

FRACT. OF TOTAL PONER IN DIRECT HEATING OF COOLANT

FRACT. OF TOTAL POHER IN DIRECT HEATING OF STRUCTORE

POHER DATA FOR CHANNEL

1

STEADY STATE TOTAL PONER IN THE PIN

RADIAL POWER FACTOR

RELATIVE FLUX DISTRIBUTION IN EACH RADIAL NODE

$$
\begin{array}{rr}
2 & 4.06000 \mathrm{D}-01 \\
6 & 5.09000 \mathrm{D}-01 \\
10 & 1.00000 \mathrm{D} 00
\end{array}
$$

$34.14000 D-01$

$7 \quad 5.710000-01$
5. 25710D 01

$1.78200 \mathrm{D} 03$

$1.00000 \mathrm{D}-02$

0.0

$5.00000 D-02$

5.94000002 1.00000D 00

NORMALIZED PONER GENERATION IN EACH AXIAL NODE

$\begin{array}{rlrlrlrl}1 & 0.0 & 2 & 0.0 & 3 & 0.0 & 4 & 6.16000 \mathrm{D}-01 \\ 5 & 7.72000 \mathrm{D}-01 & 6 & 8.60000 \mathrm{D}-01 & 7 & 9.28000 \mathrm{D}-01 & 8 & 9.68000 \mathrm{D}-01 \\ 9 & 9.80000 \mathrm{D}-01 & 10 & 1.00000 \mathrm{D}-00 & 11 & 9.68000 \mathrm{D}-01 & 12 & 9.28000 \mathrm{D}-01 \\ 13 & 8.20000 \mathrm{D}-01 & 14 & 7.76000 \mathrm{D}-01 & 15 & 6.15000 \mathrm{D}-01 & 16 & 5.72000 \mathrm{D}-01 \\ 17 & 4.9600 \mathrm{D}-01 & 18 & 0.0 & 19 & 0.0 & 20 & 0.0\end{array}$

PROGRAMMED POWER

$$
\begin{array}{cl}
\text { NORMALIZED } & \text { POWER } \\
1.00000 D & 00 \\
1.00000 D & 00 \\
1.10000 D & 00 \\
1.20000 D & 00 \\
4.28000 D & 01 \\
4.28000 D & 01 \\
4.28000 D & 01 \\
4.28000 D & 01 \\
6.16000 D & 01 \\
1.12000 D & 02 \\
1.97400 D & 02 \\
2.40100 D & 02 \\
1.20400 D & 02 \\
3.20000 D & 00 \\
2.80000 D & 00
\end{array}
$$

FADIAL NODE TO CHECK FOR STAET OF SLUMPING TEMFERATURE FOR START OF SLUMPING

FUEL MEIT FRACTION BOA START OF SLUMPING

** operational CONTROLS ***

* STEADY STATE*
0.0

TIME

$2.00000 \mathrm{D}-02$

1. 30000D 00

2. $60000 \mathrm{D} 00$

$2.90000 \mathrm{D} 00$

4.02000000

7.02000D 00

1. $18200 \mathrm{D} 01$

1. $20200 \mathrm{D} 01$

1.25000D 01

1.30200D 01

1. 34200001

1.35000D 01

1. 42200001

1.80200001

4. $33000 \mathrm{D}-01$

6. $10000 D-01$

0.0

8

$2.766900 \quad 03$ $5.000000-01$

0.0

0.0 
MORGALIZED PUMP PRESSURE-TIME

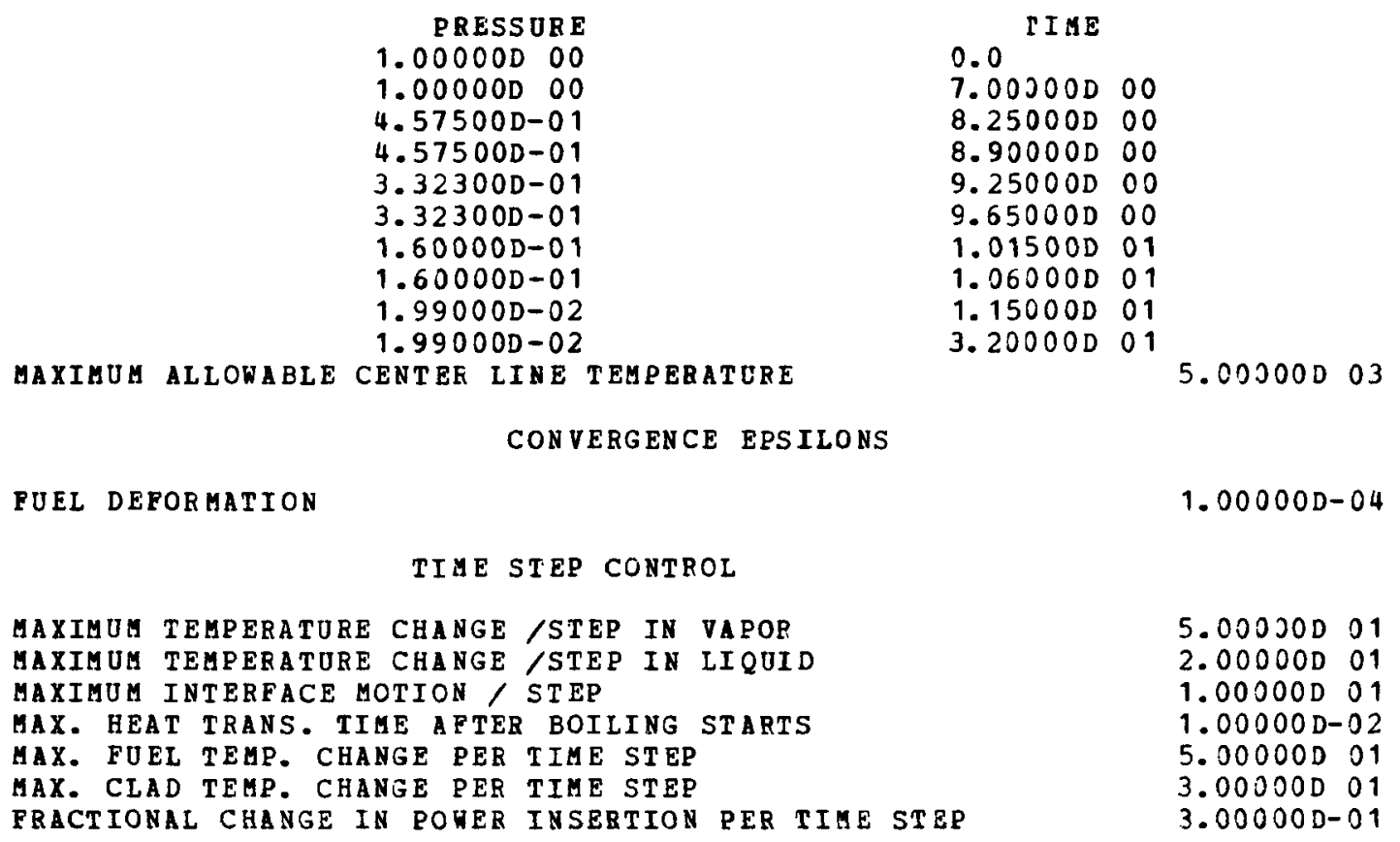


THE SLUGPING DEBOG PARAMETEE

THE LOGICAL UNIT NOMBEF FOR CALCOMP OOTPUT

VALUE OF ITEMP. IF GREATER THAK O, FUEL TEMPERATURES VILE INCLUDE HEAT OF VAPOBIZATIOH

HAX NUMBER OF SLUAPY TIUE STEPS PER ENTEY BEFORE ATTEUPTING ARTIFICIAL EQ. OF STATE

HEAT TRANSFER FRCM SLUMPED REGION TO STEUCTURE

THE NUMBER CF NODES FROM CORE OSITTED FROH REACTIVITY CONSIDERATIONS

THE NUMEER NODES IN COEE + BLANKET OHITTED FROA INERTIA CONSIDERATIONS IN UPPER SEG.

DECAY EXPONENT ABCVE FUEL FOR FUEL WORTHS

THE FRACTION CF GRAVITATIONAL ACCELERATION IS

DENSITY OF LIQUID FUEL FOR CALCULATING KEZONIGG AHD FISSION GAS PRESSURES

VISCOSITY OF MOLTEN FUEL

MULTIPLIER CF THE PSEUDO-TISCOUS PRESSURE

THE HEAT TRANSFEP COEFPICIENT FBOH RESTRUCTURED TO UNRESTRUCTOEED FUEL

HALL FRICTION FACIOR FOR SLUAPING FUEL.

HYD. DIA. IN SLUAPED ZONE

HYD. DIA. IN UNCLAD FUEL ZONE

HYD. DIA. IN CLAD ZONE

EXTRA MASS TO ASSOCIATE WITH THE TOP FUEL SEGMENT

EXTRA AREA AVALLALE IN THE SLUMPE REGION IS

HEAT TRANSFE COEFFICIENT FEOL EUEL TO ENTEAPPED STEEL

THE FUEL THERHAL CONCUCTIVITY IN SLUAPY

THE FUEL HEAT CAPACITY IN SLUUPY

THE MOLTEN STEEL HEAT CAPACITY I SLUMPY

THE MOLTEN STEEL CONDUCTTVITY IN SLUMPY

THE MOLTEN STEEL DENSITY FOF SLUMPY THEBMAL CALCULATIONS

0
12
1
5000
0
0

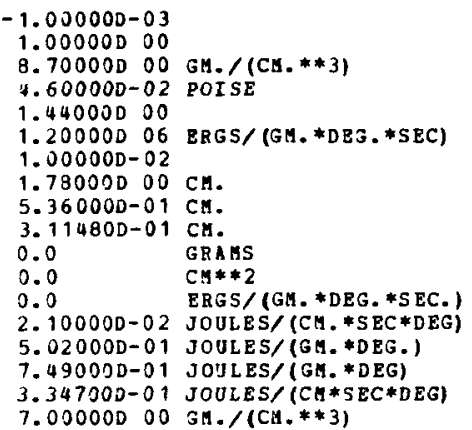

CHANNEL DEPENDENT INPUT

BUIN IS THE LOHER CLAD BLOCKAGE POSITIOH.

GJF IS THE EXTRA UPPEE SEGHENT PORCE(DYRES).

RMAX IS THE UPPEE CLAD BLOCKAGE POSITION.

QSODOH IS THE SODIUM VAPOR FRICTION MULTIPLIER.

PPOSUP IS IHE MAX UPWAEL PLENOH LOVEGENT.

IRETON IS THE BASIC LOGICAL CONTROL PARAHETER.

VISFU IS THE SOLID FUEL VISCOSITY ADJUSTEENT.

FESSR IS THE (GM. OF STAINLESS STEEL)/(GM. OF FUEL) IN THE SLUMPED RQGION.

PABBER IS THE AMBIENT PRESSURE IN THE CHANNEL (DYNES/CH**2)

PDHTR IS THE MULTIPLIER FOR FUEL TO STRUCTURE HEAT TRANSFER

SLFLRT IS THE VAPOR FLCW RATE NECESSARY POR START OF SLUMPING (GRAAS/(SEZ*Za**2)

\begin{tabular}{|c|c|c|c|c|c|c|c|c|c|c|c|}
\hline CHANNEL & 1 & & 2 & 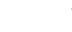 & 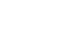 & 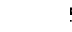 & 6 & & 8 & 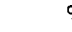 & 10 \\
\hline $\begin{array}{l}\text { RMIN } \\
\text { GJF } \\
\text { FGHRAT } \\
\text { RMAX } \\
\text { QSODUH } \\
\text { EROSUF }\end{array}$ & $\begin{array}{l}0.0 \\
0.0 \\
1.0000 \mathrm{D} \\
3.0000 \mathrm{D} \\
3.0000 \mathrm{D} \\
0.0\end{array}$ & $\begin{array}{l}08 \\
02 \\
02\end{array}$ & $\begin{array}{l}0.0 \\
0.0 \\
0.0 \\
0.0 \\
0.0 \\
0.0\end{array}$ & $\begin{array}{l}0.0 \\
0.0 \\
0.0 \\
0.0 \\
0.0 \\
0.0\end{array}$ & $\begin{array}{l}0.0 \\
0.0 \\
0.0 \\
0.0 \\
0.0 \\
0.0\end{array}$ & $\begin{array}{l}0.0 \\
0.0 \\
0.0 \\
0.0 \\
0.0 \\
0.0\end{array}$ & $\begin{array}{l}0.0 \\
0.0 \\
0.0 \\
0.0 \\
0.0 \\
0.0\end{array}$ & $\begin{array}{l}0.0 \\
0.0 \\
0.0 \\
0.0 \\
0.0 \\
0.0\end{array}$ & $\begin{array}{l}0.0 \\
0.0 \\
0.0 \\
0.0 \\
0.0 \\
0.0\end{array}$ & $\begin{array}{l}0.0 \\
0.0 \\
0.0 \\
0.0 \\
0.0 \\
0.0\end{array}$ & $\begin{array}{l}0.0 \\
0.0 \\
0.0 \\
0.0 \\
0.0 \\
0.0\end{array}$ \\
\hline $\begin{array}{l}\text { IRETUN } \\
\text { VISFU } \\
\text { FESSR } \\
\text { PAMBER } \\
\text { PDHTR } \\
\text { SLFIRT }\end{array}$ & $\begin{array}{l}1.0000 D \\
0.0 \\
2.0500 D \\
1.0000 D \\
-1.0000 D\end{array}$ & $\begin{array}{l}02 \\
06 \\
00 \\
02\end{array}$ & $\begin{array}{l}0.0 \\
0.0 \\
0.0 \\
0.0 \\
0.0\end{array}$ & $\begin{array}{l}0.0 \\
0.0 \\
0.0 \\
0.0 \\
0.0\end{array}$ & $\begin{array}{l}0.0 \\
0.0 \\
0.0 \\
0.0 \\
0.0\end{array}$ & $\begin{array}{l}0.0 \\
0.0 \\
0.0 \\
0.0 \\
0.0\end{array}$ & $\begin{array}{l}0.0 \\
0.0 \\
0.0 \\
0.0 \\
0.0\end{array}$ & $\begin{array}{l}0.0 \\
0.0 \\
0.0 \\
0.0 \\
0.0\end{array}$ & $\begin{array}{l}0.0 \\
0.0 \\
0.0 \\
0.0 \\
0.0 \\
0.0\end{array}$ & $\begin{array}{l}0.0 \\
0.0 \\
0.0 \\
0.0 \\
0.0\end{array}$ & $\begin{array}{l}0.0 \\
0.0 \\
0.0 \\
0.0 \\
0.0\end{array}$ \\
\hline
\end{tabular}

FISSION GAS INPUT FCA SLUMPY

THE GAS CONSTANT

THE FUEL PABTICLE DI AMETER

$6.34000 D 05$ (DYNES-CH.) / (GH.*DEG. K)

THE FISSION GAS VI SCOSITY

FISSION GAS CCNCENTRATIONS CALCULATED IN SSFUEL

THE CHANNEL DEPENDENT PISSION GAS INPUI

IF ISLIP IS GEEATER THAN ZERO, SLIP IS CALCULATED

FGASBP IS THE DENSITY OE FISSION GAS BELON THE SLUAPED REGION

QON 1 IS THE TOTAI FRACTION OF STEADY STATE FISSION GAS AVAILABLE FOR SLUMPY UTILIZATION

YCON1 IS THE TIME CONSTANT (SECONDS) FOR BELEASE OF GAS FROM MOLTEN PURL

YCON2 IS THE TIME CONSTANT (SECONDS) FOR BELEASE OF GAS FROM SOLID FUEL

YCON3 IS THE DEPAULT FOR GAS CONCENTRATION (GH. GAS/GH. FUEL)

QON 2 IS THE PRACTION OF FISSION GAS AVALLABLE TO SLUMPY UPON INITIATION OF SLUAPING IN A FUEL NODE

\begin{tabular}{|c|c|c|c|c|c|c|c|c|c|c|}
\hline C HA NNE L & 1 & 2 & 3 & + & 5 & 6 & 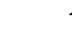 & 8 & 9 & 10 \\
\hline $\begin{array}{l}\text { ISL IP } \\
\text { QON } 1 \\
\text { YCON1 } \\
\text { YCON2 } \\
\text { YCON } 3 \\
\text { QON2 } \\
\text { FGASBP }\end{array}$ & $\begin{array}{l}1 \\
5.0000 \mathrm{D}-01 \\
1.0000 \mathrm{D}-01 \\
3.0000 \mathrm{D} 00 \\
2.4000 \mathrm{D}-03 \\
1.0000 \mathrm{D}-01 \\
0.0\end{array}$ & $\begin{array}{l}0.0 \\
0.0 \\
0.0 \\
0.0 \\
0.0 \\
0.0\end{array}$ & $\begin{array}{l}0.0 \\
0.0 \\
0.0 \\
0.0 \\
0.0 \\
0.0 \\
0.0 .\end{array}$ & $\begin{array}{l}0.0 \\
0.0 \\
0.0 \\
0.0 \\
0.0 \\
0.0 \\
0.0\end{array}$ & $\begin{array}{l}0.0 \\
0.0 \\
0.0 \\
0.0 \\
0.0 \\
0.0 \\
0.0\end{array}$ & $\begin{array}{l}0.0 \\
0.0 \\
0.0 \\
0.0 \\
0.0 \\
0.0 \\
0.0\end{array}$ & $\begin{array}{l}0.0 \\
0.0 \\
0.0 \\
0.0 \\
0.0 \\
0.0\end{array}$ & $\begin{array}{l}0.0 \\
0.0 \\
0.0 \\
0.0 \\
0.0 \\
0.0\end{array}$ & $\begin{array}{l}0.0^{3} \\
0.0 \\
0.0 \\
0.0 \\
0.0 \\
0.0\end{array}$ & $\begin{array}{l}0.0 \\
0.0 \\
0.0 \\
0.0 \\
0.0 \\
0.0\end{array}$ \\
\hline
\end{tabular}


FUEL THERHAL CONDUCTIVITY

$$
\begin{aligned}
& \text { CONDUCTIVITY } \\
& 8.46289 D-02 \\
& 5.58610 D-02 \\
& 4.17819 D-02 \\
& 3.52417 D-02 \\
& 3.05928 D-02 \\
& 2.71768 D-02 \\
& 2.46240 D-02 \\
& 2.27129 D-02 \\
& 2.13042 D-02 \\
& 2.03074 D-02 \\
& 1.96619 D-02 \\
& 1.93273 D-02 \\
& 1.92761 D-02 \\
& 1.94900 D-02 \\
& 1.99572 D-02 \\
& 2.06707 D-02 \\
& 2.16269 D-02 \\
& 2.23986 D-02 \\
& 2.39177 D-02 \\
& 2.38576 D-02
\end{aligned}
$$

TEMPERATURE

$$
0.0
$$

$2.000000 \quad 02$

4. 00000002

$5.50000 \mathrm{D} 02$

7. 00000002

8.50000002

$1.00000 \mathrm{D} 03$

1. $15000 \mathrm{D} 03$

$1.30000 \mathrm{D} 03$

$1.45000 \mathrm{D} 03$

1.60000003

1.75000003

1. 90000003

2. $05000 \mathrm{D} 03$

2.20000003

2.35000D 03

2.50000003

$2.60000 \mathrm{D} 03$

$2.765000 \quad 03$

$5.00000 \mathrm{D} 03$

FUEL DENSITY

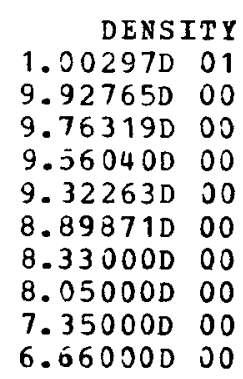

FUEL SPECIFIC HEAT

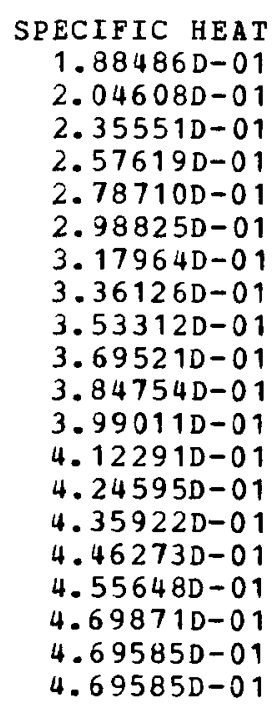

SPECIFIC HEAT 86D-01

2. $35551 \mathrm{D}-01$

2. $57619 D-01$

. $78710 \mathrm{D}-01$

3. $17964 \mathrm{D}-01$

$3.36126 \mathrm{D}-01$

3. $53312 \mathrm{D}-01$

3. $99011 \mathrm{D}-01$

4. $122910-01$

4. $35922 \mathrm{D}-01$

$273 D-01$

4. $69871 \mathrm{D}-01$

$4.69585 \mathrm{D}-01$
TEMPERATJRE 1.0000JD 02 $5.000000 \quad 02$ 1.000JJD 03 $1.50000 \mathrm{D} 03$ 2. $0000 J 003$ 2.76700003 $2.76700 D \quad 03$ 3. 00000003 4. $00000 \mathrm{D} 03$ $5.000000 \quad 03$
TEMPEEATURE

1. $00000 \mathrm{D} \quad 02$ 2. $00000 \mathrm{D} \quad 02$

4. $0000 J \mathrm{D} 02$

$5.50000 \mathrm{D} 02$

7. $00000 \mathrm{D} 02$

8. $50000 \mathrm{D} 02$

1. $00000 \mathrm{D} 03$

1. $15000 \mathrm{D} 03$

1. 30000003

$1.45000 \mathrm{D} 03$

$1.600000 \quad 03$

1.75000003

1. $90000 \mathrm{D} 03$

2. $05000 \mathrm{D} \mathrm{O3}$

$2.200000 \quad 03$

2. $350000 \quad 03$

2.50000D 03

2.76600D 03

2.76800D 03

$5.000000 \quad 03$ 


$$
\begin{aligned}
& \text { YIELD POINT } \\
& \text { 8.48000D } 09 \\
& 7.580000 \quad 09 \\
& \text { 7. } 14000 \mathrm{D} 09 \\
& 6.96000 \mathrm{D} 09 \\
& 6.76000 D 09 \\
& 6.36000 \mathrm{D} 09 \\
& \text { 4.62000D } 09 \\
& 2.62000 \mathrm{D} 09 \\
& \text { 1.38000D 09 } \\
& 3.45000 \mathrm{D} 08 \\
& 0.0
\end{aligned}
$$

TE MPERAT URE $-1.78000 \mathrm{D} 01$ 9.33000D 01 2. $04400 \mathrm{D} 02$ $3.15600 \mathrm{D} 02$ 4. $26700 \mathrm{D} \mathrm{O2}$ 5. $37800 \mathrm{D} \quad 02$ $6.48900 \mathrm{D} 02$ 7.60000002 8.7110OD O2 $9.82200 \mathrm{D} 02$ $1.37500 \mathrm{D} \mathrm{O} 3$

CLAD YOUNGS MODULUS

MODULUS

8.41800011

$7.41800 \mathrm{D} 11$

$7.44800 \mathrm{D} 11$

$6.81000 \mathrm{D} 11$

$6.06000 \mathrm{D} 11$

5. 18400D 11

4. 16500D 11

0.0

0.0

0.0
TEMPERATURE $1.00000 D 02$

$5.00000 \mathrm{D} \quad 02$

1.00000D 03

$1.1 \mathrm{COOOD} 03$

1.20000003

$1.30000 \mathrm{D} 03$

1.40000003

1.50000D 03

2. $00000 \mathrm{D} 03$

3.00000003

*** TABULAR PROPERTIES ***

FUEL TYPE 2

FUEL THEEMAL CONDUCTIVITY

$$
\begin{aligned}
& \text { CONDUCTIVITY } \\
& 1.70000 D-01 \\
& 1.90000 D-01 \\
& 2.15000 D-01 \\
& 2.20000 D-01 \\
& 2.40000 D-01 \\
& 2.60000 D-01 \\
& 2.80000 D-01 \\
& 2.95000 D-01 \\
& 2.99000 D-01 \\
& 3.21000 D-01 \\
& 3.42000 D-01 \\
& 3.67000 D-01 \\
& 3.67000 D-01 \\
& 3.67000 D-01 \\
& 3.67000 D-01 \\
& 3.67000 D-01 \\
& 0.0 \\
& 0.0 \\
& 0.0 \\
& 0.0
\end{aligned}
$$

TEMPERATURE 0.0

2.00000002 4.00000D 02 $5.500000 \quad 02$ 7. 00000002 $8.500000 \quad 02$ 1.00000003 1. $15000 \mathrm{D} 03$ $1.30000 \mathrm{D} 03$ $1.45000 \mathrm{D} 03$ $1.60000 \mathrm{D} 03$ 1. $75000 \mathrm{D} \quad 03$ $1.90000 \mathrm{D} 03$ $2.05000 \mathrm{D} 03$ 2. $20000 \mathrm{D} \quad 03$ 2.35000D 03 2.50000003 2. $60000 \mathrm{D} 03$ $2.76600 \mathrm{D} \quad 03$ 5.00000003

FUEL DENSITY

DENSITY

$7.80000 \mathrm{D} \mathrm{00}$

$7.70000 \mathrm{D} \quad 00$

$7.50000 \mathrm{D} \quad 00$

$7.24000 \mathrm{D} 00$

$7.06000 \mathrm{D} 00$

$7.06000 \mathrm{D} 00$

7.06000D 00

7.06000000

7. $06000 \mathrm{D} 00$

$7.06000 \mathrm{D} 00$
TEMPEEATURE 1.00000D 02 5. $00000 \mathrm{D} 02$ $1.000000 \quad 03$ 1. $50000 \mathrm{D} 03$ $2.00000 \mathrm{D} \quad 03$ 2.76700D 03 2.76700D 03 3. $00000 \mathrm{D} 03$ 4. $00000 \mathrm{D} 03$ 5. $00000 \mathrm{D} 03$ 
FUEL SPECIFIC HEAT

$$
\begin{array}{r}
\text { SPECIFIC HEAT } \\
5.45000 D-01 \\
5.50000 D-01 \\
5.63000 D-01 \\
5.72000 D-01 \\
6.00000 D-01 \\
6.20000 D-01 \\
6.30000 D-01 \\
6.40000 D-01 \\
6.57000 D-01 \\
6.60000 D-01 \\
6.60000 D-01 \\
6.80000 D-01 \\
6.95000 D-01 \\
7.15000 D-01 \\
7.15000 D-01 \\
7.15000 D-01 \\
7.15000 D-01 \\
7.15000 D-01 \\
7.15000 D-01 \\
7.15000 D-01
\end{array}
$$

CLAD YIELD POINT

$$
\begin{array}{ll}
\text { YIELD } & \text { POINT } \\
6.670000 & 09 \\
5.97000 D & 09 \\
5.65000 D & 09 \\
5.48000 D & 09 \\
5.32000 D & 09 \\
5.00000 D & 09 \\
3.64000 D & 09 \\
2.36000 D & 09 \\
1.09000 D & 09 \\
2.720000 & 08 \\
0.0 &
\end{array}
$$

CLAD YOUNGS MODULUS
TEMPERATURE

$1.000000 \quad 02$

2. $00000 \mathrm{D} 02$

4.00000D 02

$5.50000 D \quad 02$

$7.00000 \mathrm{D} \quad 02$

$8.50000 \mathrm{D} 02$

$1.00000 D 03$

$1.15000 \mathrm{D} 03$

1.30000D 03

1.45000003

1.6000गD 03

$1.75000 \mathrm{D} 03$

1. $90000 \mathrm{D} 03$

$2.05000 \mathrm{D} 03$

2. $20000 \mathrm{D} 03$

2. $35000 \mathrm{D} 03$

2. $50000 \mathrm{D} 03$

2.76600003

2.76800D 03

5.00000003

TEMEERATURE $-1.78000 \mathrm{D} 01$ 9.33000D 01 2. $04400 \mathrm{D} \mathrm{O2}$ 3. $15600 \mathrm{D} 02$ 4. $26700 \mathrm{D} 02$ 5. $37800 \mathrm{D} 02$ $6.48900 \mathrm{D} 02$ $7.60000 \mathrm{D} 02$ $8.711000 \quad 02$ 9.82200002 1. $375000 \quad 03$

TEMPERATURE 1.0000OD 02 5.00000002 1.00000D 03 1.10000003 1.20000D 03 1. 30000003 1. 40000003 $1.50000 \mathrm{D} 03$ 2.0000OD 03 3.00000003

FUEL-COOLANT INTERACTION INPUT

FUEL TYPE FOR FUEL DENSITIES AND THERMAL CONDUCTIVITIES

FUEL-COOLANT INTERACTION PRINT OPTION

WO FUEL-COOLANT INTERACTION PRINT

NO FUEI-COOLANT INTERACTION RESULTS SAVED FOR PLOTTING 


\section{APPENDIX F}

\section{Tabulation of Test Data}

The test data from L5-2, averaged over 40-ms time intervals, are tabulated in this Appendix. Because of the averaging, some of the fluctuations evident in the graphs drawn from data averaged over smaller intervals are not evident in the tabulated data. SAFl is the TREAT power monitored by an instrument with this designation. At the time of the test, SAF 1 had an $8 \mathrm{MW}$ bias, which has been included in the tabulated data. This bias was removed from the data before the graphs in the other sections were drawn. INT 1 is the TREAT energy monitored by TREAT Integrator \#1. UPT and LPT refer to upper and lower pressure transducers, respectively. UFM and LFM refer to upper and lower electromagnetic flowmeters respectively, and LFPM refers to the lower permanent magnet flowmeter.

The tabulation includes the erratic thermocouple data recorded after thermocouple failure. The failure time for each thermocouple is given in Table D-1. The data tabulated for each thermocouple after its failure should be disregarded. 


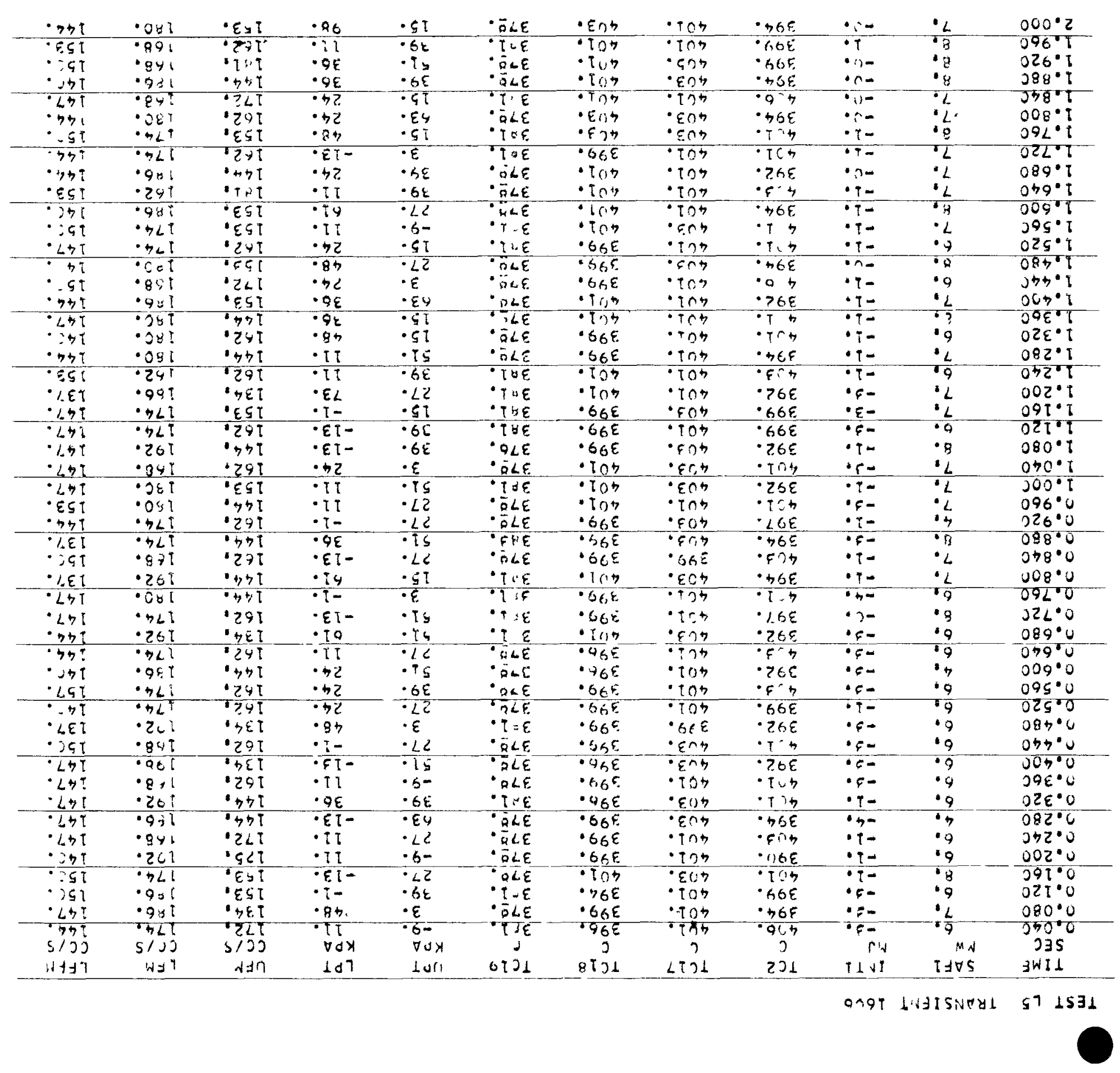


TEST L5 TRAISIE I I600

\begin{tabular}{|c|c|c|c|c|c|c|c|c|c|c|c|}
\hline $\begin{array}{l}\text { TIME } \\
\text { SEC }\end{array}$ & $\begin{array}{l}S A F 1 \\
N W\end{array}$ & $\begin{array}{l}11.71 \\
4 J\end{array}$ & $\begin{array}{c}\Gamma^{c} 2 \\
c\end{array}$ & $\begin{array}{c}\mathrm{TC} 17 \\
\mathrm{C}\end{array}$ & $C^{T C}{ }^{8}$ & $\begin{array}{c}T<19 \\
r\end{array}$ & $\begin{array}{l}\text { UPT } \\
\text { KPA }\end{array}$ & $\begin{array}{l}\text { LPT } \\
\text { KPA }\end{array}$ & $\begin{array}{l}J F i A \\
C C / S\end{array}$ & $\begin{array}{l}L F M \\
C E / 5\end{array}$ & $\begin{array}{l}\text { LFF } 11 \\
C C / 5\end{array}$ \\
\hline $2.04 \mathrm{C}$ & 7. & -1. & $4: 3$ & 403. & 401. & $3 \div 1$. & 39. & 36. & $17 ?$ & 162. & $15 \mathrm{C}$ \\
\hline 2.080 & 8. & -10 & 392. & $4,1$. & 401. & 370 & 03. & -1 & 153. & 360 & 144. \\
\hline $2.12 \mathrm{C}$ & A. & $-\dot{v}$ & $4 \cap 3$. & 463. & 491. & $3+1$. & 3. & 24. & 172. & 158. & 144. \\
\hline 2.160 & 12. & -6. & 399. & 401. & $4 \cup 3$. & $37 \stackrel{0}{0}$ & 15 . & 73. & 172. & It: & 156. \\
\hline 2.200 & B. & -3 & 394. & 401. & 403. & $3 \div 1$. & 75 & 24. & 162. & 100. & 147. \\
\hline 2.240 & ค. & $\because$ & 43 & 403. & 401. & $3 \div 1$. & 39. & 24. & 181. & 162. & 147. \\
\hline 2.230 & 19. & -1 . & $37:$ & 401. & 401. & $3 \cap 1$. & 27. & 48. & 144. & 196. & $14 \mathrm{C}$. \\
\hline $2.32 \mathrm{C}$ & 12. & -2. & 4.3. & 401. & 401 . & $3=1$ & 39. & $4 \theta$. & 151. & 162. & 153. \\
\hline 2.360 & 10. & $-\cdots$ & 399. & 403. & 403. & $3 \times 1$. & 51. & 11. & 172. & 148. & 150. \\
\hline 2.400 & 112 & $-v$. & 394. & 401. & 443. & 391. & 15. & $6:-$ & 162. & 180. & $14^{\circ}$ \\
\hline 2.440 & 13. & $-\because$ & $4 \times 3$. & 401. & 401. & 378. & 39. & 48. & 172 & $1 \cap 2$. & 157. \\
\hline 2.490 & 14. & -3 & $39 \mathrm{~L}^{\circ}$ & 403. & 401. & $3=1$. & 52. & 11. & 144. & 190. & 147. \\
\hline 2.520 & 15. & 3. & $4+1$. & 403. & 401. & 370. & 15. & -1. & 172. & 174. & 145. \\
\hline 2.560 & 15. & i. & 391. & 403 & 401. & 370. & 27. & 24. & 162, & 174. & 150. \\
\hline 2.600 & 18. & 1. & 397. & 403. & 401. & $3: 1$. & 75. & -1 . & 162. & 180. & 147. \\
\hline 2.640 & 22. & 1 & 413. & 403. & 401. & 378 & 51: & 48. & 101. & 160. & 253. \\
\hline $2.68 \mathrm{C}$ & 22. & 3. & 394. & 431. & 403. & 370. & 39. & -13. & 144, & 196. & $14 \mathrm{C}$ \\
\hline 2.720 & 24, & 0. & $4+1$. & 401. & 401. & 370. & 27. & 36. & 172. & 274. & $25 \mathrm{C}$. \\
\hline $2.76 \mathrm{C}$ & 25. & 3. & 397. & 401. & 401 . & 301. & 43. & 11. & 162. & 174. & 153. \\
\hline $2.80 \mathrm{C}$ & 29. & 4 , & 391. & $4 ! 1$. & 401. & 301. & 27. & -1 & 153. & 126. & 144. \\
\hline $2.84 \mathrm{C}$ & 34. & 0. & 403. & 401. & 401. & 370. & 39. & -13 & 172. & 148. & 157. \\
\hline 2.380 & 42. & 0. & 392. & +03. & 403. & $3 \times 1$. & 87. & $-5^{\circ} \cdot$ & 134. & 180. & 147. \\
\hline 2.920 & 48 & r. & $4 \sqrt{3}$ & 403. & $40 \overline{3}$ & 376. & 39. & -62. & 181. & 162 & 153 \\
\hline 2.960 & 48. & 19 & 379. & 403. & 401. & 311. & 39. & -25 & 153. & 174. & $15 \mathrm{C}$. \\
\hline 3.000 & $4 n$ & 11. & 394. & 403. & 401. & $3 \times 1$. & 87. & -38. & 153. & 186. & 147. \\
\hline 3.040 & 59. & 14, & $4+3$ & 403. & 401. & $3 \div 1$ & h3. & $-5 !$ & 181. & 156. & $15 C$ \\
\hline $3.08 \mathrm{C}$ & 48 & 14. & 396. & 405. & 401. & 3.1 . & 39. & -5. & 134. & 196. & $14 c$. \\
\hline 3.120 & $4 B$ & 17. & $4 \cdot 1 \cdot$ & $4 \times 3$. & 401. & $3 \times 1$. & 51. & -62. & 172. & 168. & $15 \mathrm{C}$. \\
\hline 3.160 & 48. & 19. & $394:$ & 401. & 401. & $37 \%$ & 75. & -62. & 162. & 138. & 153. \\
\hline 3.220 & 46. & 10. & $39 \%$ & 401. & 401. & 378. & 39. & -5. & 162. & 174. & 144. \\
\hline 3.240 & 40. & 21. & 413. & 403. & 403. & 378. & 39. & -38. & 181. & 156. & 147. \\
\hline 3.280 & 48. & $2 \ldots$ & 392. & 405. & 399. & 311. & 57. & -5. & 134. & 186. & $14 \mathrm{C}$. \\
\hline 3.320 & 49, & 25. & $4 \div 3$ & 4US. & 401. & $3 \% 1$. & 51. & -87 . & 181. & 156. & 156. \\
\hline 3,360 & 48. & 21. & 394. & 405. & $4 \mathrm{C}_{3}$ & 391. & 39. & $-5^{\wedge}$ & 142. & 274. & 144. \\
\hline $\begin{array}{l}3.400 \\
3.440\end{array}$ & $\begin{array}{l}46, \\
49\end{array}$ & $\begin{array}{l}27 . \\
29\end{array}$ & $\begin{array}{l}397 . \\
496 .\end{array}$ & $\begin{array}{l}405 . \\
405 .\end{array}$ & $\begin{array}{l}401 . \\
401 .\end{array}$ & $\begin{array}{l}3 \times 1 . \\
3-1:\end{array}$ & $\begin{array}{l}63 . \\
63 .\end{array}$ & $\begin{array}{l}-5 \\
-62 .\end{array}$ & $\begin{array}{l}153 . \\
172 .\end{array}$ & $\begin{array}{l}100 . \\
156 .\end{array}$ & $\begin{array}{l}144 . \\
153 .\end{array}$ \\
\hline 3.480 & 48. & 32. & 392. & 401. & 401. & 3.1. & 39. & $-5 n$. & 134. & 286. & $14 C$. \\
\hline 3.520 & 49. & 32. & 4.6. & 405. & 403. & 375. & 39. & -62. & 172. & 168. & 144. \\
\hline 3.560 & 46. & 34. & 394. & 408. & 403. & $3 \times \overrightarrow{1}$. & 87 & -75 & 153. & 180. & 156. \\
\hline $3.60 \mathrm{C}$ & 40. & 32. & 297. & 405. & 403. & $3 M+$. & 75. & -62. & 162. & 174. & 144. \\
\hline 2.640 & 48. & 36. & $4 \sqrt{3}$. & 408. & 403. & 378. & 51. & -5 & 172, & 168. & 147. \\
\hline 3.680 & 46. & 36. & 392. & 408. & 403. & 370. & 87. & $-5 i$ & 144. & 186. & 144. \\
\hline 3.720 & 48. & 42. & 403. & 400. & 403. & 301. & 75. & -62. & 181. & 162. & 147. \\
\hline 3.760 & 43. & 42. & 401. & 408. & 405. & $3: 1$. & 39. & $-5 \%$ & 153. & 174. & 144. \\
\hline 3.800 & 48. & 43. & 397. & 410. & 403. & $3 \div 1$. & 51. & -38. & 162. & 186. & 144. \\
\hline 3.840 & 46. & 40. & $4: 1$. & $4+2$. & 405. & 3.1. & 87. & -75. & 172. & 162. & 157. \\
\hline 3.880 & $4 E$ & 48. & 394. & 422. & 405. & $3 n 2$. & $5 i \cdot$ & -37. & 1340 & 196. & 137. \\
\hline 3.920 & $4 \%$ & 49. & 406. & 412. & 405. & 370. & 39. & -62. & 172. & 162. & 144. \\
\hline $\begin{array}{l}3.960 \\
4.000\end{array}$ & 48. & $\frac{52 .}{52 .}$ & $\frac{397 .}{399 .}$ & $\frac{415}{415}$ & $\frac{408 .}{405 .}$ & $\frac{370}{35.2 .}$ & $\begin{array}{l}63 . \\
75\end{array}$ & $\frac{-75}{-75}$ & $\frac{153 .}{153}$ & $\frac{174 .}{174 .}$ & $\frac{130 .}{140}$ \\
\hline
\end{tabular}


TEST L5 IRANSIEAT 1600

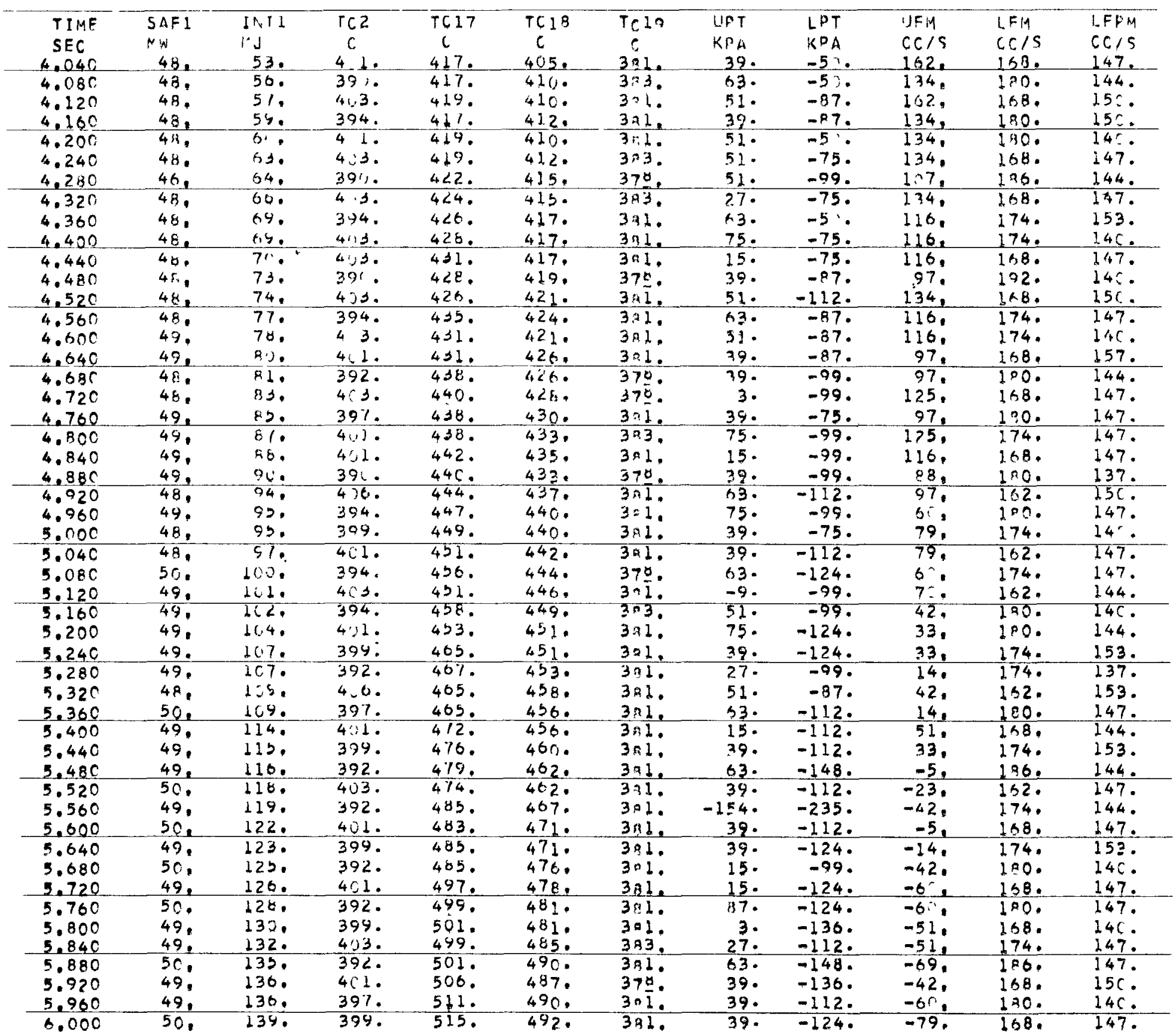


TEST LS TRAINSIENT 1620

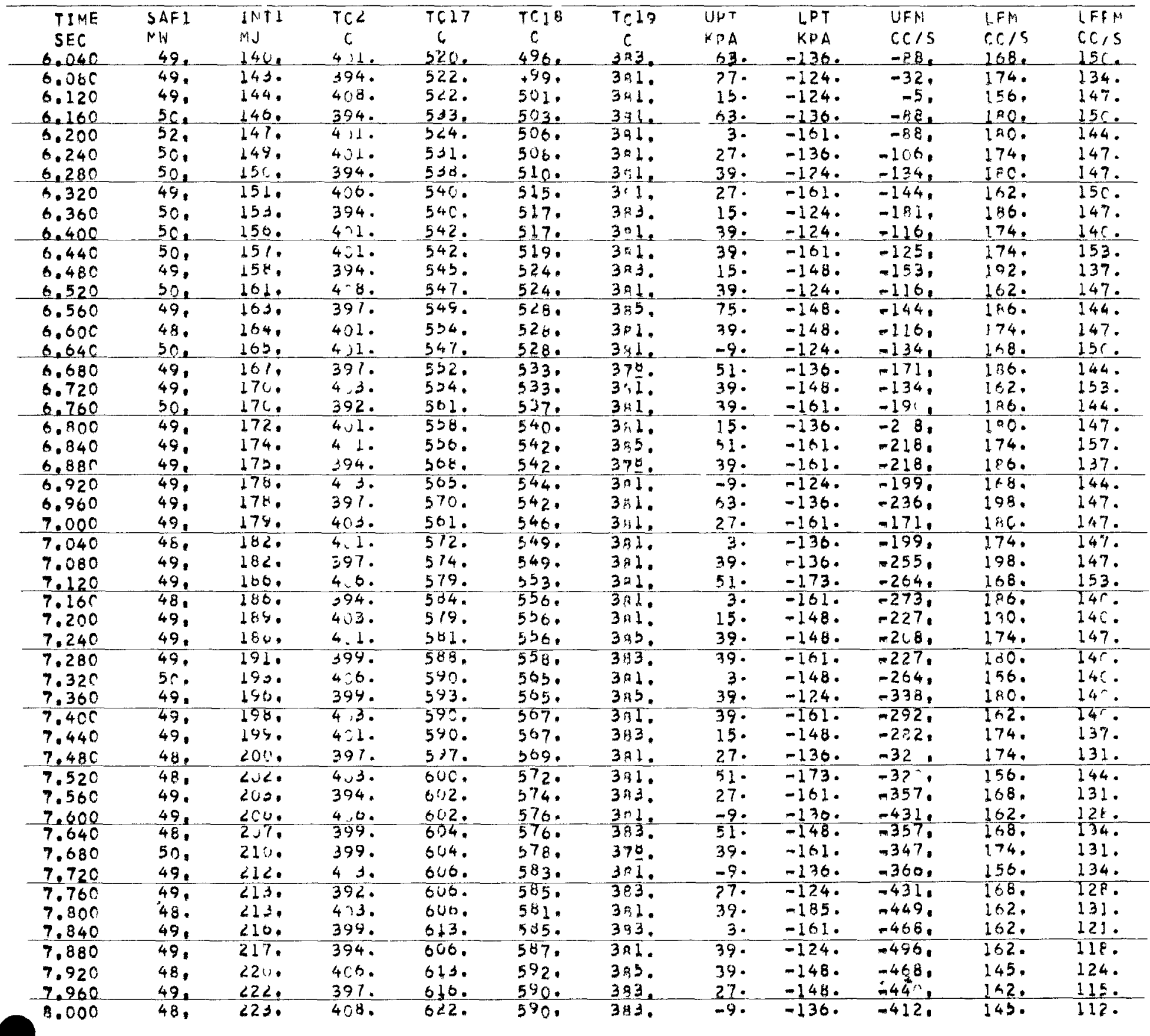


TEST L5 TRANSIENT 1600

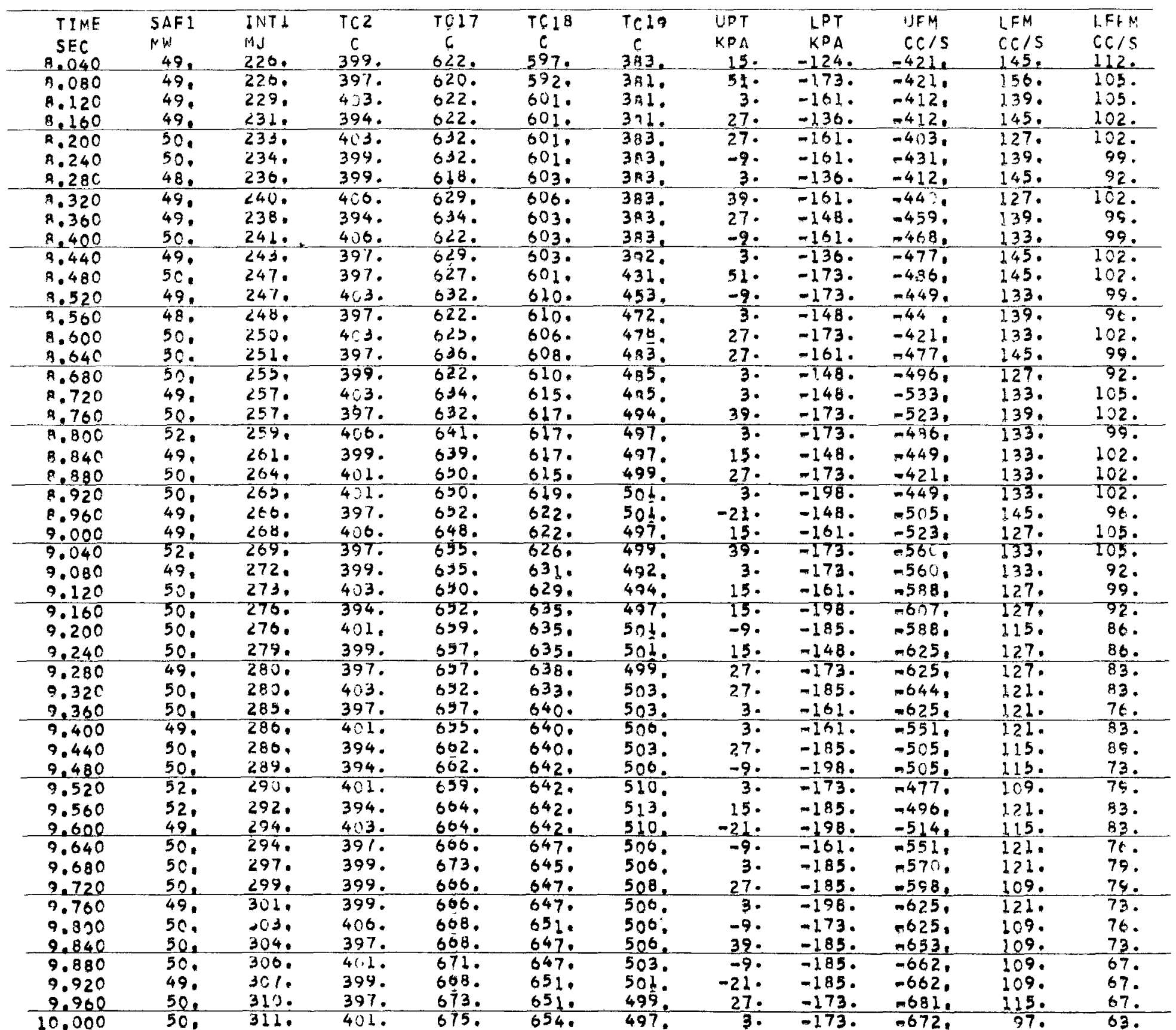


TEST LS TRANSIET.T 1600

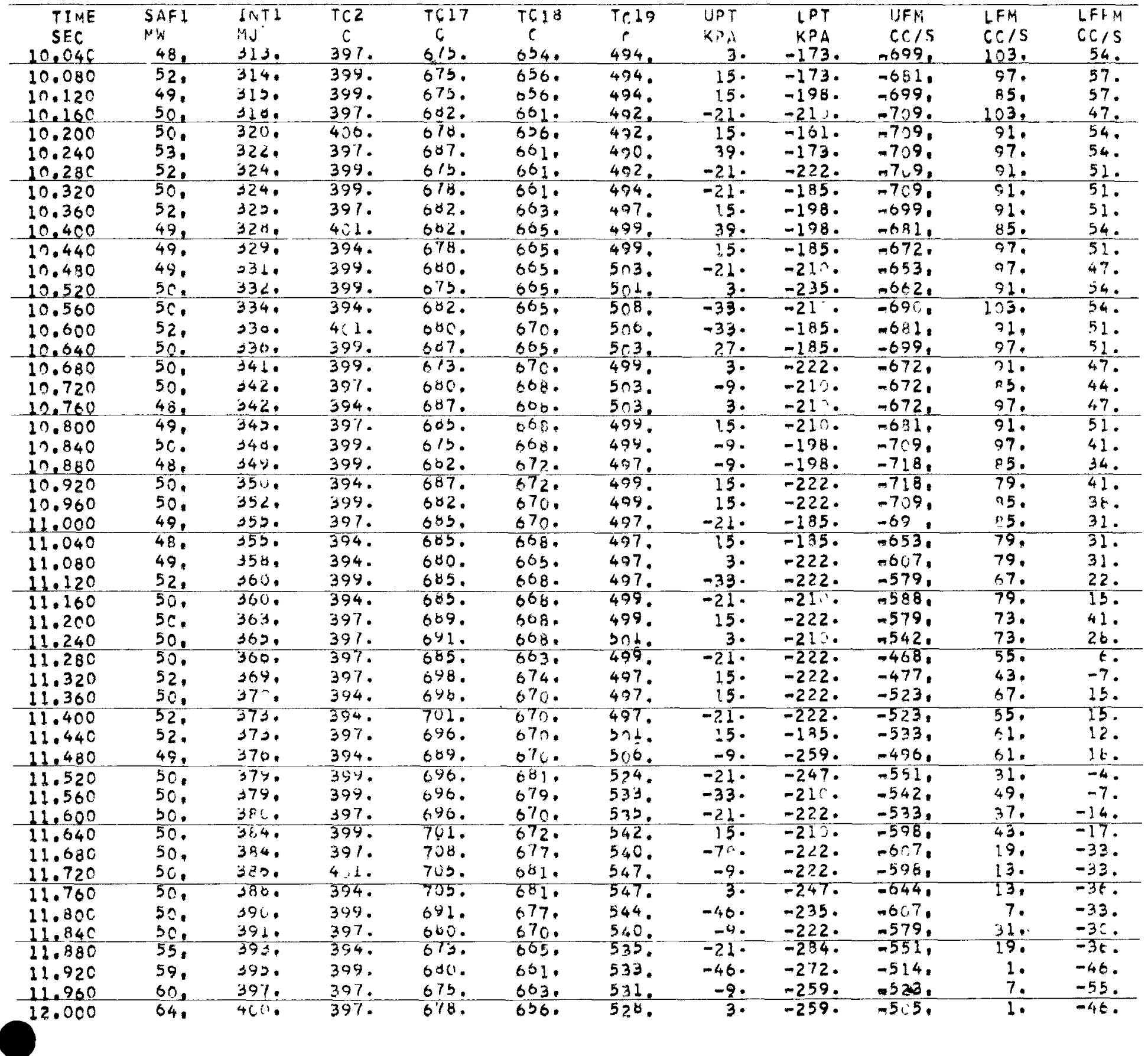


TEST L5 TRANSIENT 1606

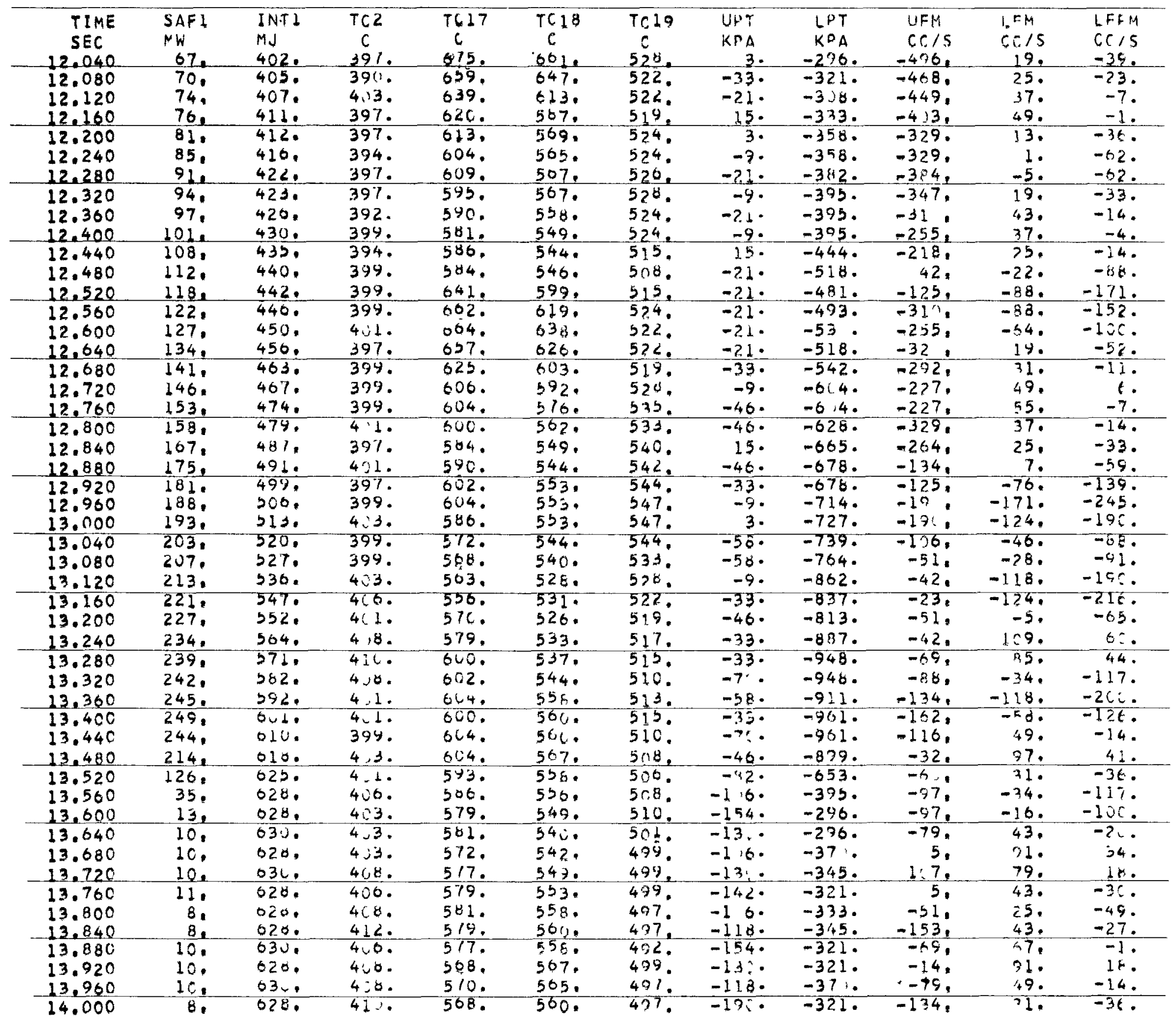


TEST LS TRANSIEIT IHJO

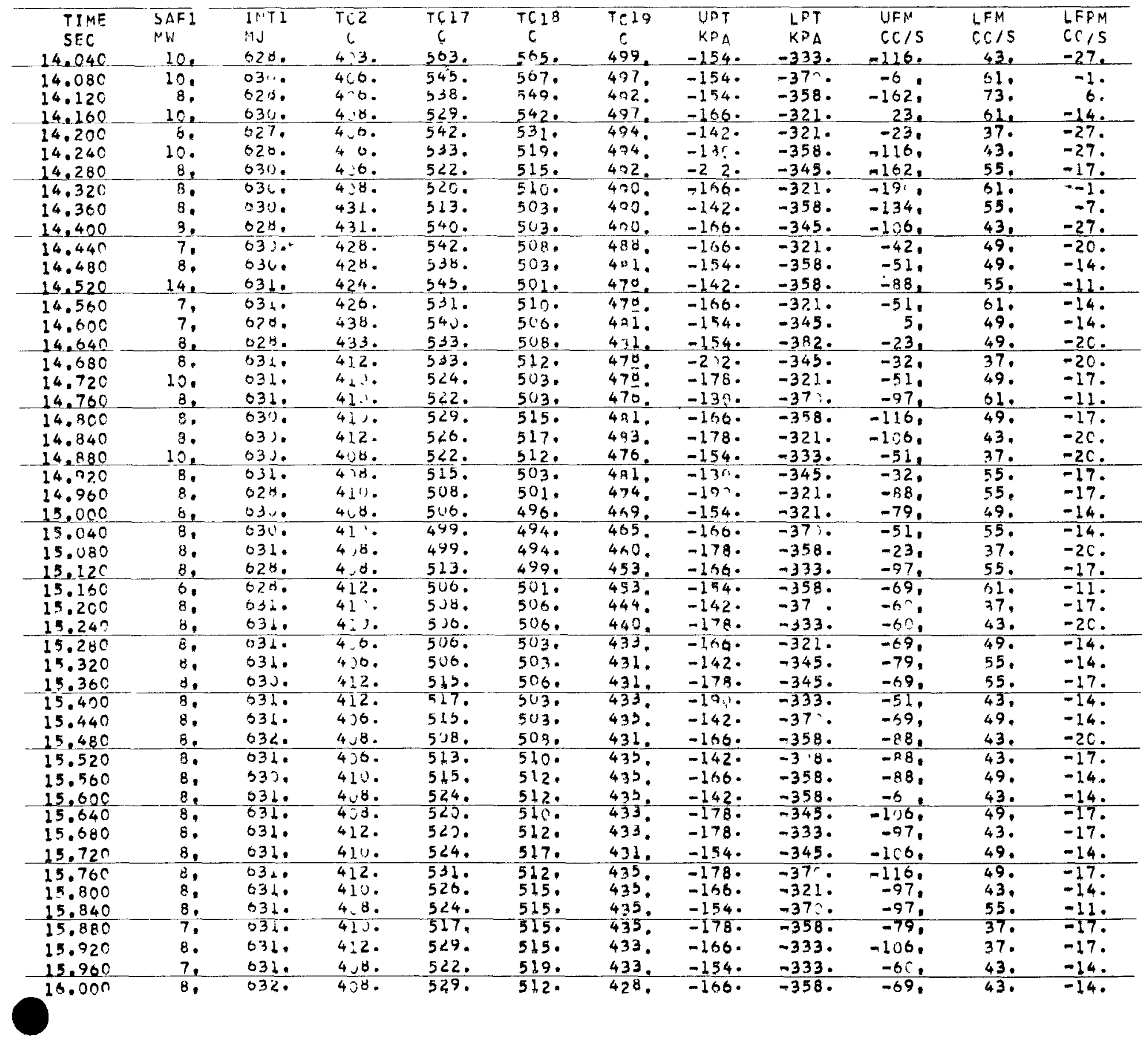


TEST LS IRANSIEPT $16: 30$

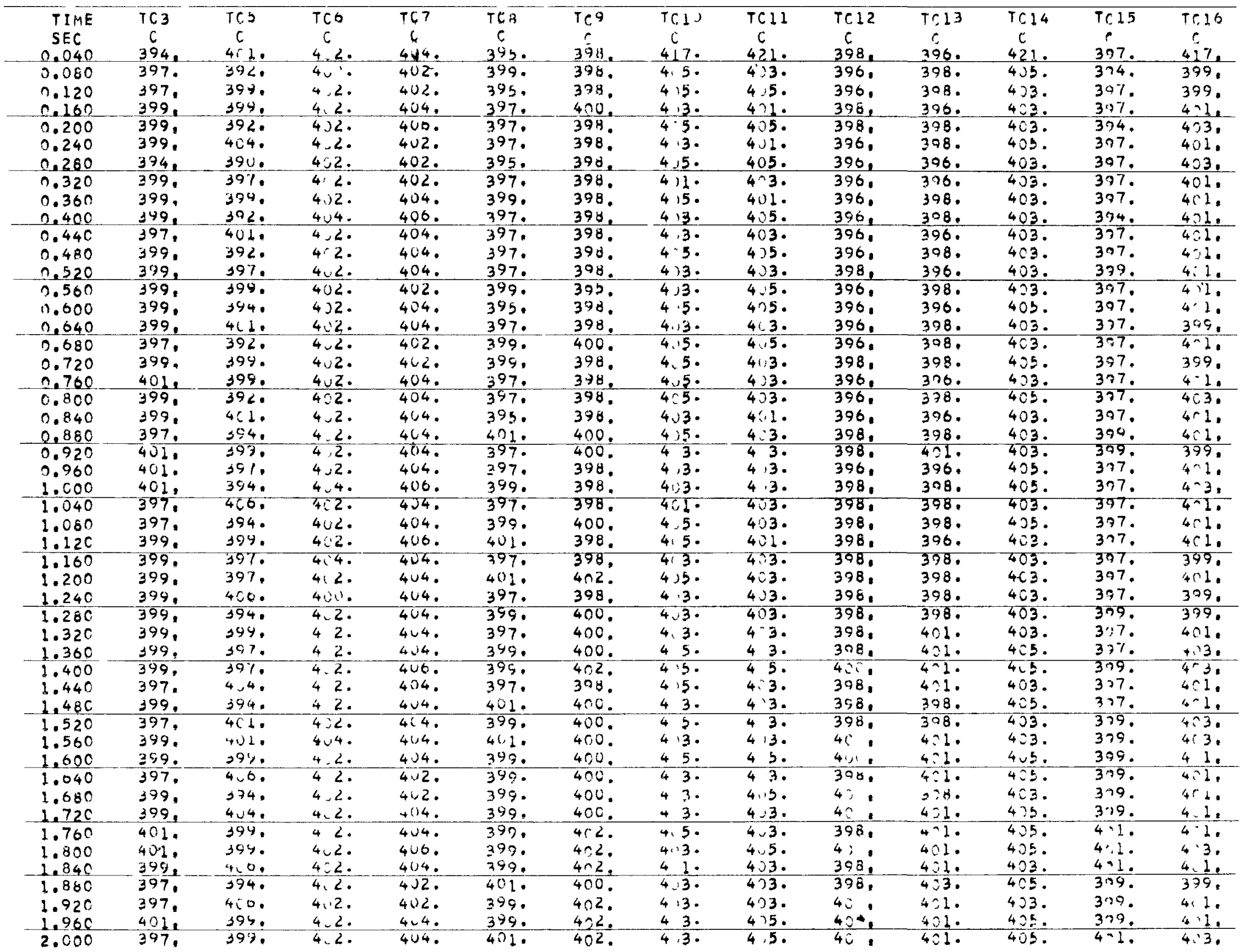


TEST L5 TRANSIENT 1600

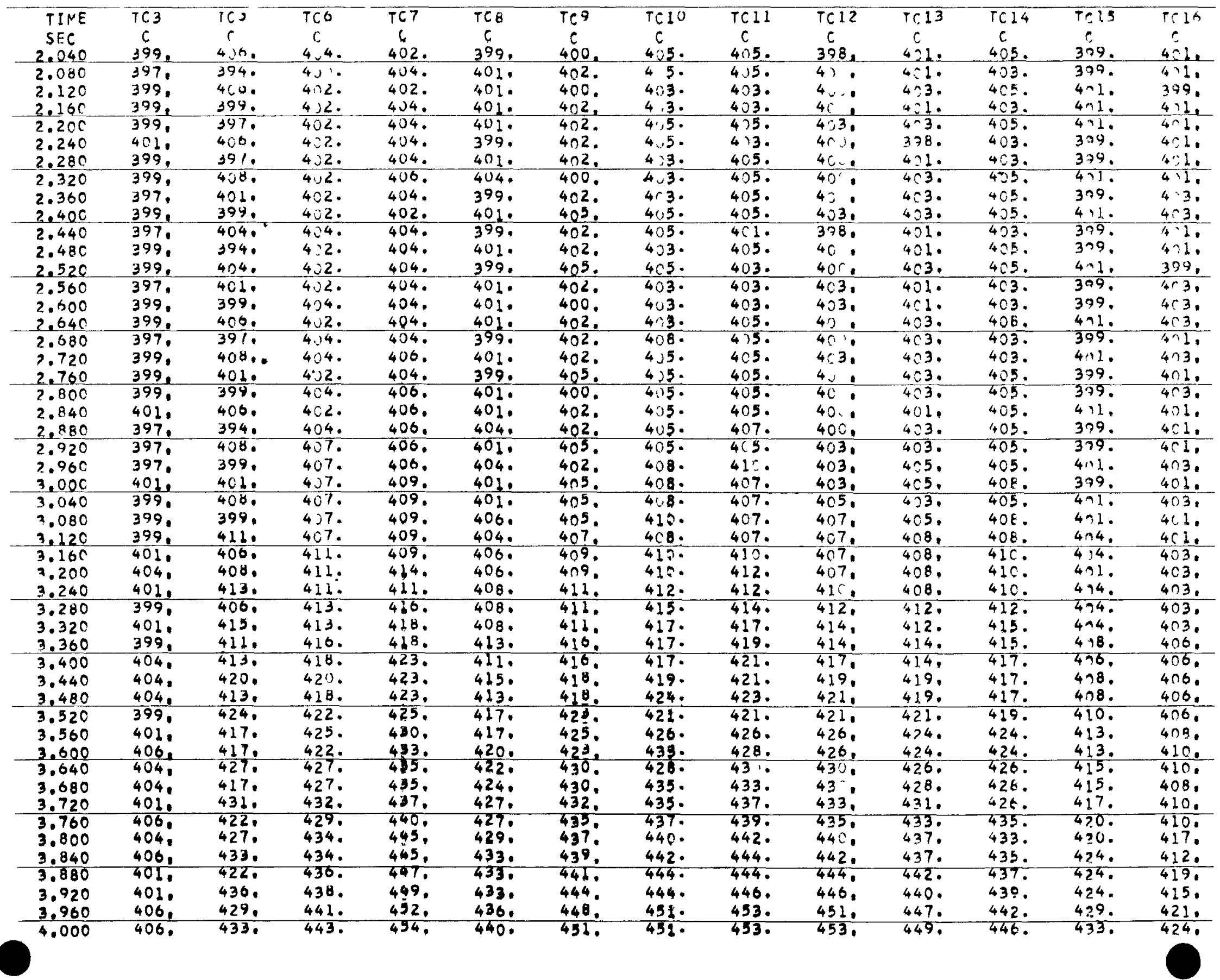


TEST L5 TRANSIEAT 1600

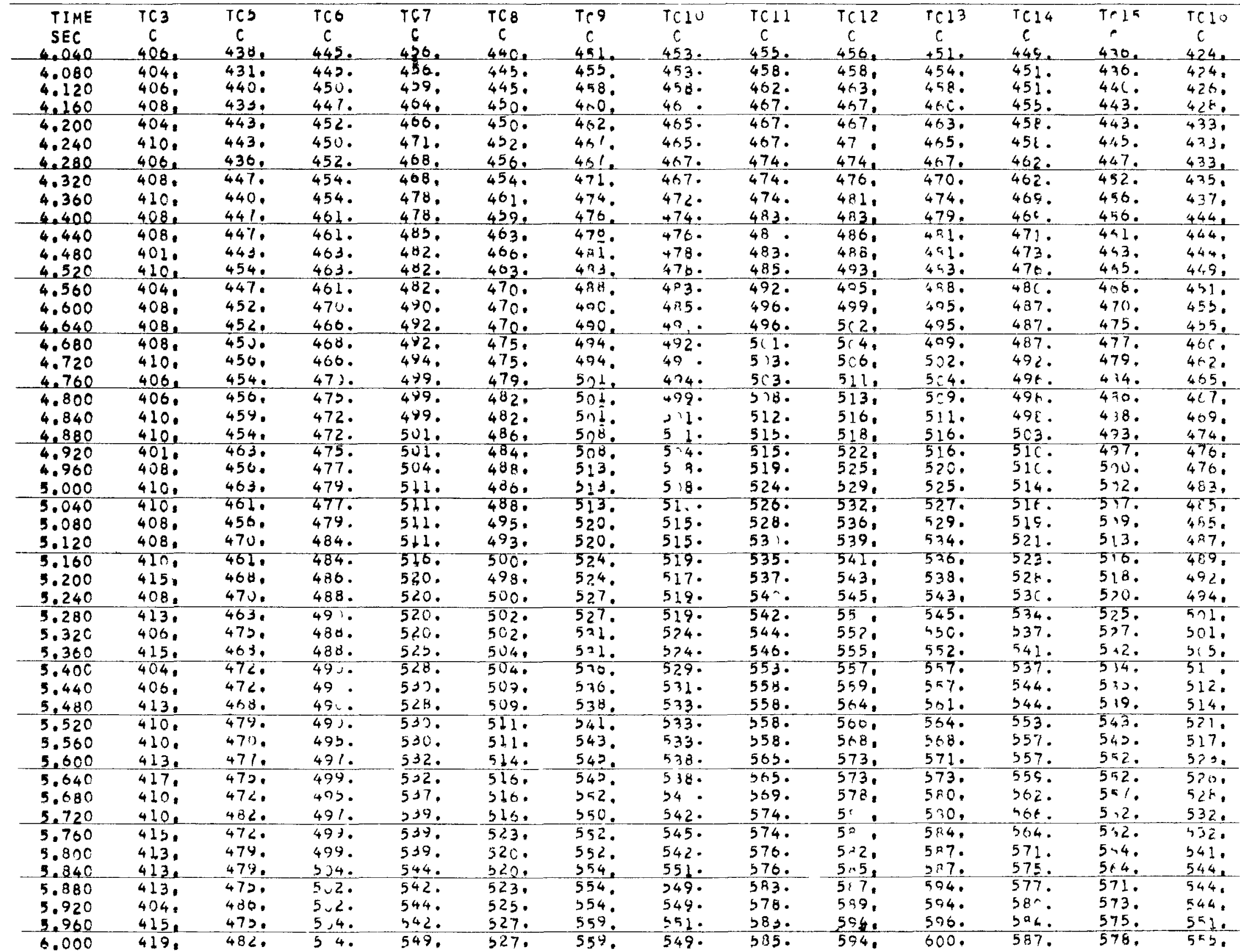


TEST L5 TRARSIENT HGJO

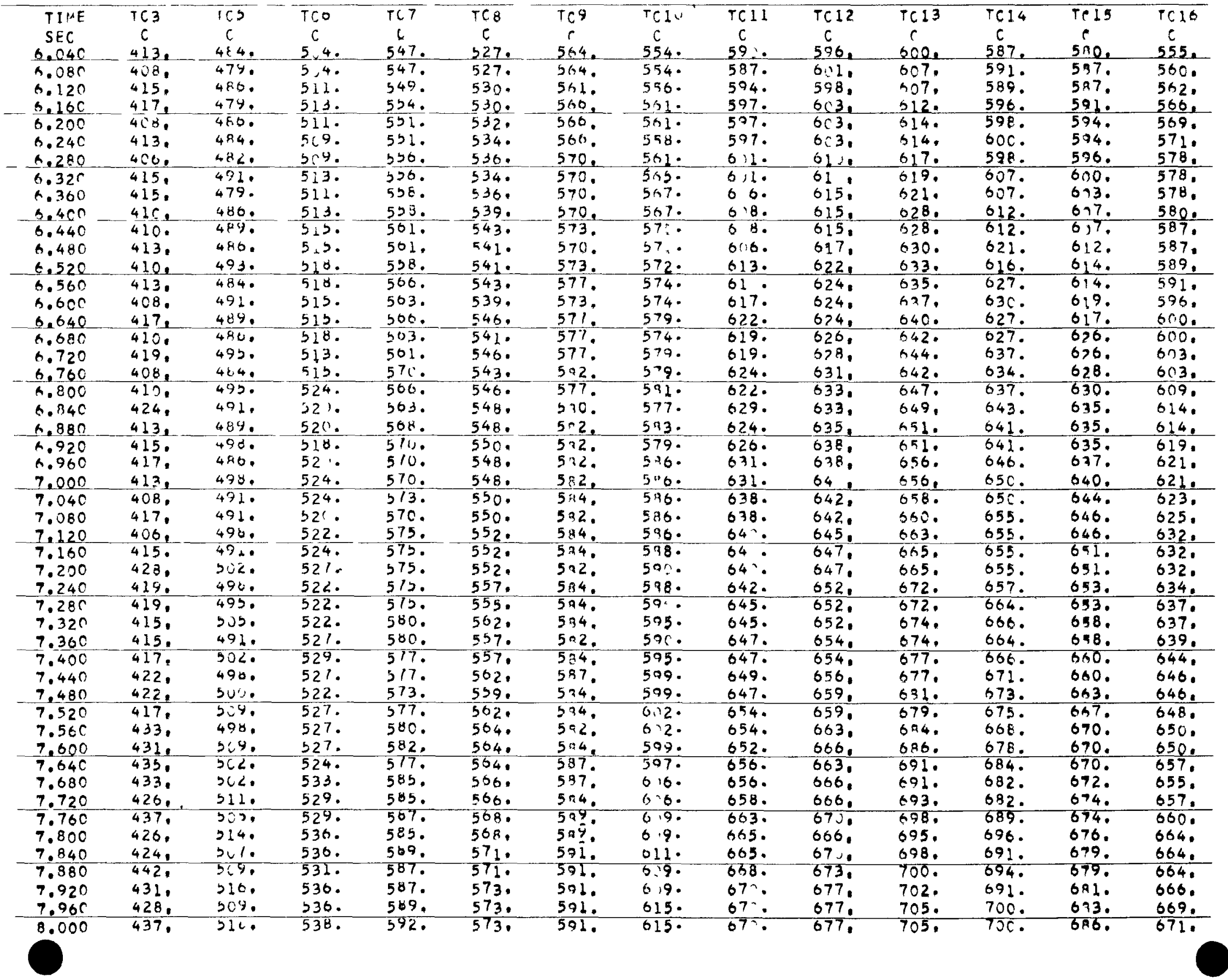


TEST L5 TRANSIENT 16:6

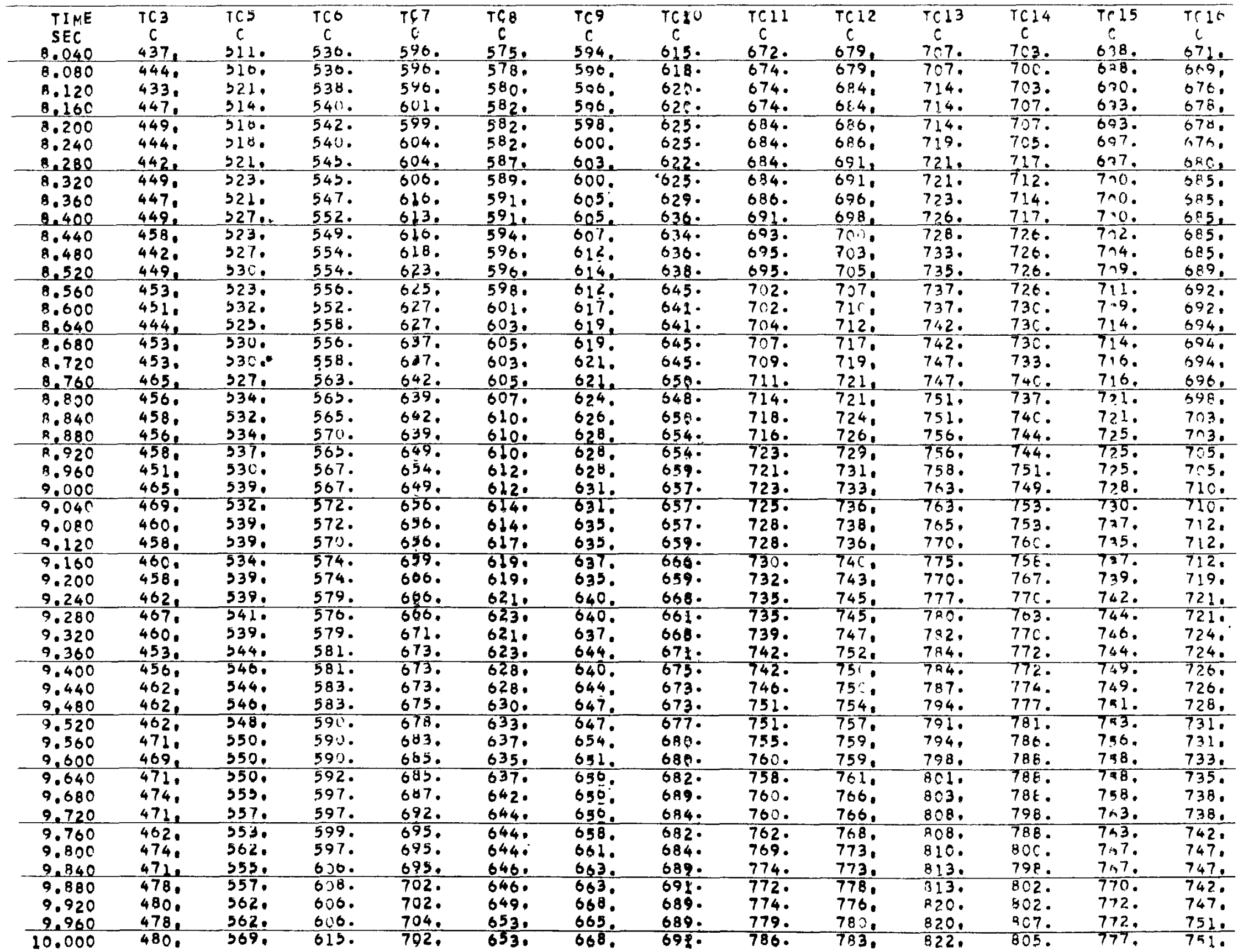


TEST L5 TRAREIEAT 16:0

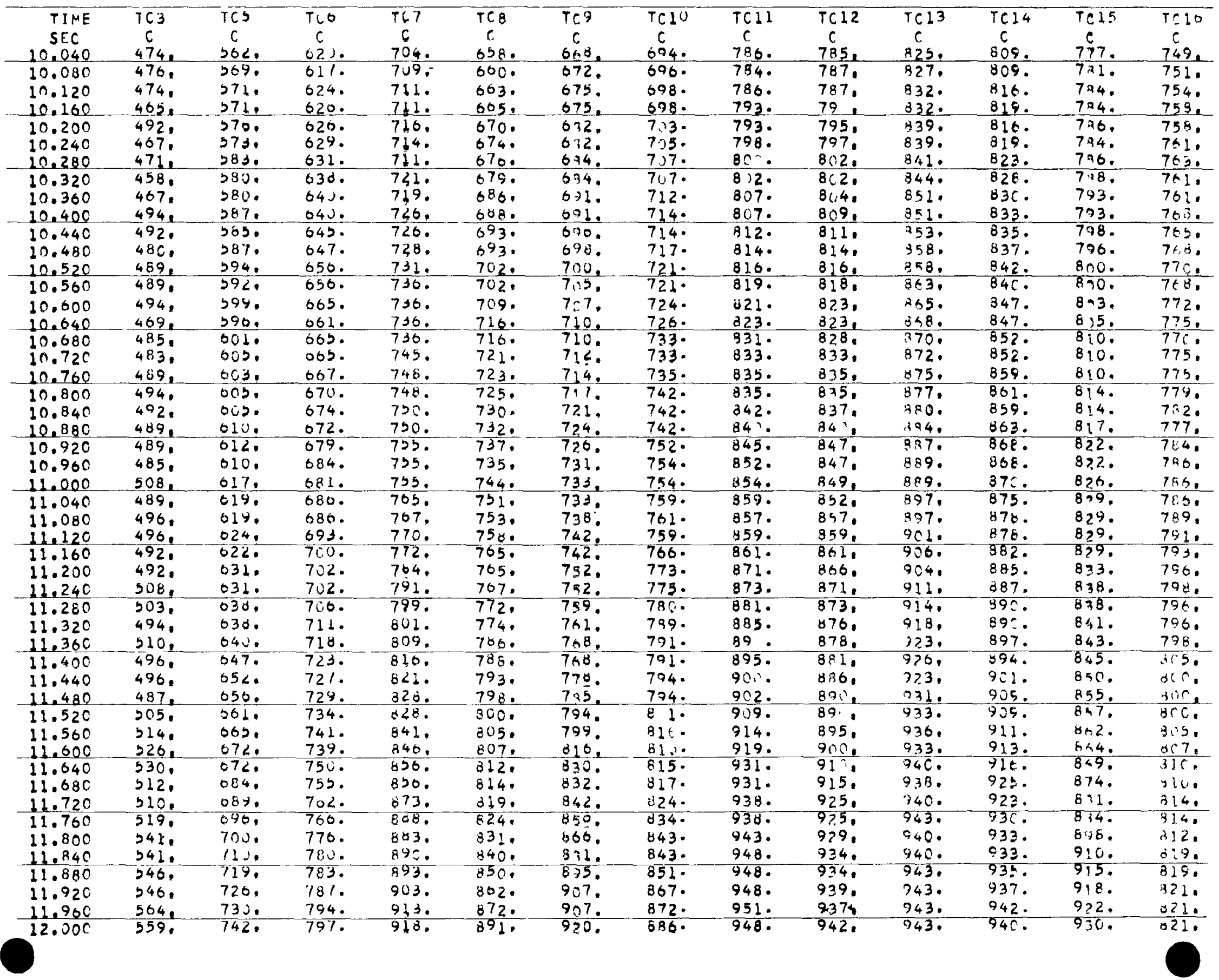


TEST L5 TRANSIENT 1600

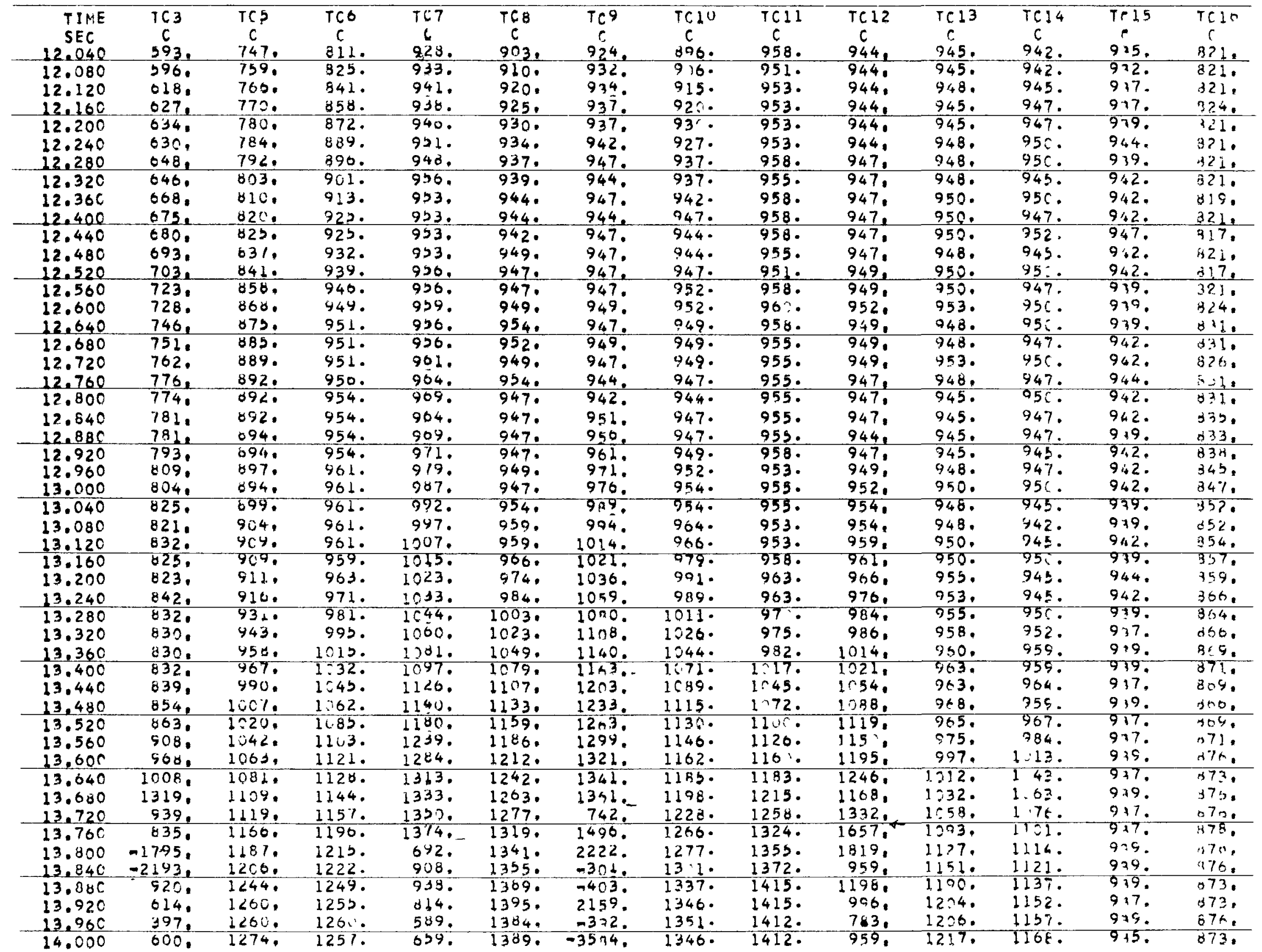


TEST L5 TPAHSIEN I JEUS

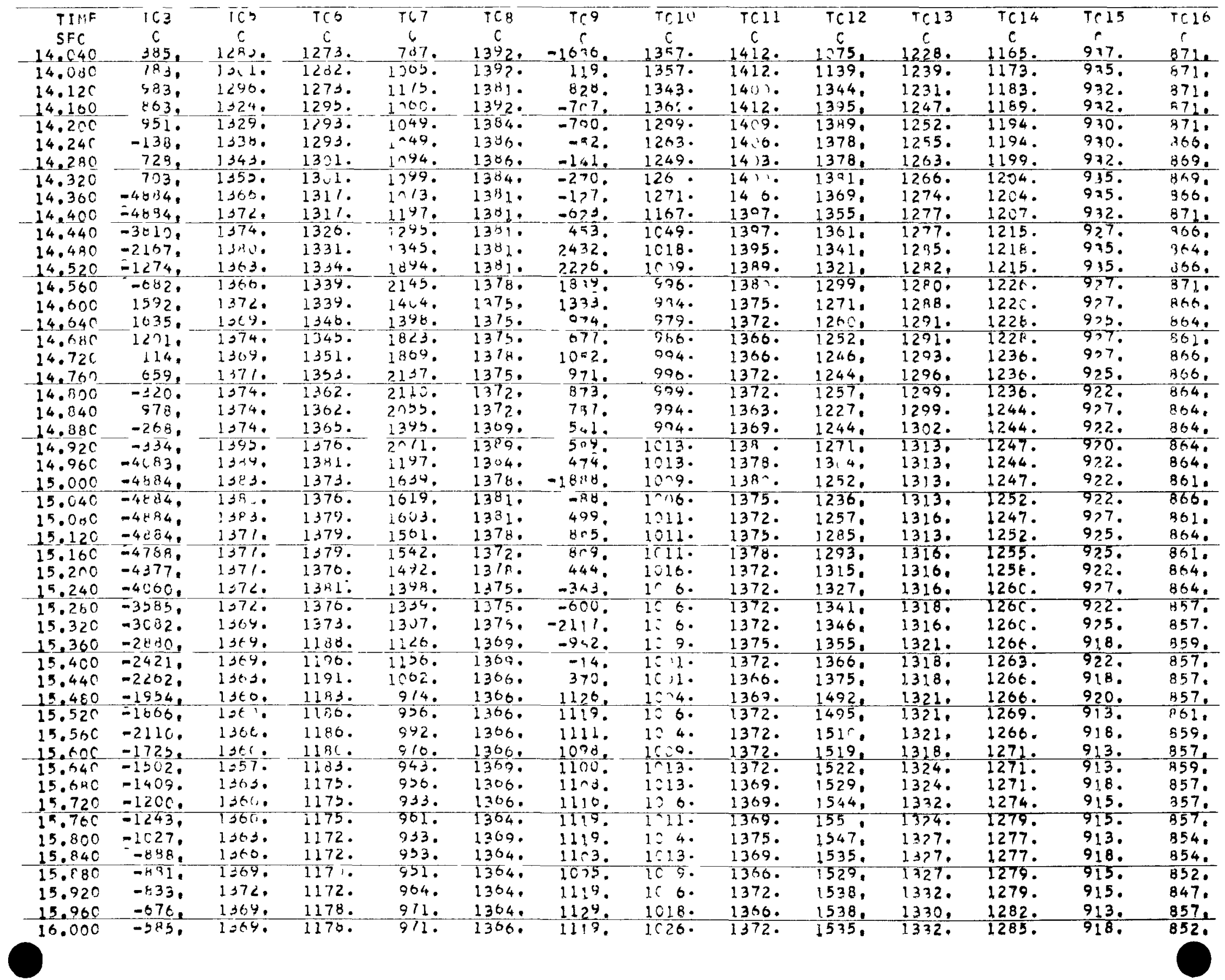




\section{ACKNOW LEDGMENTS}

The successful conduct of Test L5 and its associated calibrations depended on the work of many individual contributors at Argonne, both in Illinois and in Idaho. The overall direction of the program was the responsibility of Charles Dickerman. Bob Noland was responsible for the test hardware and experiment operations. Larry Harrison, at TREAT, provided the facility management for running the test.

Vern Kolba, John Bednarcik, and Mike Barczak handled the engineering design for the test hardware. Jim Matousek and A. J. Lang were responsible for converting the drawings into hardware by their coordination with and within Central Shops. Fuel and HFEF coordination were handled by Howard Rhude. George Trahey was the quality-assurance representative.

The following technicians played a key role in converting the hardware to a working experiment: Gene Maslowicz, Joe Burghardt, Jim Emerson, Charley August, and Jerry Dewey. Their contributions cannot be overstated.

Bob Land performed the many computations with the SAS code needed to plan the L5 transient. Gerry Klotzkin assisted with the problems related to reactor physics. Frank Yaggee and Gabe Dragel devised the method for core-drilling pellets. Extensive radiochemical work for the calibrations was done by Bob Villarreal and Roland Armani. Paul Froehle handled the data reduction that led to the graphic displays.

At HFEF, Jay Cook, Jim Kerr, and Ken Teraguchi worked the details of hot-cell operations needed to assemble and disassemble L5. At TREAT, Leo McVean was the experiment coordinator. Gerry Larson handled the online program control of the reactor. The operations personnel at TREAT is acknowledged for its efforts both for the actual test and the calibrations.

The personnel at the alpha-gamma hot-cell facility under the direction of Larry Neimark was especially helpful in sorting through the test remains.

Special thanks are due to Ed Johanson, Dick Purviance, and Ken Schmidt for their efforts associated with the experiment operation, experiment control panel, and data acquisition at the time of the test. 


\section{REFERENCES}

1. F. L. Yaggee, An Analysis of Fuel-Element in the L5 TREAT Transient Test Simulating a Loss-of-Coolant-Flow Accident in an ETR-Type Reactor, Trans. Am. Nucl. Soc. 19, 261 (1974).

2. F. E. Dunn, T. J. Heames, P. A. Pizzaca, and G. Fischer, "The SAS2A Accident Analysis Code," Proc. Conf. New Developments in Reactor Mathematics and Applications, Idaho Falls, Idaho, CONF-710302 (1971).

3. J. C. Gustafson and G. E. Culley, Engineering Test Plan for the Mark II GETR/TREAT Test Series, HEDL report (Feb 1971).

4. F. L. Yaggee and G. Dragel, An ULtrasonic Trepanning Technique for Radial Sampling of Ceramic Fuel Pellets, Nuc1. Tech. 27, 292 (1975).

5. R. R. Stewart, ANL, personal communication (Apr 1977).

6. D. R. Porten, HOP 3-3C/3-3A Transient Test Final Report, HEDL-TME 76-54 (Aug 1976).

7. W. F. Murphy and J. C. Florek, ANL, personal communication (June 1976).

8. M. G. Stevenson, W. R. Bohl, F. E. Dunn, T. J. Heames, G. Hoppner, and L. L. Smith, "Current Status and Experimental Basis of the SAS LMFBR ACcident Analysis Code," Proc. Fast Reactor Safety Meeting, CONF-740401, Beverly Hills, Calif. (1974). 
Distribution of ANL-78-24

Internal:

J. A. Kyger

R. Avery

L. Burris

D. W. Cissel

S. A. Davis

B. R. T. Frost

D. C. Rardin

R. J. Teunis

C. E. Till

R. S. Zeno

C. E. Dickerman

H. K. Fauske

S. Fistedis

B. D. LaMar

J. F. Marchaterre

H. O. Monson

R. Sevy

A. J. Goldman

D. Rose

I. Bornstein

D. R. Ferguson

L. Baker

P. A. Lottes

T. C. Chawla

W. C. Lipinski
R. A. Noland

R. K. Lo (2)

G. S. Stanford

A. B. Rothman (2)

B. A. Korelc (3)

R. Simms (10)

J. P. Burelbach

N. J. Carson

A. DeVolpi

R. C. Doerner

P. H. Froehle

R. N. Koopman

O. R. McNary

R. J. Page

R. G. Palm

T. H. Bauer

H. V. Rhude

R. R. Stewart

L. A. Semenza

A. E. Klickman

J. P. Tylka

A. E. Wright

H. U. Wider

L. W. Deitrich

D. H. Cho

M. Kurtz (2)
C. C. Meek

C. H. Bowers

R. E. Henry

D. R. Pedersen

J. H. Tessier

D. H. Lennox

S. M. Gehl (2)

W. F. Murphy

E. W. Johanson

V. M. Kolba

L. J. Harrison

R. L. McVean

R. Villarreal

F. L. Yaggee

A. M. Barczak

J. T. Bednarcik

G. M. Trahey

G. Klotzkin

R. J. Armani

J. F. Kerr

R. T. Purviance

A. B. Krisciunas

ANL Contract File

ANL Libraries (5)

TIS Files (6)

External:

DOE-TIC, for distribution per UC-79p (282)

Manager, Chicago Operations Office

Chief, Chicago Patent Group

Director, Reactor Programs Div., CH

Director, CH-INEL

Director, DOE-RRT (2)

President, Argonne Universities Association

Reactor Analysis and Safety Division Review Committee:

S. Baron, Burns and Roe, Inc.

W. Kerr, U. Michigan

M. Levenson, Electric Power Research Inst.

S. Levy, S. Levy, Inc.

R. B. Nicholson, Exxon Nuclear Co., Inc.

D. Okrent, U. California, Los Angeles

N. C. Rasmussen, Massachusetts Inst. Technology 